Chapman University

Chapman University Digital Commons

Summer 8-31-2016

\title{
Operation Transition: Post-9/11 Combat Marines Transitioning to Civilian Life and the Role of Higher Education in their Identity Formation
}

Jamie M. Fenton

Chapman University, jamie.fenton@gmail.com

Follow this and additional works at: https://digitalcommons.chapman.edu/education_dissertations

Part of the Educational Leadership Commons, and the Higher Education Commons

\section{Recommended Citation}

Fenton, J. M. (2020). Operation Transition: Post-9/11 Combat Marines transitioning to civilian life and the role of higher education in their identity formation [Doctoral dissertation, Chapman University]. Chapman University Digital Commons. https://doi.org/10.36837/chapman.000175

This Dissertation is brought to you for free and open access by the Dissertations and Theses at Chapman University Digital Commons. It has been accepted for inclusion in Education (PhD) Dissertations by an authorized administrator of Chapman University Digital Commons. For more information, please contact laughtin@chapman.edu. 
Operation Transition: Post-9/11 Combat Marines transitioning to civilian life and the role of higher education in their identity formation.

\author{
A Dissertation by \\ Jamie Mikelle Fenton \\ Chapman University \\ Orange, California \\ College of Educational Studies
}

Submitted in partial fulfillment of the requirements for the degree of

Doctor of Philosophy in Education

August 2016

Committee in charge:

Penny Bryan, Ph.D., Co-Chair

Kris Tunac De Pedro, Ph.D., Co-Chair

Lilia Monzo, Ph.D.

Glenn Allen Phillips, Ph.D. 


\section{Operation}

\section{Transition}

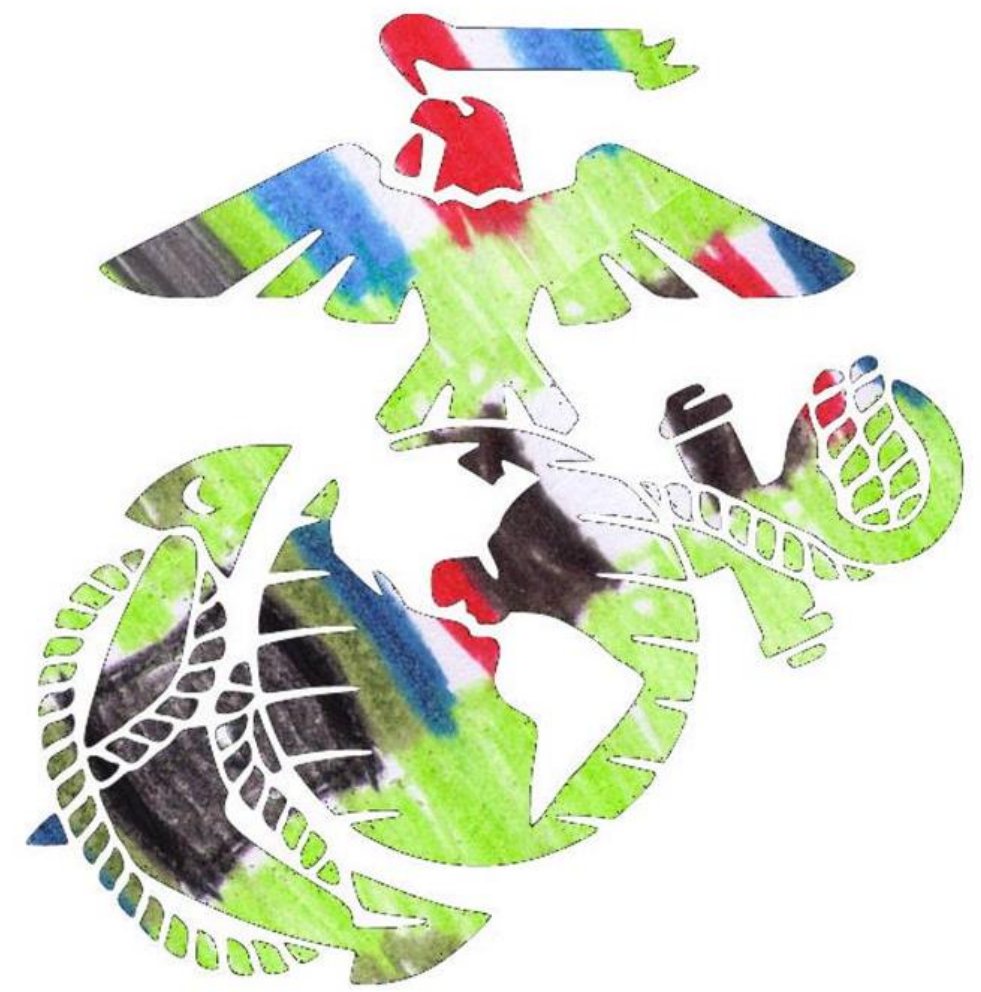

"The Colors of a Marine through the Eagle, Globe, \& Anchor"

by Michael W. Fenton (age 6) \& Jamie M. Fenton

\section{A Dissertation by Jamie Mikelle Fenton}

Chapman University, Orange, California

College of Educational Studies

Submitted in partial fulfillment of the requirements for the degree of

Doctor of Philosophy in Education

August 2016

Committee in charge:

Penny Bryan, Ph.D., Co-Chair

Kris Tunac De Pedro, Ph.D., Co-Chair

Lilia Monzo, Ph.D.

Glenn Allen Phillips, Ph.D. 
The dissertation of Jamie Mikelle Fenton is approved.

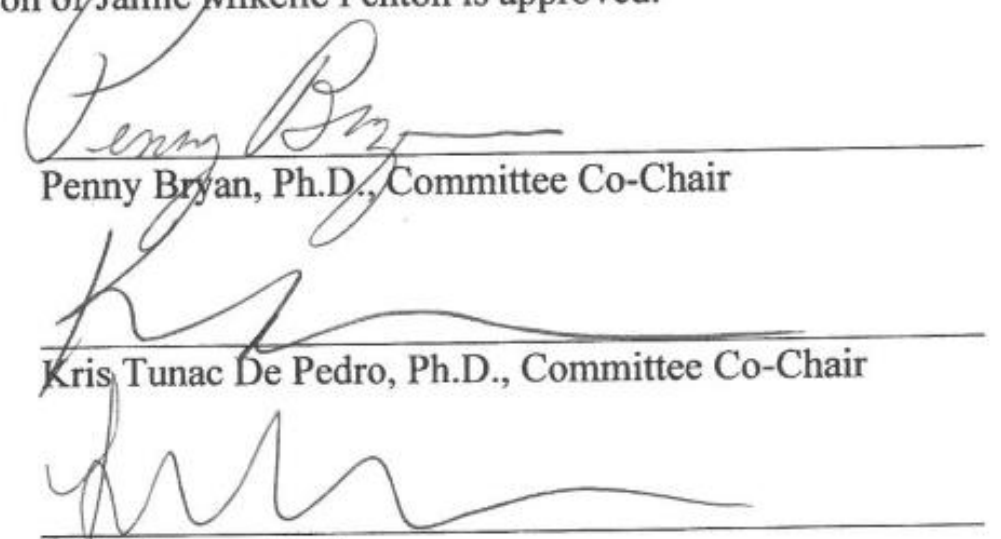

Lilia Monzo, Ph.D.

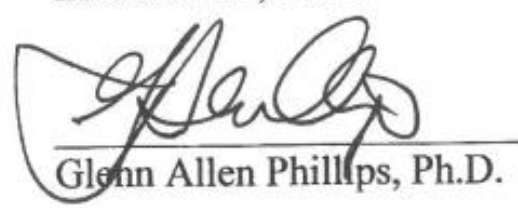

August 2016 
Operation Transition: Post-9/11 Combat Marines transitioning to civilian life and the role of higher education in their identity formation.

Copyright (C) 2016

by Jamie Mikelle Fenton 


\section{ACKNOWLEDGEMENTS}

\section{Thank you for your service!}

These acknowledgements are more than just words on a page, as I would not have been able to do this work without the following people...

Dad, aka Sgt. Stepo, you bleed through these pages! You are one of the first and finest teachers I have ever had. You challenge me to think bigger, dig deeper, and be better daily! Thank you for being my father, my guide, and my friend. Because of you, I am the daughter of a Marine.

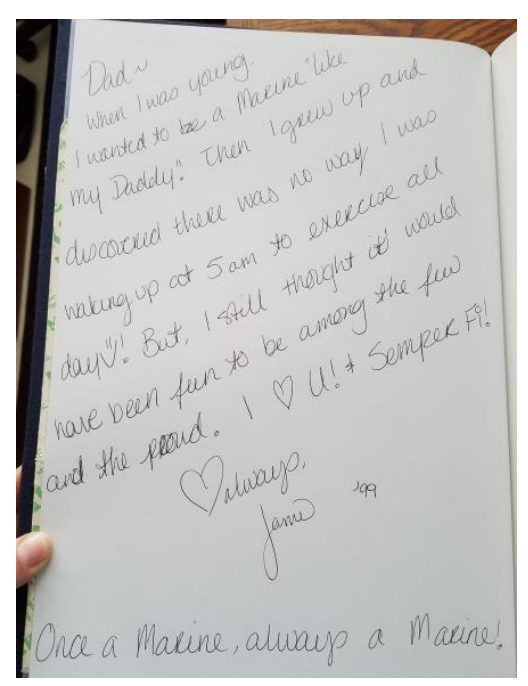

My committee... Penny, you mused in a class presentation, "Wouldn't it be great to have a dissertation that was a work of fiction?" You changed the course of my life and supported me in making such a brave effort for Arts Based Research!

Kris, you never gave up on me. Lilia, you challenged me to see all sides. Glenn, you came up with Veteran Critical Theory... and said YES when I asked!

My PhD Colleagues ... Charlotte, Kevin, Anat, Principal Resnick, Coach Danny, and so many others. Thank you for listening, dialoging, and helping me walk through this process, and at times, talking me off the ledge of doubt!

My sidewalk sister... Tonjia, you helped me work through so much on the sidewalk in front of the elementary school. Thank you, just thank you! 
My family... Mother Belle, thank you for your support, and the 5:00am phone calls to hear your voice \& increase my productivity! Michael, you supported me through this process and took care of my babies. Thank you! Mikey and Danny, thank you for understanding when I had to work and still giving me the best hugs and snuggles when I came home. I love you to Pluto, and back, and back, and back, and back, and back, and back, and back, and back, and back, and back, and back, nambatat,wame-

The Unit... Sgt. G, Lance, V, and Beaver - you let me into your lives, you allowed me to listen, you trusted me with your stories, you gave up your time - at lunch, in the afternoon, on Sunday mornings - and you changed my life. I don't have the words to tell you how much it all means to me. So, I will humbly, and with every ounce of my soul, say Thank you for everything! 


\begin{abstract}
Operation Transition: Post-9/11 Combat Marines transitioning to civilian life and the role of higher education in their identity formation. by Jamie Mikelle Fenton
\end{abstract}

Operation Transition is an excavation of the experiences of Post-9/11 combat Marines, who have been Honorably Discharged, as their transition to civilian and student life. The work of Operation Transition was conducted with a group of Marines, called The Unit, and presents the variety of stories that exist among Veterans, beyond the highly publicized and limiting narratives of Hero, Wounded Warrior, or Killer. The fictive piece represents the experiences of transition that illuminate a civilian privileged higher education system and society-at-large. Operation Transition exemplifies and acknowledges that value of stories for understanding and community building. As such, Operation Transition, which includes critical pedagogy and narrative inquiry, concludes that in order for improvements to be made in higher education, both those in the academy and Veterans need to listen to each other's stories, with humility and respect, so they can understand each other, honor each other, and work together to make change. 


\section{TABLE OF CONTENTS}

Land Navigation for Operation Transition ..................................................................

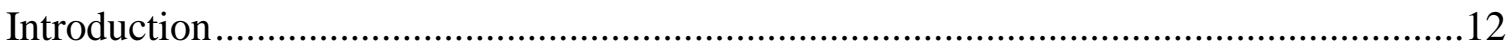

Two Marines and a Sailor Walked Into a Classroom, Jamie's Story ................................28

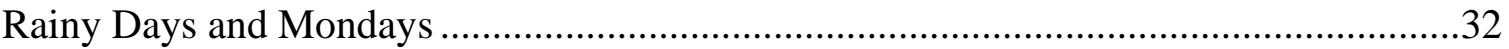

Honor, Courage, Commitment, Sgt. G's Story …………………………………..........

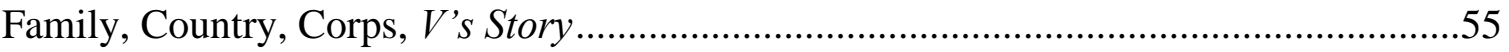

Once a Marine, Always a Marine, Lance's Story ………………………………….........77

No Greater Friend, No Worse Enemy, Beaver's Story ....................................................104

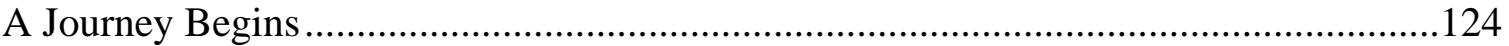

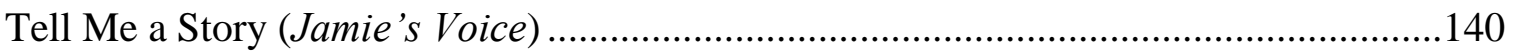

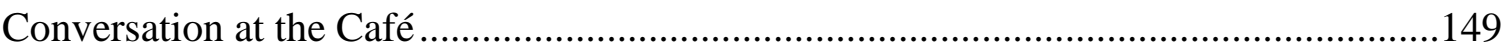

Dreams, Dialogue, and Other Developments ............................................................180

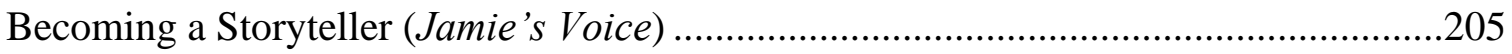

Reconnaissance: The Listening Guide ......................................................................221

What are you doing, Mom? (Jamie's Voice) ………….....................................................23

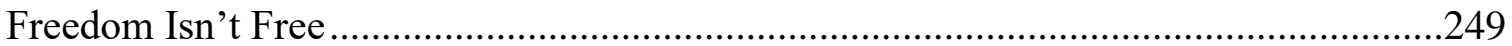

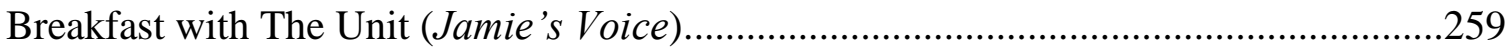

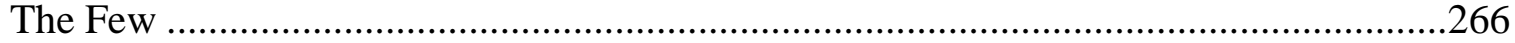

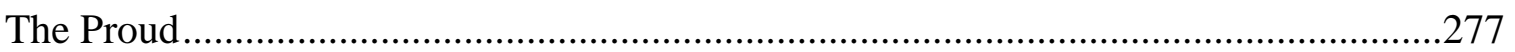

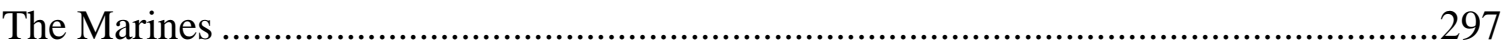

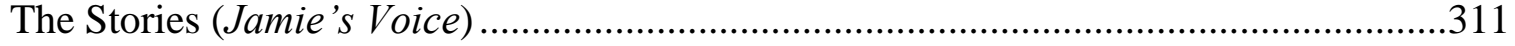

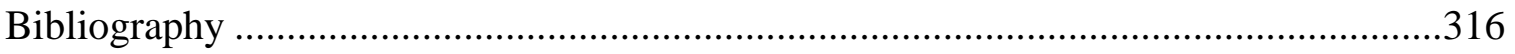

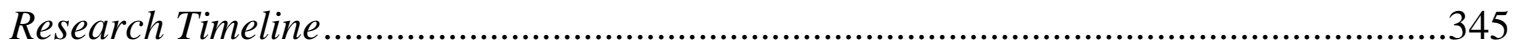

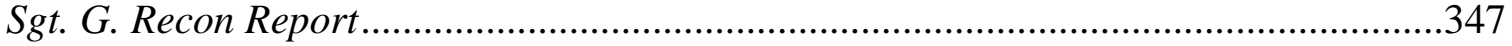

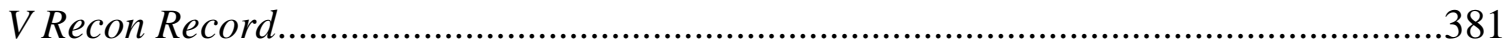

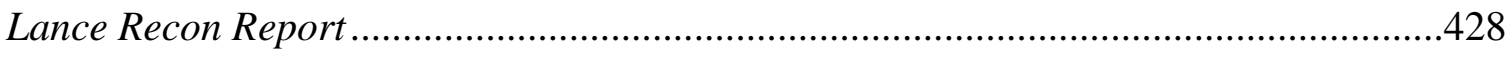

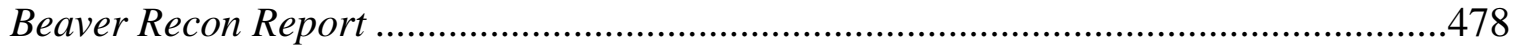

Please note, all photos and artwork by Jamie Fenton, unless otherwise noted. 


\section{Land Navigation for Operation Transition}

This dissertation is not a traditional dissertation, and includes all the blood, sweat, and requirements of the traditional five-chapter doctoral dissertation submission. The representation of the data and analysis is done through Arts Based Research; it is by far not the first of its kind (Knowles \&

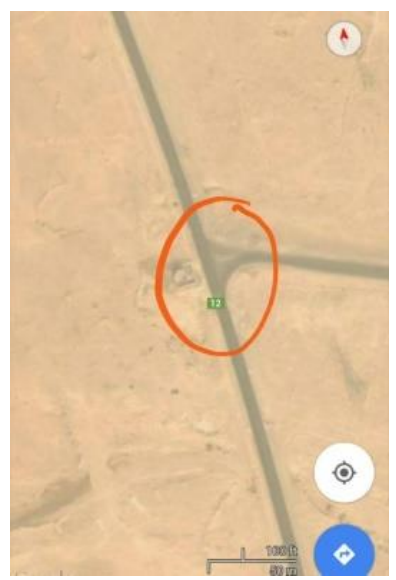
Promislow, 2008). However as "stories (narratives, myths, or fables) constitute a uniquely powerful currency in human relationships" (Gardner, 2011, p 40), it made sense that this investigation use Arts Based Research to advance the knowledge of the role of higher education in the transition for Veterans. The use of Arts Based Research will increase the audience as well (Knowles \& Promislow, 2008). As "study after study after study finds that stories are far more persuasive than just stating the facts" (Smith, 2016), the use of a story will make a greater impact on those who experience, or read, it.

This piece is not meant to definitively answer a question; instead it is meant to add to the pool of knowledge by showing the diversity of narratives of Veterans, particularly Marines. It is also meant to inspire additional inquiry about the role of higher education in the identity formation of Marines and other Veterans (Bach, 2007; Bowman, 2006; Clandinin, 2013; Chase, 2011; Delgado, 1989; Gilligan, 2015; Higgs, 2008; Leavy, 2015; Sermijn, Devlieget, \& Loots, 2008; Siegesmund \& Cahnmann-Taylor, 2008) so that better support, resources, inclusion, and transitions can occur for the generations of Veterans, and civilian students, to come. As the method of narrative inquiry, or fluid inquiry, is effective in aiding the disruption "when the longstanding assumptions and norms of a field are reexamined" (Connelly \& Clandinin, 2006, p 478), it is a fitting tool 
for this piece. For "no one's stories are quite like everyone else's" (Cole, 1989, p 11) and Marines are certainly as diverse as any other group (Hammond, 2015; Phillips \& Lincoln, 2017). Thus, through the use of narrative inquiry and story, this piece is designed to be more accessible to everyone, having a greater impact on the public perceptions and everyday practices of those who work with Marines, and well as contribute to the research literature (Connelly \& Clandinin, 2006).

This land navigation system will dispel any tension or unease you may feel at reading something that deviates from the traditional academic dissertation. Consider this a compass of sorts to help with the navigation of this new terrain: an artistic presentation of theory, research, data, and analysis.

\section{Roadmap}

Each traditional five-chapter dissertation contains six important elements, all of which are included in this piece.

1. The statement of the problem can be found in the Introduction, pages 18-20.

2. The literature review exists throughout the work, thus the Literature Coordinates are provided below for your convenience.

3. The theoretical framework is outlined in a detailed conversation with the theorists themselves in Conversation at the Café (included at the end of this chapter).

4. The methodology \& methods are discussed here, in Land Navigation for Operation Transition, in addition to the methodology being discussed at length in Dreams, Dialogue, and other Developments, while the actual methods are presented mostly in Becoming a Storyteller, Reconnaissance: The Listening Guide, and What are you doing, Mom? with a few additional pieces in Breakfast 
with The Unit, as they are built into the story of The Unit.

5. The results of the research are included in the stories from the Marines themselves, and their introduction is included in the Navigation Guides below.

6. The conclusion and recommendations for the future are included in The Few, The Proud, The Marines, and The Stories

\section{Literature Coordinates}

Dewey, 144, 159, 173, 198, 200, 201, 203, 207, 208, 217, 250

Freire, 153

Conscientizaçāo, 137, 153, 165, 175, 181,183

Creativity, 250

Critical Pedagogy, 8, 177, 241, 242, $248,249,250$

Curiosity, 243

Humanization, 176, 178, 179, 241, 242, 250, 251

Liberation, 242

Naming, 26, 249

Praxis, 154, 174, 252

Unfinishedness, 136, 138, 155, 175,

176, 181, 207, 249

Fromm

Being, 155, 208

Belonging, 163, 166

Critical Theory, 29, 174

Democracy, 162, 178

Having, 138, 182

Humanism, 179, 252

Love, 154, 182

Identity, 52, 131, 133, 134, 135, 136,

137, 138, 139, 140, 141, 142, 150,

218, 224, 277, 278, 305, 311, 314, 315

Leadership, 68, 113, 115

Poor Example, 44, 46, 66

Through Service, 35, 128, 129, 179,

211, 245, 246

Transactional, 66
Transformational, 44, 128, 129, 246, 247

Rogers, 182

(In)Congruence, 77, 135, 141, 178

Becoming, 155, 159, 180

Dialogue, 8

Humanistic, 154, 165, 175, 177

Unconditional Positive Regard, 158, 176, 178

Veteran Critical Theory, 2, 169, 170, 171, 277, 278, 281, 287, 289, 290, 295, 300, 303, 304, 310, 315, 316, 322

Veterans, 26, 65, 99, 147, 149, 204

Transition, 43, 44,45, 49, 100, 101, 102, 104, 119, 121, 126, 138, 139, 189, 191, 272, 273, 277, 285, 291, 292, 293, 294, 305

Organizations, 96, 98

Veterans in Higher Education, 14, 20,

93, 130, 131, 281

Benefits, 282, 300

Campus Resources, 29, 94, 99, 121, 295, 296, 297, 298

Challenges, 26, 43, 47, 70, 100, 119, 191, 287, 305

Federal Resources, 298, 300

Other Support Systems, 46

Other Veterans, 121

Other Vets, 29, 50, 71, 72, 121, 191, 192, 267, 274, 278, 280, 285

Post-9/11 GI Bill, 50, 51, 69, 119, 120

Transition, 285 


\title{
Navigational Guides
}

Athena: Primary Storyteller; Inspiration for the creation of The Unit

\author{
I am a God \\ of wisdom \\ of justified warfare \\ of heroic endeavors
}

I am a meddler in the lives of mortals, including the others in this story

I am Athena

Jamie: Secondary Storyteller; Main character in A Devil Dog's Daughter and Two Marines and a Sailor Walked into a Classroom; Member of The Unit

I am Mom, Mama, Mother

I am the daughter of a Marine

I am a researcher, full of curiosity and questions

I am an educator and student, a lifelong learner

I am a listener and lover of stories

Beaver/Tony: Marine in No Greater Friend, No Worse Enemy Member of The Unit; description in his own words (The Unit Meeting, 12/13/15)
I am funny
I am grateful
I am a son
I am a brother
I am a boyfriend
I am kind
I am friendly
I am frustrated
I am not a drinker
I am honest
I am a Marine

Lance: Marine in Once a Marine, Always a Marine; Member of The Unit; description in his own words (Individual Meeting \#2, 12/28/15)

I am driven by honor

I am dedicated

I am the sole driver of my destiny

I am me 
Sgt. G: Marine in Honor, Courage, Commitment; Member of The Unit; description in his own words (The Unit Meeting, 12/13/15)

I am simple...

I am grateful...

I am a father...

I am a husband...

I am an American, who bleeds red blood like everyone else...

I am pissed at where this country is headed (at least at the idea and political influences that are current)...

I am missing the Marine Corps every single day that I'm not enlisted...

I am proud to have served, as well as proud of those who served with or and without me...

I am educated...

I am inspired...

I am a great friend and an asshole when opposed...

I am Sgt. G

V: Marine in Family, Country, Corps; Member of The Unit; description in his own words (The Unit Meeting, 12/13/15)

I am a Marine

I am good at heart

I am a son/brother

I am a hard worker

I am kind

I am easy to get along with

I am quiet

I am family oriented

I am eager to start my career

\section{Review of the Terrain}

This is a fictive piece, meaning it contains elements from the real or empirical world, as well elements of fiction that make the story relatable (Barone \& Eisner, 2012). It also means that it acknowledges that it is a work of fiction. Athena, the main story teller of Operation Transition, is not a living breathing being. However, she is able to move through time, space, and place to tell the stories of the members of The Unit (Clandinin,2013). She is able to see the research and meaning behind events, organizations, and interactions that those within the experience might miss. 
Athena begins our story with a call to action and a need to bring together a group of people to examine the transition experiences of post-9/11 combat Marines, Honorably Discharged, and to show how higher education played a role in their identity formation. Athena is the chosen storyteller as she is the goddess of wisdom, which is fitting for dissertation research that is an examination of higher education. Athena is also the goddess of heroic endeavors and justified warfare, an ideal connection for work with Marines. Also, as a Greek god, she has a history of meddling in the affairs of humans (Roberts, 2008; Schab, 1977), making her perfect for the role of inspiration and gatherer of the members of The Unit.

Athena tells a story about leadership, identity, college experiences, war, friends, family, and the coming together of The Unit. She tells a story because "stories of identity - narratives that help individuals think about and feel who they are, where they come from, and where they are headed - constitute the single most powerful weapon in the leader's literary arsenal" (Gardner, 2011, p 41). It is by listening to the stories of The Unit that we can learn about their past, their present, and their future. For stories tell us so much about "issues of self, identity, group membership, past and future, good and evil" (Gardner, 2011, p. 48). It is also through the stories that we walk along side of the storyteller, with them in the journey (Clandinin, 2013). It is important to point out, this is not the complete story. While this story and the stories of the individuals within stand alone, their stories are far from over. It is in the ongoing daily life experience that "narrative inquiry should begin and end" (Chase, 2011, p 421). Even as they read their own stories, and come to know their own identities more fully (Banks, 2008), they gain insights that alter the course of their future (Connelly \& Clandinin, 1990). Life narratives 
are simultaneously continuous, dynamic, and exhilarating.

As Athena is the storyteller, the role of the author may appear to leave my (Jamie's) hands. This is not the case. She is the storyteller, yet I am the author and writer of this piece, there is power in this position as my choices impact the stories that are told. However, the Marines' blessing and approval of their stories and the story of The Unit was crucial, so the power of my voice is supported by the power of their choice and control. My story, which is included predominately in A Devil Dog's Daughter and Two Marines and a Sailor Walked into a Classroom, is all an acknowledgement of how I entered the research and walked around the edges of the stories with these Marines (Leavy, 2009). This is similar to the Odyssey, where Odysseus is the storyteller for chapters IX and XII (Homer, 800 BCE).

Throughout the piece the term Veteran is used, as is Marine. The term Veteran is used to describe anyone "who is a current or former member of the active duty military, the National Guard, or Reserves regardless of deployment status, combat experience, legal veteran status, or GI Bill use” (Vacchi, 2012, p 17). The title of Marine is earned by those who complete boot camp, receive their Eagle, Globe, and Anchor (EGA), and become part of the United States Marine Corps (USMC or the Corps). It is a title that remains with them throughout their lives (Marines.com, 2014).

Lastly, our stories are not just about us. They involve the other people in our lives with whom we dialogue, make memories, and survive. The people in our lives help us make meaning of our ideas, work through our challenges, and write our stories. Relationships are a critical element of the story (Bach, 2007). So it is intentional and important that you meet a variety of people in the stories of this piece. Some are real 
people, who mean the world to the members of The Unit. Others, as this is a fictive piece, are a composite of a meaningful group of individuals. These meaningful composites, or combinations of people in a single character, are particularly true in the various dialogues with Jamie, as she has learned, and continues to learn, from a plethora of people. It is through the dialogue in this piece that discourse in learning (Freire, 2000; Rogers, 1967) is acknowledged and honored. The Roll Call below serves as a guide for the new people you will meet in each chapter.

\section{Roll Call}

\section{A Devil Dog's Daughter, Jamie's Story}

- Sgt. Stepo: Jamie's father, the first Marine in her life, Major influence in all realms of development, Friend, Mentor, Dad

- Ronnie: Jamie's student at East Forrest College, Army Veteran

Two Marines and a Sailor Walk Into a Classroom, Jamie's Story

- Tony: Jamie's student at East Forrest College, Marine, Major influence in Jamie's research, Friend, Later to be known as Beaver

- David: Student at East Forrest College, Marine, Died 10-10-14 (highly likely as a result of service related injuries)

\section{Honor, Courage, Commitment, Sgt. G's Story}

- Ricardo: Sgt. G's high school buddy

- Holly: Sgt. G's wife, mother of his children, support system

- Valdez: Composite Character of the faculty members who challenge the popular narratives, encourage critical thinking, and support Veterans in the classroom

\section{Family, Country, Corps, V's Story}

- Mason: Composite Character of the neighbors and community members who support $\mathrm{V}$ and his family as he grew up

- Frank: V's Brother-in-Law, Marine

- Oakland: V's Best Friend, Marine

- Rocky: V's Tattoo artist, Marine

- $I^{\text {st }}$ Sgt. Mulligan: V's First Sergeant, Marine

- Jillian: Composite Character of civilian hiring managers who see Veteran/military behaviors as cold, overly formal, and off-putting

Once a Marine, Always a Marine, Lance's Story

- Ares: Athena's brother, God of War - the bloodlust of violence

- Ms. Neesacoshy: Composite Character of teachers who gave up on Lance or 
sought out to "catch him" not support him

- Eric \& Jake: Friends of Lance, named for the founders of The Mission Continues and Team Rubicon (respectively)

- Rod: Lance's Battle Buddy, Marine

- Professor Andrews: Composite Character of the faculty members who see the military in an extremely negative light and disrespect Veterans in the classroom

- Don: Composite Character of the supportive and understanding Veteran Resource Center staff members

- Stephanie: Lance's wife

No Greater Friend, No Worse Enemy, Beaver's Story

- Grandma B: Beaver's grandma

- Harper: Beaver's high school friend, it is because of him that Beaver is a Marine

- Brandon \& Luke: Beaver's high school friends that also joined the Marine Corps

- Sgt. Diego: Beaver's Sergeant in $1^{\text {st }}$ ANGLICO, Marine

- Christian: Beaver's friend and mentor at San Gabriel Police Department

- Derek: Beaver's close civilian friend, "would have been a great Marine"

- Jennifer: Beaver's girlfriend

\section{A Journey Begins \& Tell Me a Story}

- Tallulah: Composite Character of the embodiment of Leadership through Service and the leaders and drop in teachers that Jamie has had the pleasure of knowing

- Jim, Pete, \& Randy: Composite Characters of the "Old Salty Dogs" of the Marine Corps who present what was and is for the Corps and Veterans, named for three of Sgt. Stepo's Marines, and fashioned after three Marines who met at McDonald's each morning while Jamie did research there

- Charlotte: Composite Character of the PhD colleagues who helped Jamie find her way through the research and the creation of this piece with endless discussions, encouragement, and the occasional drink

\section{Conversation at the Café}

- Paulo Freire: Educator, Advocate, most known for Critical Pedagogy, Major influence for the theoretical foundations of Jamie's work

- Erich Fromm: Psychoanalyst, Humanistic Philosopher, and democratic socialist, Major influence for the theoretical foundations of Jamie's work

- Carl Rogers: Psychologist, most known for Humanistic theories and Rogerian Therapy, Major influence for the theoretical foundations of Jamie's work

- Karl Marx: Philosopher, Socialist, Influence for the theoretical foundations of Jamie's work

- NOTE: The italicized sections of this chapter are quotations.

\section{Dreams, Dialogue, and Other Developments}

- Rose Mary: Really Athena in the body of Rose Mary, who is another teacher and mentor for Jamie 


\section{What are you doing, Mom?}

- Danny: Jamie's youngest son (born 2011), future Marine (according to Danny)

- Mikey: Jamie's oldest son (born 2009)

\section{Your Orders}

Please, enjoy the story and appreciate this representation of the research as "the text becomes, simultaneously, an empirical enterprise and a work of art" (Barone \& Eisner, 2012). As this is a piece of art, please note that you, the reader, have a central role in its existence. Your interpretations and reinterpretations are part of the experience (Barone \& Eisner, 2012). This may feel uncomfortable to the researcher in search of truth, yet, as stated before, this piece was not created to give one perspective privilege or priority over another. "Fiction allows writers and readers the freedom to remain open to new interpretation and to avoid closure on any research project" (Banks, 2008, p. 161). It is not closure, a single story, or an answer we seek. Instead, Operation Transition is a piece that hopes to inspire dialogue, reflection, and the desire to listen to the stories of others so that we can truly learn who they are. Realize that only four stories of Marines are included within these pages, and as uniquely similar as they might be to other stories, thousands of stories of transition exist. The stories of Sgt. G, V, Lance, and Beaver will bring to light the diverse and honest variety that exists among Veterans in hopes to disrupt the pervasive and limited narrative of Veterans. The restrictive stories of Veterans commonly believed are "an improperly informed narrative of our nation's service members and veterans [that] may also lead to an unsuitable set of success expectations [in higher education] that, when not met, engender deficit thinking and perpetuate damaging stereotypes" (Molina \& Morse, 2015, p 2). The insight gained from reading Operation Transition will lead to a more varied, deeper, and suitable 
understanding, which in turn leads to the creation of improved situations (policy, culture, engagement) on college campuses, and beyond, for Veterans in transition. 


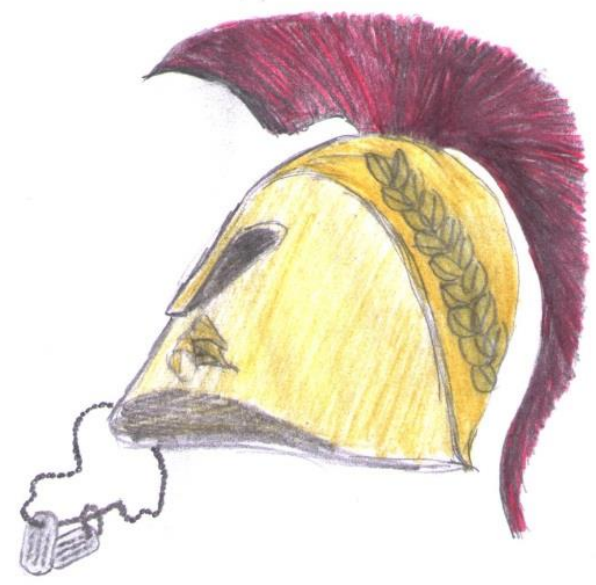

\section{Introduction}

It pained me to look upon the world and the response to military Veterans. The treatment of the heroes I stood beside, strategized with, and inspired was fitting of an ox, not a human. Cared for only while working and able to fight, they were discarded by the Department of Veterans Affairs (VA) to wait in lines or became lost in stacks of paperwork in search for the simplest of solutions or answers. The men and women, who fought, bled, laughed, risked, shared, and died for one another in a bond of brotherhood deserved and earned the community and support of the people and land that they loved. After all, they volunteered!

After battle, life should be more peaceful, but unfortunately in the civilian world, the value of wisdom and experience gained in the armed forces is nor as valued as wealth or fame. Thus, the return to society was a clash with illogical priorities that left Veterans feeling uncomfortable and guarded. Society labeled them broken. So much work needed to be done.

The need became even more obvious to me when I wandered around college campuses. As the goddess of wisdom, higher education is one of my homes on earth, 
because it is a comfortable and beautiful place of learning, sharing, and growing. Since my deepest passions are with wisdom, thinking, creativity, and imagination, I often visit colleges to recharge myself and inspire the students and teachers. However, my visits on campuses after $9 / 11$ began to remind me of my place as the goddess of justified warfare and heroic endeavors. I found thousands of former service members attending classes on the college campus; in fact, it was the greatest enrollment of Veterans in higher education since World War II (McBain, Kim, Cook, \& Snead, 2012). Each visit was another reminder about the benefits, challenges, and rich stories of the men and women who served in the armed forces.

I apologize, as I have not introduced myself. I am Athena, most well known as the goddess of wisdom. My mother, Metis, was the goddess of common sense. However, because of prophecy and fear, my father, Zeus, ate her. As a result, I was born from Zeus' head (Schwab, 1977; Roberts, 2008), and was blessed with "the power of a male warrior" (Woff, 2003, p 9). Thus, I was able to serve as an example, from Mount Olympus, of the power and ability of women, when they are perceived as equals to men (Roberts, 2008). You could certainly call me a feminist, I do. I am also connected to creativity and the arts, which is a realm of imagination and possibility (Rose, 1959). While my brother, Ares, is most identified with war, as he is the "god of war," I represent the opposing side to his aggression and violence. I, Athena, support the heroes and wars that are just, strategic, and moral, as wisdom and caution are always critical to military engagements (Athena, 2006). Throughout this story, you may learn more about me, but this story is not about Athena. It is about the Veterans who have served then returned to civilian life, and their identity transformations. 
Operation Enduring Freedom (OEF) continued for over a decade (Ostovary \& Dapprich, 2011) and just between 2002 and 2007, over 1.5 million service men and women were deployed (Hosek \& Martorell, 2009). When OEF officially ended on December 31, 2014, the campaign became Operation Freedom's Sentinel (OFS) on January 1, 2015 (U. S. Department of Defense, 2015). Add to that Operation Iraqi Freedom (OIF) from 2003 to 2010 and Operation New Dawn (OND) from 2010 to 2011 (Torreon, 2015), and it is logical that the Veteran population has increased. As those men and women left the military service, voluntarily or involuntarily due to the drawdown (a systematic decrease in military personnel through discharges or the removal of the option to re-enlist), many returned to college and utilized their Post-9/11 GI Bill to finance a portion or all of their educational endeavors (US Department of Veterans Affairs, 2013). The transition back to student led to additional challenges when placed on top of the already significant transition to civilian (Ackerman, DiRamio, \& Garza Mitchell, 2009; Brown \& Gross, 2011; DiRamio \& Jarvis, 2011; Glover-Graf, Miller, \& Freeman, 2010; O’Herrin, 2011; Rumann \& Hamrick, 2010; Whiteman, Barry, Mroczek, \& MacErmid Wadsworth, 2013). This was, unfortunately, in part because the lives of Veterans were often misunderstood by many civilians. The perceptions and expectations for members of the armed forces were often formulated from a place of worry, sympathy, or fear. Thus, the Veterans were forced to navigate a world full of opinions, often molded by uninformed civilians, which greatly impacted their employment, education, health, relationships, and daily life.

Veteran experiences and personalities since 9/11 were reduced to sound bites, or stories, that would play well in the media (Gardner, 2011). Stories hold tremendous 
power. Stories help children learn their identities in a group, the ways to behave and treat people, and the consequences for bad behaviors (Gardner, 2011). Stories also tell the world about heroes, like Odysseus and Hercules (Roberts, 2008; Schwab, 1977). Stories show everyone what it meant to be heroic. However, the narratives were incomplete, as they were part of a culture that wanted to crystalize a very specific perception of heroes (Gardner, 2011). The Battle of Thermopylae, where 300 Spartans went up against the entire Persian army, and all died heroically in a fight for freedom (Hanson, 2011). In the $21^{\text {st }}$ century the story that became both a graphic novel and a major motion picture, titled “300," had the Spartans fighting alone (History vs Hollywood, 2016). In reality, they were part of a much greater force that included Athenians (thank you), other Spartans, and other allies (Hanson, 2011). However, the story of heroes that lived was of only 300 Spartans; that perception was pervasive, and thus provided evidence of the power of stories (Gardner, 2011).

That concept of hero remained and was often reinforced by the media, particularly when came to the "superheroic killing machines" in blockbusters like Lone Survivor (Merry, 2015); a film based on the true story of Marcus Luttrell (the only survivor), Michael Murphy, Danny Dietz, and Matthew "Axe" Axelson (Luttrell, 2013). Or the service member that single handedly saved their whole unit. Although that would not be the story the Veteran would tell, it was the story that was told for them, about them, by the media. The story of the "war hero" is a powerful one (Moore, 2014) and it has an impact on the identity of Veterans (Arminio, Kudo Grabosky, \& Lang, 2015).

Although, even more damaging is the view that Veterans are heartless killers. One of the most disturbing portrayals of this narrative was recently presented in the 
Netflix sensation, Orange is the New Black, season 4 (Herrmann, Kohan, \& Bernstein, 2016; Hess \& Constantine, 2016). The idea to hire Veterans as prison guards was for the tax benefit that was created to help unemployed Veterans find jobs (ACCT, 2011). Although one executive worried about Veterans shooting everyone, he was comforted by another executive who reminded him that if anything happened, they would already be in a prison (Hess \& Constantine, 2016, 43:00). They followed through with the plan to hire the Veterans. Later in the series, in a conversation following a traumatic event for a civilian guard, one of the Veteran guards tried to console him with the following story: In Afghanistan, I killed some people. Some innocent people. So much time spent chasin' after the bad guys, and then you don't get 'em, and then they blow up your friends or shoot up your convoy, and you just get so mad, tired and bored. So you just grab a farm kid from a grape field, and you make him juggle live grenades until one of them blows up. And then you shoot him because you don't want him to grow up without arms or tell on you. Or maybe you just strangle a girl that you've had sex with in a small village because her family's gonna kill her anyway, right? And you just gotta get over it” (Herrmann, Kohan, \& Bernstein, $2016,12: 52)$

Not a single Veteran on the show was portrayed in a positive light. In an experience common for many marginalized groups, their depiction failed to represent the variety within the Veteran community; an (Delgado, 1989). The story of the "killer" also influences the view of self or identity for Veterans (Arminio, Kudo Grabosky, \& Lang, 2015).

More pervasive than a story of Veterans as malicious, was the narrative that of the 
"damaged combat vet" (Moore, 2014), who was a ticking time bomb just like the Navy SEAL from American Sniper. Another film based on the true story of sniper, Chris Kyle (Kyle, 2013). That story and negative perception was reinforced and maintained in part by the media portrayal of combat Veterans. Haynie (2012) found that the New York Times published numerous articles in 2008 highlighting cases of OEF and OIF Veterans committing killings, however research by the Department of Justice implied that "veterans might actually be less likely than their non-veteran, age-group peers to commit a violent homicide" (para 7). Most civilians were unaware of the facts, and were misled by the media's presentation of Veterans. As a result, many civilians engaged with Veterans as if they were fragile (Sammons, 2005), this was far from the respectful foundation needed to build a healthy relationship.

Most civilians, inside and outside of higher education, think that Veterans returning from combat suffer from Post-Traumatic Stress Disorder, more commonly referred to as PTSD (Military.com, 2014). The connection between Post-9/11 combat Veterans and PTSD was solidified in society to the point that PTSD and Traumatic Brain Injury (TBI) were “dubbed 'signature injuries' of the Iraq war” (Hoge, 2010; National Council on Disability, 2009, p 1). However, research findings suggest that the most common service-related disability is hearing loss, effecting approximately $80 \%$ of Veterans (Miller, 2013) and costing the Veterans Administration $\$ 1$ billion a year (Roach, 2016, p. 68). Also, military service training itself may result in behavior that could be identified as PTSD symptomology. Part of the survival for a combat unit, and each individual member, relied on the ability of each service member to be aware of their surroundings at all times. Police officers have similar training. Thus, it may be the 
training, and not trauma, that leads to hypervigilance (Rumann \& Hamrick, 2010). Another result of training is learning to function on little sleep, as many Veterans no longer require the same amount of sleep as they did before service and some cannot sleep, or sit still, for long periods of time (Ackerman et al., 2009). These behaviors may look like PTSD, even if they are not.

The reason the flawed belief that all Post-9/11 Veterans are suffering from PTSD is so dangerous was because it is associated with another misconception, that Veterans with PTSD are all unstable, aggressive, and ready to explode. There are also the structural responses that result in significant career limitations as many employers, coworkers, and customers have decreased confidence in someone with PTSD (Sammons, 2005). For many civilians, Post-9/11 Veterans did not even need the diagnosis to be doubted, as the association between service and PTSD was so strong. I found this association disheartening, particularly when it occurred on college campus.

College campuses are supposed to be a place of learning, personal growth, and student support. The university is a place of critical thinking, discussion, and inquiry in hopes to create "a more just, democratic, and human public sphere" (Pollard, 2015, para. 6). So, when a group of students is marginalized, that needs to be remedied. When it came to Post-9/11 Veterans, unfortunately, civilian collegiate faculty and students sometimes failed to see the benefits of having Veterans on campus, and even belittled or disrespected the military at times (Arminio \& Kudo Grabosky, 2013; Cropsey \& Hendrickson, 2013; DiRamio Ackerman, \& Mitchell, 2008; Persky \& Oliver, 2011; Rumann \& Hamrick, 2010). Such experiences made Veterans feel unwelcome on campus and led to increased attrition rates. It also increased feelings of isolation, already 
present because of the separation from the military family (Rumann \& Hamrick, 2010). The identity of the Veteran was greatly impacted, as they moved from belonging to a group willing to die for one another to being a single individual (DiRamio \& Jarvis, 2011). The loyalty of Marines specifically may make the transition to civilian and student life even more difficult, as the stronger the military identity, the more difficult the transition to civilian will be (Castro, Kintzle, \& Hassan, 2015a).

Because of the numerous financial benefits that accompany Veterans on campus, as they are a fully funded population because of the Post-9/11 GI Bill, many institutions of higher education intentionally recruited Veteran students (Sander, 2012). Recruiters of for-profit institutions were often the ones that took the most blame for this practice (Obama, 2013), however all institutions of higher education began to be more "Veteran friendly" after the creation of the Post-9/11 GI Bill mostly because it was a good business decision. Yet, the same institutions that actively sought out service members often failed to serve the men and women who served in the military once they were on campus. The research on the needs and challenges for Veteran college students was full of stories of disconnection, difficulties processing benefits, and issues readjusting to the culture of higher education (Ackerman et al., 2009; Brown \& Gross, 2011; DiRamio \& Jarvis, 2011; Glover-Graf et al., 2010; O’Herrin, 2011; Rumann \& Hamrick, 2010; Whiteman et al., 2013). There was just as much research that told success stories of campus programs that created places for connections, developed policies that made the dealing with the VA more palatable, and facilitated the readjustment to being a student and a civilian (Arminio \& Kudo Grabosky, 2013; Brown \& Gross, 2013; DiRamio, \& Jarvis, 2011; Jackson, Fey, \& Ewing Ross, 2013; Lokken, Pfeffer, McAuley, \& Strong, 2009; McBain et al., Kim, 
Cook, \& Snead, 2012). What was missing, however, was an investigation into the lived experiences of Veterans themselves that did not focus on their deficits.

Veterans are people with all their faults and virtues. They are also complex texts for a society to read and interpret... Their stories bend and twist down many roads, assaulting our assumptions about ourselves and our world. That's one reason why we continue to search for the right metaphor." (Casey, 2014, para 9). There was a need to excavate the challenges that Post-9/11 Veterans faced as a result of systems and structures that often failed to acknowledge their past experiences or, worse, assumed knowledge of their lives and ignored the intricacies and variety within the very diverse population. There was much to be learned by investigating the changing identities of the service members as they returned to civilian life, and the role that higher education played in that transition.

In order to deal with this gap, I looked for and found someone to investigate the story in a manner that was based on mutual respect. I chose to inspire that daughter of a Marine, who was a mother of two boys, a teacher, and a feminist as well. She possessed the sensitivity and compassion to find the other stories and share them with others. She was able to work in a group of Marines, collectively called The Unit. Her part in the group was hearing and retelling the stories of Marines, as well as leading the critical conversations and discussions of the group. Together they investigated how higher education contributes to the identity formation of Marines, after military service. The examination was not about what Marines lack or how they are not successfully becoming civilians. The Unit examined their experiences in higher education to see if they illuminated a civilian privileged educational system. Through twenty-six (26) hours of 
individual conversations, thirteen (13) hours of group discussions over breakfast and artistic creations, and over one-hundred and seventy-five (175) hours of analysis (using the listening guide within narrative inquiry) and first-draft writing, The Unit began to untangle the identity transformation of honorably discharged Post-9/11 combat Marines, a branch that has a harder transition experience than members of other branches of the armed forces. As a group, they discussed important issues, as identified by the Marines in The Unit. The results of their work live within this tale of authentic transition experiences for Marines as they returned to civilian and student life. Enjoy this artistic retelling of the stories of V, Sgt. G, Lance, Beaver, Jamie (Sgt. Stepo's daughter), and their journey as The Unit. Listen both the melody of the research, and the harmony of the art, and do not turn away from the sound! 


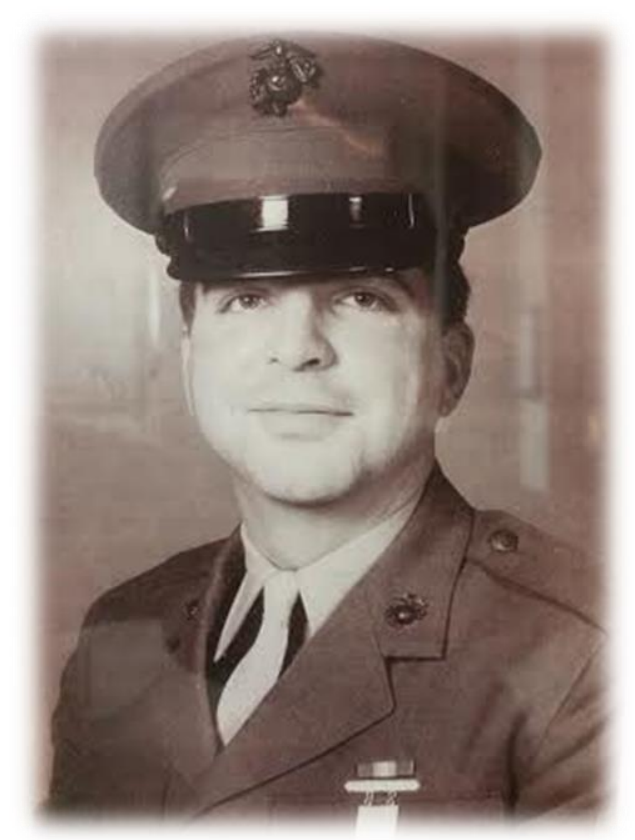

Photo courtesy of Sgt. Michael Steponovich

A Devil Dog's Daughter, Jamie’s Story

"I cannot remember learning my father was a Marine,” Jamie began, “just as I cannot remember learning how to swim. I know I had to learn it at some point in my life, I just cannot tell you of a time that I didn't know it to be true."

I was so excited, I had found my mortal to inspire; she was the daughter of a Marine, a mother of two, and an educator of numerous Veterans, teaching them about psychology and communication. She was an outsider and an insider of higher education, military service, and came into both roles with an open mind and an open heart.

She continued, a smirk slowly creeping onto her lips. "I can remember being at a concert with the Marine Corps Band. You know, the Marine Corps Band is referred to as 'The President's Own' as they are the band that plays at most major Presidential events. Anyway, I must have been about 6 years old sitting and listening to the music as they were playing a variety of songs. They were an amazing band, and of course we had to attend because my dad was a Marine. 
"While I cannot remember most of the concert, I can tell you that when the Marine Corps Band started to play the Marine Hymn, my father stood. Just as every Marine does when they hear that song. As the child of a Marine taught to stand as a sign of respect, I stood too. So did the rest of the row, and every row behind us. People can be marvelous followers! While I don't know how many Marines were in the auditorium that day, I know that everyone behind us stood when they heard 'From the halls of Montezuma, to the shores of Tripoli..." She laughed.

Jamie was perfect for the civilian investigator role within the Unit. The smile in her eyes as she spoke of her Marine father led me to believe that inspiring her involvement would not take much. I would never be mistaken for one of Apollo's muses, I am the goddess of wisdom, but I am more than capable, and experienced, at meddling in the lives of mortals. My past spoke for itself with my infamous support of those heroes who remained just, moral, and truthful (Rose, 1959; Woff, 2003), such as Perseus, Odysseus, and Heracles (Hercules in Roman) (Roberts, 2008; Schwab, 1977). But The Unit was not about me.

“Being raised by a Marine wasn't painful, really. I was raised to respect the military, respect police officers, and respect authority in general. I was raised in a house with guns, and taught from a young age to respect them, almost to the point of fear. It was ingrained in me that my best performance was always expected. This meant that my effort and focus in any activity, academic or athletic, should always be the best I could do. I didn't have to win or get an A, if I could walk away and honestly say I gave it everything that I had. And I always have to finish what I start.” Jamie smiled as she stopped to remember the past. 
It was a race she was running with her dad. I was there as well. Her father, his Marines called him Stepo, had found running as his new daily PT (physical training) and wanted to involve his children in the fun. So, at one of his races, he signed up Jamie for the one-mile run. At only a mile long it was something easily achieved by her 8 -year-old abilities.

She was ready. She had on fashionable jogging shorts that matched the sweat bands on her head and her wrists while she jogged in place to warm up for the competition that lay ahead. Her dad, next to her, talked her through the warmup process and the etiquette of starting a race. Each minute increased her nervous excitement.

Finally, the air horn sounded, and the race began. Jamie took off with the plethora of other runners, determined and focused on the race ahead. Unfortunately, she was not focused on the pavement and tripped. Jamie fell flat on her face; skinned both knees and the palms of both hands in her attempt to brace her fall. At that moment, the race was over. She had failed.

As she started to get up slowly and dusted the asphalt out of her palms and knees, the tears began to roll down her cheeks. Her father stretched out his hand, helped her stand, and told her it would be okay and to breathe.

"Let's get moving, we are in the back of the pack now." He said to wide, surprised 8-year-old eyes, quickly filling with more tears. “The race isn't over, you'll be okay. Let's move."

She continued to cry and frequently mentioned the blood slowly leaking from numerous scratches and scrapes in her skin. Each time, her father told her, "You'll be okay. We finish what we start. Keep moving." She must have whined that WHOLE 
mile, but she finished. She finished dead last.

As Jamie remembered about the race, she realized the impact that one major event, accompanied by a childhood full of reinforcement, had on her life. "I have to finish everything, or it seems to loom over me. I am a runner now, too, like my father before me. And because I am a runner, my children run the fun kids races at the $5 \mathrm{Ks}$. Every time we run, they listen as we repeat, over and over 'We can slow down, but we don't stop.' They know quitting is not an option! Heck, I even went back to finish a second Master's degree because of the 'Die or finish, but don't quit' mentality."

"And don't forget 'Pain is weakness leaving the body', Mom." One of Jamie's sons yelled from behind her. She chuckled. It was true, when they slowed down, she would remind them about keeping up because the pain was temporary, but glory lasts forever. As she thought those words, she heard her father's voice.

She often heard her father's voice, partly because she remained in touch with him frequently. Jamie was lucky to have a father who offered her a sounding board when she needed it or was available to help her come up with the word for a paper that was eluding her. He was often an editor (luckily, he learned early in her college career that she ignored the stylistic edits) and a friend to pull her off a ledge or push her a bit past her comfort zone. Being a Marine and a father, he regularly employed tough love. One such occasion was when Jamie momentarily doubted continuing her doctoral program.

"You can finish, or you can die trying. But if you give up, we're going to have a problem." He told her as he walked away from the table to refill her water. Nothing like being raised by a Marine, and he was never even a Drill Instructor. It is what she needed to hear though. Because, realistically those were her only two options. She would never 
be satisfied wondering what might have been possible, or if she could have done it. So, she buckled down, got to work and was able to stumble upon numerous breadcrumbs I left her in path to move her toward her role in The Unit. It was clear, by the way she spoke, that I had found the right person to investigate Marine transition to civilian life and the role higher education played in their identity formation.

Jamie was in one in the middle of a PTSD discussion as part of the Abnormal Psychology course she was teaching. One of her students, Ronnie, began to share his own story about his experience with PTSD.

“After I got back from Iraq, I refused to drive under overpasses. I would completely freak out when a helicopter would fly overhead. I didn't talk to anyone about it and tried to deal with it on my own (Ackerman et al., 2009; Livingston \& Bauman, 2013; O’Herrin, 2011; Phelps, 2015; Vance \& Miller, 2009; Vacchi, 2012). Later, I started to hear more about PTSD. It wasn't until I was sitting in a psych class, about three years after I got back, that I realized that it was PTSD. I finally had a name for it, and naming it helped me deal with it."

Ah, the power of naming, I thought. My friend Paulo Freire, a man with much wisdom, would smile at the mention of the power of naming things (Freire2000). Although, he would also wish that it was something named by those experiencing it, instead of by psychiatrists and researchers who look at the people with symptoms, instead of at their struggles with them (Freire, 2000). However, this was a great inspiration for Jamie, I could see her mind began to marinate on the numerous bits of information she had just received. 
This was not the first class she had with Ronnie, he had been her student for over a year. The thought of his years of struggling, without guidance and without support, tore her apart inside. I could hear her thinking "There has to be a better way. Is the culture of the military such that weakness is so unacceptable that genuine need is ignored? Is pain and discomfort so part and parcel to the experience that to complain, or talk to someone about it, is not even a thought that comes to mind. What is the military saying to these men and women that they return unable to ask for help? How can we make getting the help one needs something free of judgement and a perception of failure? How many other Veterans are suffering in silence?"

This was a beginning. Yet, Jamie was still looking at what was lacking with Veterans. Indeed, this would need to be a subtle inspiration that built slowly. She would be investigating through a deficient model for some time. That was part of the reason her involvement with The Unit is so critical. So much of what existed in the world media or research for Veterans was about what they needed to succeed, their struggles with addiction and aggression, their difficulties with PTSD, TBI, and transitioning. The world was looking at Veterans as wounded, broken, and in need of support. Such a view helped no one, really.

I had only begun to plant the seeds for Jamie, and I needed to find others to help inspire her in a greater, deeper perspective. But, little did she know that she was about to meet a Marine to help guide her on her journey. 


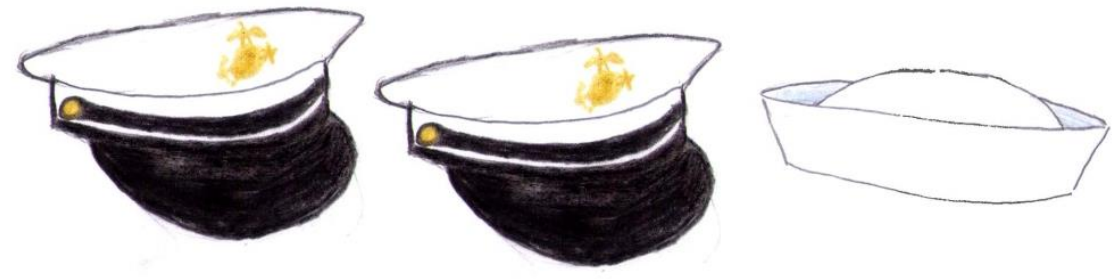

\section{Two Marines and a Sailor Walked Into a Classroom, Jamie's Story}

Jamie met Tony in an Introduction to Psychology class; he was one of her students. It wasn't until his time in the Abnormal Psychology class that his significant role in creating The Unit would become noticeable. Jamie would later get to know Tony as Beaver, a nickname from his Marines. For now, he was Tony in the civilian world. Tony, with two other Veterans, would truly inspire Jamie into embracing her role in The Unit and the examination of identity formation and transition of Marines through higher education. Jamie would later joke that "Two Marines and a Sailor walked into a classroom and changed this girl's life" all because of the experiences in the Abnormal Psychology class.

My role in making this class so impactful was quite fun. You see, being the goddess of wisdom means that I get to listen and engage in places of learning all the time. When I am on a personal mission to inspire a certain journey, I play more than normal. For that Abnormal Psychology class, I often had the conversations during the class veer more toward Veteran issues than purely that of psychological disorders and treatments. At times, it was the conversations about a military perspective on a disorder, while other situations were a complete tangent from the lesson plan to a different, yet still valuable, subject matter. It was this time in the classroom with civilian and Veteran students that 
Jamie began to really investigate, at a deeper level, her own beliefs and perceptions of Veterans transitioning back to a civilian identity, specifically in higher education.

One particularly critical moment occurred because of another Marine student close to the Two Marines and a Sailor, whom Jamie never met. David was a Marine who was loved by many, as a combat Veteran and former military arms instructor with quick wit and genuine spirit, there was never anything negative said about him. Unfortunately, he was diagnosed with a brain tumor, as a result of cancer that was highly likely a result of his service in Iraq (the radioactivity from the detonation remotes and improvised explosive devices or IEDs). Jamie witnessed the VA Hospital's treatment of David, through Tony and the other Veterans, and it gave her greater insight into how Veterans were treated, compared to their treatment while on active duty. This discovery was a crucial element in the critical theoretical lens through which Jamie viewed Veteran transition. My friend, Erich Fromm, would nod his head at this observation that production has become more important than people (Wallace \&Fromm, 1958).

Tony was also the Marine who started the Warrior Alliance, a group of Veterans and Reservists who could come together in a relaxed and informal setting on campus (Bellafiore, 2012; Kok, 2015; Livingston \& Bauman, 2013; Phelps, 2015; Rumann \& Hamrick, 2010). Their community served as a resource for one another when navigating school, the VA, or life outside of the base. Jamie supported Tony in his formalization of the Warrior Alliance as a recognized club on campus; even though he had been serving as a leader and support of numerous Veterans on campus long before the creation of the Warrior Alliance (Cook Francis \& Kraus, 2012; Cropsey \& Hendrickson, 2013; DeSawal, 2013; Hawthorne, Bauman, \& Ewing Ross, 2013; Mikelson \& Saunders, 2013; 
Osborne, 2013). However, her role in the creation of the student group, as well as working with Tony, began to solidify a perception among her civilian peers as the "Veteran lady." Soon, Jamie started getting emails about the military and Veterans, she was being tagged in Facebook posts about Veterans, by her civilian friends of course, and she began to have deeper, more authentic conversations with Veterans. She noticed that her knowledge base of the military, particularly the Marines because of her father and other exposure, was growing and, as a result, led to a greater level of trust with the Veterans she met. It was a beautiful process and it made the inspiration for her piece in The Unit stronger with each passing day.

Jamie, with the help of Tony and two other Army Veteran students (a male and female), conducted a Faculty Training for East Forrest College (Jackson, Fey, \& Ewing Ross, 2013). She touched on the differences between military and higher education cultures and challenged the faculty to examine their own beliefs and perceptions, as they impacted how they taught their civilian and Veteran students alike (Arminio \& Kudo Grabosky, 2013; Osborne, 2013). It was an accessible and impactful training for faculty and staff and an effective way to support the Veterans on campus (Arminio \& Kudo Grabosky, 2013; Cook Francis \& Kraus, 2012; Cropsey \& Hendrickson, 2013; DiRamio et al., 2008; Nichols-Casebolt, 2012; Osborne, 2013; Rumann et al., 2011).

The last essential piece of Jamie's journey to The Unit was when she began her role as a "researcher" as she became not only an educator, but an academic in pursuit of her Doctoral degree. The opportunity to officially begin an investigation into an issue that was near and dear to her heart created the perfect situation for the formation of The Unit. Jamie finally had the passion, the basic knowledge, and now the opportunity to sit 
with the Marines who possessed the stories that could make her investigation a deep, meaningful, and productive exploration of transitions, systems of power, and identity. 


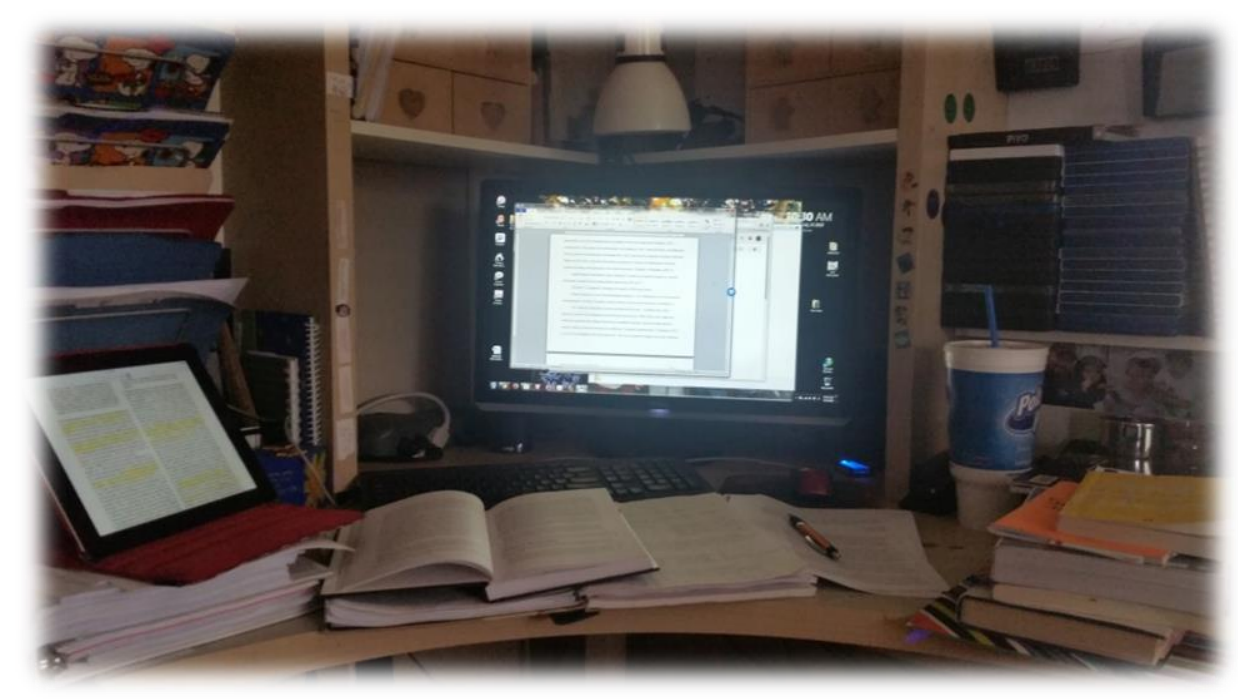

\section{Rainy Days and Mondays}

Jamie was getting in the habit of being productive while the boys were at school or at camp. So, like most workdays, when she was alone in the house, she prepared to work and turned on her computer. However, that Monday no work was going to happen that day. Although the sun was shining outside, and the air smelled of summer, Jamie opened her email and her heart broke. There are occasions I feel powerless, and this was one of those moments.

A few months before, Jamie applied for the Professor of Counseling - Veterans position at a local community college. It would have been a perfect fit, with her psychology and education background, previous teaching experience for most of the courses in the Counseling department, and her work with Veterans (not based from a deficit model). She was one of the best civilians for the job. I was excited when I pushed it into the job boards she often searched. Yet, the story read that it would have been perfect because it did not come to be.

On that Monday, she read:

The Academic Senate has completed the equivalency evaluation review of your 
application for the PROFESSOR OF COUNSELING - Veterans position. Your application packet did not include evidence of meeting the minimum qualifications for equivalency as indicated in the job posting. Your application, unfortunately, will not be considered further for this position... (Human Resources, Personal Communication, July 2015).

She stopped reading, as her lungs lost air. It was not the job rejection; she had read those numerous times before. It was the fact that now she had lost the opportunity to be of the most use to the people who she so desperately wanted to serve. She sat alone, among the piles of scholarly articles about Veteran transition, mountains of books about critical theory, Veteran and military stories, and research methods. When she was able to breathe again, it was to cry. It was in that moment she cursed the group she was trying to join. It was at that moment, she began to leave academia, even if she did not fully realize the departure for many months.

Jamie asked herself if it would impact her work with The Unit, and it of course it would. However, it did so in a way that made her research richer and fuller, as she was able to analyze higher education from an outsider position, even while she was immersed in academics as a professor and in the midst of the hazing ritual and tolerance test, or boot camp of the academic world, the Doctoral Dissertation.

That experience was crucial for Jamie, as it made her reevaluate the purpose of her work. As a lifelong student, she had always felt accepted and welcomed on campus. She had several degrees to "prove" her worth. Her pursuit of a PhD was never about getting an academic position, even if many classroom and colleague conversations were about creating a marketable research agenda that could also lead to publications for their tenure file.

After that email, it became completely about the Marines in The Unit. Jamie 
knew that her responsibility was to ensure that their stories were heard by those within the ivory tower of academia, so that their Veterans were not as easily dismissed as she was based solely on the paper qualifications. Academics sometimes have a tendency to ignore the massive experience and significant learning that can occur outside of the classroom, within life. Inside the ivory tower, they occasionally begin to believe that only the learning happening inside campus walls is valid or respectable.

It took a few weeks after that rejection for Jamie to finally be able to really focus on the work with The Unit. She needed to get the group together, so they could become The Unit to do their work. They would have to process through the group development stages, forming, storming, norming, and performing stages (Tuckman, 1965), and that would take some time. Yet, Jamie needed to find the Marines that would be in The Unit and meet with them individually first.

She was disappointed about the job, but nothing could quell her excitement about the opportunity to begin the work with The Unit. Once she finally got her head in the game, she sent a text to Beaver. That was the easiest text, because Beaver and Jamie had already had numerous conversations, about all sorts of interesting topics, over lunch. Of course, he said yes. He was always willing to help Jamie if he was available. The second request she sent was to $\mathrm{V}$, as he was another former student that she knew was a Marine. She wondered if he just said yes because she used to be his professor. He didn't; he too wanted to help. The third Marine was a bit trickier to recruit, and it was actually through Sgt. G's wife, Holly, that Jamie came to meet Sgt. G. He, too, was happy to be part of the group and easily joined the conversation. The final request Jamie sent was via email to Lance. Jamie met Lance when she joined Team RWB, she knew he was a Marine, and 
he had mentioned he was working on his Bachelor's in psychology. So she figured, why not ask.

All of the Marines in The Unit were males who served in the USMC after 9/11, were deployed during their service and experienced combat, after which they were Honorably Discharged. As a result, they were all in their late 20's to early 40's. They were all currently or previously students from various institutions including community colleges, four-year colleges and universities, and for-profit colleges. The Unit's racial and socioeconomic make-up was a mixture of Latino and Caucasian males born into lower and middle-class families. Together, they were The Unit.

You might wonder why Jamie did not select any female Veterans for the group. She thought about it, as did I. Yet the experiences of females in the military are so significantly different from males, that to include them in a group would deny them the attention and focus they deserve. So, The Unit consisted of only male Marines.

It did, however, mean that Jamie was the only female in the group. She was an outsider as a civilian and as a woman. However, as she was raised by a Marine, she was not completely unconnected. The fact that she had some connection facilitated her entrance into the group. Also, the fact that she was a female meant that the Marines did not include her in the immediate comparisons of where they fell the hierarchy of military, MOS, unit membership, and combat experience. In many ways, she was privileged as the researcher, the host, and a professor. In other ways, she was not even viewed as existing on the same playing field as these combat Marines. They did not view her as being superior. Although it went against my feminist beliefs, it was a benefit for the group dynamics, as it allowed Jamie to lead through service (Greenleaf, 2008; Wheatley, 
Spears, \& Noble, 2004; Zander \& Zander, 2000).

At last, the stage was set. The players were all in place. The inspiration has been successful. Additional influences from wise and genuine souls awaited Jamie, to guide the work. She was ready and so were the Marines. 


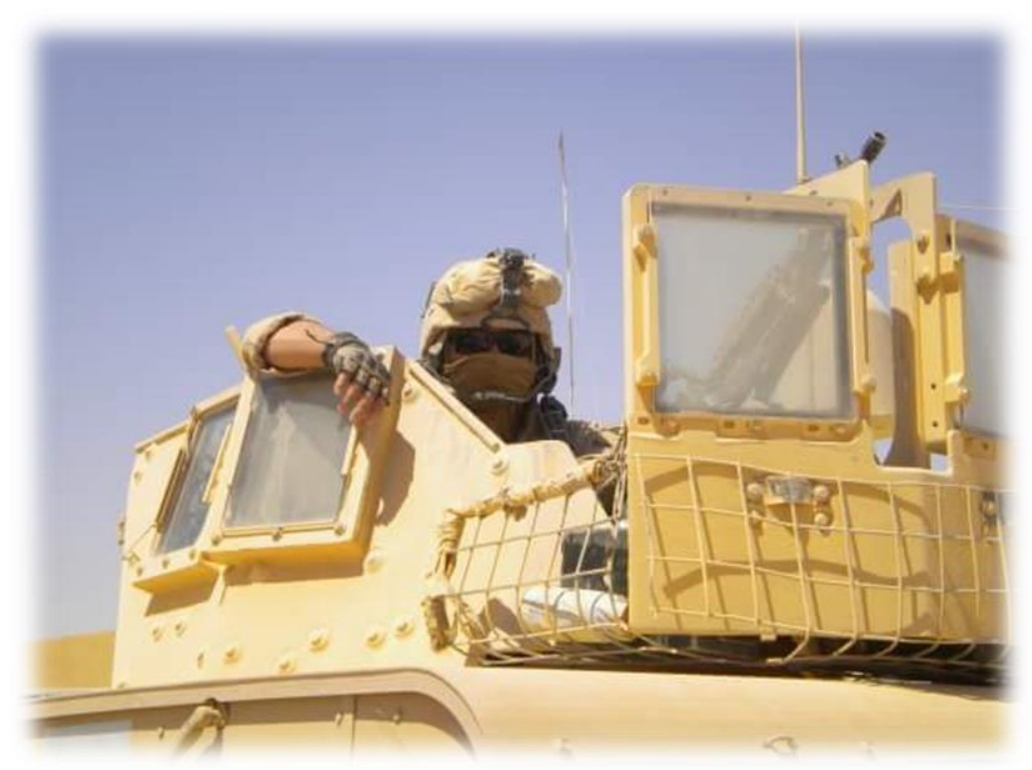

Photo courtesy of Sgt. G

\section{Honor, Courage, Commitment, Sgt. G's Story}

As the goddess of justified warfare, I admit there were occasions when I selected, or added a bit of motivation, to those who I believed would make quality service members. I sought out those who considered military service to serve, not for fame, glory, or kill numbers. It was through one of these motivating occasions that I meet Sgt. G. He was thinking about joining but wasn't doing anything more than thinking. Sgt. G was a potential service member, whose desire to serve others and be a mentor was palatable. His desire to put himself last, behind his country, his community, and his family was evidenced in his stories and witnessed in his life. So, one day, when he was riding down the street with a friend, I took the opportunity to intervene.

Sgt. G was a local Orange County boy, born and raised. Riding bikes along the trails and streets of the foothills was a common afternoon activity.

“Come on man, speed up!” Sgt. G. yelled back to his friend Ricardo. Ricardo took the request as a challenge, and went full speed down the hill on Chapman Ave, next to Rancho Santiago College. 
Sgt. G refused to be outdone. He sped up, passed Ricardo, and turned back to laugh. I took that moment, while he was looking back and failing to see that the curb was only an inch away from his tire, to give the bike an extra push. I only needed an inch.

Sgt. G's front tire hit the curb with such speed that he immediately flew over the handlebars. His face collided into the concrete sidewalk with a sound that hurt Ricardo, who immediately stopped to ensure his friend would survive. Sgt. G. was bleeding all over his face, hands, arms, and shins. His attempt to protect himself and failure to completely dismount his bicycle resulted in scratches, aches, and pains that would last for weeks. The bike was a mess; it looked like a giant had tried to tie it in a knot, as the front tire was twisted around the back one.

Sgt. G, sat up, slowly, and winced with pain. His eyes took a second to refocus, and he could tell by Ricardo's expression that he looked awful. So, in attempt to seem tough and to let his friend know he would be okay, he smiled.

Ricardo clutched his stomach as he let out a laugh that at once comforted and worried Sgt. G. His concerns were confirmed when his eyes followed Ricardo's outstretched hand pointing to a bloody tooth on the ground.

"I lost a tooth?!" he exclaimed. All Ricardo could do was nod in response, as he doubled over in laughter.

At that, Sgt. G knew that only thinking about joining the service was over. At that moment, he had some sense knocked into him. It was sitting on that curb, missing a tooth, that he thought to himself, "I have to do this." All he needed was a little push, literally, which I was happy to provide. A few weeks later, he sat in the recruiter's office, which was the second time I had to intervene. 
Sgt. G sat across the desk from an Army recruiter. That wasn't what I wanted at all. I admit my biases, and there are times that certain individuals are meant to serve in a specific branch. Sgt. G was meant to be a Marine; his potential enlistment with the Army was not acceptable. Luckily, I was able to bring forth a medical condition in his application that could be easily cleared later. So, when he returned to find the Army recruiter absent, and the Marine recruiter available (both a result of my influence), the medical condition was addressed, signed off, and Sgt. G was one step closer to becoming a United States Marine.

Sgt. G would tell you part of his decision was due to the Marine Dress Blues, the formal uniform that is thought by many to be the best-looking military uniform. Yet, it was his desire to do more, and be more, that drove him to test his limits by enlisting in the Marine Corps. He signed the paperwork in December 2001. In March of the following year, he found himself on the yellow footprints at the Marine Corps Recruit Depot (MCRD), in San Diego, California. "Every recruit begins their transformation into a Marine on the same iconic yellow footprints" (Marines.com, 2016b, para 1). Yet, it was not until he completed the Crucible that he felt like a real Marine.

I can still remember hearing him think "if I don't get past this evolution, I'm not gonna be a Marine." He made it, received his Eagle, Globe, and Anchor (EGA), and cried like a baby at Boot Camp Graduation. I smiled every time I watched those hardened men and women, who survived at least 12 weeks of intense training, conditioning, and challenges, begin to sob uncontrollably during their graduation. Although many keep it together, with only quiet tears trickling down their cheeks, many Marines are emotionally moved as they officially become a Devil Dog (a nickname 
earned during WWI, according to Marines). Each time I witnessed such a visceral response, it reminded me that the title of Marine is always earned. I feel that is a testament to the immensity of earning the title of United States Marine.

It is no coincidence that Sgt. G was on the road when he decided to enlist and was on the road during most of his time in Iraq and Afghanistan. He served in Motor Transport (Motor T) as a driver for his first two deployments. During these two deployments, and the four-month visit home between them, his wife gave birth to their baby girl, decided being married to a deployed Marine was not for her, and found someone else to talk to late at night.

Sgt. G was married in December of 2002 and deployed shortly after that in January 2003. While the honeymoon was short, it was even shorter for his bride because she was pregnant and gave birth to a baby girl in June of 2003, while Sgt. G was still deployed. He tried everything possible to get home for the birth of his daughter, but even I was unable to help him get back to Orange County. When he was finally able to see her, hold her, and look into her big brown eyes, I heard his fragmented thoughts:

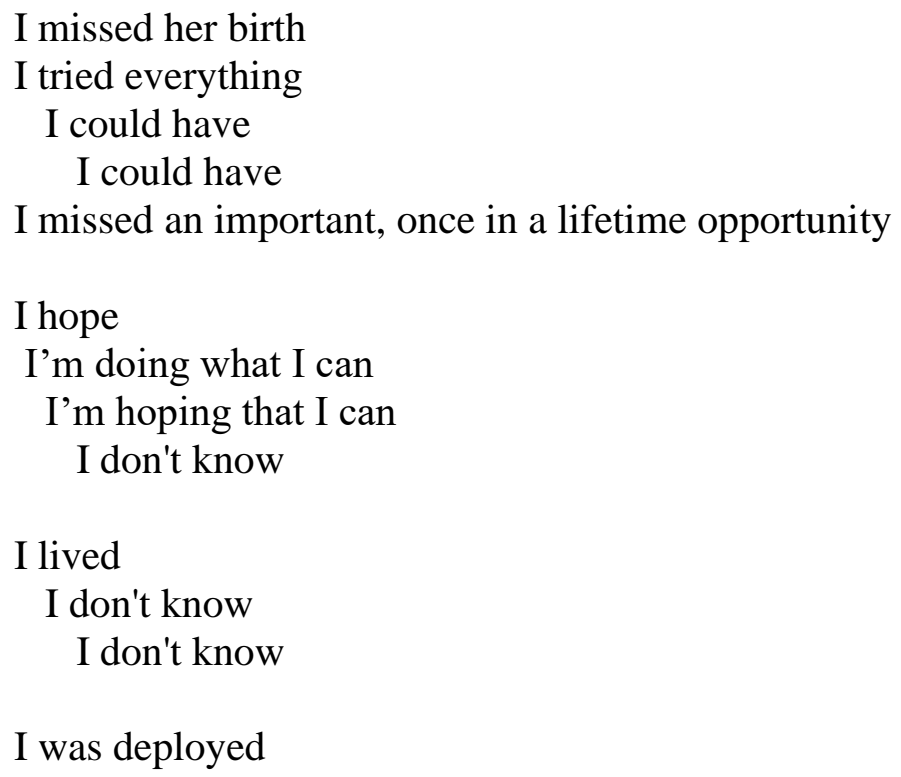


I was gone

I came back

I don't know

I Poem from Individual Meeting \#1, 10/12/15

He tried everything he could; other Marines had even volunteered their leave so that he could go home for the birth. Yet every attempt and request were denied. Sgt. G stayed overseas and took turns providing security while a dozen other Marines played video games or slept. It was a reminder that he was not in charge of his life. When he finally returned home, he was only able to spend four short months with her, before he was back in the Middle East. The second deployment was a bit more eventful than the first. It began the first night in Al Assad with a Marine killed by a mortar attack. At that moment, it became real for Sgt. G. "That could have been one of my friends. That could have been me." The mortar attacks continued weekly, each time met with a prayer that everyone would survive, followed by a status check, and then a return to "normal" until the next attack on the base.

As a driver, Sgt. G spent most of his time on road. But the road was no safer than staying on base. Strategic warfare included cutting off supply lines, which meant attacking the trucks. One particular convoy would always stick with Sgt. G.

I remember going through this traffic circle I don't remember what it was I remember they had all stopped to watch the convoy go by

I remember feeling like, there's something about this trip just doesn't sit well I got that gut feeling I mean the roads were typically busy, but that day they were kind of empty

I remember seeing a large cloud go off I had a gunner in my truck I remember hearing him shoot I remember hearing the guys I had a, what is it, about 12 guys in the back 
I don't want to say the Iraqis, the Insurgents took casualties

I didn't get to see it firsthand

I returned fire

I was like doing a drive by

I know there was a vehicle off in the distance

I saw

I'm not the only one that saw it

I remember

I drove through the smoke

I was the last vehicle

I was the last vehicle to get out of there

I went through that smoke

I was going pretty fast

I'm like shaking out of my pants

I'm like, "Fuck man"

I'm just glad

I made it out of there.

I remember that whole incident

I Poem from Individual Meeting \#1, 10/12/15

Each time Sgt. G told the story, I was taken back to that day. Each time, I

watched him speed through the smoke as it curled up around his truck making it look like it had wings. Each time, I heard his fellow Marines tell him "It looked so bad ass. You looked like a fucking hero" while he remembered just being happy to be alive.

Time overseas, whether on base or on the road, meant that Sgt. G was on guard. That constant vigilance of the second deployment would forever impact Sgt. G. It was also during this deployment that hours spent in line to call home went unanswered, even after continuously trying for 20 minutes, and Sgt. G always left mail call empty handed. The supportive Marine wife was gone, and his return home was met with evidence of his wife's infidelity. Sgt. G was crushed. The loyalty that was core to who he was as a person, and as a Marine, was not reciprocated by his spouse. While overseas he lost his 
whole family, as his ex-wife took their baby with her. Sgt. G discharged for the first time to get his life in order, which meant finalizing the divorce.

It was also during this break from the Corps that Sgt. G enrolled in the local community college. It was only two classes, and that introduction to civilian students made the parting from his Marines even more significant.

\author{
I lost my team \\ I couldn't connect \\ I don't know \\ I didn't want to talk \\ I didn't think they'd understand \\ I went through all that hell, they didn't
}

(Cropsey \& Hendrickson, 2013; DiRamio et al., 2008; Glover-Graf et al., 2010;

Rumann \& Hamrick, 2010; Whiteman et al., 2013)

The familial relationships formed with his unit, or battle buddies, provided a place for him to share his fears and desires for home (Bellafiore, 2012; Hinojosa \& Sberna Hinojosa, 2011; Hosek \& Martorell, 2009; Kok, 2015; Livingston \& Bauman, 2013). It was part of the Marine culture and community to love each other to the point that each Marine was willing to die for the others, especially within a specific unit (DiRamio \& Jarvis, 2011; Junger, 2014). So it was not a surprise that Sgt. G's move from such a structured, united, and cohesive community of solidarity (DiRamio \& Jarvis, 2011; Wiliams, 2013) to the selfish civilian world was difficult (Lighthall, 2012; Livingston \& Bauman, 2013; Phelps, 2015). Numerous Veterans will tell you this, and yet some civilians do not believe it until there is a statistic to support it. For that, the University of Southern California, School of Social Work's Center of Innovative Research on Veterans and Military Families (CIR) can help, since their recent study of Veterans in Orange County, California found that $61 \%$ of Post-9/11 Veterans had difficulty with the 
transition to civilian life (Castro et al., 2015, p. 14).

During the separation from the Corps, Sgt. G received news that one of his Marines had died in Iraq. Sgt. G should have been deployed with the Marine, except his personal life had pulled him away. Although he was a Reservist with the National Guard, he was not with his Marines. He thought, and continues to think, about how he might have changed the outcome if he had been there with his Marines. It was no surprise, that he was only a Reservist for less than a year and reenlisted in the Marine Corps in 2007.

The second enlistment began on the other side of the wheel, as he was now in charge of the mechanic shop on base. The position brought with it the opportunity for Sgt. G to fine tune his role as a mentor and guide to other Marines. Growing up, he never had brothers who looked up to him as a role model, so the chance to serve and support others through his leadership was one of the memories that Sgt. G has cherished the most. It developed him into the transformational leader he is today, one who leads by taking care of his people first and the bottom line second (Cashman, 2008; Goleman, 2004; Greenleaf, 2008).

But the deployment was not without its struggles. While Sgt. G was given the opportunity to lead, he was also experiencing the inconsistent communication and accusatory discipline of a poor commanding officer $(\mathrm{CO})$. The timing of the deployment meant that Thanksgiving, Christmas, and New Years were celebrated in the desert, instead of at home with family. The combination of being away and dealing with his NCO (Non-Commissioned Officer), led to Sgt. G seeking seclusion when he came home.

"Dad, I told you I didn't want a party. I'm out of here." His mother heard the words but could not change the fact that the whole family was at the house to celebrate 
another safe return home from war. This time something was different, he was not happy to be back. He seemed to miss his other home (Kintzle, \& Hassan, 2015b), and when he went out at night, he still felt empty in the morning. Although his family did not notice, Sgt. G was still healing from the heartbreak of his failed marriage and missing his Marine family. So, he volunteered to go back to Iraqi. Being part of the Border Transition Team for his fourth deployment, in 2008, meant that Sgt. G had another opportunity to be a mentor, guide, and leader. I had another opportunity to see that I was right, he was always meant to be a Marine.

"Yeah, but what did he really say?" Sgt. G asked the translator as they joked about life on the border of Syria and Iraq. He was one member of a small group of Marines responsible for training the Iraqi Border Patrol tactical skills as well as other necessary aspects of the job. Specifically, Sgt. G shared his knowledge of Motor T to teach them about preventive maintenance and care for Humvees, trucks, and trailers. The team also went out on patrol with the Iraqis, each time carefully passing unexploded ordinances from the Iran/Iraq war; hoping that each patrol resulted in a safe return.

In addition to becoming a more experienced mentor and teacher, Sgt. G was also able to find a partner who was able to help him heal his broken heart. After a casual Facebook message, followed by hours of honest and uninhibited conversations, both Sgt. $\mathrm{G}$ and Holly agreed to get married. I witnessed their love develop, and it was one of the truest moments they had ever had. Sgt. G loved, and still endlessly loves, Holly. She is one of the biggest reasons he is no longer an active duty Marine.

I may not be the goddess of love, that is my sister Aphrodite, but that does not mean that I ignored the power of love and acceptance. Sgt. G joined the Marines to 
serve, and with Holly in his life, and his heart, his duty to serve shifted from the Corps to a more personal responsibility. It did not take a goddess of wisdom to think that one through. Holly wanted a family, and Sgt. G was not going to lose this one. He knew that he loved the Corps, but he loved Holly more. While the Marines gave him an opportunity to support and serve others, they also failed to provide him with the support and coaching that he needed to successfully promote up the ranks. So, Sgt. G left the Marines to commit to his other family, the family that he made with Holly. As he drove away from Camp Pendleton in 2010 for the last time, he cried even more than when he received his EGA and became a Marine.

Since Sgt. G discharged from the Marines for a second and final time, to move into a new role of husband and father; my involvement in his life would also shift from the battlefield to the classroom. Again, I intervened with Sgt. G as he began his academic career in higher education. This was in part because Sgt. G thought he wanted to be a police office, but I knew he had other skills that would be more useful to the world. So, I made sure that he was able to uncover his own previously overlooked abilities in academic encounters. The support from Holly made this much easier (Campbell \& Riggs, 2015). His first class was in psychology, so I was confident that I could impact his perception of himself and his intellectual abilities.

Getting Sgt. G into Psychology 101 with Professor Valdez was another time I interfered, and it paid off. Valdez, as all of the students called the professor, had a soft spot for Veterans. Having three sons in the military will do that to a person. So, when Sgt. G met Dr. Valdez, they instantly connected.

Throughout the course, Sgt. G sought out Valdez whenever he had questions, 
wanted advice, or just needed to talk. Psychology professors often take on the additional role of listener, and Valdez was no exception. So, when the class began to discuss mental health disorders and diagnoses, Sgt. G was more comfortable in the vulnerability of the conversation that he might have been in another class with another professor.

Valdez began the class by talking about depression and other mood disorders, such as Bi-polar Disorder, then moved onto the other stress and anxiety disorders.

"What do you think of when you hear PTSD?" Valdez asked.

It was quiet for a moment, until someone in the back said, "Military Vets (Military.com, 2014).”

"Why?" probed Valdez.

"Because killing people messes them up" was the response from somewhere in the room. Sgt. G felt his heart begin to race.

"Well," began Valdez, "that belief is based on a few assumptions. It is important to remember a few things. First, not all service members are deployed. Not all deployments involve combat. Not everyone in combat kills people. Not everyone who is in combat, whether or not they kill people, develops PTSD. Also, a traumatic event can vary for people as it could be any actual or threatened death, serious injury, or sexual violation (American Psychiatric Association, 2013). In fact, it is often the victims of sexual assault that are most likely to develop PTSD (Kilpatrick, 2000). Why do you think that is?"

While the students were taking in the information, Sgt. G responded, "Because a sexual assault victim is not prepared or aware of any threat before the attack, and they probably suffered alone.” 
"Exactly!" explained Valdez. "Trauma can happen anywhere, and anyone can develop the symptoms of PTSD. Now this is not to say that Veterans do not have PTSD, some do. But not all of them do, although that is the assumption. Do you know what the most common service-related disability is?"

"Back injuries?” Sgt. G guessed.

Valdez replied. "No, it’s hearing loss (Roach, 2016). Some amount of hearing loss affects approximately $80 \%$ of Veterans (Miller, 2013). Yet, when talking with most civilians, they would assume it is PTSD. Maybe that is because sometimes hearing loss leads to people not being able to fully engage in conversations, and thus withdrawing for social interaction (Roach, 2016). While that may be a symptomatic of PTSD, it is not worthy of a diagnosis.

"So, let's talk about PTSD. In order to receive the diagnosis for PTSD there are three main elements: 1) re-experiencing the trauma through nightmares or flashbacks, 2) avoiding reminders of the traumatic experience, and 3) changes in arousal, which includes hypervigilance and/or a greater startle response (National Council on Disability, 2009). The symptoms will vary for each person and will also be expressed at varying degrees. Also, some of the symptoms may be present after trauma, even if the individual does not meet the full criteria for a PTSD diagnosis. Going back to Veterans, for example, it is necessary for survival that military service members learn emotional regulation or avoidance to maintain control in combat and other high stress situations (Canfield, 2014). When that avoidance behavior continues past active duty service, it could be seen as a symptom of PTSD.

"Because of military training, most Veterans are continuously alert about their 
surroundings (Kimble, Fleming, \& Bennion, 2013; Rumann \& Hamrick, 2010; Koenig, Maguen, Monroy, Mayott, \& Seal, 2014). I imagine if I asked the Veterans in this classroom right now to tell me their exit strategy in case of emergency, they could tell me immediately without pause. This is because they have already planned for it. Research has found that combat Veterans without PTSD have the similar levels of hypervigilance to civilians with PTSD; presenting the possibility that combat deployment alone might be the cause of the hypervigilance (Kimble et al., 2013, p. 1684).” As Dr. Valdez was speaking, several heads began to nod in the classroom.

Sgt $\mathrm{G}$ was one of the students nodding. He lived that experience. Although, he knew that the impact of his deployments was beyond training hypervigilance.

Dr. Valdez continued, "The transition to civilian, after being trained for combat, is rarely fully complete (Paquette, 2008). So, it is important that we recognize that the transition process is not only about PTSD, much of it is due to a significant cultural shift that occurs when one leaves the military." Sgt. G knew that statement to be truer than anything else said in class.

The discussion about PTSD, and other anxiety disorders, continued for some time. Yet, the important work had already begun. It was because of the conversations in class, that Sgt. G discovered several truths: 1) He was experiencing symptoms of PTSD; 2) He wanted to major in psychology; 3) He knew he wanted to help other Veterans transition and heal; and 4) He was a much better a student than he remembered. Sometimes, imparting wisdom is not so much about inspiring people to learn, as much as it is to have them believe in themselves. To "give themselves an A" in the class, if you will, so they would listen to their own thoughts and opinions (Zander \& Zander, 2000). 
Also, the second time in school presented a different student climate for Sgt. G. This time he was attending the University of Phoenix, which had a significantly higher portion of Veterans in the classroom. Unfortunately, the greater proportion of military service members was in part due to the school actively targeting Veterans, because of the benefits of the Post-9/11 GI Bill (Obama, 2013; Executive Order No. 13607, 2013). Nevertheless, the benefit of such a student body was that it provided a safe place for Sgt. G to become comfortable with his student self, which was much more civilian than his Marine self.

\author{
I had to motivate myself \\ I found the other Vets \\ I found them \\ I was able to relax \\ I was back with my unit \\ I could be myself \\ I honestly believe \\ I hadn't found the other Veterans \\ I wouldn't have been able to succeed \\ I was able to get and give support \\ I did
}

(Ackerman et al., 2009; Bellafiore, 2012; DiRamio et al., 2008; Hammond, 2015; Kok, 2015; Livingston \& Bauman, 2013; Olsen et al., 2014; Phelps, 2015;

Rumann \& Hamrick, 2010; Summerlot, Green, \& Parker, 2009)

Once Sgt. G started to believe in his student self, the same way he believed in his Marine self, there was little I needed to do. He successfully completed his BA in less than three years. In the process, he discovered that education gave him a similar feeling of accomplishment to what he felt while he was an active duty Marine. As a result, he also completed his Masters in an additional two years. He then began to consider pursuing his doctoral degree in psychology. School was always something he had 
wanted to do, and he was now able to successfully achieve that goal.

While Sgt. G was always mentally capable, the funding to pay for higher education had been a challenge. The Post-9/11 GI Bill changed that for Sgt. G, as it was developed to increase funding for tuition and housing for those who were honorably discharged after serving in the military for 36 months (for full benefits; at least 90 days for a percentage of the benefits) after September 10, 2001, or were discharged with a service related disability after 30 days (U.S. Department of Veteran Affairs, 2013c). Sgt. G earned the benefit, so he wanted to ensure that he used it to the fullest extent possible. Notably, it was not only higher education that helped Sgt. G transition, it was his relationship with Holly.

Holly, and the family that Sgt. G built with her, became the main mission for Sgt. G. They were the reason he didn't reenlist. He was able to fill some of the void missing from his Marines with his family. He became a father; an identity that he found was more difficult than being a Marine.

I got to see it all.

I was there

I'm like "Oh geez."

I actually got to hold my baby

I had a little person relying on me for everything

I try to keep the cussing down

I mean that - that's just a small thing

I mean, you know, just being a father

I think everything about being a father, or parent, Is - is much harder than being a Marine.

I spoil those girls

I want to

I like to get them things

I'm sure a lot of people do

I wanted to 
I got them

I Poem from Individual Meeting \#2, 11/25/15

While being Dad, Sgt. G was never not a Marine. He was always a Marine, a father, a husband, a learner, and Sgt. G. He maneuvered through these identities; that combined to make Sgt. G (DiRamio \& Jarvis, 2011; McAdams \& Janis, 2004; Stryker, 1968; Styker \& Burke, 2000). At times, that meant picking up his children a little bit later from daycare so that he could deal with the chaos of the VA.

“Hello? Anyone?" Sgt. G yelled as he stepped out of the examination room and looked up and down the hallway. He was losing his patience; he had been at the VA for several hours at his point. Even in 2015, the VA was known for taking too long to process claims (Shane, 2016) and not for outstanding customer service.

"What's going on over here?" asked one of the nurses, as she rounded the corner. "Well," he began, "I came yesterday, and the doctor couldn't see me. So, I came back this morning. I have been in two different waiting rooms, and now this exam room, and still haven't seen a doctor. And now it is three in the afternoon."

"I see," she replied as she motioned him back into the examination room. "Unfortunately, the doctor is unable to see you today. However, we can give you a medication for your pain and schedule you for another day."

“Are you fucking kidding me? You haven't even examined me, and you're going to give me drugs. I need a doctor to look at me, order a CAT-scan or x-ray or something. This is ridiculous." Sgt. G got up and walked out; he was done with the VA... until a few weeks later, when he could not sleep because of arm pain and numbness.

"So, they go numb from my armpit down to fingertips. Both sides. I end up doing this a lot" he made a fist then opened his hand all the way, then made a fist again. 
He kept repeating the motion, several times, with a look at discomfort and annoyance on his face. "It's been going on since 2008 during my last deployment. But it didn't use to last as long as it does now.

"Now, I wake up in the middle of the night because my hands are completely numb. They feel like they're going to burst because they feel so tight. I have no circulation, and, and it hurts, to the point where I can't sleep for an hour." He looked at the doctor hoping to get something more than a prescription for ibuprofen.

The doctor looked at him, nodded slightly, and began to write the orders while he was speaking "Let's start with a muscle test; it will test the electric activity in the muscle. I see in your chart you've been having issues with your back for some time. So, let's get a CAT-scan for your spine."

Sgt. G, sighed, finally someone who listened and did not just simply give him medications. After he was done with the doctor, he decided that, since he was there, he might as well investigate possible internship or volunteer opportunities with other Veterans at the VA. Interestingly, Veterans volunteer more often than their civilian counterparts (Klay, 2016).

I got sent to one office

I went to the mental health

I just wandered

I wandered

I could find the right spot

I decided to go look

I walked, I wandered around, I didn't find the spot

I ended up finding a PTSD meeting

I walked into the room.

I met the main doctor, the person in charge of psychology at the VA I actually shook his hand. 


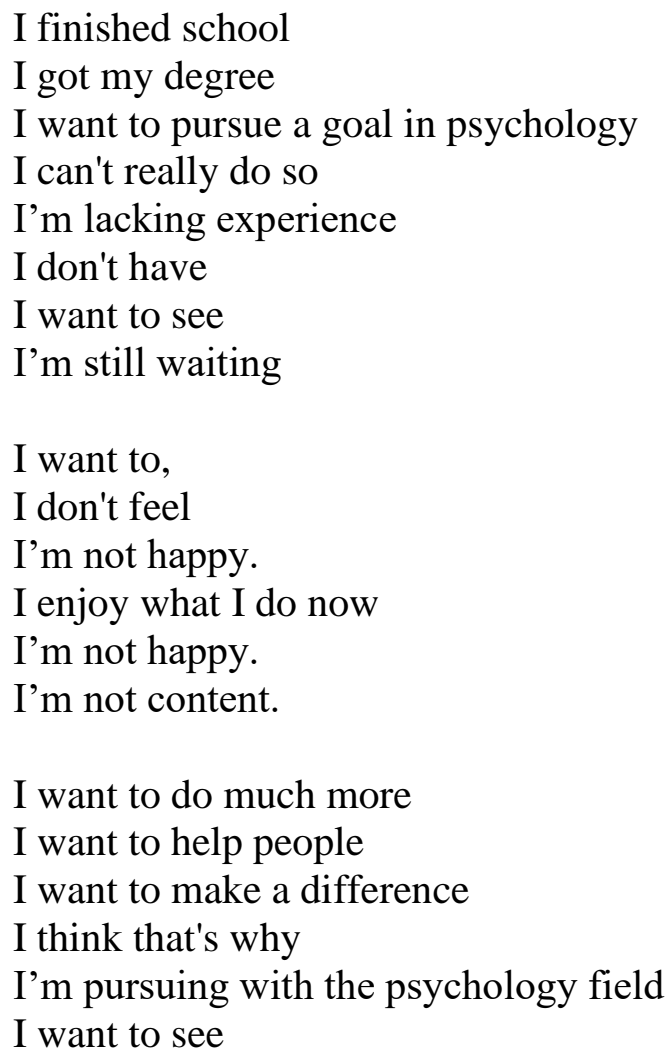

I Poem from Individual Meeting \#3, 12/16/15

Sgt. G was not just waiting for that right opportunity; he was going out and

looking for it. He knew in his head, and his heart, that his next step in life was to support Marines and other Veterans, either while they were moving up the ranks in active duty or after they had left the service and were transitioning to civilian life. His mission was not over. With a Master's in psychology and 8 years of active duty Marine experience, his next mission with The Unit would be perfect. 


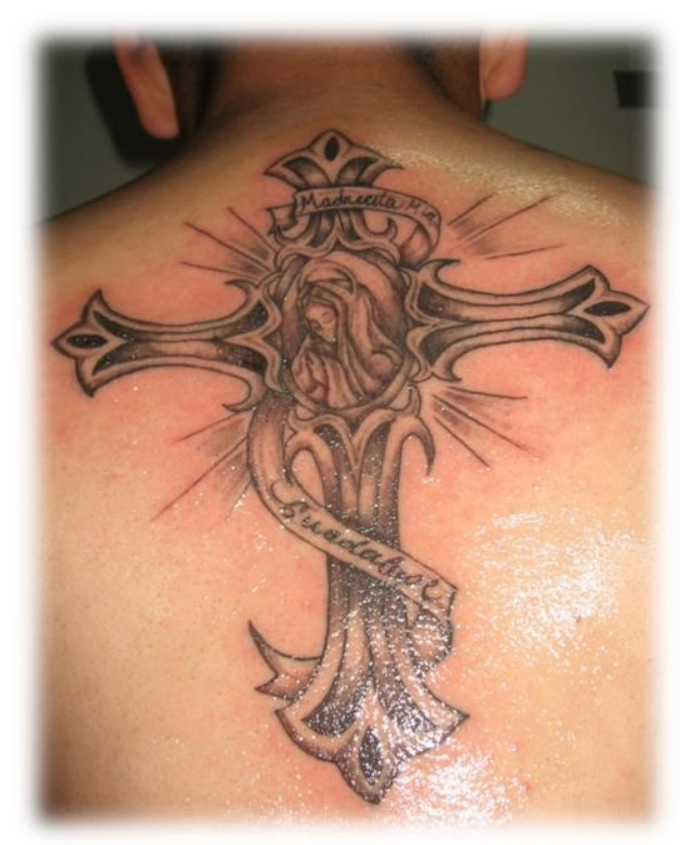

Photo courtesy of $V$

\section{Family, Country, Corps, V's Story}

V was only five years old when his life was changed forever, and thus began his journey into the Marine Corps. His father had been offered a job running a warehouse in Colorado and was in the process of getting everything in order so that $\mathrm{V}$, his older sisters, and mother could move to join him. Unfortunately, the drive to California on Christmas Eve in 1993, resulted in V's father becoming a completely different man. The car went off the icy road, through the guardrail in the cold Colorado Rockies, and V's father was launched through the windshield into the ice and snow (I was not involved in the accident, although shortly after I began to keep an eye on V). Since V's father was a marathon runner in excellent physical condition, he survived the frostbite, broken hip and femur, and punctured lung and colon. The family awoke that Christmas morning to a uniformed police officer knocking on the door, to inform them that V's father had died. In a way he did. When V's father awoke from a coma four months later, he remembered his first son (who had died) and did not remember V. 


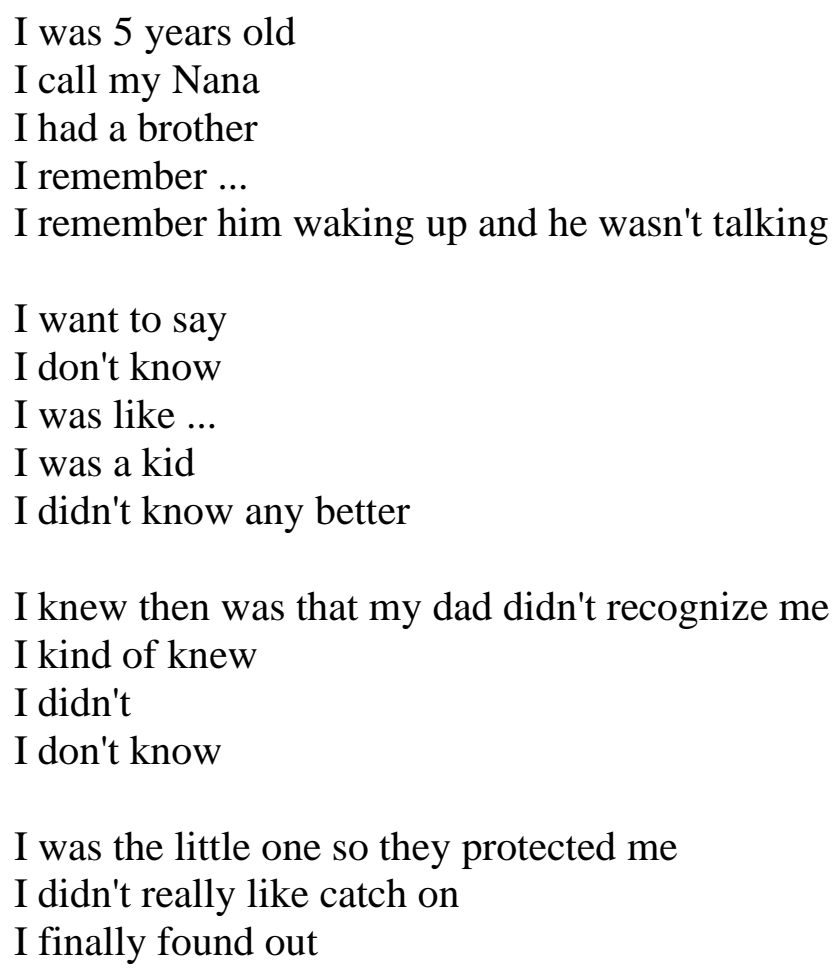

I Poem from Individual Meeting \#3, 12/19/15

At five years old, V became the "man" of the family in his eyes. It fell to him to protect and care for his mother, father, and sisters. Yet, to his mother and older sisters, he was the little boy they needed to protect. That conflict would continue until V enlisted, 13 years after the accident. Within those 13 years, V learned so much about what would make him a great Marine, although he was unaware that he was already in training at the time.

"I can help you with that?" V offered to the neighbor, as they were tilling the garden. It was just like $\mathrm{V}$ to constantly offer to help, regardless of the situation. He was a natural caretaker.

"Sure" the neighbor, Mason, replied. He looked at the 13-year-old boy, and saw an ethic and selfless concern that most of the young boys in the neighborhood lacked. He 
saw a potential opportunity with V. So, after a day of help in the garden, Mason gave V some cash and asked him to come back tomorrow for more work.

Mason was a local attorney who knew that V's family had survived some traumatic events. After V's father came home from the hospital, V's mother began to clean houses to support her husband and children. V's father could not work; he suffered from brain damage as a result of the accident in Colorado. Sometimes he had temper tantrums and behaved much like a toddler. V's mother worked multiple jobs to take care of her family. At times she was forced to decide which bill, electricity or gas, would be paid each month. So, as soon as V was old enough to do something to help, he found ways to make it happen. Mason was always impressed with the caretaking desire that filled every aspect of V. Even though he also saw how V was sometimes embarrassed by his father. Mason knew that deep down it was part of V's development to work through it, much like all adolescents trying to find where they fit in this world.

V showed up at Mason's door the next day ready to work. That was the start of V's first job. He became Mason's assistant in the office and at home. No job was too small for $\mathrm{V}$; he saw the need to help his mom and would do whatever it took to provide extra money (good money) for his family.

A few years later, V graduated from high school. Together with his sisters, they were the first in his family of 13 aunts and uncles, with all their children, to successfully complete high school. It was one his most proud moments. As the goddess of wisdom, I too was proud. V was an intelligent young man, and his achievements helped to bolster his beliefs about his own abilities. During his senior year, V had focused on enlisting in the Army; as it was not just academics that he respected. V was determined to become 
the "man of the family" he thought he should be, even if his sisters and mother did not see him that way. He also felt that the military would be able to provide additional support for his family.

His mother, who was a woman without a formal education, possessed years of life experiences which could not be taught in any classroom. She refused to sign any enlistment papers until V first tried college. So he appeased her, briefly. While attempting to go to college, he worked. V was always working. Unfortunately, graduating from high school at 17 had its drawbacks, as he was restricted by child labor laws. As a result, he felt he was not able to be the man, the provider, he thought he should be.

I must take a minute to point out the overtly sexist perspective within his beliefs. The thought that it was solely his job to provide and care for his family, while his sisters, who each went on to form families and lives of their own, failed to acknowledge the full familial unit responsibility they owed to each other. Such circumstances were the opposite of many Latino families, where the obligation to assist in caring for the family fell to the oldest daughter. Regardless of the bias, V's belief was based on the fact that he was the only male, and he should provide and care for his family. While it was gender biased, such thinking was at the core of $\mathrm{V}$ and his beliefs about who he should be. Growing up without a traditional male role model, as his father was more like another child in many ways, V hungered for the knowledge of what it really meant to be a "man."

V tried college. He attended a Cal State University, until he saw how much it really cost. He even tried a local community college but dropped out before the semester really began. It was his desire to do "something" and not continue to be a drain on his 
mother that sent him back to the recruiter's office.

"Mom, I'm going to join the Marines." V told his mother.

She looked at him, her baby; the little boy she had protected for so long was now the size of a man. She couldn't stop him.

"Like Frank?" She thought of her son-in-law, a new graduate from Drill Instructor School. She could hear him telling V he would not make it; that the Marines were not for everyone.

"Yeah. I've hung out with his Marine buddies. I can do it, Mom." He looked at her with such determination and need in his eyes. He had tried college, although she knew as soon as he began, he would quit. He always worried about taking care of her and his father. She knew he would think it cost too much and he would find a way to make the military a reality. He didn't have to say it, she knew what he was thinking; she was his mom.

I tried,

I tried going to Fullerton

I went there for orientation... I was going to start

I was going to start

I tried summer there

I dropped out. I ended up dropping out

I enrolled in Santa Ana College

I didn't even finish semester

I dropped out of there

I ...

I was still working, I worried

I Poem from Individual Meeting \#3, 12/19/15

"Okay." She would never tell him everything that SHE worried about. Mothers 
tend to keep those thoughts to themselves. Yet, even as I watched her worry, I knew he would become a great Marine. He had been on this path since that Christmas Eve when he was five years old. Sometimes, the armed forces call to those who want destruction. But, for V it was growth, structure, respect, and an opportunity to prove he could be everything that he wanted to be for his family. He felt he had so much to prove because as the only son, the baby boy. The manner of protection offered by his older sisters was not empowering. They teased him mercilessly, restricted his opportunities so that he was always available to care for his father, and essentially created their own Cinderella. Yet instead of heading to a ball, $\mathrm{V}$ went to boot camp.

“Did you just say 'yeah' to me, recruit? What, are we fucking drinking buddies now?" The Drill Instructor, or DI, yelled into his face with such intensity and vitriol that everyone around V tightened up a bit. He was so close to V that he could feel his breath on his cheek. But two months ago, they were drinking together with Frank, V's brotherin-law.

"Fucking asshole," V thought to himself. "I guess the teasing and harassment from my sisters was just a warmup for this shit." That notion was more accurate than V wanted to be.

Every recruit was tortured in boot camp at the MCRD. It was 12 weeks of destroying boys and making men; the female recruits were all at Camp Lejeune, in North Carolina. Yet, V was related to one of the other DI's, so following orders and flying under the radar was not a possibility. All of the other DI's knew who he was, and if a DI knows who you are, they make it their mission to test you a little bit more, to make sure you can make it in their beloved Marine Corps. As a result, boot camp was hell for V. 
But what they didn't know is that he had been preparing for that since he was five years old.

At five years old, his father did not recognize him, and he survived. An intimidating, angry Marine in green, yelling uncontrollably would be just another hurdle to overcome. And he did it.

I didn't ...

I never cried.

I never bitched and complained.

I don't know

I've never bitched and complained, I just went along with it I ended up pushing through and making it on my own.

I mean boot camp was bad

I mean, I used to get picked on, I used to get asked to dumb crap or dumb shit

I Poem from Individual Meeting \#1, 10/25/15

Not to mention, his sisters had been training him to take a verbal beating, with his head up and shoulders back, for years. So, he did it. He completed the Crucible, a final exercise and test that lasts three days, allows for eight total hours of sleep and only two MREs (which stands for "Meal, Ready-to-Eat"), to test the teamwork, endurance, and skills of Marine recruits on a 45-mile march with over 30 training obstacles (Chenoweth \& Nihart, 2005; MarineParents.com, 2016). After the Crucible, V attended graduation and received his EGA; he could then call himself a Marine. But V didn't feel he earned the title of United States Marine until he hit the fleet, after completing Marine Combat Training (MCT) and MOS (or Military Occupational Specialty) school.

It was at MOS school for Artillery that V met Oakland, aptly named since he was from Oakland, California. Oakland became the brother V never had. Together they 
survived Iraq, drank a ton of alcohol, and left the Corps to begin the transition back to the civilian world. While they were both in Artillery, they were actually attached to another unit out of Hawaii when they served overseas. So, it was 15 months of patrol, after patrol. Fifteen months of walking the streets, "head on a swivel," constantly on high alert to ensure the safety of the other six guys walking along the streets in a defensive/offensive formation.

"V sweeps" were patrols in a "V" formation. The first Marine ran "point," in case of attack, 10 steps behind him, to his right and left were two more Marines, and 10 steps behind them, one more step out were two more. The last two Marines in the formation were walking backwards, to ensure that the rear was covered. Throughout the patrol, all the Marines were communicating and alternating positions, as needed. They worked together, a group of seven individuals, as one seamless unit moving through the streets. Every position was covered, and each Marine was ready and willing to protect and die for the other six in the formation. V had already learned that the family, whether his biological family or this Marine family, was more important than his own personal needs.

Before they went to Iraq in 2008, Oakland and V spent quality time at Camp Pendleton during the weeks and at V's home on weekends. The weekends were full of drinking and partying for V, with his girlfriend, and Oakland, with various friends of V's girlfriend. That was until they received their orders to deploy. That deployment changed $\mathrm{V}$ as a person, and it would forever impact his romantic relationship, because it did not survive the distance and separation.

I gave her a chance to take a break

"I'm not married to you"

I went on with our relationship.

I ended up deploying 
I'm like all right we're doing fine

I started noticing little things...

"I'm busy right now"

"I can't talk right now"

I get it

I just started noticing

I was in Iraq... she cheated on me

I felt like dying

I just could not exist anymore

I was over there

I couldn't do anything about it

I was angry, angry, angry, angry

I talked to him about it and he calmed me down,

I was just rambling

I Poem from Individual Meeting \#3, 12/19/15

"She sent me a fucking 'Dear John' letter to let me know it's over. Who the fuck does that shit?" V was screaming. Oakland was listening, even though they had just finished throwing punches. Oakland knew the fight was not about him, it was V's way of dealing with his heartache. Yeah, he was bleeding, but so was V. They would heal.

"She was carrying my fucking baby, lost it, and then goes and finds some other dick..." The tirade went on for some time. Oakland knew that this was going to take some time to get over. V had never been the one to put himself out there with women. Oakland knew V had fallen hard for this girl; he had known her since high school. He was angry. He was hurt. He was reaching for the Jack Daniels. This was going to be a long night, but long nights were common in Iraq.

The bond between Oakland and V reminded me of the warrior ethos that I had seen with my heroes of days long past. I thought of Odysseus briefly. It was that comradery, formed in part by the warrior ethos, that helped warriors, in this case $\mathrm{V}$, get through the toughest challenges in battle and at home. V was able survive combat, chaos, 
and boredom with, and because of, his unit, and Oakland in particular (Bellafiore, 2012; DiRamio \& Jarvis, 2011).

Eventually, V found a way to cope. He had to, because he spent Halloween, Thanksgiving, Christmas, and New Year's Eve in Iraq. So, he began to log numerous hours lifting weights, bulking up his body quite a bit. Also, being in great physical condition was a way to connect with the father he remembered from before the accident on Christmas Eve, so many years before. It was also during his time in the gym that V found his first tattoo artist. They were in the desert, which meant they were "sleeves down" all the time, so in the gym was the only place you saw another Marine's forearms. Since V spent so much time in the gym, he noticed a certain Marine, Rocky, had new tattoos on his forearms.

“Hey man, you know who's been doing these tats? I kind of want one, but I don't know where to go." V casually mentioned, as he spotted Rocky while he was on the bench press.

"Yeah, it's me.” Rocky replied. "If you're interested let me know, because I only brought so many needles with me. And you do NOT want to get inked with dirty needles in the middle of Iraq. Not like I do that; one time use only, Devil."

A few weeks later, V sat backwards in a chair for a few hours while Rocky permanently drew the Virgen de Guadalupe with "Madrecita Mia (My Dear Mother), Guadalupe" on V's back. It was V's first tattoo, a large back piece for his mother, Guadalupe, the only woman he knew would always have his back, literally and figuratively.

V came back to the States with a fresh back piece for his mother, and 35 pounds 
of lean muscle mass had not been there on the plane ride over. That put him at 225, outside the height and weight standard for a Marine at 6'1"; which meant that even though he performed first rate on his Physical Fitness Test (PFT), he was placed on a Body Composition Program. While that may sound like a good idea, the reality of losing 10 pounds of muscle, while an active duty Marine, is easier said than done. Marines work out, all the time. So, it took six long grueling months for those 10 pounds to come off. While $\mathrm{V}$ was worrying about making a weight requirement that had nothing to do with physical abilities, he was also dealing with poor leadership from a First Sergeant.

$1^{\text {st }}$ Sgt Mulligan was in a position designated for a Sergeant Major, a position one rank above his E-8 grade. Such a reality put Mulligan in a place where he foolishly felt he needed to prove his value, by demeaning his Marines and asserting his power in situations where it was unnecessary. Mulligan became more obsessed with tasks and forgot about his people, in true transactional leadership form (Gill, 2011); as illustrated in the lack of guidance or connections to the Career Planner that Mulligan failed to provide $\mathrm{V}$, concerning possible re-enlistment or extension opportunities. Instead, Mulligan spent his time focused on numbers, instead of acknowledging that the extra muscle improved, not hindered, his Marines.

When it was time for $\mathrm{V}$ to discharge from the Marine Corps, he had to check out of his Unit, as well as a variety of other places on base. He made his way to the places on the checkout list, until finally he had to take it to Mulligan. It was an interaction of disdain and disrespect for all the involved parties.

"Did you meet the requirements?" Mulligan asked without looking up.

"Yes, sir." V replied, even though he did not believe that Mulligan earned the 
respect shown by his response.

"Well it only took you six goddamn months." He still had yet to make eye contact with $\mathrm{V}$, as he continued "Get the fuck out of my office."

V stepped outside and stood beside the open door. As he saw papers fly through the door, he heard Mulligan yell, "Stay the fuck out of my Marine Corps."

"Okay" V replied as he bent down and picked up the checkout list. As he continued on his rounds to complete all the discharge paperwork, he kept thinking to himself, "Four years of great people, and this fucker is the last person I have to answer to. It is time for me to get out."

He drove away from Camp Pendleton in 2010 and called Oakland. Oakland had discharged three weeks before V and was already up in Northern California.

"Hella weird, huh?" Oakland asked V. "You should just come straight up. Stop by your house, grab some civvies, and keep driving north until you get to my door in Oaktown. This week is going to be one long party." That is exactly what V did, and he almost remembers some of that week.

When V said so long to Oakland, it was time to spend time with his family. Although many of V's weekends before deployment had been at home, the time had been spent with his girlfriend. So, after a week of intense parting with his brother, $\mathrm{V}$ returned home to make up for lost time with his family. It was not long before $\mathrm{V}$ found himself sitting on the couch, relaxing next to his dad, watching basketball.

"I need to get a fucking job." V thought to himself. When V was enlisted, he saved what he needed to pay off his truck, while the rest of his pay went to his mom to help support the family. Now that the paychecks from the US Government had stopped, 
V needed to get out there and help support his family a different way.

One would expect that a decorated combat Marine could easily find a position suiting his experience and abilities. V had been a Corporal, but he had never been treated as such, and held the duty of a higher rank. Such a responsibility over other Marines is part of the Marine Corps philosophy to build leadership and resiliency in each Marine (Fleischaker, 2015; Stewart, 2015). Yet, to the civilian world, such a history did not matter. In an interview with 24 Hour Fitness, for a front desk attendant position, V was brutally confronted with the stark difference between Marine and civilian life.

"So, tell us why you think you applied for this position?" Jillian, the manager asked him. V, now 215 pounds of lean Marine, sat straight up in his chair with his right hand on his right knee, his left hand on his left knee.

"I'm looking for a job that will allow me to support my family, while I learn more about customer service and provide excellent service to the clients." V replied.

“Can you work flexible hours?" Jillian asked. She was confused about why V had applied for this job. He certainly looked the part of someone who worked in a gym, but he was so confident, almost rigid, and his direct eye-contact was something she was not used to.

"Yes, ma'am." V replied. It was not going to work. The people who worked out at 24 Hour Fitness would never make it past the front desk with this much intensity. A Veteran was not the right fit for this job (Castro, Kintzle, \& Hassan, 2015b). Jillian continued the interview for a bit more, before she tried to let $\mathrm{V}$ down easy.

"You know. I don't think this is going to work. We like our front desk attendants to be talkative and a bit quirky. I don't think this would be the right fit for you. Thank 
you for your time and best of luck in your job hunt." Jillian tried to be nice.

"This is an interview. You cannot expect me to come in here and act all immature and unprofessional." In his mind he added, "fucking civilians (Bridge, 2015)." V got up and left, before they could continue what, he thought, was a useless conversation.

He got home, took a seat on his couch, and decided it was time to go back to school and use the Post 9-11 GI Bill. He looked into the local Cal State again, but even with the Veteran preference there was no guarantee that he would get the classes he needed to graduate in four years. So he kept looking, and eventually found a program that would only take three years for him to complete his bachelor's degree. That sort of speed and efficiency was what he was used to, so he applied and was accepted.

V began attending East Forrest College, a for-profit institution with locations across the county. Like many for-profit institutions, East Forrest College was accredited nationally, and could take federal aid for students, which allowed it, like numerous forprofit institutions across the country, to target Veterans looking for an efficient way to utilize their Post-9/11 GI Bill (Obama, 2013). Luckily, since East Forrest had a program set-up that appealed to many Veterans, $\mathrm{V}$ was able to easily connect with other Veterans on campus:

I survived combat because of Marines

I was able to make it through school

I started to feel like I could live in 'normal' society

I think that was the hardest part

I left my brothers.

I felt safer when I was with them

(Ackerman et al., 2009; DiRamio \& Jarvis, 2011; Kok, 2015).

I returned back to my civilian family 
I felt alone

I know they meant well

I had just lost my military family

(Phelps, 2015; Rumann \& Hamrick, 2010; Koenig et al., 2014)

the civilians on campus were a whole other story.

"I was five minutes late, and she took away the car for a whole week. And she told me that I have to start paying for my own gas. Can you believe it? It is just so unfair." V looked at the spoiled and undisciplined girl complaining in class and stopped himself from giving her a verbal lashing (Hoge, 2010; Koenig et al., 2014; Olsen et al., 2014; Schiavone \& Gentry, 2014; Wilson, 2014).

"This is going to be a very long three years" he thought to himself. "These whiney, immature kids have no idea what it is like to suffer (Barry, Whiteman, \& Wadsworth, 2014; Koenig et al., 2014; Olsen et al., 2014; Schiavone \& Gentry, 2014; Wilson, 2014). Mommy and daddy pay for everything and they don't pay attention in class or anything." V had been working since he was 13; he felt it was his responsibility to make sure that no one had to take care of him. He had other people to take care of. The fact that he had survived some real chaos in Iraq, and now had to listen to kids complain about what he considered "stupid bullshit," made the transition that much harder (Barry, Whiteman, \& Wadsworth, 2014; Hoge, 2010; Koenig et al., 2014; Olsen et al., 2014; Schiavone \& Gentry, 2014; Wilson, 2014). He still needed a job.

Luckily, East Forrest had a decent career center and they were able to connect V with a security firm that utilized his military background, while providing experience and transitional job skills for his dream career in law enforcement, or diplomatic security to be more exact. So, V started to work the graveyard shift, which finished at 6:00am. 
Then he headed over to campus for a full day of classes, including a 7:30am

Communications course with Jamie as his instructor. Being tired made tolerating the students a bit tougher, but luckily V was able to connect with some great Veterans on campus.

One day V was walking on campus when he walked by a car that looked very familiar. He knew he had seen it before; he just could not place it. That was until he saw the Marine Corps decal and a specific Unit sticker on the back window. That car was from Pendleton. So, V made it a point to find the owner.

"Hey, you're a Marine right?" he asked, once he had located David, the car's owner.

"Yeah." Replied David, intrigued but still cautious.

"Did you ever work at Pendleton?" V questioned.

"Yeah, 2006 to 2009." David replied, a bit less cautious.

V smiled, "I think you were one of my field instructors." And that was the beginning of another military friendship. $\mathrm{V}$ began to help David where and when he could, be it tutor for classes, a meal at lunch time, or giving him a few bucks if he was short on cash for his bills one month. V would tell you "It wasn't anything big," but to David it was V who was able to get him from one month to the next sometimes. David was one of many Veterans, and civilians who came to $\mathrm{V}$ for advice and guidance. At times it was civilians who were thinking of joining the military, and they wanted to get some input. Being the man he was, $\mathrm{V}$ advised them to enter the National Guard or the Coast Guard for better networking, not the Marines. He was a caretaker, to his core, and he continued to fulfill that role in school as well. 
The other Veterans on campus did help V begin the transition to civilian (Ackerman et al., 2009; Kok, 2015; Livingston \& Bauman, 2013; Olsen et al., 2014; Summerlot et al., 2009). Many times it was the ability to give each other a "ration of shit" for being in different branches. Other moments where appreciated because of the comfort they had for not having explain the service experience, since everyone else already understood (Ackerman et al., 2009; Bellafiore, 2012; Kok, 2015; Livingston \& Bauman, 2013; Phelps, 2015; Rumann \& Hamrick, 2010;Summerlot et al., 2009). It was bit like being back with his unit (DiRamio et al., 2008; Livingston \& Bauman, 2013; Summerlot, Green, \& Parker, 2009). It was not the educational experience itself that did much; that was just another job. One more mission. School was the next thing he needed to complete in order to move onto the career he wanted. It was very obvious to $\mathrm{V}$ that civilians did not care about military experience, military accommodations, or ribbons. Most civilians could not tell you the difference between a Lance Corporal and a Sergeant Major. But there was indeed a great difference to those who served. So, V took up another mission. He went to school, and he worked. In between, he took care of his family and saw his friends occasionally.

That also meant, when David got sick, he was not able to be around to support him as much as he wanted to.
I guess
I lost track
I'm always constantly working.
I mean
I hope he knew that
I was working, going to school
I was still working
I didn't want
I didn't want to 
I worked

I lost track of people

I didn't want

I got ...

I got bills to pay,

I got a life too,

I got,

I got my family to take care of

I Poem from Individual Meeting \#2, 11/22/15

V went to David's funeral. He also visited David's grave in the Veteran's

Memorial Park in Los Angeles. When he went, he made sure that the grave was always clean and well taken care of. Again, he will always be a caretaker.

Once school was done, $\mathrm{V}$ just kept working. Time had passed since he first left the Marines, he was a little bit softer with his interactions with civilians. But V was still a Marine. He would always be. V saw the discharge as the beginning of a never-ending transition for himself. He would become more civilian but would never be a "civilian." He would run in the rat race to pay the bills and continue to take care of his mother, father, and other family members whenever it was necessary. He would continue to take care of others, yet he would still feel a void left by not being active in the Marine Corps (Klay, 2016; Naphan \& Elliott, 2015).

Sometimes it felt better to talk about it, if someone would listen. Jamie offered to listen over lunch, and V said he would love a smoothie. He had a difficult time taking things from others, or letting other people pay for him. He could do a smoothie, but lunch would be too much of an imposition. Again, V was the caretaker and he would not be a burden.

"I have yet to find anything with the same sense of purpose as being in the 
Marines." V looked at Jamie and was brutally honest. "I am trying to work toward a career in diplomatic security. It is an agency federalized through the state department. You guard embassies and diplomats; you work security details for diplomats, or the President. So if the President travels within the US or outside the US, you could get put in charge of it. You're a federal agent. You're essentially still a law enforcement officer. But like $60 \%$ of your career you spend overseas."

“So, what is stopping you from applying?" Jamie inquired.

"My family," V began. "When my dad was in the accident, we stopped traveling. The strong family tree we once had sort of fell apart. I'm helping build it back up. If I leave, who will take care of my mom. She doesn't drive, you know. Her vision is impaired because of diabetes, and she was a witness to a really bad accident a few years ago. So, she just doesn't drive. Who will take care of her? My sisters are always taking care of their families, I'm the single one. I have to take care..."

Jamie interrupted V, "But who takes care of you?"

"No one. I am a Marine. I can take care of myself. I always have. I have always kept my nose clean. I have a great fucking background. I need to get my career going so I can take care of my family and take care of myself." V explained.

Jamie looked at the Marine in front of her. He would always be a Marine. It was through the Marine Corps that V built numerous, incredibly deep relationships (Styker, 1968) based on trust and mutual respect; they formed a bond of brotherhood that meant they would sacrifice themselves for their fellow Marines. Deep bonds and deep relationships like those formed in combat led to being a Marine becoming core to V's identity (Jones \& McEwen, 2000). It was a relationship so significant and deep that 
nothing in the civilian world really came close (Junger, 2014). It was so core to his identity that it manifested itself in so many of his habits and routines. Due to his training, $\mathrm{V}$, like many other Veterans, was constantly on guard and aware of his surroundings (Kimble, Fleming, \& Bennion, 2013; Rumann \& Hamrick, 2010; Koenig, Maguen, Monroy, Mayott, \& Seal, 2014); he would never forget the "Complacency Kills" reminders posted all over Iraq. He had an almost unachievable standard for cleanliness that made living with a roommate difficult. He was incredibly organized; his idea of a messy closet looked better than Jamie's the day after it was organized. He was always respectful and greeted everyone with a "sir" or "ma'am" accordingly. He hid the fact that he was a smoker, because when people found out, he thought, it changed their perception of him. He also saw himself as the protector of his family.

If there was only one thing the Marine Corps did for V, it allowed him to be the quiet kid he always was, and it showed him that he was also able to be assertive when needed. V would tell you that he learned "how to be an asshole when necessary" which tended to be when his family was threatened. He had, more than once, used that newfound side of himself (Jones \& Abes, 2013). That included dealing with other "assholes," like when his sister was confronted by an ex-boyfriend, the biological father to her child. V made sure his sister was safe and that deadbeat dad was no longer allowed in the house.

But the thing about always being a Marine, a protector, a caretaker, was that it was exhausting. He never thought of his family as a burden, but each encounter with them made him miss the simplicity of being overseas. The dark brought him comfort. It reminded him of being in Iraq. Watching a movie or television show on his laptop in bed 
instead of on his actual television, reminded him of "being in the suck." Part of the reason he kept smoking was because he enjoyed going outside at night and, just for a moment, being back in Iraq. But all of that meant he was often alone.

The other side of $\mathrm{V}$ being a caretaker was his not being to be a burden on anyone else.

I came back.

I realized

I'm pretty strong by myself

I don't need anybody.

I'm still alive

I'm still breathing

I Poem from Individual Meeting \#3, 12/19/15

That meant $\mathrm{V}$ never asked for help from anyone else. He found a way to take care of himself, always. He found a way to take care of his family as well. Part of the reason he shied away from additional relationships, or going after the things he really wanted, was because of the fact that in the past it never worked out. So, he often fell into the thought that it was not worth even really trying. He had been picked on his entire childhood, had his heartbroken as a young Marine, discharged from the Corps before he was really ready to leave, and had always made it through. He was a survivor, a protector, and a caretaker, since that was what people expected of him and he was used to it.

What V failed to see in himself, and what his involvement in The Unit might help, was that he was capable of so much more. He admitted that he was still trying to find his purpose in life, finding himself. It was this openness that was both a blessing and a curse for V. Identities are based on the stories we tell ourselves (Demers, 2013; Pasupathi et al., 2006). The story that $\mathrm{V}$ had always told himself, and everyone else, was that he was 
not a burden. He willingly went without, so others did not suffer, or suffered less. He watched his mother struggle to pay bills and his sisters complain about not being able to go out, so he made sure that would never happen again. To him, "Son" meant that he protected, provided, and cared for this family. So, the addition of "Marine," an identity based on honor, courage, and commitment, was an intensification of the already core pieces of V's identity (Burke, 1991; Stryker \& Burke, 2000). Yet, the fact that he felt he was no longer actively serving, that his responsibility and purpose had decreased, meant that V felt unfulfilled and anxious most of the time (Castro, Kintzle, \& Hassan, 2015b; Junger, 2016). It was no longer enough to care for his parents; he had done so much more when he was overseas. Now... now, it was just a day by day existence that was a distant second to what life used to be like. V was a Marine becoming more civilian; and Marines are never not Marines. That emotional turmoil alone was enough to lead to anxiety (Rogers, 1959) and stress (Jones \&McEwen, 2000; Styker \& Burke, 2000). His participation in The Unit would be very helpful, as he was in the middle of a transition that thousands of other Marines shared with him. 


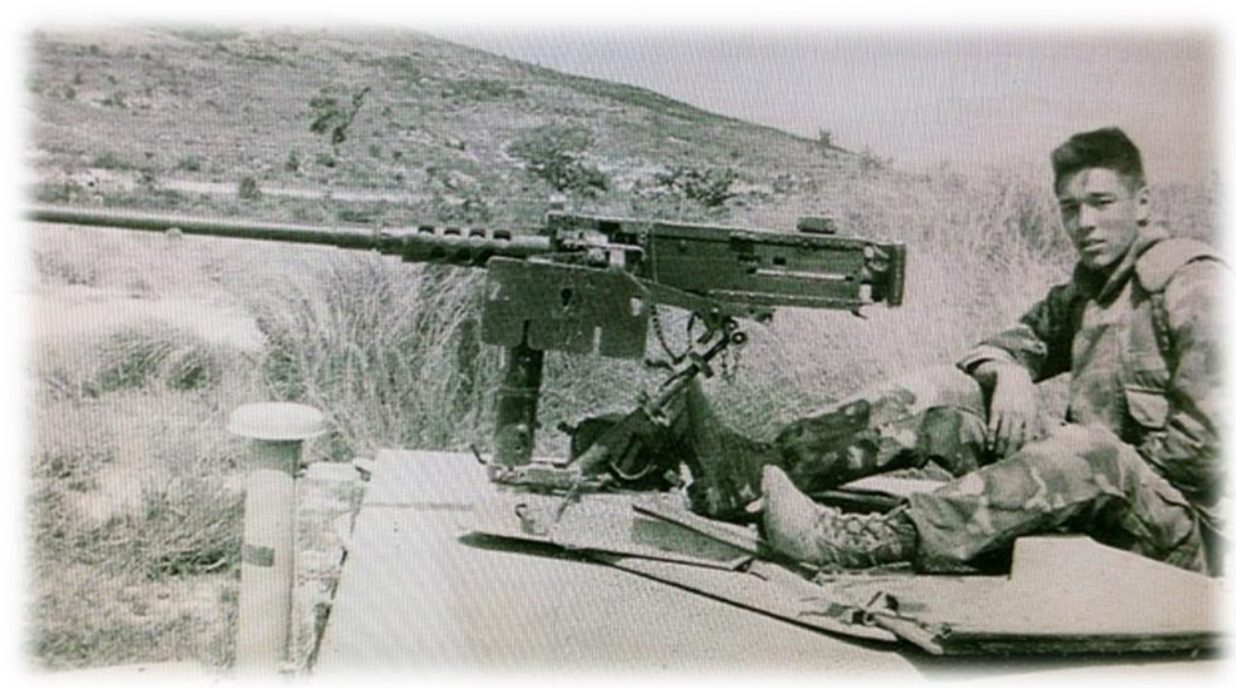

Photo courtesy of Lance

\section{Once a Marine, Always a Marine, Lance's Story}

Lance was selected for the Marines by my brother Ares. Lance had been

preparing for battle since he was a child, and Ares knew that Lance's anger would serve him well on the battlefield. Ares started his meddling in Lance's life when Lance was just a boy, only in second grade. Lance was the son of a hard-working German father and a quiet Japanese mother. He was blessed with the opportunity to attend school in Japan, only for a year, where he received "a real education for a while and came back to a really defunct school system.” As a result, that blessing quickly turned into a burden that impacted Lance mentally and physically.

Lance's return to the United States school system resulted in boredom, mistaken as lack of ability, and he was held back a grade. While Lance knew he was intelligent and loved to learn, that negative academic milestone resulted in years of his hating school. Unfortunately, even the best intentions sometimes have the most destructive consequences. Lance was half Japanese, but to the kids in East Oakland he was "Chinese and knew Kung Fu." His lifetime of fighting would begin before he was even 10 years 
old.

Growing up in a rough neighborhood, among drug dealers, sex trade, and gangs was far from the healthy development and education his parents hoped for him. Like all parents, they were doing the best that they could, until bad became worse. Lance lost his father to cancer in the beginning of $7^{\text {th }}$ grade. It was a return of a cancer from a year earlier that the doctors thought they had removed. They were wrong, and while other boys "had the talk" with their fathers, Lance was saying goodbye to his. Less than 30 days from the second diagnosis, Lance lost his father and his anger with the world increased. Most of his teachers knew, so they cut him some slack, even though he held the record of in-school suspensions for fighting and other troublesome behavior. But some of the teachers saw him as a troublemaker and immediately assumed the worst about him.

It was unfortunate for Lance that, while I was very aware of his intelligence, I was unable to pull my brothers attention away from him. Lance's love of history was almost tarnished by a high school teacher who assumed his excellent test scores and lack of follow through, with homework and other assignments, were a result of cheating, instead of disdain for the education system.

"Lance, you're taking your test at break today, instead of during the class." Ms. Neesacoshy announced as soon as he walked into third period.

"Whatever." Lance replied, with more apathy than disrespect, as he made his way to his desk.

"Why don't you sit in the back of the room while the other students work. You'll have to answer the questions verbally, and alone." Her voice carried with it the 
victorious tone of a skeptic who had finally exposed a magician's illusion.

"You know what. You could give me those questions any time. Put me in this room, naked, on a table if you want. This shit is easy." At that, one of the girls in the front row, turned to look at him as she blushed just enough for Lance to notice. He winked at her, and she quickly looked away. He would find her after school and see if she wanted to give him her own sort of test.

"Lance!" Ms. Neesacoshy yelled, bringing his attention back to his now angry teacher. "That is completely inappropriate. Go wait in the principal's office." She pointed to the door with a scowl so deep that he thought he saw the vein in her forehead pulsating.

"Sure thing. Haven't been there yet, this week!" He made sure to walk by the shy girl in the front, on his way out the door.

At the break he answered every question successfully. He knew his stuff, and that angered Ms. Neesacoshy to no end. He never completed any homework, yet he excelled at testing. She continued to give him a different test, separate from everyone else, for the rest of the year. She continued to believe that he would never amount to much. She was one of those teachers who gave up on students who had wasted potential, and that was something that would never sit well with me.

After school, he ended up getting into a fight with someone before he could find the girl who blushed. He let the thought go; he was not really into dating in high school. Part of that was because, even though I hated to admit it, Ares had done his job well. Lance wanted to kill everyone; he told people that regularly. Anger became part of who Lance was, and would continue to be, and his affinity for violence would serve him well 
in war. He tried to enlist as a sophomore yet was told he was too young. So, finally, on his seventeenth birthday, Lance and his mother signed his enlistment papers for the delayed entry program with the USMC.

LtCol Vernon, Ret., another one of Lance's teachers, discovered that "this young turd wanted to join 'his' Corps" and tried vehemently to stop it. That was not my doing, honestly. That was the free will of a Marine trying to maintain the standards and traditions of his beloved Marine Corps. But the recruiter did not care, since Lance tested well, passed the physical, and met all the requirements for another body in a uniform. And Lance wanted to get out of there, so he wouldn't end up dead or in prison.

On the last day of school, Lance ran from class to class to ensure he had graduated. He did. That night, while his classmates walked across the stage to Pomp and Circumstance, he was on a plane headed south to the MCRD. A few months later, he was a Marine.

Lance would travel the world with the Marine Corps, and he would see some amazing and some horrific events.

I was like 17 or 18 maybe

I was a heavy machine gunner

I was leading a training

We had these automatic grenade ... it's a machine gun of grenades

I had $4 \ldots 4$ or 5 trucks lined up on line

I was practicing doing

I said, you know, "On my command fire, fire."

And right then, a kid, a local Filipino kid had run out.

They ... they live off our scraps.

So he went out to get scraps off of some of our unexploded ordnance

We ended up blowing up a kid

I gave his family a box

I was all like freaked out 
I just thought he probably just wanted the box just to build their house I Poem/Found Poem from Individual Meeting \#2, 12/28/15

Although Lance witnessed numerous training accidents, he still wanted to be tested on the battlefield. So, Desert Storm was, in some ways, welcomed by Lance. That was until the knowledge of a poisonous gas's kill rate (only $10 \%$ would survive) led to reoccurring nightmares:

I was going out pissing by our dead camel

I went out there

I'm out there using the restroom

I started coughing a little bit

I realize my lungs start burning

I look down and my privates are on fire and burning

I had that for three months

I Poem from Individual Meeting \#1, 11/19/15

Yet Desert Storm was only a small part of the Marine Corps experience for Lance. The nightmares were the worst part. Yet the end of the Gulf War did not mean that Lance was completely safe from any and all risk.

It was during a helicopter ride off the coast of Somalia that Lance should have died. The helicopter exploded, killing four Marines instantly. As it plunged into the ocean, it flipped over, since helicopters are heavier on top. Lance struggled to get off all his gear, so he could get out of the cabin and into the water so he could swim to the surface. He was unable to do so, started inhaling too much water and passed out. When he awoke, he was on his way to Germany.

"What the fuck happened?" Lance asked the Marine next to him.

Slowly, as a result of a combination of amazement and pain medication, the Marine began to speak. "From what they told me, some Lance Corporal was able to get out of his gear, cut everyone lose, then get us into the water and on our way up to the 
surface before the damn can imploded. We were fucking lucky!” He never looked at Lance when he told the story, but kept his eyes focused out the window across from him.

Lance looked out the window to the grey skies and thought about surviving. I thought about how lucky it was that I knew that Lance Corporal.

He spent the next few weeks in Germany healing. He returned to such good health that he was able to play football and rugby for the USMC. Lance had many adventures during his first enlistment, from sports to traveling. Everywhere he went, from Thailand to Hawaii, he felt most at home with the drug dealers and prostitutes.

Lance loved women. He was even married at 19, although it was a contract marriage to a women 14 years his senior. Her oldest daughter was only three years younger than Lance. He never saw himself as her father, or the father to her three siblings. Instead, he saw himself as someone to hang out with or play volleyball. He later found another woman and left his contract marriage, one he described as a "kinda real, kinda like fake marriage." He continued to support that family after his departure, didn't make the divorce official for almost 10 years, and maintained a façade with the kids that he was still deployed (and single) 15 years after the divorce. Women, and the desire to be with them without lifelong commitment, would be a repeated behavior for Lance.

When he discharged for the first time, he met a bartender

I was down here in San Clemente, I met a really nice bartender who was more nurturing I would say four or five years older than me

Her parents bought us a house

They planned for us to get married

I used to be married and that was hurtful for her I didn't mention it

I was like it was not a real marriage or whatever 
I'm horrible about taking care of things

I still haven't paid my taxes from last year

I'll get to it

She broke up over that

I started working in FedEx

I met my current wife

I needed to get that break

I was still playing around and dating everybody

I had just gotten out of active duty

I was with the other girl for like two, three years.

I was pretty serious with her.

I was bartending with her

I broke up

I was bartending in three or four different bars so

I knew every single available female in Orange County

I went through as many of them as I could

I Poem/Found Poem from Individual Meeting \#3, 1/5/16

It was also after his first enlistment that Lance went into law enforcement with the

Los Angeles Sherriff's Department. After graduating the academy at the top of his class, Lance had his choice of where to work.

"Congratulations, Lance. You will be an asset anywhere in the county. Where do you want to work? The beach? The Valley?" Lance thought about it for less than a second. His comfort zone was in the middle of the "hood."

"South Central." He said with such conviction. He was certain that with the street smarts from his youth and the training from the Corps, he could harness his enthusiasm to make a difference. So, Lance worked the graveyard shift in South Central.

I was like okay

I was active

I was aggressive

I tazed and beat people

I had to 
I was respectful to gangsters, unless they were disrespectful to me.

I saw white and black

I could chase a gang member, committing an actual crime, chase them, get in a minor scuffle, injure them a little bit put the cuffs on them, put them in the back.

I look in the mirror and say, are we cool?

They will look me, right in the eyes in the mirror "yeah I understand. We have to run, your ass has to chase us, that's the whole part of the game. I committed the crime, you have to let me know not to do that crime. That's just how it goes."

I had partners that were crazy

I tackled to the ground and tazed, but it wasn't uh, spiteful.

I started getting to that point

I was getting spiteful

I was becoming racist

I started becoming a straight racist.

I was an a-hole all the time

I became a cop all the time, always on

I look at that guy, look at that girl

I was like all right, then $9 / 11$ changed everything

I had to go back

I Poem/Found Poem from Individual Meeting \#1, 11/19/15

"How much money do we have?" Jake asked.

Lance, Eric, and Jake had all gathered together on the evening of 9/11 to make their plan. Lance looked down at the table and grabbed the pile of bills and change. $\mathrm{He}$ counted as quickly as he could, but it took a while since so many of the bills were from tips. All three Marines were all tending bar and bouncing to help pay the bills.

"\$400 total" he announced, before he sat down at the table in defeat. He surveyed everything on the table:

Five (5) handguns

One (1) revolver 
Two (2) rifles

Three (3) KA-BAR knives (these were Marines)

Two (2) shovels

Eight (8) boxes of various ammunitions (none of them completely full)

One (1) pickaxe

Three (3) water bottles

“We don't even have enough money to drive there!” He added. They weren't thinking, really. They were processing the news of 9/11 in their own way. When Marines feel attacked, they prepare for retribution. Years later, Lance would think about that event with awe at the lack of any real action happening as a result of the supplies on the table. Or the "pickle" he was in. He would never forget that it was 9/11 that sent him back to the Corps for a second time.

The second enlistment was not to run away from a future of prison or jail time, like the first. Instead, he was running to protect, and for payback. He did have a girl he was pretending not to see, since they were friends. However, after enlisting again in 2002 and preparing to deploy, the thought of going off to war led to a night reminiscent of a World War II soldier heading out to take on the Nazis in a romance novel. The result was his friend became a single mother to Lance's first-born son, and he went to Iraq.

He arrived in Iraq for the initial push and found that not only was he able pass the test of his abilities on the battlefield, he excelled at it. Each time he was in combat he felt the rush, the anticipation and fear of what could happen, to kill or be killed. Each moment in battle, time slowed to the point of complete situational awareness and the intense training of the Marine Corps enabled his muscles to effectively and efficiently keep him alive.

The key element about Marine Corps training was that missions are often not planned out to specific detail. Through the intense training, communication, and 
comradery that exist in the units, each member knows their role in supporting the mission completion; a role that might forever be changing, as combat is a very dynamic and chaotic event.

There was a guy that was hiding behind a couch, playing tricky peek I can't see him. I can't shoot him You just get in that mode.

"It's just a fucking couch."

"Oh yeah."

We all started dumping in the couch

Poor guy

All four of us just dumped into the couch

The guy was gone

Problem solved

Keep going

And we laughed

It was fucking stupid

The guy held us up for a minute

We learned our lesson

We kept on going

Found Poem from Individual Meeting \#3, 1/5/16

Combat, although many have thought it was something for just "dumb Marines" was really for the intelligent warrior. As General Mattis once said, "The most important six inches on the battlefield is between your ears." Lance would describe it as a "thinking man's wild west" and anyone who has survived it would tell you that there are reasons I, the goddess of wisdom, was also the goddess of strategic warfare and heroic endeavors.

Lance loved it all! All the power, all the adventures, all the stories. One of his favorite stories about the power and abilities of Marines was about guarding a bank. With only 11 Marines, a couple of machine guns, and some barbed wire they were holding a bank. Out of food, the Marines survived only because they were trading bullets 
for chickens and being fed by a group of Kurdish children. When the 11 Marines were replaced by a section of tanks and an entire company of infantry from the Army, they finally found out that inside the bank was the entire Iraqi National Reserve. He always had a slightly puffed chest whenever he told that story.

Although his most amazing story was the result of an accident on a bridge, as it led to a blockbuster worthy adventure with his fellow Marine and friend, Rod.

I had got hurt I got thrown out of my vehicle I was supposed to be Medivac-ed

I mean honestly, we'll try to make it a movie one day

I got hurt

I was sitting between the ... the cabin, the bed, like in that space in between I yell at my driver, yell at my gunner, yell at my guys to try to control everything. I went out

I kind of ...

I didn't have anything holding me in there

I got like launched out

I was like sideways

I went out and flew about 30 feet

I got thrown about 30 feet, hit my head fractured a vertebrae in my neck and two in my back

I was one of the first ones awake, and we started digging people out. I remember like landing and then like hitting this rock, I'd seen this rock I fell .... Luckily it was like soft, like riverbed mud, clay...

I should have broke my neck, like completely fractured...

I could have drowned or hit my head

I should be lucky

I didn't pass out

I'm thinking we're going to Germany

Fuck that, you know

We got off the stretchers and we wandered around 
The planes took off without us

They were looking for us

"We can't, we have to get this bird out of here."

So they took off

Then we ended up running away from that unit

Hitchhiking all the way through Iraq to a certain point

They wouldn't take us any further

I had bought a map at Barnes \& Noble prior to the war, of Iraq

I was tracking where we were going.

I kind of knew... our increments from it

I kind of had a plan ... a pre- ... pre-planned position of where we were

I kept on, everyday kind of like, okay, 10 to 15 miles a day.

I kind of knew where we would be, after about a week of trading grenades and rockets

So we hitched rides and did everything

We finally caught up with a helicopter pilot

We got dropped off

That's our battalion commander, and our original sergeant major there

I was pretty much completely useless at that point

I kind of just,

I was just a figure head

I can't see or move anything.

I was throwing up every time we started going anywhere

I was kind of useless

I Poem/Found Poem from Individual Meeting \#2, 12/28/15

Even after returning home, Lance suffered from the results of the accident on the bridge.

The VA found nothing, thus he remained with symptoms of neck trauma, the cause of

which could not be found in any x-ray or MRI. Nevertheless, if he moved his head in any

back and forth motion, he would get nauseous and nearly vomit. He was a Marine, so he

endured.

Lance wasn't deployed at all time. In between his time overseas, leading patrols, clearing houses, and guarding banks, he volunteered as a docent in the wetlands. That is where he found his solace, where the water met the land. Water would become a part of 
Lance, as he learned how to surf when he was dating the bartender, and never returned to always staying on the sand. So that was how life went - deploy, return, volunteer, surf, repeat. And women. Lance always made sure he found time to enjoy the company of women, usually not the same woman for long.

After Lance discharged again, with a Combat Action Ribbon (CAR) added to his uniform, he finally considered himself a combat Marine, a Veteran. It was different from the first time, after his first enlistment he had "only served." Now he was a valid, combat tested and proven Marine. He would judge other Marines by the presence or absence of their CAR. Although, he would often acknowledge, after such judgement, that it was a bit unfair. He measured others by the test he had passed, on the battlefield, among the chaos of war.

It was the appeal of control within the chaos that called Lance into "contracting," once he was done with his active duty military service. Ares still had a firm grip on Lance. He spent four years working with Triple Canopy and Blackwater, two private security companies that provided high threat security services by "contracts" with the State Department and other agencies. By the time he quit contracting, Lance had spent over two decades carrying a gun. He had led 130 Marines in combat, survived numerous attacks and protected national reserves, been trusted with millions of dollars of equipment and numerous lives, to then return to the civilian world qualified only for law enforcement, security, or some other form of physical influence.

In addition to an anticlimactic return home, Lance found he did not want to return to law enforcement. After 9/11, his Marine ethos had kicked in and he found daily street level policing and city politics did not make him a better person. In fact, the opposite 
was happening. He was beginning to constantly watch everyone, everywhere, just

waiting for them to break the law, so he could "protect" people and make it right. He was starting to lose hope that he could really make a difference. As his training officer had told him "I have worked the streets for 30 years. See that kid, I arrested his grandfather, his father, and now I'm arresting him. That's what you'll have to look forward to". The problem was, Lance started to see that as the only eventual reality. So, Lance enrolled in a few classes, and began to look for other ways to serve.

I kind of started off with environmental science I wanted to do something law enforcement related I didn't want to do policing, street level policing I wanted to do like the park ranger route I wanted to make myself more compatible

I was like an easy hire for the park system I pretty much got, "you're kind of overqualified"

"Why don't you do the police department"

"Make almost twice as much, more responsibility, we'll give you any ... a gun"

"You don't want to be a park ranger with mace and protecting the squirrels"

I got turned down ... or

I got my ...

I got pretty much like ...

I'm like, thanks.

I didn't get a straight ... shake from the get-go

I called, and like, hey, how's it going?

I'm like, did he get promoted?

I kept calling, finally got a hold of her.

I took it on my own to drop something off I have this information.

I went to the police headquarters

I could see her

"Why would you leave your department?"

I had to explain the whole Marine Corps ethos

I was looking at the bigger picture

I joined 
I did too but

I found something bigger than that

I didn't make that first cut

I Poem/Found Poem from Individual Meeting \#2, 12/28/15

Lance was disappointed, yet he was still enjoying life as an environmental studies major. He got to go sailing. It was at that time that Ares backed off of Lance, and I was able to step in a bit more. In fact, when Lance first started at the local community college in 2011, he avoided the Veteran Center because it was a bit "too Marine," or maybe just not the type of Marines he wanted. School was just like a job in his mind (Naphan \& Elliott, 2015). Fortunately, Lance was soon able to see the beauty in art and expand his knowledge beyond weapons and tactical strategy. Of course, every transition is not without its difficulties, particularly when two cultures collide.

"Finally, the horrors begun by Bush are going to end, but not soon enough. Leaving 50,000 soldiers over there is still too many, when we never should have been there. No weapons of mass destruction, all lies and deception enacted by the mindless drones that serve in the armed forces, which some call heroes." The professor continued to speak, while Lance had stopped listening. It was his only option for survival in Professor Andrews' class. It was a normal occurrence for Lance to feel angry, offended, or belittled in this class (Arminio \& Kudo Grabosky, 2013; Cropsey \& Hendrickson, 2013; DiRamio Ackerman, \& Mitchell, 2008; Persky \& Oliver, 2011; Rumann \& Hamrick, 2010). Nevertheless, school was his current mission, and he had survived far worse. As soon as the class was over, Lance nearly ran out the door. His feet moving with such conviction, he was at the Veteran Center in minutes.

He had been there a couple of times before, but this time he really needed it. He walked in, found a seat in the back corner, so he could keep his eyes on the door, and sat 
down.

Not a moment later, one of the Veteran Center staff members, Don, came over. "Hey, Lance. How ya doing today?"

"Have you ever had Andrews?" Lance asked, his question laced with frustration. "Oh, yeah. I've heard that guy can be a bit of an ass." Don laughed as he stood next to Lance, his back to the wall.

“"Ass' doesn't begin to cover what a fuck head that guy is..." Lance shot up so he could move around the room, full of military flags and other Veterans, while he ranted about Professor Andrews. The tirade, which lasted a few minutes, included numerous obscenities and several well-crafted insults. Finally, Lance sat back down.

"Feel better?” Don asked, without judgment or condensation.

"Yes." Lance grabbed his backpack, stood up again, and headed for the door. "I have to get back to class."

Don yelled, as the door opened and Lance walked into the quad, "All right, man. See ya later."

It was the ability to be himself, raw anger and all, that made the Veteran Center so appealing to Lance (Community College Times, 2012; Cook Francis \& Kraus, 2012; Cropsey \& Hendrickson, 2013; DeSawal, 2013; Osborne, 2013; Sander, 2012b; SmithOsborne, 2012). It was also a sort of one stop shop to get information, referrals, support, and answers (Brown \& Gross, 2013; Caspers, 2013;Community College Times, 2012; DeSawal, 2013; DiRamio \& Jarvis, 2011; Ford et al., 2009; Griffin \& Gilbert, 2015; Jackson et al, 2013Osborne, 2013; Persky \& Oliver, 2011; Sander, 2012b). Lance was sure that having the Veteran Center on campus increased the recruitment, retention, and 
graduation rates of Veterans (Abel, Bright, \& Cooper, 2013).

Lance began to get more involved with Vets in the Student Veteran Organization. Since Veterans were more likely to join a group of other Vets on campus when they can see what they were doing (Griffin \& Gilbert, 2015), Lance's participation was crucial. He made sure that the Veterans were there for all of the fairs, events, and activities that the other clubs participated in. Because of his involvement with the Veteran Club, he was able to serve as an advocate for Veteran needs (DiRamio et al., 2008; Livingston \& Bauman, 2013) and created further opportunities for the Veterans on campus, by becoming an official chapter of Student Veterans of America (SVA), which lobbies for further support for Veterans on a national level (Summerlot et al., 2009). SVA also provides employment support for graduates, scholarship opportunities for Veterans, and connections between chapters (Hawthorne et al., 2013).

Lance then took his school involvement even further and became a leader in student government at school. It was a very different experience for him. He had gone from the school troublemaker to a student leader. That transition was significant because, although he had significant leadership experience, Lance had always identified himself as a "grunt," he would never be an officer. Now, in his student role, he was serving as a student government officer; although it was his grunt mentality to get things done that added to his effective leadership (most certainly leadership through service).

Lance had also become a father, again. Between deployments he had lived with his friend-turned-mother-of-his-child. His first son had communicated that he was bored, so Lance took it upon himself to "make him a brother" and was successful. His "friend" had been by him all that time, and he figured she had "paid her dues," so he agreed to 
marry Stephanie. It was a far cry from a romantic proposal. They supported each other and tried to make things work, as they moved through the world together with their children. At least until Hurricane Sandy hit New York.

"This is my chance to go help New York. The chance I didn't get on 9/11." Lance said.

Stephanie thought it was more for the glory, not to really help. She also knew there was nothing she could really do to stop him.

I have to go back

I need closure

I need to go back to work and fix New York ...

I want to

I'm leaving

I'm out of here

I Poem from Individual Meeting \#1, 11/19/15

Team Rubicon, an organization of Veterans that provides disaster relief, was just getting started, and they had not yet developed their full network of support. So, Lance called other Marines to join in and help. Then, he left.

I left her in a lurch

I went there and initially it was a bunch of guys

I was like you're just a fat guy in uniform, you're not a soldier anymore

I found a bunch of Marines

We can do two times as many more

I started working with them

One of the founders of the organization came up to me

Hey you're a Marine right?

You're a Platoon Sergeant?

You handle a bunch of troops?

100 spontaneous volunteers that showed up

I was like yeah

I can do that

I had responsibility, accountability 
I have a mission

I know what to do now

I started delegating

I was working - it was amazing

Fifteen, sixteen, eighteen hours a day

Fatigued, muscle fatigue, memory... physical and mental

You're just completely worn down

I did all the raids in Afghanistan

I became an emotional wreck.

I was there from Halloween, to almost Thanksgiving.

It was different

We're going to get this guy, this is what he's done

He did all these bombings

He's done all this stuff

Let's go in and get him

When you come into an American house

You see a pair of bronze booties

Baby's first christening

"This is everything I own"

One week, two or three after the disaster

Still no power

Still living in a foot of water

"Where's the National Guard at? I'm glad you guys are here."

You disassociate

Military mode.

My last house

A lady, 90+ years old

In and out of dementia

One minute she loved us, next minute...

"Why are you doing this to my house?"

There was black mold on the walls Three and half weeks post disaster

Living in foot and a half of water

We're just knocking everything out

We're moving a car

Blown into her living room

Picking it up and moving it out 
We lifted this piano

Old leather-bound album

Her wedding album

I'm like, crap.

I called her in there, and she had me in there for about fifteen minutes.

I had really bad allergies

I'm done.

I'm like emotionally like done.

I sat with a Vietnam vet. You know, he was crying and hugging me

I'm like okay

I just want to get on my plane

I was in the Marines. She's like, oh my son was a Marine.

I know a lot of guys from there. She's like, yeah he was killed in 2007.

I was like ah

I heard about her dead son for seven hours

I came back

I was like rah.

I went to the VA, started getting help

I Poem/Found Poem from Individual Meeting \#1, 11/19/15

Lance slowly became more and more engaged with Veterans, at the community

college and then with Team RWB, a national non-profit that supported Veteran

reintegration by "connecting them to their community through physical and social

activity” (Team RWB, 2016). He had already worked with Team Rubicon, and even

participated in one of The Mission Continues programs (Klein, 2015). I encouraged his

involvement as those are my three favorite Veteran organizations. These organizations

didn't form to fix what was wrong with the Veterans; instead they focused on the

community that was lost when a service member left the service. It was Lance's

involvement with Team RWB (and a little help from me) that led to his position with the

VA in Public Relations, which included reaching out to Vet Centers at local colleges and

universities (Brown \& Gross, 2013; Caspers, 2013;Community College Times, 2012; 
DeSawal, 2013; DiRamio \& Jarvis, 2011; Ford et al., 2009; Griffin \& Gilbert, 2015;

Jackson et al, 2013Osborne, 2013; Persky \& Oliver, 2011; Sander, 2012b). Lance would be wonderful resource for The Unit, and beyond that, he was a great spokesperson for Veterans. It really was an honor to finally be free of Ares, so that I could move Lance further toward finding his own wisdom.

He transferred to a local private university and switched his major to psychology.

I want to say it was a grand noble gesture but ...

I was doing environmental first

I wanted to transfer out of the school

I really liked it ... and it had a low math requirement

I wanted to help people

I would like to be a medical doctor

I just don't have the time to do all that background work

I just turned 43, it's an easier place for me to be.

I get to attain quicker

I really like the program

I really like learning about psychology, it's really attainable.

I really understand it, it's something meaningful.

I Poem from Individual Meeting \#1, 11/19/15

The psychology education has also helped Lance deal with his PTSD diagnosis

(DiRamiro \& Spires, 2009; Hoge, Auchterlonie, \& Milliken. 2006; Tanielian \& Jaycox, 2008; Reynolds, 2013) and what that meant in his relationship with Stephanie. He began seeking treatment, while his wife thought he was getting massages for his neck and back injuries (another treatment he received regularly). He became the face of PTSD and VA services for many people, while his wife felt the need to walk on eggshells around him.

"You okay?" Stephanie asked, as the friends she invited for the barbeque grew louder with laughter.

"I'm fine. Please stop fucking treating me like some baby; especially in front of 
your stupid friends." He hated that others might think he was weak. He walked away from Stephanie, grabbed a beer, and made his way to an empty lawn chair. As he sat down, he nodded an acknowledgement at one of the guests, who came over to talk football.

Later that night, Stephanie apologized. Then she asked him about his most recent PTSD presentation.

"So, why is it that everyone else knows all your stories? They think I'm your rock, but you don't tell me anything. You're just a complete narcissist who wants attention and control."

He heard her, and knew every word was true. Yet, at the same time he could not handle her knowing everything that had happened over there. It was one thing to tell your story so people had a more humanistic perception of PTSD (Osborne, 2014). It was another to tell your story to your wife, the mother of your children. The stories of war that made you sound like a monster (Paquette, 2008; Rafool Bidwell, 2012). He would never tell her everything. He wanted to protect her naïve view of him; and he thought she did too, really. He always spoke highly of his wife and supported her work with the Parent-Teacher Organizations. Lance would often speak in awe about her ability to create life, his sons, with almost the same reverence of his abilities in battle. In the next breath, he would tell you he didn't really care about his family. I often wondered if people knew his defenses were so convoluted, even for him.

Deep down, what many missed was that Lance was in a place of atonement (Klay, 2016). Once Ares let go, he kept his warrior spirit, yet this mission was different. He began to feel guilty about some of the things he had done on the battlefield, the way he 
had left his family so many times. He would say yes to helping friends and family, to make up for all the time he had been away - deployed, contracting, or volunteering. Yet, at the same time, he was a Marine. The element of lifelong service would never leave his identity. While he did appreciate the attention, part of it was genuinely to add more good in the world.

I played Santa all through the holidays

I did my ... the Vet Center Thursday night.

I did CHOC on Friday.

I did the VA Hospital on Saturday

I was in the pregame for the Chargers as Santa, Sunday

I took Monday off

and then Tuesday

I did my old Battalion 3/1

I did their ... their holiday

I did CHOC

I went to go talk to the kid

"My wish is to be home by Christmas"

I was like, buddy, that's not really in Santa's hand

That's all in your hands

You have to really work hard

It's up to your body

It's up to you listening to your mom and your doctors

I really kind of put it on him

I'm not going to take that on

I'm like it's not on me dude

I can't

I don't want to set him up for failure

I kind of like ... pffft, you know, blocked it

I went up ...

I was going upstairs and like, Santa ... Santa ... that kid wants to take a photo with you

I'll go back

I went to go catch up with him

"Santa, I didn't have the right to make that wish"

"I'm really a bad boy"

"I'm yelling at my mom all the time"

"I'm on medication"

I'm like, crap, so it's like a 10 minute like cry fest 
I went upstairs, like the third or fourth floor

"That kid came back down."

I'm like, it's killing me.

"He wants to see you before he leaves"

"He wants to apologize for making Santa cry"

I'm like, give up kid

I kind of didn't care to have all that responsibility

I like doing it

I mean look at that little dude

I'm a ham.

I like being the center of attention

I did the VA Hospital

I looked at ... like they have this sign, like no visitor for your safety.

I have a knife, as always, like underneath my Santa suit.

I'm like, crap

I shouldn't be really in here with this.

"Santa, what's going on?"

I was a Marine Corps Santa

"I was Army"

We talked mainly military branch

Just like, hey, how it's going?

Trying to wish ...

Treat them like people.

I Poem/Found Poem from Individual Meeting \#2, 11/19/15

Lance would continue to serve (Klay, 2016; Klein, 2015; Schultz \&

Chandrasekaran, 2014). He would continue to be the PTSD guy, because he wanted everyone at the VA to know that it did not matter what their role was, they could be the link for someone else.

"Now that you work at the VA, you're going to have friends coming out of the woodwork like 'Hey you work at the VA, right? Can you help my friend out?" He would tell all the employees at the VA Orientation.

He would continue to seek treatment for his pain, his sleeplessness, and his aggression. He would continue to be "on" for Veterans, "full moto," as much as possible 
so that Veterans and civilians could find the resources, they needed to build community together again. When he was at home, he would be able to completely shut down, off from the world, in attempt to recharge. It was there, with Stephanie, that he felt safe to be completely real.

He would forever be a Marine. It was his identity in every aspect, at school, at work, at home, and in the community. He was the "Vet guy" quoted in the newspaper, in the documentary, and on the school website. Because

It's so ingrained and instilled in you.

You see alumni plates

That was four years

Whether you want it to be or not

You're going to hate the Marine Corps

That's all you live and breathe

Do physical harm your body

if you're not doing everything right

A high standard that you always have to maintain

Through straight peer pressure

One ounce of body fat

One second slower

You're going to get it

from everybody

Found Poem from Individual Meeting \#3, 1/5/16

He would never be a civilian. Never! His life was forever changed when he joined the Marine Corps at 17 years old. He spent 14 years in and had been forever altered to his core about who he is. At times it meant that he was the "world's sheriff," ensuring that everyone was held accountable (Carey, 2016). A need to keep everyone to a certain standard would not go away easily; it was part of his Marine conditioning. He would continue to live as a Marine in a civilian world. When you asked him if the transition to civilian was harder for Marines, he would unquestionably confirm that it was. Marines 
are Marines, always!

Air Force is a job

Navy is a club

Marine Corps is a cult

We're different

We live off of our traditions

You're raised to greatness

You can never let down your past

We're better than ...

Definitely better than civilians

Always better than the Army, Navy

And all those other services

We've done so much

We can do more with less

It is a point of pride

We pride ourselves on not having anything

Live in the crappiest conditions

Always make due

The underdog in the fight.

We like that mentality

Always worked for us

Orders in combat

The commander's intent is the end state

Progressive leadership

Any Marine could be a leader

Comradery

I'm going to rush forward in the traditions of the Marine Corps

Live up to what I've been told

All Marines do,

Second nature

My own personal life

I'm not going to let you down

You're a fellow Marine

I stepped across that line, for the Marine Corps

I'm continuing because of you

Found Poem from Individual Meeting \#1, 11/19/15

Lance was moving forward personally, on his own journey of Post Traumatic 
Growth. He was going to begin his PsyD, a doctorate in psychology, and work toward starting his own non-profit to serve Veterans. Lance would maintain his same level of passion for great work, to make a difference. He would be a huge asset to The Unit, if he could accept that Jamie was a female.

As you might have noticed, Lance often saw women as something, not someone. He often referred to himself as a "man whore" who would have been uncomfortable in recruiting duty, with all those teenage girls, and did not want to be responsible for a girl in his house. His backup plan for the future was an island in the South Pacific, alone... with a bunch of naked women. His idea of a good time was getting drunk and topless. He believed female Marines were best to "sharpen our swords" or sexually satisfy the male Marines. Female Marines had never been in combat (although that would change in 2016) and thus were not full Marines.

But Jamie was a woman, a woman with a unisex name. So, when she extended the invitation to Lance, I intervened. They both had much to learn from each other, and the rest of The Unit. It wasn't difficult to make him assume that she was a male. It was a $\mathrm{PhD}$ student interested in researching Veterans, Marines in particular. Why would that individual be female? Just a little thought placement, inspired by me, to send the reply "Sure thing, brother."

When Jamie read it, she almost replied to correct him. Almost. One more little thought placement. The rest, they may say is history, but I would say is the story on these pages, as Lance became a powerful addition to The Unit. 


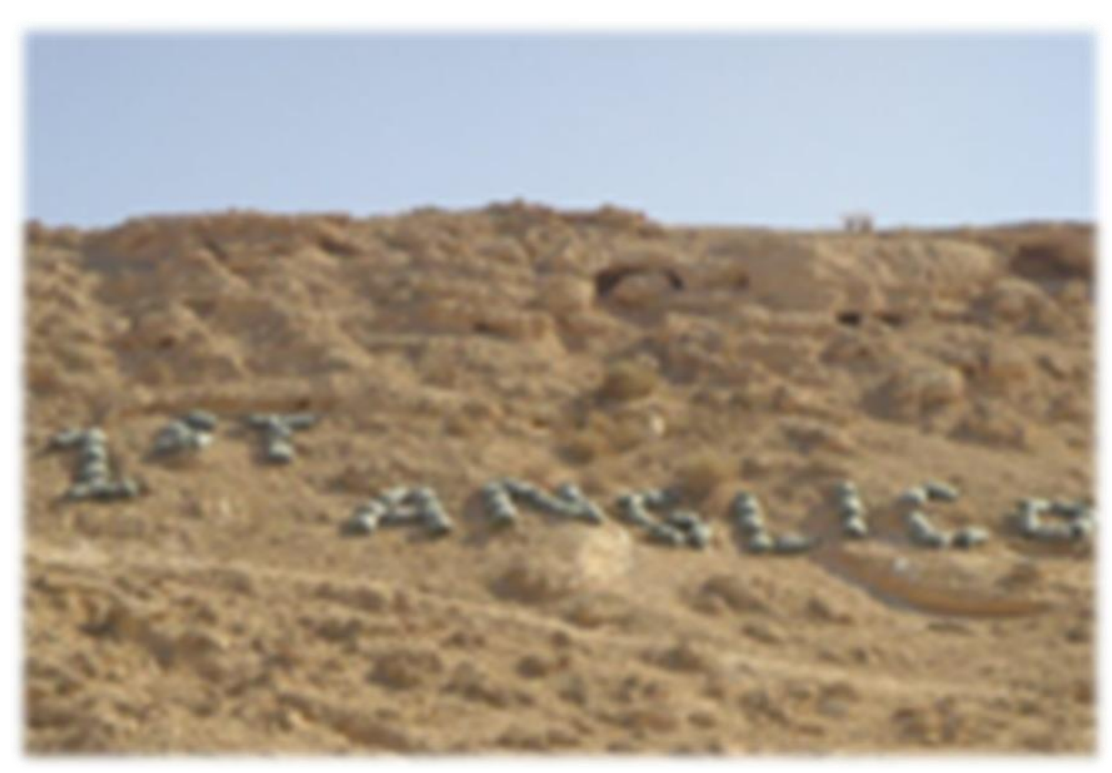

Photo courtesy of Beaver

\section{No Greater Friend, No Worse Enemy, Beaver's Story}

As a child, Beaver spent most of his time with the "coolest, meanest, most awesome bitch" in the world, his Grandma B. One day, as the theme song for Cops began to play, Beaver (then Tony) and Grandma B took a seat together on the couch. Beaver loved spending time with Grandma B; he was a total grandma's boy.

"You know, Tony,” Grandma B began, "I think you would be a good cop. You are smart, brave, honest, and you would look good on the TV, too." She looked at him the way grandmas look at their grandchildren, full of hope, love, and a hint of a threat that he better not disappoint her. I didn't need to inspire Grandma B; she saw the best in her grandson without help. So, at only six years old, he decided he wanted to be a cop, and never looked back.

Grandma B passed away when Beaver was 11, but that did deter him from pursuing his dream to become a police office. He would slide by through school, doing the bare minimum to make it to the next grade and continue playing club hockey. He 
never cheated; he was honest. Beaver earned those Ds and he passed.

During his senior year, Beaver and his friends started to think about life after high school. Harper, Beaver's buddy had enlisted in the Marine Corps, because his sister's boyfriend was a Marine. After a few conversations, Harper had convinced Beaver to at least take a look.

I told you before, the Marine Corps was only chosen

based on what my buddy went to

I followed my buddy

I swear to God, we could be talking about the Army right now

I went to the Marine Corps because of him

I weighed some of my options

I never even talked to another recruiter

I was sold

Talk to him for about half an hour

I was like fuck it, four years

I get to do all this crazy shit, you know?

Get myself in, you know, killer shape

Look really promising to departments

I Poem/Found Poem from Individual Meeting \#2, 12/28/15

A week later, Beaver was driving around with his buddy Brandon, and talking about

future plans. Brandon was headed to a local Cal State University to play soccer, until

Beaver convinced him to visit the recruiter, too. That recruiter was well trained. He had

signed at least three young Marine recruits in one week. Or just maybe, he had a little

help from a Greek goddess with a soft spot for Devil Dogs (I would bet on the latter).

So, Harper, Brandon, Beaver, and another one of their friends, Luke, all graduated from high school together, and then headed off to boot camp. Yet they didn't all stand on the yellow footprints on the same date. Harper started mid-July, Luke at the end of July, and Beaver at the beginning of August. It was the fact that two of his friends had already 
started, and not given up, that kept Beaver in boot camp past Black Friday.

Once Friday comes, your whole life changes.

They come out of their damn duty huts

Like the devil was just built up inside of them

They just let it all out on you for the next three months

You know how mad you get when you step on shit

And you're wearing some new shoes that got lots of grooves

A pattern design

How pissed off you get

It's like we were the shit in their shoe

They are pissed off at us all the time

They are just taking it out on us.

That's the best way I can describe it.

They try to kill you

It's like they are just trying to throw away that shoe

but they can't.

They got to train that shit into a well-trained, elite fighting machine

Everybody died in boot camp

If you don't, then you're drill instructor didn't train you right.

Found Poem from Individual Meeting \#5, 12/15/15

The values and priorities of Marines at boot camp graduation are often different from when the recruit stood on those yellow footprints (Bridge, 2015), because boot camp is designed to transform recruits into Marines (Chenoweth \& Nihart, 2005); individuals who could do more than they originally thought possible. Beaver had one such transformative experience during swim week.

Beaver had always considered himself a strong swimmer, until he was in boot camp. One of the exercises during swim week included treading water for 15-20 minutes while wearing full combat gear. That may not seem like a very long time, but once all the gear was on, it began to slowly pull even the strong swimmers down into the water.

Beaver was experiencing just that and began to move toward the security of the edge of the pool. 
"Two minutes." The DI yelled, as Beaver slowly moved a little closer to the edge.

He was still about a foot away from the edge, when he slowly began to sink to the point that only his nose remained above the water. At this point, Beaver was desperately hoping for the final count so he could grab the edge.

"Five, four, three, two..." the DI announces. Beaver was so relieved that he made it. He saw the hand of god coming to help him out of the water, so he let all the breath out of his lungs. But Beaver was wrong. The hand grabbed Beaver's chest and dunked him in the water. With no air left in his lungs, he went into panic.

"This is how I'm going to die, right here." He thought. "I'm not even going to make it out of boot camp, because I'm going to fucking drown. In about a millisecond, I'm going to take the biggest gulp of breath that I can take. And, unfortunately because I'm not a goddamn fish, I'm going to drown."

At that moment, he began to move upward, toward fresh air. "I saw you fucking creeping to the edge, you little bitch." The DI was not pleased, as Beaver sat on the edge of the pool for a moment to catch his breath. Nevertheless, he had passed. He had almost died, but he passed.

The rest of boot camp was less eventful for Beaver. He eventually graduated and moved on to MOS school.

I got sent to Missouri for my MOS school there

Supposed to be in your alphas

Fresh haircut

Fresh shave

I didn't get a haircut

I didn't have a fresh haircut

I had my mom cut my hair

Bless her heart, she tried her best. 
Didn't quite meet the mark when it comes to the fade

It was basically a solid line to naked skin.

I checked in

I had my ass handed to me so fast

I didn't even get to do the general orientation

They sent my ass straight to the fucking barber

"Get a fucking haircut right now"

I went over there, got a haircut, came back

I had to do like a mock orientation

I was just getting my ass chewed left and right

"I'm a Marine, I'm the shit"

I was labeled as a shitbag

I had to work my ass off to prove that that my haircut

didn't basically make who I was

They full board attacked, like sharks

It was crazy

I remember that

I Poem/Found Poem from Individual Meeting \#1, 10/14/15

Beaver hit the fleet, after completing boot camp and MOS school, he was sent to $1^{\text {st }}$ ANGLICO, which stands for Air Naval Gunfire Liaison Company. He was Marine number 63 assigned to the company, which would have 111 Marines before their first deployment, and a little over 200 Marines when fully staffed. Harper ended up in the Reserves and Beaver lost contact with him. Eventually, Beaver would run into Luke in the chow hall in Iraq. Beaver and Brandon would remain close, even though they did not end up in the same unit.

Being in 1st ANGLICO certainly had its advantages. As a small, special operations unit, they were the test group for new equipment and enhanced gear. Once they tested it, and knew that it worked, the new resources were then sent out to the bigger units. Also, as a special ops unit, they were always training. Survival, Evasion, Resistance and Escape (SERE) school and Marine Corps Martial Arts were among the numerous schools that the men of 1st ANGLICO completed in order to "provide Marine 
Air Ground Task Force Commanders a liaison capability with foreign area expertise to plan, coordinate, employ and conduct terminal control of fires in support of joint, allied and coalition forces" (Marines.mil, 2016, para 1). Such a mission meant that they could be requested by any service branch, at any time, to assist with fire teams or air support. It was the strong working relationships with aircraft and other artillery units that enabled $1^{\text {st }}$ ANGLICO to quickly and efficiently complete their missions in Iraq, Afghanistan, and throughout history.

Training happened when they weren't deployed, and $1^{\text {st }}$ ANGLICO deployed a lot. For Beaver, that was the biggest drawback of being in the unit. Beaver deployed three times, in three years $(2005,2006,2007)$. His numerous trips over the Atlantic Ocean, to a place he despised, would leave him with an inability to live on that coast later in life. Yet, he was a Marine with $1^{\text {st }}$ ANGLICO, so he went.

On his first deployment, Beaver noticed that the $2 \mathrm{x} 4 \mathrm{~s}$ that the turret gunner stood on in the vehicles would often get slippery. As a kid who spent a significant amount of time on a skateboard, so he had an idea. Beaver stood in line for the phone for about an hour and made a call to his old skate shop back home in Southern California.

"Hey, my mom is going to come by your store in a bit to buy some grip tape. But she doesn't know what she is looking for, so can you pull it out for her?" He asked the cashier who answered the phone.

"Sure. What is this for?"

"Well, I'm calling from Iraq, and we need it for our gunners in the vehicles."

"Iraq? Hell, man, how much do you need? It's on us!"

Beaver hadn't planned on asking for a donation, but it worked out. Once the 
shipment arrived, they wrapped the $2 \times 4 \mathrm{~s}$ with the grip tape and the gunners no longer slipped around out on the convoy. It was that initiative and problem-solving skill, evidence of his leadership, which earned Beaver a Navy Achievement Medal (NAM). The award didn't change Beaver as a Marine, or as a member of $1^{\text {st }}$ ANGLICO. He still had other missions to complete.

The usual mission for Beaver's unit was to move in small groups into areas where the United States would later conduct or operate various missions. As a result, they were the first Marines in a variety of areas, most of which were potentially quite dangerous. They moved in small groups, at night, quickly and quietly. Beaver never lost anyone in his unit. He did, however, realize that not all the other units were so lucky.

I was deployed

I was used to seeing him on a fairly regular basis maybe every couple weeks or whatever.

I was like, "Oh, where's so-in-so, is he convoying or whatever?"

He had passed on

He was killed by an IED on a convoy.

At that moment, it made it much more real.

I mean like, 'cause

I never lost anyone in my unit

We'd go

Complete the mission

Come back

That was it

Someone I had seen on regular basis and no longer be there anymore That was eye opening.

I was like, "Fuck

Signs all over Iraq and Afghanistan

'Complacency kills'

You get so used to it

You've done one mission, you've done them all

You've done one convoy, you've done them all

Foot patrol. Same thing. You've done them all.

They all seem to have the same repetitive pattern and routine. 
When somebody dies on

a basic convoy

a basic foot patrol

You realize that it's not basic

They're still out there

Big eye-opening moment

Realize how real shit is out there.

I Poem/Found Poem from Individual Meeting \#5, 12/15/15

Beaver loved and hated the Marines. He always hated being deployed. His first

deployment brought with it a natural curiosity, which was replaced by realistic

expectations for his second and third deployments. His knowledge came with a "fuck

this place" attitude for Beaver.

We crossed a bridge one time

There was like a clusterfuck

A couple of ... fender benders

Pulled off to the side of the road

Iraqi males approaching

Waving their shit, "hey no, we're, we're friendly."

We still proceeded with caution,

By "proceeding with caution"

You barrel through as fast as you fucking can

The slower you go, the more bunched up you get

We tried to barrel across

Sure as shit, we hit an IED

Pissed us off

You know, one of them had some part of that

About seven of them, you know, you know it

Shit like that just pisses you off.

Found Poem from The Unit Meeting, 12/13/15

It was constant activity for Beaver, between the deployments, due to the training

regime for $1^{\text {st }}$ ANGLICO. As a result, Beaver usually was not on base for long; instead he was traveling and seeing parts of the world - Iraq, Afghanistan, Kuwait, Germany, Ireland, Florida, Maine, Texas, Arizona, and, occasionally, back home to California. With travel came the opportunity to meet new people and try new foods. Yet, it also 
meant that at times he had to eat things he normally wouldn't have, in order to be polite.

Choke it down

You're in somebody's home

Trying not to be disrespectful

I'm going to have diarrhea for sure

How much longer are we going to be here?

That would fuck my stomach up

How the fuck can I get back?

I need to call Quick Reaction Force, get me out of here.

QRF, man down!

I never really took a lot of things serious.

I would always joke about everything

I can't even tell you how many times they told me to shut up

"I didn't finish what I was saying"

I guess I'm done talking.

"When can I talk again?"

"When you go on another team, you can talk."

Found Poem Individual Meeting \#2, 10/20/15

Such was the nature of Beaver's first three years in the Marines. The fourth, and final, year of active duty service for Beaver was with the Commanding General, or CG's Office, because his sergeant, Sgt. Diego, saw his potential and believed in him. Sgt.

Diego played an important role in Beaver's leadership development; since he was a Marine who role modeled good leadership qualities. He taught Beaver that if you know your stuff, do the right thing, and don't let the perceptions of other people impact your perception of yourself, you can do amazing things. Beaver would take those lessons with him beyond the Corps, always grateful to Sgt. Diego.

It was Sgt. Diego who nominated Beaver for a position working for the highestranking Marine on the West Coast. Beaver was selected from the five ANGLICO Marines, to become one of 10 Marines that then met with a Brigadier General (one star, 
BGen) and a Sergeant Major (SgtMaj), who was an ANGLICO Marine from the past. Beaver moved on from that interview to be one of five Marines sent to MHG, the Marine Headquarters Group, on Camp Pendleton, where they became a group of three. Beaver was the first Marine selected from the three for an interview with the SgtMaj, who was then reporting to General Mattis.

"Come on back, Corporal" the SgtMaj turned and walked into his office, knowing that Beaver would be right behind him. Beaver walked into the office and sat down at attention in the green chair in front of a strategically organized desk. He straightened his back to sit at attention, right hand, right knee, left hand, left knee.

The SgtMaj looked Beaver directly in the eyes with honest inquiry and intensity "Do you want to be here?"

"Yes, sir. I'm ready."

"So, nobody's making you be here? Command isn't making you sit here. You want to do this? And, you know what you're going to do?"

"Actually, sir, no. I have no idea what I'm going to do. That's the problem. That's the only problem I really have with this. I know exactly what I'm going to do at ANGLICO. But I have no clue what I would do here. But my commander told me the significance of working with the star Officer, and what that means as far as the Marine Corps is concerned."

The SgtMaj quickly explained that the position included general office work. There was no mention of deployments, yet he did say that it was at the discretion of the CG whether or not the Marine in the position would go with them to wherever they went. Then, as the SgtMaj was a Mustang enthusiast who knew that Beaver drove a 2007 
Mustang GT Deluxe, he asked, "Is your Mustang outside?"

"Yes, sir."

After a quick trip to the car for some conversation about V8 engines and horsepower, they returned to the office where Beaver was instructed to go check out with the Sgt. As Beaver was told about what would happen next, the SgtMaj wrote a short email to General Mattis.

"Not sure if you want to see any other Marines or not, as the Marine who just left my office is somebody who I think would do really well."

"Your call" was the even shorter reply.

That afternoon, Beaver received a phone call from the Sgt at MHG. "I don't know what you did with the Sergeant Major but he turned away the other applicants and you start next Wednesday." So, on Wednesday, Beaver began at the CG's Office in what he described as "the fucking easiest job I've ever had in my entire life and I worked at Little Caesars," and that is where he spent that last year of his active duty Marine Corps experience.

Even though Beaver had his love/hate relationship with the Marine Corps, there was no denying he was good at it. He became a Marine to advance himself on a path to becoming a cop. So, when the CG kept asking Beaver if he was sure that he wanted to be discharged, Beaver kept assuring him that he was. When that day finally came, nothing was going to stop him from leaving base.

I'm checking out

I'm filling out all my stuff

I going to where you get your DD214

I explained to some female, some Lance Corporal I tried to explain to her 
I want to be very clear here

I'm not trying to be a dick or anything

I'm not telling you how to do your job

I'm just telling you where I'm gonna be and it ain't gonna be here

"Where's your Staff NCO?"

SSgt who knew I was

"I don't know where he's at now,

"Oh, where's your boss at?" this is my last day."

"Well, she doesn't want to sign my paperwork

"Oh, well, what's going on?" because my discharge date isn't until Sunday, and it's Friday."

I'm pretty sure she got spoken to

"Oh, give it to me."

I was out

I called my mom

I go off base

I'm out

I'm discharged. That's it. Never again.

I Poem/Found Poem from Individual Meeting \#1, 10/14/15

I put the Marine Corps in my rearview mirror

I tried to keep it there

I tried to keep the actual Marine Corps in my rearview mirror

I Poem from Individual Meeting \#2, 10/20/15

It was after Beaver returned home that he realized the economy had significantly impacted police departments, as many of them had put a hiring freeze into place. So, Beaver spent almost a year without a job, until he received an email from a buddy letting him know about a position with the San Gabriel Police Department in Parking Enforcement. He applied, got the job, and began working next to his dream career.

San Gabriel, and the year prior to beginning his work there, was a time for Beaver to learn how to deal with civilians again. What Beaver loved about the Marine Corps was that everyone was held to the same standard. It was clear cut and maintained by 
everyone within the unit (Naphan \& Elliott, 2015). However, civilians did not follow those same principles. Beaver learned how to "dumb it down" for civilians, or lower his expectations for what civilians were willing and/or able to do. Some of the police officers, who were also Veterans, helped Beaver with that process, as difficult as it was. While working at San Gabriel, Beaver became friends with many of the officers in the department. One in particular, Christian, who had 35 years on the force, became somewhat of a mentor for Beaver. Beaver looked up to Christian as a season officer who had worked in homicide and burglary, as well as been a detective, motor officer, and field training officer. Christian looked at Beaver as a Marine, not a parking enforcement officer. They had many conversations, over the course of which Christian encouraged Beaver to use his GI-Bill for a degree, which would give him a pay raise when he was hired on at a police department.

So, when Beaver saw the commercial from East Forrest College, with a bachelor's degree in three years, he gave them a call. Three years fell in line perfectly with the speed and tenacity that had become part of normal functioning for Beaver. Even though he was no longer an active duty Marine, there were pieces of the Marines that would never leave him. That included his desire to do things quickly and efficiently.

Once Beaver arrived at East Forrest, he was Tony again. He didn't tell most people he was a Marine. He felt they didn't need to know, and he had found that, once you told civilians a little bit, they always wanted to know more. Including the disrespectful inquiry about how many people he had killed (Ackerman et al., 2009; DeSawal, 2013; DiRamio et al., 2008; Glasser et al., 2009; Glover-Graf et al., 2010; Rumann \& Hamrick, 2010; Rumann et al., 2011; Street, 2014)) 
I can't even tell you how many times

It is the lack of respect

What difference does it make if I killed somebody or not?

Does that bring that person back?

Did you know them?

Does it bring you closure?

if they knew absolutely everything

Would it change their feelings about me?

I didn't want that to affect the way people looked at me

I wanted them to be able to separate

Tony the individual

Beaver the Marine

There was a difference between the two

I always wanted to make sure that there was a difference

When people found out I was a Marine

it blew their fucking mind

Most active duty Marines

Very arrogant, cocky, full of themselves

They have every right to be

The strongest fighting force in the world

Have that right to be like that

Found Poem from Individual Meeting \#1, 10/14/15

Beaver was at East Forrest for almost a year before he let others know that he was

a Marine, although, in that year he was still utilizing the Post-9/11 GI Bill (ASHE, 2011b;

DiRamio et al., 2008; Vacchi, 2012). While Beaver was not the valedictorian, he was

much better in college than high school when it came to his studies. Beaver was able to

make new friends, Veteran and civilian alike, but he realized he missed his Marine

buddies.

The difference between being in The Corps and being in civilian society was in relationships with people. In the Marines, Beaver had formed intense bonds with individuals who started off as complete strangers; people he never would have even 
talked to outside of the Marines. Those strangers became his brothers, his battle buddies (Bellafiore, 2012; Hinojosa \& Sberna Hinojosa, 2011; Hosek \& Martorell, 2009; Junger, 2014; Junger, 2016; Kok, 2015; Livingston \& Bauman, 2013; Naphan \& Elliott, 3015). There was only one civilian he ever felt that close to, his buddy Derek. With everyone else, he missed the comfort of being with a group of people who were willing to die for each other, who took care of each other, and who made fun of the "shitbag" Marines who couldn't get things right. He was able to get some of that back, when he started to hang out with the other Veterans on campus.

While Beaver was in school, he ended up taking two psychology classes with Jamie. As you may recall, he was one of the Marines who I introduced into Jamie's life (as part of her journey to The Unit). He was also one of the unofficial Veteran leaders at East Forrest College, getting Vets together casually or connecting them with resources. So, when he founded the Warrior Alliance on campus, with support from Jamie, it made perfect sense. The Veterans, and Reservists, on campus often turned to each other first when they needed anything, from social support to guidance about procedures (Ackerman et al., 2009; Bellafiore, 2012;Cook Francis \& Kraus, 2012; Cropsey \& Hendrickson, 2013; DeSawal, 2013; DiRamio et al., 2008; Glasser et al., 2009; Glover-Graf et al., 2010; Hawthorne, Bauman, \& Ewing Ross, 2013; Livingston \& Bauman, 2013; Mikelson \& Saunders, 2013; O’Herrin, 2011; Osborne, 2013; Persky \& Oliver, 2011; Rumann \& Hamrick, 2010). They began the process of getting the group registered with the SVA (Hawthorne et al., 2013). Unfortunately, both Beaver and Jamie ended up leaving East Forrest before it was official. Beaver graduated and began again the process of applying to police departments. 
Getting into a police department proved to be difficult for Beaver. In fact, getting any job was difficult.

I have a stack of fucking awards this fucking high

Three negatives

I score really high on the test.

I score really well on the physical agility

I interview well

I don't understand

"I have to find to find something else."

I started trying

at Amazon

Home Depot

Lowe's

Nobody wanted to hire me.

For a $\$ 12$ an hour job

Nobody wanted to hire me

I ... I don't ... I don't get it

I'm overqualified

I'm fucked for the rest of my life

I Poem/Found Poem from Individual Meeting \#1, 10/14/15

It was going through the background screening process for various departments that Beaver found Veterans were treated differently, and not positively. Because of the public perception of PTSD, in relation to combat Veterans (Sammons, 2005), any Veteran who went through screening received a closer examination. Also, there was a huge stigma associated with any mental health support, to the point that many Veterans avoid getting help to keep their eligibility (Zoroya, 2016). Beaver fell into this group, even though his friends encouraged him to get "rated" for the money.

I was getting gas

Military plates on my truck

Range Rover pulls up

This guy gets out 
He looks at me, "Oorah!"

"Oorah...Marine?"

"Army"

What the fuck?

Why you Oorahing me then, you're totally off your game here.

That's the wrong branch for you

He hands me his fucking card

He works at Veterans' Affairs

He's uh this that and the other for psych help and blah, blah, blah

My buddy, he's just trying desperately to convince me

Go to the VA and get rated.

Even going so far as to tell me to put in a claim for PTSD.

To put in a claim for PTSD.

He says I deserve it

He says that all Veterans deserve it He says that as Veterans we don't get enough

Benefits and perks and stuff like that

Nope, forget it

He was like oh, if you ever need anything blah, blah, blah

Put in a claim for PTSD Send you to a ton of different doctors and meetings

One-on-one sessions

A ton of questions

Five or six of these stupid meetings

Found Poem Individual Meeting \#4, 11/23/15

Go away,

You're damaging to the rest of my life

$\mathrm{Be}$ in a file somewhere

You diagnosed me at a fucking gas station

I'm not ...

I'm not going to talk to anybody

Until I feel like I've exhausted all avenues

Found Poem Individual Meeting \#1, 10/14/15

No.

Before I left the pump

His card went in the trash somewhere

Maybe a homeless vet found it

Out of the trash and contacted him

But this veteran will not be contacting him. 
Beaver would not go to the VA for a PTSD claim, even though he had a valid claim for his hearing. In boot camp, his left ear plug fell out during an obstacle course training exercise. A few seconds later, a grenade went off not far from his left side. His whole body shivered with the pain, and he continued the exercise. His hearing was greatly impacted, which would eventually mean that he wouldn't pass the hearing test as part of the checkout process upon discharge. Beaver was dead set on discharging that Friday. Not passing the hearing test meant they would delay his discharge to investigate the problem. So, he problem solved, and some Corporal nearby completed his hearing test for him. The paper was signed noting that "he" passed; he was able to drive home, with the Marine Corps behind him.

Beaver was still a Marine; the impatience, the need for order and cleanliness, and his defense of the troops were something that had become part of him. Sometimes, when he and Jamie would go to lunch, he would get riled up about certain topics.

"You know, I'm one of those Veterans who wish we were never sent over there. So, when people chastise the government, I don't have a problem with that. Fuck the government; they make stupid decisions all the time. But most people don't stop there, they like to talk shit about the troops. 'Oh, you know the fucking Marines over there killing innocent people. Of course, the Iraqis are going to retaliate.'

"First of all, shut up." Beaver was getting a little bit louder and talking a little bit faster. "We don't ever kill innocent people purposely. At least, I can speak for myself and my unit and units I worked with. I've never seen that happen, purposely. Never, ever. Had we known for a fact that there were innocent people in there, we would have 
changed the tactic. Send in a smaller team to actual location to engage hand to hand or with weapons, because you're more accurate with a weapon than you are with fucking explosives.

"Don't ever chastise the troops who were sent there, especially if you never wore the uniform. If you never wore a uniform and sent your ass over there, you cannot chastise the troops for being there. Next time I go, come with me, I'll take you with me. See how you like it. You can see how it is really, out there.

"So, I hate that. I hate when I hear people chastise the troops. It's not the fucking troops' fault. Did it happen? Absolutely, it does, but it is not on purpose.” Beaver finally took a breath and sat back in his chair.

"So, tell me how you really feel." Jamie smiled as she teased him.

"Fuck, I think I just did.” Beaver replied, also smiling. Jamie and Beaver often talked about a variety of interesting topics. Including Beaver's relationship with Jennifer, his girlfriend, and the woman he planned to marry. Beaver had numerous stories about how his Marine side made life with him a little more hurried, even if for no reason. Yet, Jennifer stood by him, and often tried to run interference for the blender or exhaust pipe that was bothering him. Even though it bothered him when he just wanted to let his anger roll off him, he still loved her.

Jennifer tried to use her connections to help Beaver get a position with a local police department, yet she had been unsuccessful. So, she was very optimistic when he decided to do the police academy on his own and hoped that a department would pick him up when he was done. Unfortunately, the first day of the academy was worse than Black Friday, and he had to do all the pushups, runs, and planks it in a suit. That would 
have been his life for six months, with no paycheck, no department sponsoring him, and no guaranteed position at the end. It just wasn't worth it. So, he quit. Then he had to defend his decision to everyone who told him that as a Marine, he should be invincible.

Beaver was still not a police officer, and as a result he saw himself as still waiting for it to happen. He had the dream since he was six years old, sitting next to Grandma B, watching Cops. It was a dream that was still alive, even after he felt like he had to beg for his graveyard stocking job at Home Depot.

Beaver was a Marine, a college graduate, and future police officer (hopefully). He was frustrated that his life had not followed the path he had planned. For a Marine used to working to mission completion, it was incredibly maddening. His impact on Jamie, her life and her work, was not enough for him to feel purpose. So, like thousands of other Veterans searching for their purpose after the service, he was just maintaining (Junger, 2016). His role in The Unit might help him find something, be it healing or a helping hand to connect him to the career of his dreams. 


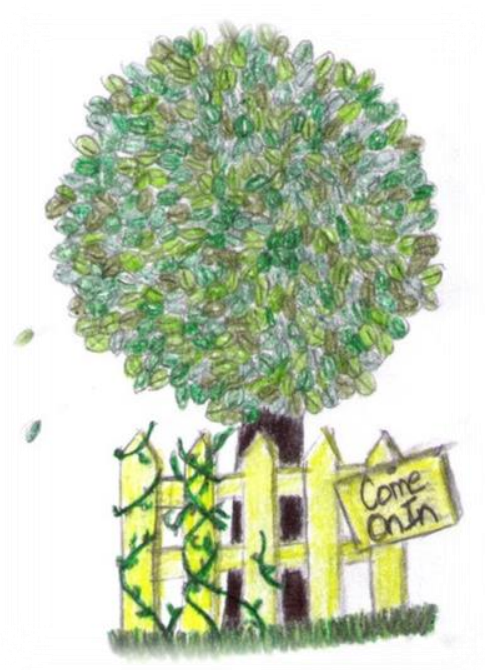

\section{A Journey Begins}

I have always loved being a god as it provides amazing opportunities and responsibilities that many humans are not able to experience. For example, those unexplainable feelings you have had in certain places, the spa that immediately relaxed you or the big box store "treasure hunt" that always led to a receipt over $\$ 100$, I have seen the rationale and plan to create such feelings. This was true whether or not I was present for the creation of the thought. I didn't have to think about why or investigate motivation; I actually saw the thoughts, the wisdom, that led to great ideas coming together. It has always been one of the many perks of being the goddess of wisdom. So, when Jamie began frequenting Café Intelligentsia to study, read, and write, I saw more than just a warm, comfortable coffee house.

To Jamie, and other mortals, Café Intelligentsia was a locally owned cafe that served the best coffee around in a cute cottage style house, complete with garden patio seating. It was the perfect place to sit and study, read, work, or converse with others. The inside contained numerous mismatched chairs that were incredibly comfortable to sit in for hours, yet no one ever fell asleep. The chairs were always arranged in a way to 
bring about great conversation with the other patrons, while being surrounded by the artwork from local artists.

To me, a goddess, a visit to the cafe was a visit to the embodiment of transformational servant leadership. The cafe had been designed to serve every individual who entered, be they customer, staff, or owner, to "grow as persons... [and] become healthier, wiser, freer, more autonomous, and more likely themselves to become servants" (Greenleaf, 2008, p. 15). In fact, over the front door, painted in large script, were the words “Create Dangerously" (Greenleaf, 2008, p. 13). As a result of such intentional leadership within the cafe, the environment was one that encouraged dialogue and engagement. The conversations that occurred at Café Intelligentsia often led to community action projects by the customers who met there. Some held their meetings at the cafe, others just happened to find each other, along with the necessary resources and passion to make change happen. Again, not an accidental occurrence! Everything in the cafe - from the safe and comfortable physical design of the cafe that facilitated honest conversations and collaboration among the guests, to the management style of the owners (who were also servers), to the experiences and transformations of the customers themselves - was perfectly aligned with leadership through service (also known as servant leadership). Café Intelligentsia was the epitome of transformational leadership to "be authentic, be vulnerable, present, accepting, and useful” (Autry, Spears, \& Noble, 2004, p. 53).

Jamie's first visit to the cafe was on a Sunday afternoon. She decided to sit inside in a big blue chair that seemed to call to her. It was tucked a bit in a corner, with a few other chairs around it. As soon as she sat down, I noticed the table was the perfect size 
for her notebook, laptop, and a drink. The cafe was providing just what she needed.

Jamie looked up as she heard a joyous voice say, "Good afternoon and welcome to Café Intelligentsia! I am one of the owners/servers. The name's Tallulah!" she spoke as she offered Jamie her hand in greeting.

"I'm Jamie. Nice to meet you." She replied, grinning, as they shook hands.

Tallulah looked at Jamie with a gaze full of care and acceptance. It was a look that was a sort of breathing in of who Jamie was in that moment. I have witnessed few people with such an ability; even as a god it is always an awe-inspiring and impressive experience. In an expression of the transformational leadership, Tallulah was learning about Jamie so that she could effectively support her in her time at the cafe. It was that focus on people, and not just tasks (Cashman, 2008; Goleman, 2004; Greenleaf, 2008) that bled through the entire cafe.

Tallulah nodded to herself, with a satisfied grin, and asked Jamie "What can I get for you today?" Jamie ordered an iced tea. As Tallulah walked away, Jamie pulled out her laptop. While it was loading, she grabbed her notebook and began to jot down some ideas. Unaware that the cafe would soon help her gain more knowledge and support her with her hopes of building a better society (Greenleaf, 2008).

Jamie became so absorbed in her own thoughts that she didn't notice when a group of older Marines sat next to her. It was easy to see that they were Marines. One had a black hat with the Eagle, Globe, and Anchor. Another was wearing a red cap with "Semper Fi" embroidered in dark yellow. The third had a grey hat with a red "USMC" across the front. Once she noticed the three Marines, she paid a bit more attention to their conversation. It was probably more than was socially polite, yet Jamie defended in 
eavesdropping in the name of research.

Jamie would come to find out that the man in the black hat was named Jim. Jim served during Vietnam, earned a Purple Heart (for being wounded in combat), and had a grandson who was currently a Staff Sergeant in the Corps. Pete, in the red cap, had also served during Vietnam, had never married or had any children. The final gentleman in the grey hat and his grandson were both named Randy. Grandson Randy had just finished eight years in the Army and was going back to school at a local community college.

Randy was talking about his grandson going back to school, with a tone of disbelief, "A few of the other Vets on campus told Randy not to tell others he was military. Said that when they got to campus they noticed, very quickly, that it was not the place to be a proud service member (Glover-Graf et al., 2010; Whiteman et al., 20130. To add to that, unfortunately, he's had some civilian faculty and students fail to see the benefits of the service or even belittle or disrespect the military in class (Arminio \& Kudo Grabosky, 2013; Cropsey \& Hendrickson, 2013; Glasser, Powers, \& Zywiak, 2009; Glover-Graf et al., 2010; DiRamio et al., 2008; Ford, Northrup, \& Wiley, 2009; Olsen, Badger, \& McCuddy, 2014; Persky \& Oliver, 2011; Rumann \& Hamrick, 2010; Rumann, Rivera, \& Hernandez, 2011).

"He said he's found that it is easier to just not be identified as a Veteran, than having to explain or justify why he enlisted. Just last week at dinner, he told me, "Pops, if no one knows I'm a Veteran, no one asks me how many people I've killed" (Ackerman et al., 2009; DeSawal, 2013; DiRamio et al., 2008; Glasser et al., 2009; Glover-Graf et al., 2010; Hammond, 2015; Rumann \& Hamrick, 2010; Rumann et al., 2011; Street, 
2014). I don't know if it is a different generation or a completely different world, but no one ever asked me that after 'Nam. Maybe they were afraid of the answer. Hell, maybe they realized we would never talk about it with a civilian."

Jim nodded, "My grandson says the same thing. Either they ask him about his kills or they give an inauthentic "Thank you for your service' and change the subject."

Pete chimed in, "At least they get a thank you, instead of being called a baby killer."

"I believe there are too many Vietnam Vets who raised kids for that to happen again, well at least I hope.” Jim replied, as Randy nodded in agreement.

At this, I heard Jamie think "Wow, these men and women return from serving their country in organizations that are built on a very specific and cohesive identity. An identity that:

has been compared to the priesthood. It involves a total commitment on the part of the individual - long hours, danger, and pay that is often below that of their civilian counterparts... Without this sense of self sacrifice, and commitment to the group, a military entity could not exist. Group cohesion is a critical part of combat. Without it, people die (Herspring, 2011, p. 522).

It is an identity that becomes core to an individual's values, attitudes, and motivation (Hammond, 2015; Johansen, Laberg, \& Martinussen, 2013). Yet, when they return home, and venture onto a college campus and into a classroom, the interactions and experiences with civilians send the message that 'Veteran' is an identity that is better left unannounced.”

As the goddess of heroic endeavors, I could not imagine anyone who had offered 
to give their life for the protection of someone, or something, else thinking that it was best to keep the military part of their identity hidden. Yet, as the goddess of wisdom, I understood that every battle has multiple sides; heroes to some are enemies to another. Jamie and I were both thinking about Veteran Identity, when she looked up to find her friend and fellow academic, Charlotte, walk into the cafe.

The subtle nature in which Café Intelligentsia expressed leadership through service was again witnessed as it brought together people who could better each other. It was impossible to believe that the café staff could provide each visitor with everything that they needed; yet serving those needs was part of the leadership strategy in the cafe's design, and a large part of their success.

“Charlotte!" Jamie exclaimed. "Join me. You are just the person to help me." Charlotte was one of those rare, and beautiful, individuals who had immense knowledge of things learned in books, as well as things lived in the world. In addition, she had a calming and joyful demeanor that, all at once, made you smile, breathe, and think deeply about the conversation. This was partly because she was one of my direct descendants (yet that is a story for another time).

"Of course," she replied with sweetness and knowledge that only a few could master. "What is it that you are pondering today?"

"Identity," Jamie replied as Charlotte took a seat in a comfortable green chair, then ordered a tea from Tallulah.

"Ah, yes. Well, so much of what we think of others and how they think of themselves is based on identity. And identity is not formed in a vacuum, you know. It is constructed by culture, history, politics, and societal influences such as family, 
organizations, and communities (McAdams \& Janis, 2004). It is also far from one single identity. Our identity is really a multifaceted, complex, and sometimes contradictory assortment of identities (Abes, Jones, \& McEwen, 2015; DiRamio \& Jarvis, 2011; Mc Adams \& Janis, 2004; Stryker, 1968; Stryker \& Burke, 2000). But before we get too deep into the interplay of identities, let me begin by covering some of the basics. Do you know much about identity theory, Jamie?" Charlotte asked.

Jamie shook her head, "No, I know very little. Well, I know that Zander \& Zander (2000) describe it as the 'set of patterns of actions and habits of thought that get [us] out of childhood in one piece' (p. 82).”

Charlotte nodded. "Sort of. Sheldon Styker (1968) explains identity as the complex parts that make us who we are. These parts are formed through the relationships we form in society, from family to occupation. For example, some of my identities are female, daughter, educator, poet, traveler, and lifelong learner.”

“Okay..." Jamie thought for a moment. "So, my identities would also include female, daughter, educator, and lifelong learner. I would have to add that I am a mom."

Charlotte smiled as she began to speak again. "Yes, and as we both know, we are much more than those identities, and at times one identity or another is more significant or prominent than another. Actually, our identities are placed in a hierarchy that ranks those identities that are most significant above those that are less so (McAdams \& Janis, 2004; Stryker, 1968).”

"So, am I consciously deciding that my mom identity is more important than teacher within a given moment? For example, when my son is sick and I have a class at 4:30. When that happens, I tend to cancel class, usually because their dad is unavailable. 
So, does that mean that teacher is never more important than mom?" Jamie questioned.

"Not exactly. Stryker (1968) found that an identity becomes more significant or meaningful based on two factors - the number and depth of relationships. The first factor, the number of relationships or connections that are formed because of an identity, is important as it creates a frequent identity for an individual. For example, each of your students sees you as a teacher, even when you are out of the classroom. Because so many people see you in that role, it would be a significant identity. The second factor, the depth of the relationship, is equally important. So, even though you have had several hundred students and you only have two children, the depth of the relationship with your boys is immeasurable. Which is why Mom, is one of your most significant identities, I would say one of your core identities (Jones \& McEwen, 2000). As such, in every situation, even when you are away from your children, you still see yourself as a mother.

"Now, what that means, is that what you associate with being a mother, or what it means to you to BE a mother, needs to be present in your interactions with others. For example, if you see yourself as being heard and respected as a mother and in a situation where you feel that you are being ignored, you will change your tactics, or behavior, so you feel that your voice is acknowledged. Now, if you view being a mother is taking care of people, and not necessarily being heard, then the same situation would illicit a different response.

"This is why Peter Burke (1991; Stryker \& Burke, 2000) recognizes that 'the identity process is a control system' (p. 837). Within the process, each interaction involves four elements. First, there is the standard meaning associated with a particular role or identity, for example, being heard because you are a mom. Second, there is the 
input from the situation (the reality and perception of what is happening). So, keeping with the mom example, being in a situation where you feel that your voice and your opinions are being ignored. The third element is a comparison of the standard and the situation. The feeling of being ignored does not match with the identity of being a mother and being heard. This leads to the fourth element, the behavioral output that is the response in hopes of changing the input to match the standard. This process is continuous, and these negotiations can become extensive as the desire for interactions with friends, family, and society that are congruent with our identity is the ultimate goal. Peter Burke found this to be true even if the imbalanced comparison results in a perception that is more positive than the standard identity."

Jamie nodded, as she added, "Carl Rogers (1959) referred to this as a form of congruence of the self and the experience. An occurrence of incongruence between the two can lead to a perceived threat which leads to anxiety and defensiveness. Or, if the individual has a level of self-actualization that enables them to process the experience through awareness, they are not defensive and will respond in that moment."

Charlotte nodded, "Rogers appears to agree with Burke, like many other researchers. Burke's (1991) identity theory states that our identity is a continuous dynamic process between ourselves, our experiences, and the stories we tell about our lives (Bruner, 1987; Demers, 2013; Howard, 1991; McAdams, 1993; McAdams \& Janis, 2004; Pasupathi, Weeks, \& Rice, 2006; Stryker \& Burke, 2000). It is through the storytelling that we become who we are and make meaning of our lives (Bruner, 1987; Howard, 1991; McAdams \& Janis, 2004; Pasupathi et al., 2006). As Jerome Bruner (1987) argues, 'Life is not "how it was" but how it is interpreted and reinterpreted, told 
and retold' (p. 31). Each moment is experienced through our own perceptions and interpretations. Thus, it is through our individual experiences and relationships with our friends and family, in any given moment in history, society, and culture, that we form our identity (McAdams \& Janis, 2004; Pasupathi, Mansour, \& Brubaker, 2007). Or more accurately, each individual writes the story of their identity that is 'coauthored by the person and the person's world' (McAdams \& Janis, 2004, p. 169).

"In the formation of identity, or a person's story of who they are, we cannot separate the dynamic interplay of the external and internal influences (Burke, 1991; McAdams \& Janis, 2004). We cannot deny that as we are part of the world in which we live, we are impacted by the society and culture around, and we also impact and maintain that society and culture (Pasupathi et al., 2007). In many ways, culture sets the limitations of the story possibilities (McAdams, 2006). This interplay is important when it comes to identity because the individual is the one writing the story, yet they are deeply impacted by their place in time, society, politics, and culture (Demers, 2013; Howard, 1991; McAdams \& Janis, 2004).”

Jamie added, "And Freire (2000) states that 'humans exist in a world which they are constantly re-creating and transforming' (p. 99) as a result of our experiences and our perceptions of those experiences. He goes as far as to say that our existence is because of our engagement in the world, or that 'human beings are because they are in a situation' (p. 109)."

"Exactly!" Charlotte exclaimed. "It is our experiences that shape our stories. It is our stories that tell about who we are. It is our stories that teach us about others. We learn the stories of our culture as children, they impact our values, how we see our own 
life stories, and how we create future plans, or the stories we hope to make (Demers, 2013; Pasupathi et al., 2006). We live the stories, just as Miller Mair (1988) said: Stories are habituations. We live in and through stories. They conjure our worlds. We do not know the world other than as a story world. Stories inform life. They hold us together and keep us apart. We inhabit the great stories of our culture. We live through stories. We are lived by the stories of our race and place. It is this enveloping and constituting function of stories that is especially important to sense more fully. We are, each of us, locations where the stories of our place and time become partially tellable (p. 127).

Yet, even though we hear similar stories, we take different pieces from those stories to make part of our own (Howard, 1991). 'This is because there are many different roles described in any story, and each of us must choose the role we will play' (Howard, 1991, p. 194). Which role we see ourselves able to fill is greatly impacted by our perception of reality. To go back to Freire, this is when we discover a new perception of reality as we begin to investigate and analyze our reality more deeply (Freire, 2000).

"It is true that individuals develop across a lifetime, and identity is constantly 'under development', or as Freire would call our process of becoming (Freire, 2000), as we remember stories and alter ourselves to incorporate new or additional identities (Pasupathi et al., 2006). Yet, one could not say that identity is so fluid that it is able to change quickly and without stress. At times, there can be interruptions in the identity process. For example, when the process I already explained, to try to reach congruence, doesn't work (Burke, 1991). If the process becomes ineffective because of the external influences, like ineffective behavioral changes, or internal influences, such as inaccurate 
perceptions, result in an incongruent identity, it will cause distress for the individual (Burke, 1991). Even more stressful can be the complete loss everything associated with an identity, as a result of the loss of a job or loved one (Burke, 1991).”

At that, Jamie responded, "This is often what happens to Veterans, as they lose their job, their title, and their community when they are discharged. In a world where what we 'have' defines us (Fromm, 1976), being discharged, or retiring, is a HUGE loss for many Veterans. They 'feel disoriented and suffer losses of identity. [They are] not just disoriented, but deeply alienated from the rest of America; not just sad over the loss of friendships, but devastated over the loss of brothers and sisters; not just a temporary destabilizing of identity, but a complete identity crisis' (Lighthall, 2012, p. 80-81). That loss of identity can be accompanied by a loss of self-worth (Litwack \& Foster, 1981). So, it means that Veterans in transition are really individuals working on their identities (Schiavone \& Gentry, 2014).”

Charlotte nodded in agreement, "And in times of such stress, sometimes the only answer is to change the identity (Burke, 1991)."

"That is easier said than done." Randy added. At some point in the conversation, Jim, Pete, \& Randy had started listening more to Charlotte than each other. Jamie and Charlotte welcomed the additional conversationalists; in part because of the environment of Café Intelligentsia, and partly because they both were eager to hear a Veteran specific perspective.

Jim continued, "Being a Marine is more than a label for me, it is core to who I am (Hammond, 2015). I am a Marine if people know it or not, whether they see me that way or not, and whether or not being a Marine is important to the situation. Being a Marine 
brings other standards into the world about how I act and am treated. To just change my identity as a Marine wouldn't happen. It certainly hasn't happened in the last 40 years."

"That is because it is such a significant identity, a core identity." Jamie acknowledged and was greeted with non-verbal agreement from everyone in the group. Charlotte was the most pleased, as she was smiling with satisfaction that Jamie understood what she had heard.

Pete replied, "And in my experience, those of us who really embraced the Corps into our identity had the toughest time trying to become a civilian again (Castro, Kintzle, \& Hassan, 2015a).”

"It's hard to take off the Marine hat, figuratively and literally." Randy said as he pointed to the baseball caps that adorned all three of the gentlemen's heads

Charlotte smiled. "Some identity theories don't ask you to ever take it off. True, there are those who believe it is purely a hierarchy, with one identity being more significant than another based on the commitment to that identity (McAdams \& Janis, 2004; Stryker, 1968). Yet, others feel it is more of a merging of sorts. There are identities we collect, as a result of our own behaviors, thoughts, and interactions. Marine could certainly fall in this category. Then, there are also the identities that are given to us, 'assigned by others such as society, college student peers, or family' (Jones \& McEwen, 2000, p. 406); this is often where gender and race fall. Such variety in identity is made even more complex with layers of identity that can weave together to create a core identity that is made of the essence of multiple identity stories (Jones \& McEwen, 2000). An example of this would be Women of Color, as they are women and people of color. The identities on the outside are 'easily named by others' and often less important 
to the individual. The inner core selves are too full of depth and complexity to name, so they are kept safe from external examination (Jones \& McEwen, 2000). These layered and connected identities, that surround the core self, include the identities that are placed upon us, such as race, gender, class, and so on (Jones \& McEwen, 2000). 'Assigned identities' are more salient for individuals when they are associated with oppression. Again, with the example of women, race is more significant for Black women than white women (Jones \& McEwen, 2000, p. 410).

"However, the same researchers have recently added that how we make meaning of our core identities is due to our own filter through which we view societal and cultural pressures (Abes, Jones, \& McEwen, 2007). It is through a lens of meaning, created by our experiences, that we acknowledge the extent of external influences on the creation of our core identities, or the intersectionality of the variety of identities that are often unprivileged (Ibid.). This small shift is important, because it recognizes that society and other contextual influences impact how we see ourselves, even in regard to our perception of the core aspects of who we are (Ibid). So, two individuals, with a similar core identity, will have a different response to why it is at their core. For one, it may be because they feel that identity defines who they are; the Marine who is Marine because the Corps is a part of who they are and will be always. For the other, it is a result of how others see them; the Marine who is constantly identified as a Marine and has accepted that it is part of his identity (Ibid.)."

Charlotte paused to let Jamie take it in. After a moment, Jamie began, with a look of questioning in her eyes. "So, a Marine could see themselves as Marines because they really see themselves as a Marine, or because everyone else does. Even if everything else 
is the same, it is their perception of what made Marine a core identity that leads to such multiple dimensions of the identity (Abes, Jones, \& McEwen, 2007)?”

"Yes!" Charlotte replied with satisfaction. "Now add to that when two, or more, identities conflict with each other, that situation can also create stress (Jones \& McEwen, 2000; Stryker \& Burke, 2000) or anxiety (Rogers, 1959). The individual is put into a role choice dilemma, in which various factors impact the final choice. One of the most powerful factors in that decision is, again, the commitment to the role (Stryker \& Burke, 2000), and the identity or role that is the most significant to the individual is the identity, and accompanying standards of experiences and behaviors, that remains. Or it may be the core identify which changes how 'meaning making' of the other core identity (Abes, Jones, \& McEwen, 2007). So if is an identity that was formed through years of experience accompanied by physical and mental transformation, like military service, the level of commitment to the identity would certainly be greater than something that occurred for only a short period of time with little personal investment. Or, if it was an identity that altered how one viewed all other identities and the world, it would not just go away. We must note that self-concept and value are tied to group memberships (Tajfel, 1978), and that would certainly include the military. However, just because someone served in the military, does not mean that they internalized the identity (Stryker \& Burke, 2000); the internalization of a role is something that cannot be assumed."

Pete shook his head. "I've always said there are two kinds of Veterans. There are Veterans who wear their colors every day of their life. Then there are individuals who were in the military for four years, and it was just another job listed on their resume. I've met them both in my life." 
Jim agreed, "Although, I will admit most Marines I've met fall in the former grouping, which is a sign of the effectiveness of the Corps' indoctrination, or brainwashing, process. I confess, I am proud of the lifelong Semper Fi among myself and my brothers in arms."

"It's true." Randy agreed. "You can tell a Marine by the way they talk, and by the way they tell their stories."

At this Charlotte nodded, "Again, it is the stories we tell that are key to our identity (McAdams \& Janis, 2004).”

"I think the stories are the key." Jamie replied, more to herself than anyone else in the cafe. In the next moment, The Unit became less of an idea and more of a reality. "I think I need to gather stories, of Marines, to really examine their identities through their transition." She was almost there.

"I cannot ignore that I came to this through teaching, I have to examine how higher education impacts their identity formation." Finally, she was there, and the work of The Unit was about to begin. Let me have Jamie tell you what happened next. 


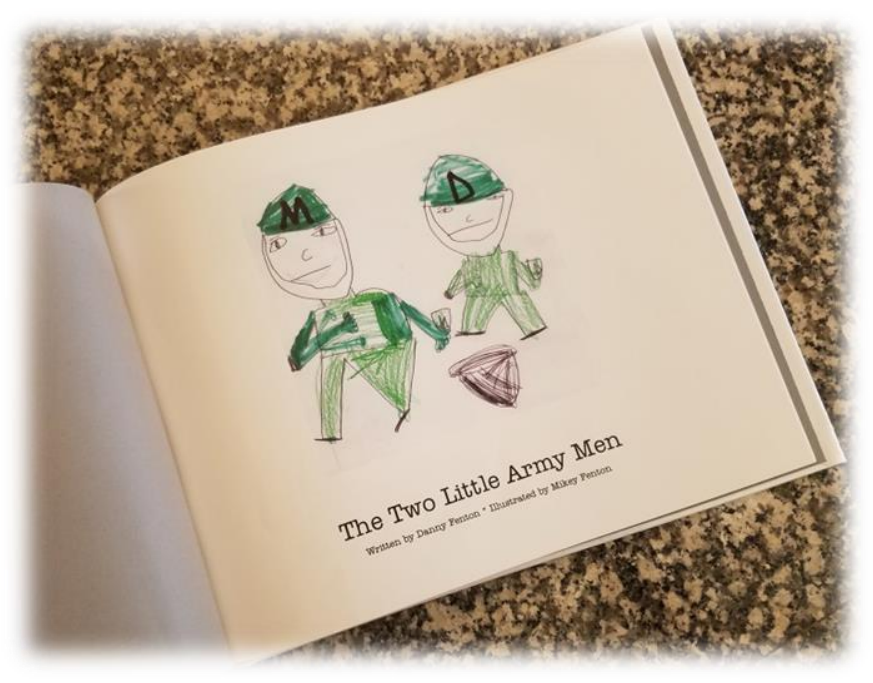

\section{Tell Me a Story (Jamie's Voice)}

I looked at Charlotte and the old Marines and smiled. "You know, they say, all 'good research tells a story' (Siegesmund \& Cahnmann-Taylor, 2008, p. 239). So, I think what I need to do is get some Marines together, gather their stories, and use narrative inquiry to help me retell a deeper story."

Charlotte nodded, of course she also knew about narrative inquiry. "Narrative inquiry was born from the desire to further develop experience as defined by Dewey (Clandinin, 2013), it acknowledges that 'people by nature lead storied lives and tell stories of those lives' (Connelly \& Clandinin, 1990, p 2). The focus remains on 'people, values, intentions, and actions as opposed to entities, properties, rules, logic, and "behavior"” (Bowman, 2006, p. 2013). Stories and storytelling are part of traditional oral histories. They have the power to shape the perception of history and the present. Stories are 'a universal gift to share with others' (Cole, 1989, p 30). Oppressed and marginalized groups have used stories as a way to endure and work toward liberation (Delgado, 1989). Most people find out who they are through the stories about their various groups (Gardner, 2011).” 
Jim added, "Specifically within the military, 'stories have always been used by soldiers to teach less experienced colleagues, inspire others, cope with different organizations, and strengthen societal support' (Geerts, 2015). What Marine hasn't heard the story of Chesty Puller at the Chosin Reservior. The Marine First Division was surrounded by 15 Chinese Divisions, to which Chesty replied 'So they've got us surrounded, good! Now we can fire in any direction, those bastards won't get away this time!' The Marines decimated 3-5 Chinese Divisions and left that battle with all of their Marines (living and dead) and equipment (M. Steponovich, personal communication, 4 July 2016). A story like that lives on!

"And now my grandson talks about how the Corps has 'narrative led operations' (Nissen, 2012 as cited in Fleischaker, 2015). Stories are influential. 'Of the multitude of commanders and sergeant majors who spoke to us - from battalion to MEF [Marine Expeditionary Force] level - the only talk that had any lasting impact (and of which more than a vague recollection remains) was from a commander who linked the Marines' actions during deployment into a grander story of what the United States is working to accomplish' (Fleischaker, 2015, p. 38). It was the stories that made it stick, that made it matter."

I agreed, "Stories bring people together; they educate and build community as they let us see the world through another set of glasses (Delgado, 1989; Gardner, 2011). They also tell us about the groups we belong to (Gardner, 2011). What other stories told you about what it meant to be a Marine?"

"What about the flag raising at Iwo Jima. I mean that was all about raising a larger flag so it would be visible from the sea, hence the 'second flag raising' (Hoffman, 
1998)." Randy made the air quotes with his hands as he said it. "But the image is iconic, because it is symbolic of the incessant resolve of Marines to scale a mountain while in the midst of battle, not once, but twice to raise a flag to raise morale. That is why it is sculpture for the Marine Corps War Memorial in Arlington, and numerous other Marine memorials across the United States.”

"Symbols, hymns, stories... Those are very powerful things" Jim began.

"Consider that there are five branches of the armed forces. Each has their own song Anchors Away, The Army Goes Rolling Along, The U.S. Air Force often known as Wild Blue Yonder, and Semper Paratus. However, the only hymn is The Marine's Hymn (Mundy, 1998). It is always growing, because 'every campaign the Marines participate in gives birth to a new, unofficial verse' (U.S. Department of Veteran Affairs, 2016)"

Pete smiled, "I remember some of those. I can also remember some of my own stories that seem to connect with every other Marine I've met, mostly from boot camp. I think everyone had a DI who made their life hell. Yet, it was through that experience that every Marine learned that they could do more than they originally thought. I can remember my Gunny yelling, 'If you pass out on a run, that's okay. But if you stop, if you give up, we're gonna have a problem' (M. Steponovich, personal communication, 17 December 2014). There is a reason the whole 'Pain is weakness leaving the body. And Marines have experienced a lot of pain' is a t-shirt."

Both Jim and Randy were nodding and smirking the whole time Pete told his stories. It was true, every Marine I spoke with had a story of suffering and survival from boot camp.

"There are also a lot of stories of sacrifice." Randy began, with a more somber 
tone. "I can't tell you mine without crying. But there is a telling example in American Sniper about a Petty Officer who saved his team. Apparently:

The grenade hit him in the chest and bounced onto the deck [here, the Navy term for floor]. He immediately leapt to his feet and yelled 'grenade' to alert his teammates of impending danger, but they could not evacuate the sniper hide-sight in time to escape harm. Without hesitation and showing no regard for his own life, he threw himself onto the grenade, smothering it to protect his teammates who were lying in close proximity. The grenade detonated as he came down on top of it, mortally wounding him.

Petty Officer Monsoor's actions could not have been more selfless or clearly intentional. Of the three SEALs on that rooftop, he had the only avenue of escape away from the blast, and if he had so chosen, he could have easily escaped. Instead, Monsoor chose to protect his comrades by the sacrifice of his own life. By his courageous and selfless actions, he saved the lives of his two fellow SEALs ‘(Kyle, 2013, p. 308).

There are thousands of stories of men sacrificing themselves for their brothers in arms. That is just the most recent one that I have read."

Jim added, "It is that sacrifice that is part of the warrior ethos or respect for all the warriors in the fight (on both sides), as well as military traditions 'which often involved putting [ourselves] in danger for the protection of their country and not leaving fellow soldiers behind' (Rafool Bidwell, 2012, p. 21). Life in the military is about the unit, uniformity, and solidarity (Williams, 2013). Service men and women are part of a group that is part of them and their identity; it is a brotherhood (DiRamio \& Jarvis, 2011). 
Brotherhood has nothing to do with how you feel about the other person. It's a mutual agreement in a group that you will put the welfare of the group; you will put the safety of everyone in the group above your own. In effect, you're saying "I love these other people more than I love myself"' (Junger, 2014, 9:38).

Service members 'are discouraged from looking unique, because that would encourage them to feel unique, to feel unique like an individual. The problem with individuals is that they think for themselves and of themselves, rather than for and of their unit' (Roach, 2016, p 32). It is stories of sacrifice that help build 'trust, confidence, and deep camaraderie that is critical among those who fight together' (Fleischaker, 2015, p.39). Stories are the way that leaders, and other Marines, can communicate what is important in the culture of risk, sacrifice, and purpose that is the United States Marine Corps.”

Pete agreed, and then added, "It is stories that motivate the Marines of every generation to keep going. The stories that are told about their own military experience are equally important. While each Marine's experience and the relationships they form with their unit, while deployed, 'might overshadow their sense of the broader mission... people join the military to be a part of something greater than themselves, and ultimately it's deeply important for service members to be able to feel their sacrifices had a greater purpose' (Klay, 2016, para.49). We don't want to think we were part of something evil; that is not why we enlisted. So sometimes the stories society tells can greatly and negatively impact Veterans. That includes the stories that are told about Veterans, some positive, some less so, that impact how civilians view us."

“Have you seen Daredevil?" Randy asked.

"The movie from a few years ago?" Pete thought he knew which one Randy was 
referring to.

"No, the Netflix TV show. It actually has a pretty good presentation of a Marine Vet. I guess the Punisher character, Frank Castle, has always been a Marine. His entire family was murdered, so his ability to endure intense pain and his 'obsession to righting the wrongs of the world' (Beauchamp, 2016, para. 5) led to his transformation into a vigilante that tortures and kills criminals and other wrongdoers. Yet, the important part of the show is that when his defense team wants to claim that he has PTSD, he is adamant that he will not claim something that is not true for him (Kalteux \& Girotti, 2016). Castle says it is disrespectful to all of the men and women who actually do have it, and that not all Veterans have the disorder (Kalteux \& Girotti, 2016).”

Pete looked satisfied, "That is a refreshingly different statement to hear." Jim was nodding, as he began to speak, "You know, if they just had a variety of portrayals of Veterans instead of only broken, malicious, or hero, I think everyone would be okay. Anytime only one, or a few, stories are told, it becomes the story most people hear. By default, it is the one they believe."

Charlotte added, "One day, the Veterans on screen will be represented as a diverse group of people, just like civilians. The history of military service for the character will be a piece of who they are, not their entire personality, will help make Veterans more normal (Merry, 2015), instead of these separated 'others' that some people like to think we are.”

"That is part of what I hope to do." Jamie interjected. "If I can tell a variety of stories, it might help disrupt the extremely limited narrative of Veterans that exists in the media today. And while 'a narrative is, simply put, a story' (Leavy, 2009, p 26) the 
process of narrative inquiry is not simple.

"I've got to find the life story or narrative of the individual (McAdams \& Janis, 2004). So, through the narrative inquiry, I will be investigating the identity of the Marine telling the story. It is through their stories that we will be able to see 'the self's unity, multiplicity, or both; how self and society contribute to people's construction of narrative identity; and how people's stories display stability, growth, or both in their identities' (Chase, 2011, p. 422). Since identity is made up of a plethora of connected and separate memories, emotions, thoughts, and experiences (Sermijn et al, 2008), getting them to talk about the Marines, their discharge, and school will give us insight into their identities, as our identities are the 'stories we live by' (Clandinin, 2013, p. 37)."

"Remember, Jamie, that our identity, or our stories, are never done. It is a process that continues as long as we live (Bruner, 2004). 'No autobiography is ever completed, only ended' (Ibid., p. 8). And those stories can change as we retell them, in a 'ongoing dialectic [that] is the narrative process (McAdams \& Janis, 2004).” Charlotte reminded me.

I loved every minute of this. Narrative inquiry was a tool that went beyond the story; as it is a relationship between the storyteller and listener, or each Marine and me. It allowed a 'walk around the edges of stories, to see beyond factuality to the humanism hidden on the other side' (Leavy, 2009, p 26). It was a collaborative effort, as the experience of sharing naturally brings people together. The relationship, based on respect, created a safe place that was crucial for the vulnerability that often-accompanied storytelling and sharing (Connelly \& Clandinin, 1990; Leavy, 2009). Part of that respect was in the inaction of the believing game, a process of connecting and knowing the 
Marines by being in their story with them, without detachment, to empower their voice (Elbow, 1986, as cited in Connelly \& Clandinin, 1990, p 4). This didn't mean that I became a character in their story, but that I purposefully put my life alongside theirs to think with the story being told (Clandinin, 2013). It was a process of being invited into the story, it really was a great honor for me, and the story was also drawn into me so that I was able to internalize and analyze it (Bresler, 2006, p. 28).

“So, who are you going to listen to? Who will you ask for their stories?" Jim asked.

“I could give you Randy's number. I am sure he and the other Vets would love to talk with you." Randy offered.

I looked at all three Marines, and thought of my dad, Sgt. Stepo. "Randy, no offense, I think I have to honor my father and first examine the transition of only Marines. I think I'll call them 'The Unit', it seems fitting."

At this, all three Marines, smiled. 'No offense taken, ma'am. Carry on. Your father should be proud." Randy tipped his grey USMC hat just slightly. It was a blessing and a call to arms in a very simple gesture. I felt as if I had been given permission.

"You know," Pete became serious as he spoke, "you might hear some war stories. 'War evokes both what is most terrible and most divine about being human' (Hoge, 2010, p. 117). Jamie, if you are able to listen to those stories, even the hard ones, and let those guys find the words, and the emotions, that would be incredible. I think having the opportunity for someone to really listen is quite an amazing, supportive, and, I guess, healing experience (Ibid.).”

Randy, Jim, and Pete looked at each other, and then me in a way that seemed to 
give me more than permission. I had just received their blessing. It was a beautiful moment.

The three Marines went back to their own conversation, about the good old days, family, grandchildren, and retirement. While Charlotte and I moved on to talk about less intellectual things, such as my two boys and their recent baseball games. With Danny in T-ball and Mikey in Single A, every Saturday in Spring was a Baseball Saturday. As we parted ways later that afternoon, I felt inspired and ready to call a few Marines, including my former student Tony.

Charlotte gave me a hug and a few important parting words. "Remember, 'Listening is hard work. Being available, being "present," having an open heart to the participants matters' (Bach, 2007, p. 292). Often, we listen to others so we can categorize their experiences into what we already know, yet this is disrespectful (Gilligan, 2015). If you can create a space for listening to the Marines so they feel that you're really listening and will retell their story authentically, you will be honored to hear their stories. Just be sure that before anything else, you listen (Shay, 1995, as cited in Gilligan, 2015).” 


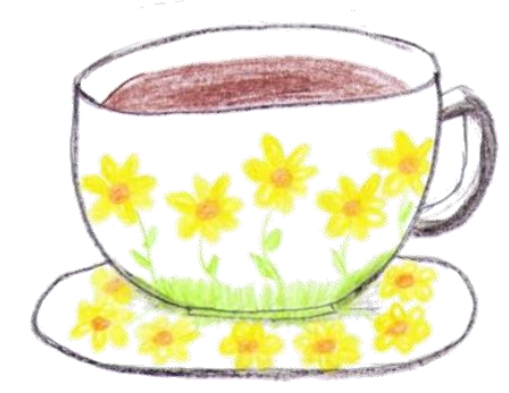

\section{Conversation at the Café}

Café Intelligentsia was a haven for Jamie to study, to learn, and to reflect. It was the same great cerebral sanctuary for me. So, when I needed to set up a meeting with some wonderful intellectuals to dialogue together about the theories that were going to play the biggest role in creating the research story with The Unit, I couldn't think of a better location. I had asked Paulo Freire, Erich Fromm, and Carl Rogers if they would join me for coffee and conversation, and was thrilled when they all accepted the invitation. Such a conversation was only possible because I am a goddess, as these three scholars are no longer physically with us, although they certainly live on in their works.

The first invitation was sent to Paulo Freire, a Brazilian educator and activist. In 1921, Paulo was born in Brazil, where he later became a professor working with adult literacy. He worked with the poor, helping them learn to read "the word" and "the world" (Freire, 2000). Paulo was motivated by curiosity, critical thinking, and hope, and he encouraged those traits in others as well (Freire Institute, 2015). His most popular work, Pedagogy of the Oppressed, focused on honoring and respecting the knowledge and experiences of others, in particular the people who were oppressed (Freire, 2000). It is through the process of conscientizaçāo, or critical consciousness, that reflection and action, or praxis, can lead to liberation from oppression (Freire, 2000). Paulo passed 
away in 1997, yet made a distinct mark on the world with his advocacy of critical pedagogy, which we will talk about at the cafe.

The second invite was accepted by Erich Fromm. Fromm was born in Germany in 1900. After escaping Nazi Germany in 1934, Erich came to the United States where he was "at once a sociologist, philosopher, historian, psychoanalyst, economist, and anthropologist - and, one is tempted to add, lover of human life, poet, and prophet" (Dollard, as cited in Funk, 2006, p. 2). His "best known and most enduring" work, The Art of Loving (Funk, 2006, p. 5), examined love in all aspects, and the misdirected focus of individuals on their need to be lovable instead of their capacity to love (Fromm, 1956). While one of his other well-known works, "Escape from Freedom (1941) suggested that modern man, afraid of freedom, escapes into authoritarianism, conformism, or destructiveness" (Funk, 2006, p. 4). His political activism and warnings against nuclear power, technological domination, and war were part of his anticapitalistic and peace movement (Funk, 2006). While his great works remain, Erich died in 1980, 5 days before his $80^{\text {th }}$ birthday.

The last invitation was sent to psychologist Carl Rogers. Carl was born in 1902 and went on to be the "most influential psychotherapist in American history" (Kirschenbaum \& Henderson, 1989, p. xi). As a speaker, teacher, and writer, he worked to change the process in therapy to be more client directed. As Carl said "It is the client who knows what hurts, what directions to go, what problems are crucial, what experiences have been deeply buried... I would do better to rely upon the client for the direction of movement in the process." (Rogers, 1961, p. 12). Carl and Paulo had very similar ideas, although Paulo's focus was education while Carl focused on psychology, 
counseling, and other relational fields. While some academics may not think highly of Carl's work, "it continues to have a significant impact on the real world" Kirschenbaum \& Henderson, 1989, p. xiii), even beyond his death in 1987.

These three scholars are all from the same time in history, born in the early $20^{\text {th }}$ century. Yet come from separate areas of the world and similar, yet different, fields of study. They all lived through wars, the industrial age, the introduction of technology and huge technological advances. They were men who married women who led their own lives and supported each other's work (Funk, 2006; Rogers, 1961; Stone, 2013). They saw tremendous evil during World War II and all three sought to make the world better by examining various angles of humanity. Be it power, privilege, oppression, respect, mindfulness, or love, Paulo, Erich, and Carl all agreed that life was a process in which we all are continuously learning (Fromm, 1976) and becoming (Rogers, 1961; Freire, 2000).

The four of us were set to meet at Café Intelligentsia in the afternoon for what would be an intense, invigorating, and wonderful conversation. So, I arrived early to select the best table possible. As it was a beautiful day out, with blue skies and a gentle breeze that softly rustled the trees surrounding the patio, I grabbed a table near the corner with four chairs. That particular location gave me a view of the whole cafe. Tallulah walked up to the table with my iced tea and a plate of beautiful fresh fruit, mostly grapes and strawberries. Just as I like it!

“Good morning, Athena!" She almost sang, confident that it was indeed a good morning.

“Good morning, Tallulah!” I replied.

As she placed my tea and fruit on the table, she sweetly reminded me, "I'll bring 
you refills on the tea as you need it, okay?"

With genuine gratitude I said thank you. Then, I sat for a moment, listening to the birds and feeling the cool breeze on my face. This was a perfect afternoon!

While awaiting the arrival of the great minds who were joining me for coffee, I decided to write, so I put my hood on. I am not someone who others generally would notice in human form. I know that the armor and helmet do command more attention when I am in god form, yet in human form, those are a bit conspicuous. However, I find that my customary helmet helps when I need to think, and as the goddess of wisdom and strategy, thinking occurs frequently. While in human form, I make do in public by putting the hood of my jacket on. It enables the same intensity of focus as the helmet. So, there I was sitting in the corner of the cafe patio in human form, an average girl with a black hoodie, jeans, and Converse shoes writing away in my journal.

Apparently, the hood is just as effective as the helmet at gaining attention, as numerous sideways glances happened my way. What is she doing? Is she a threat? Should I move away? One could almost hear the momentary concerns as they glanced my way to assess the threat in such a beautiful cafe. Most of the time, I glanced up to smile, although occasionally I remained focused on my writing. I was anxious for my guests to join me as I was ready to engage in the conversation that I knew would be instrumental to the next steps of this journey. The chance to have a dialogue with Paulo Freire, Erich Fromm, and Carl Rogers was a rare blessing. The combination of these three gentlemen represented the blending of critical and humanistic theory. These where the theories that would create the glasses to look through as Jamie worked with The Unit. Finally, I saw him walk into the cafe. 
Carl Rogers walked into Café Intelligentsia with a calm, peaceful presence about him. He saw me and smiled, like he was meeting an old friend. He looked like a typical grandpa, with a friendly, approachable air about him in his khaki slacks and navy-blue polo shirt. He greeted me warmly and took a seat in one of the iron chairs. He chose the one with the pale blue cushion. I was glowing with excitement, because although I have long been a reader and follower of his work, this was my first opportunity to sit down and really engage with Carl about what he thinks about humanistic psychology, and more specifically his theory about personality transformation through client-centered therapeutic techniques.

"How are you today, Athena?" Carl asked with genuine care and interest.

"I'm well, thank you. I am thrilled to have this opportunity today. I cannot thank you enough for taking the time to come and dialogue with the group. How are you?"

"Invigorated! It has been sometime since I have had such an opportunity, to meet with others and engage in what I hope to be an insightful and spirited discussion, Athena. So many questions have started to emerge in my thoughts; the first of which I must ask before the others arrive. Why did you select me to be among the other thinkers who are planning to join us?" Carl raised his eyebrows with authentic curiosity beneath his vintage grey and wire-rimmed glasses.

As I took a moment to collect my thoughts about why Carl was the last person to be added to the list for invitations to this meeting. He was certainly the biggest theoretical influence in Jamie's life, Tallulah brought out a cup of coffee and placed in front of him. After Carl thanked her, with a smile, he looked back at me, anxiously awaiting a response. 
"Carl, I don't think there is a way that the conversation could have occurred without your presence. You see, while this may be our first in depth engagement together, I have been eavesdropping, if you will, on your conversations for years. I've witnessed many young scholars, including Jamie, come upon your theory about clientcentered therapy. The concept of unconditional positive regard changed the way that they saw the whole world. Suddenly, life was no longer full of good or bad people, just individuals with different experiences and emotions (Rogers, 1957). Watching so many people change, particularly Jamie. She began to enter the classroom with more humility and greater respect for her students. She engaged with other people, strangers and friends, with more empathy and greater authenticity. It was amazing. Even I reflected on my own being and behaviors differently, which is saying a lot as a god.

"Yet, I am the goddess of wisdom. Part of that wisdom is the acknowledgement that I do not know everything. I still have more to question and more to learn. I continue to learn more, and engage with other theories and theorists. I truly believe that I am drawn to certain ideas because of the influence your work." At this, Carl was sincerely touched and physically moved.

"So...," I continued. "You would be in the work of The Unit and this conversation, even if you were unable to make it to the meeting. Because much of my philosophy about human nature, relationships, education, and the therapeutic change, or personal transformation, is in alignment with yours, your presence would have been felt at this meeting through me. Also, each new learning, new idea, intellectual engagement creates more questions and reflection, I was selfish in my desire to have you here to ass to my own process of making sense of everything I will learn on this journey." I took a 
breath, excited about my honest and exposing statement. Rogerian humanistic theory was a big influence for me and part of who Jamie was; it was critical that it was part of the research story. I hoped the authenticity that was crucial in his philosophies would be true in his personal interactions as well. I was not disappointed.

"Athena, I am honored and humbled by your appreciation. I hope that I can support you and Jamie through this journey. And, as you know my writings already, you already have the answers within you (Rogers, 1961). Remember, you are currently in a place of immense flexibility, and that is an exciting place to be. I have found that life, at its best, is a flowing changing process in which nothing is fixed (Rogers, 1961, p. 27). So, embrace this journey and enjoy the experience, as Dewey (1934) would call it." Carl smiled a knowing smile of assurance and took a drink of his coffee.

“That's a pretty big concept, Carl!" I said, as I leaned back slightly to take it in. "Indeed, it is." He replied. "It is also both fascinating and a little frightening. I find I am at my best when I can let the flow of my experience carry me, in a direction which appears to be forward, toward goals of which I am but dimly aware. Life is full of ever-changing complexity and when I am able to be open and guided by new experiences and new understandings I can develop and grow. I try to give others the permission and freedom to develop their own inward freedom, as well, as life is richest and most rewarding when it is a flowing process. And that process is always in process of becoming (Rogers, 1961, p. 27). So, today, and throughout your journey, embrace experiences with openness and flexibility as opportunities to learn, to be guided, and to grow in your own becoming."

I smiled. I knew that today was going to be instrumental in how Jamie entered 
into the next stage of this journey of inquiry.

I took a bite of a strawberry, and looked up as Paulo Freire, Erich Fromm, and, to my surprise, Karl Marx waked into the cafe. The three men were already absorbed in what looked to be an engaging discussion. As they approached our table in the corner, they all looked up and smiled.

"Athena, how are you doing?" Paulo asked, as he walked over to me and greeted me with a warm hug. Paulo wore metal glasses and big, white bushy beard. He wore a salmon knit sweater and a smile on his face. Right behind him was Erich, who also offered a hug of hello. Erich also wore glasses, but they were much smaller frames. His hair was dark and matched the dark suit jacket, that he wore over his blue dress shirt with no tie and the collar unbuttoned. Karl was a bit more formal, and respectfully shook my hand as he joined the group. He had an even bigger beard than Paulo and wore a black suit, and no tie, yet his shirt collar remained buttoned.

“I'm doing well, please make yourselves comfortable. What, may I ask, are you gentlemen so intently discussing?" As I offered the three scholars a seat, it was the first time I noticed that an extra chair had been added to the table. I have no idea when it happened, just that the staff at Café Intelligentsia would never cease to amaze me. It was yet another example of the leadership through service the cafe exemplified (Greenleaf, 2008).

Karl responded to my question as he sat down in the wooden chair with the red cushion. "We were talking about capitalism, and what it is doing to education today." You could feel the anger emanating from him with each word. I could not agree with him more. As the goddess of wisdom, the classroom is my home, a very comfortable and 
beautiful place of learning, sharing, and growing. However, I had been in various "educational facilities" that felt more like manufacturing plants, making cogs for the future machines, than a place of learning.

"Education, unfortunately, is not always about empowering students to think critically and becoming more human. Often, it is about learning how to conform and survive in a capitalist society. This, in turn, means the students are learning how to be good little workers." I replied, with almost as much frustration as Karl. At this, everyone at the table thoroughly engaged.

"You mean good little producers? It is the capitalists who have taken over, and they do not care about education. They care for only the constant production by workers. The life and health of the worker is ignored, unless under compulsion from society (Marx, 1867b, p. 391). One can see evidence of this in their demand for what is a 'working day'. A day that leaves no time for growth, development, and healthy maintenance of the body. It steals the time required for the consumption of fresh air and sunlight (ibid., p. 388).

This is true for future laborers as well. They only want to replace the current laborer, as such no time can be 'wasted' on arts or 'unnecessary' activities such as social or intellectual development (Marx, 1867b).”

Carl looked at Karl, with a mixture of agreement and challenge in his eyes. "So, would you say that the shortening of the work day, and limits placed on the amount of work hours per week, ages of employees, and other laws to protect employees are an example the care requirements placed by society?"

"Most definitely" Karl responded without missing a beat.

"Then, could we say that our society is one that is moving to a more caring and, 
as Erich would say, a more democratic society?" Carl asked.

Karl was about to immediately object yet paused. Erich, however, took the opportunity to share his thoughts on the matter. "I think that the idea of caring about your fellow man or woman, is a wonderful attribute, yet we still have miles to go before we are at the democratic society that I spoke of in Escape from Freedom (Fromm, 1969).”

"As politics and economics have become even more incestuous, the structural and ideological systems in society have made the gap between the proletariat and the bourgeoisie even greater. There is a perception of a middle class, but the laborers have become a commodity, as all articles of utility become commodities (Marx, 1867a, p. 382). I believe this is also happening with the military, as the men and women who serve are being used as a commodity due to their exchange value. The USA has made it very clear that their military is a force, be it in ground wars or the missions to aid other governments in their 'fight against terrorism'. Yet, how many of these military operations begin with the motivation to help people, and how many are approved by congress as cover for the personal economic growth of the politicians or their fellow capitalists? Or as Peter McLaren (2009) put it, in regard to the Vietnam War, 'Whose interests did the war serve best? Who benefited most from the war? What were the class relationships between those who fought and those who stayed home in the university?' (p. 63). What do YOU think, goddess of justified warfare?" Karl looked expectantly at me. He knew that I was not antimilitary, and he was well aware of my history with heroes in battle.

"I agree." Karl was a bit surprised. I smiled as I continued. "You only need look at the significant imbalance in health services available while on active service compared 
to the Veteran services that a require a four page guide to making an appointment (Dorman, L., personal communication, 4 June 2014) to see evidence of the commodification of the military. I do see that abuse and use of the all-volunteer armed forces and it sickens me. The existence of the military-industrial complex, which places profit over the people in the armed forces, is further evidence of the misuse of the military for the political and economic gain. Yet, if your next step is to devalue the men and women who volunteered to serve, Karl, my agreement with you has reached its end."

"But are they really all volunteers, Athena?" Erich questioned me with a tone that begged me to really reflect on that statement. He continued, "While there are a variety of reasons that an individual would enlist in the military, one cannot ignore that the majority of the men and women who do enlist and are sent to combat are not from the ruling class. Service members may enlist through the desire to belong to something (Fromm, 1969), or they may see the military as the only path after high school to improve finances or future educational opportunities (Di Ramio, D., Ackerman, R., \& Mitchell, R. (2008). I believe it was Lois Tyson (2006) who said that 'Patriotism is an ideology that keeps poor people fighting wars against poor people from other countries (one way or another, sufficient money can generally keep one out of the armed forces during war time or, at least, out of the combat units).... Patriotism leads the poor to see themselves as members of a nation, separate from other nations, rather than as members of a worldwide oppressed class' ( $\mathrm{p}$. 59). So, Athena, is it really an 'all-volunteer force'?”

I thought about this, many Veterans joined the military because it provided an opportunity to see new parts of the world and experience new cultures. For others, the duty to serve one's country is what called them to join (Ackerman et al., 2009; DiRamio 
et al., 2008). Other Veterans enlist to provide a better life for themselves and their family (DiRamio et al., 2008; Glover-Graf et al., 2010). Many Veterans join for the educational funding they will receive after their service (DiRamio et al., 2008; Mikelson \& Saunders, 2013; Wilson, 2014). So, do the benefits of enlisting create a situation that systematically and disproportionally recruits and enlists individuals who would not be able to attend college or live and work at an adequate standard of living (meaning adequate access to food, housing, and clothing)? I thought of William Francis Butler's statement that "The nation that will insist upon drawing a broad line of demarcation between the fighting man and the thinking man is liable to find its fighting done by fools and its thinking by cowards." I knew that traditionally college educated individuals commissioned in as officers, instead of enlisting, yet was it really a system that took away the volunteer nature of the service. Was it a choice that was made from only one option? This would be something I would need to discuss more with The Unit.

As I reflected on the question, Karl began to speak once more. "It is certain that one cannot deny the abuse of the military. It is important to look at the systems that replace those laborers as well, Athena. An individuals' social existence determines their consciousness (Marx, 1859, p. 380), it only makes sense that the experiences of individuals within the capitalistic society have certainly made clear to them what their place in the world is, and, just as Horkheimer \& Adorno $(1944,1947)$ said, 'freedom to choose an ideology, which always reflects economic coercion everywhere, proves to be freedom to be the same' (p. 441). Thus, they may have officially volunteered, while the act of volunteering was their only option to maintain the status quo."

Our conversation had just started and was already challenging some of the 
thoughts I had always held as truths. I was reminded of Carl once writing, "It is no longer possible, as it was in the not too distant historical past, to settle comfortably into the values system of one's forebears or one's community and live out one's life without ever examining the nature and the assumptions of that system" (Rogers, 1964, p. 160). I disagreed with the idea that it would have been acceptable in the past, and I agreed that questioning how and why was a crucial piece to our dialogue and the journey that I was hoping to take.

Karl began again, "Just as with a laborer who becomes no more than an extension of a machine, military service members become a commodity engaged in alienated labor as the product of their work belongs to the capitalist. Like other laborers who are paid the minimum for the maximum amount of work, military service members are paid just enough. Although, the risk of their position, to themselves and their family, is by no means acknowledged in their pay or other benefits. Indeed, it is only the need to have them efficient in achieving the mission, that the health and training of active duty service members are so well funded (Marx, 1887).”

Paulo shook his head slowly as he lamented, "The oppressed, as objects, as "things," have no purposes except those their oppressors prescribe for them (Freire, 2000, p. 60).”

However," Erich added, “War to some extent, reverses all values. War encourages deep-seated human impulses, such as altruism and solidarity, to be expressed - impulses that are stunted by the principles of egotism and competition that peacetime life engenders in modern man. Class difference, if not absent, disappear to a considerable extent. In war, man is man again, and has a chance to distinguish himself, 
regardless of privileges that his social status confers up on him as a citizen. To put it in a very accentuated form: war is an indirect rebellion again the injustice, inequality and boredom governing social life in peacetime, and the fact must not be underestimated that while a soldier fights the enemy for his life, he does not have to fight the members of his own group for food, medical care, shelter, clothing: these are all provided in a kind of perversely socialized system (Fromm, 1973, p 242)"

"THIS is what I love about dialogue!" Paulo exclaimed with such genuine passion and engagement that I could feel it. "This interchange is what critical theory is all about! We have an opportunity, right now, to engage together through critical discourse about the variety of perspectives and realities for Veteran and military service members (Peters, Lankshear, \& Olssen, 2003). We do this with the hope of liberation; it is the start of a wonderful journey for you and Jamie. I am so excited for you, and I appreciate you starting the theoretical part of your journey with us, here, today!”

I was truly lucky to have such amazing minds with me, discussing critical theory, over coffee. Which reminds me, sometime during the conversation, Karl, Erich, and Paulo had all been served. Karl took another sip of red wine, as Erich dipped a scone into his hot chocolate, and Paulo delighted in his cafezinho (a typical Brazilian style coffee that was plain, black, strong, and scalding hot). Occasionally, I get so wrapped up in the theoretical conversations and thoughts that I fail to notice events around me. I thought about that with a smile, and I laughed a little inside. You see, one of the criticisms Marx had of Hegel was that he focused too much on the intellectual, the thought, and Marx knew that action was the way to make liberation possible (Dunayevskaya, 1958; Peters et al., 2003). Although, both Hegel \& Marx agreed that "there are barriers in contemporary 
society, which prevents the full development of man's potentialities, of man's “universality"' (Dunayevskaya, 1958, p. 35).

Finally, I spoke. "Thank you, all of you, for being with me here today! Already, I have been challenged to think deeper and more critically. Karl, you are an unexpected treat! And we are just beginning. From my understanding, critical theory 'seeks to isolate and expose the relationships between cultural elements, economic and social processes, and the historical context. Adopting the viewpoint of oppressed social groups, it expressly seeks to become an agent in the promotion of social change and transformation' (Peters, Lankshear, \& Olssen, 2003, 2003, p. 5)."

At this, Carl took a sip of his coffee then looked at me, and then the whole group as he questioned critical theory in general. "Is there any diversity within critical theory?" "Of course," I responded. "There are various applications and focuses, yet at their core, all critical theories encourage reflection toward liberation from oppressive systems (Schwandt, 2007). For example, critical race theory focuses on how racism 'is an endemic part of everyday life, deeply ingrained through historical conscious and ideological choices about race, which in turn have directly shaped the U.S. legal system and the ways people think about the law, racial categories, and privilege' (Parker, 2003, p. 185). Critical race theory contends that race, although socially constructed, plays a crucial role in creating our world (Parker, 2003). As Karl has already explained, Marxism focuses on the power and oppression of capital (Macey, 2000). Feminist critical theory focuses on gender, also constructed, and the need to perform the 'correct' gender or be punished (Butler, 1990). In addition, feminist critical theory examines the gender hierarchy and how many circumstances are unjust for women due to the lack of a 
phallus (Mulvey, 1975). The tendency to make heterosexuality, in language, culture, and society, the norm and universalized standard is examined in queer theory (Wittig, 1980). It is through queer theory that we investigate the compulsory heterosexual nature of systems and structures in society (McRuer, 2002). There is even Veteran Critical Theory."

"Veteran Critical Theory?" asked Erich, as he took another bite of his scone.

"Yes, Glenn Phillips \& Yvonna Lincoln (In Press), from Texas A\&M University, have developed Veteran Critical Theory, or VCT, which draws from the feminist theory, critical race theory, and queer theory listed above, as well as disability theory and border theory. Border theory is thought-provoking as it brings forth the fact that many individuals live along the borders of dominate and oppressed groups, without full acceptance by either group (Anzaldúa, 1987). As a result, many individuals are forced to live in 'borderlands' where statuses, both privileged and oppressed, overlap. For example, a white, male Veteran would have a different experience with oppression than a white, female Veteran or a Black, male Veteran. Also, intersectionality, while not highlighted in all critical theories, is important in VCT as it takes into account the fact the Veterans are neither all civilian or all military (border theory) and the fact that Veterans have other oppressed/privileged identities (i.e., race, gender, sexual orientation) (Phillips \& Lincoln, In Press). Phillips \& Lincoln (In Press) examined different forms of critical theory, to create VCT which specifically examines the ways in which our society oppresses Veterans and military service members, while it privileges civilians.”

Erich leaned forward and, with one eyebrow raised, gently commanded, "Tell me more." 
"It's particularly true in higher education, yet in society citizens and civilians have privilege and are not aware of the struggles, benefits, challenges, and blessings of Veterans and military service members or their families. It is not unlike that of whites being oblivious to the experiences of People of Color or heterosexuals being unaware of the privileges that are denied to the LGBTQ community (Phillips \& Lincoln, In Press). When civilians do become aware of Veterans and/or service members, it is around a holiday that is often turned into a barbequing and drinking event, such as Memorial Day. It becomes fashionable to offer an almost obligatory 'thank you', but it is far from genuine care and gratitude for their service (Astor, 2015).

"So Phillips \& Lincoln (In Press) provided 11 tenets of VCT, which are:

1. Structures, policies, and processes (particularly institutions of higher education) privilege civilians over veterans.

2. Veterans experience various forms of oppression and marginalization including microaggressions.

3. Veterans are victims of deficit thinking in higher education.

4. Veterans occupy a third space (country) on the border of multiple conflicting and interacting power structures, languages, and systems.

5. VCT values narratives and counternarratives of veterans.

6. Veterans experience multiple identities at once.

7. Veterans are constructed (written) by civilians, often as deviant characters.

8. Veterans are more appropriately positioned to inform policy and practice regarding veterans.

9. Some services advertised to serve veterans are ultimately serving civilian 
interests.

10. Veterans cannot be essentialized. (Veterans are unknowable.)

11. Veteran culture is built on a culture of respect, honor, and trust. (pp. 7-9)

"Each tenet presents an observation of the nature of oppression for Veterans on college campuses. Colonel Jerry Smith, Retired USMC, summarized it perfectly once to Jamie: military service members move from a culture of push, where they are told where to go and what to do, to one of pull, where they have to find and ask for any and all services or supports (personal communication, February 8, 2015). Before they can even pull, they have to find the resources, as many of the policies and services in higher education can be confusing or unclear. As a result, higher education professionals, and the rest of the world, examine the transition difficulties of many Veterans through a deficit model (Phillips \& Lincoln, In Press). Also, within the classroom many Veterans are faced with numerous microaggressions (ibid.), which are subtle or hidden messages that devalue a group, or an individual because of their membership in a group, and remind them of their 'inferior status' (Sue, 2010). Part of the microaggressions for Veterans includes the maintenance of the metanarrative that all combat Veterans are suffering from PTSD, and thus forever altered by the agonies of war, constantly on edge and ready to snap at any moment. The perceived connection between Veterans and PTSD is so strong that PTSD has even been labeled one of the "signature injuries" of the Iraq war' (National Council on Disability, 2009, p 1). However, research findings suggest that the most common service-related disability is hearing loss (Miller, K., 2013). This is further support to the negative public perception of Veterans, as deviants and/or dangerous (Phillips \& Lincoln, In Press).” 
Erich, sat back a bit, processing everything he had just heard. Everyone at that table was thinking. Then Paulo began to speak.

"You know, the experience of many Veterans is not all that different from other marginalized individuals. I can see how Veteran Critical Theory, and critical theory in general, would be so important to this research journey, Athena."

"Yes, and I cannot ignore the other crucial part of the theoretical lens, the humanistic theory. So, part of what I would like to do with the great minds at this table, is think about how those two theoretical frameworks, which may at first glance appear to be unrelated, intermingle and enrich each other."

Karl immediately responded, with reserved excitement, "I had a scholar, Raya Dunayevskaya, who engaged with my writing and theories to develop MarxistHumanism. She looked at all of my work as a whole and really connected with the idea of alienation, which we have already touched on. She felt that Marxist-Humanism was 'retrospective, in comprehensiveness \& todayness' (Dunayevskaya, 1992, p. 156) as it was a theory of Marxism that focused greatly on Hegel's idea that 'the true form of reality, requires freedom, requires man to be free.' (ibid., p. 41) and moved from just the thoughts to action. In the end, 'a society in which the full and free development of every individual is the ruling principle' (Marx, 1887, p. 411) is one that is a humanistic one, and that is right in line with Marxism."

As we all nodded in agreement, Karl glanced at his watch then quickly looked up with worry and slight panic.

"Athena, Erich, Paulo, and Carl, I must take my leave. I have a community union meeting to attend, that began a few minutes ago. This has been such a wonderful and 
engrossing dialogue; I hope we can do it again sometime. I wish you the best of luck, Athena, while you zealously seek the truth. There is no royal road to science, and only those who do not dread the fatiguing climb of its steep paths have a chance of gaining its luminous summits (Marx, 1887, p. 9)." With that, he finished his glass of wine and walked out of the cafe.

Erich looked at Carl, Paulo, then me, and asked, "I know that Karl had to leave, but I feel as though there is still much to discuss about critical theory. I know Freud was a critical theorist. He felt that the historical structures of society were the only way to maintain and regulate the impulses of the id, which is the unconscious aspect of our personality that is guided by the 'if it feels good, do it' pleasure principle (Freud, 1955). It was Herbert Marcuse (1955), another critical theorist from the Frankfurt School, who directly opposed this idea, as do I, in his book Eros and Civilization. He is 'considered by some as the most prominent scholar of the Frankfurt School to influence critical pedagogical thoughts' (Darder, Baltodano, \& Torres, 2009, p. 7).

"Marcuse (1955) believed it was through embracing Eros, the erotic love instinct, that human liberation could occur. It was part of the 'Great Refusal' or the rejection of the separation between the 'inner connection between pleasure, sensuousness, beauty, truth, art and freedom' (p. 172) in 'protest against unnecessary repression, (and) the struggle for the ultimate freedom' (ibid., p. 149) which is the absence of anxiety. It is this connection between 'the senses and the intellect' that creates the aesthetic dimension, a concept I believe Dewey (1934) would agree with. Yet Marcuse and I are not in complete agreement, as Marcuse finds my 'neo-Freudian revisionism' too focused on the impact of society. I feel that Freud focused mainly on the instinctual elements of an 
individual, yet failed to realize that 'personality tends toward a standardized reaction pattern established by the hierarchy of power and functions and by its technical, intellectual, and cultural apparatus' (ibid., p. 252). Individuals are, in my belief, a product of nature and nurture, which includes historical influences (Fromm, 1969, p. 193).

"I mention this, partially to point out the further diversity within critical theory, as well as to focus on the impact of society. I think Peter McLaren (2009) said it best, when he said that 'critical theorist begin with the premise that men and women are essentially unfree and inhabit a world rife with contradictions and asymmetries of power and privilege' (p. 61).”

Carl immediately sat up, alert, and leaned further into the table as he looked at Erich and challenged, "What do you mean by 'essentially unfree'?"

Erich remained calm as he responded. "It means that we have to acknowledge the historical and social foundations for our lives. While we are all free to become more human, as social beings we are influenced by the society. For example, conscience motivates an individual to act according to wishes and aims which he believes to his own, while they are actually the internalization of external social demands (Fromm, 1969, p. 72). Yet, it is important to note that while impacted by the society, the individual is also part of the maintenance of said society, which leads to part of the dialectical nature of critical theory (Gur-Ze'ev, 2003; McLaren, 2009).”

Paulo had been listening so intently to the conversation, while jotting down seemingly random notes on napkins. Thankfully, he was on his second cafezinho, so he had received additional napkins to write on with the second cup. But he was done 
listening and writing for now, as his entire demeanor provided evidence that he was pregnant with thought. He began to speak.

"I think that critical theory is the beginning of the process, or the building blocks, if you will (Darder et al., 2009). It provides the glasses, or the lens, with which we see the world. However, it is not finished there. No, it requires praxis: the action and reflection of men and women upon their world in order to transform it (Freire, 2000, p. 79)."

Carl shot up at this, with an energy that commanded attention, "While I agree that action has to be taken for there to be change, we cannot go directly from the critical analysis to changing the world. There is an interim step that is crucial as we engage with ourselves and other people. I believe that is the value the humanistic theory that Athena spoke of.

"Many individuals suffer incongruence between what reality is and what they perceive or believe who they are and what is happening (Rogers, 1957). When the individual has no awareness of such incongruence in himself, then he is merely vulnerable to the possibility of anxiety and disorganization (ibid., p. 97). With such vulnerability people must be coached and supported through the process of simply understanding the ideas that come from engaging in critical theory. From what I have heard, critical theory aims to disrupt the status quo, to investigate the role of history and ourselves in maintenance of the status quo (Peters, Lankshear, \& Olssen, 2003), and to create a variety of 'transformative perspectives' (Kellner, 2003, p. 79). I think such goals are useful and valuable. I also think that for each individual, his experience is his reality (Rogers, 1959, p. 222). So, before one can engage in action and societal change, they 
first have to be able to accept a new perception of that reality, be it informed by critical theory or anything else.”

Paulo nodded in agreement and added, "Reality is really a process, undergoing constant transformation (Freire, 2000, p. 75), so we first acknowledge that here is an endless and dynamic nature to any reality. We must also realize that their view of the world, manifested variously in their action, reflects their situation in the world (ibid., p. 96). Thus, in order to communicate effectively, educator and politician must understand the structural conditions in which the thought and language of the people are dialectically framed (ibid., p. 96). So, we have to first learn and empathetically understand their language and reality before we begin the dialogical process."

"Definitely," agreed Carl. "Empathy is key! The other piece that I think is important is unconditional positive regard, which means that there are no conditions of acceptance, no feelings of 'I like you only if you are thus and so.' It means a 'prizing' of the person, as Dewey has used that term... It means a caring for the client, student, or individual, as a separate person, with permission to have his own feelings his own experiences (Rogers, 1957, p. 98). It means having no conditions of worth, or specific characteristics that make an individual worthy of love (Rogers, 1951).”

"It means loving them." Erich added. "Love is an active power in man; a power which breaks through the wall which separate man from his fellow men, which unites him with others; love makes him overcome the sense of isolation and separateness, yet it permits him to be himself, to retain his integrity (Fromm, 1956, p. 19). Love is about giving love, and receiving it, through the four common elements of love: care, responsibility, respect, and knowledge (ibid., p. 24).” 
Paulo was smiling, "I believe the respect element is what allows one to enter into any relationship with humility. As love is commitment to others, it is required for dialogue, as dialogue cannot exist in the absence of a profound love for the world and for people" (Freire, 2000, p. 89).

"And we humanize ourselves through dialogue with others" (Roberts, 2003, p. 176), Carl added.

Paulo was nodding, as he added, "And we are always in that humanizing process, a process of becoming and unfinishedness. So my dialogues with others, in my seeking to be more fully human, cannot be carried on in a climate of hopelessness (Freire, 2000, p 92), nor can they be true dialogues without critical thinking."

While Paulo took a drink, I seized my opportunity to ensure that I was understanding everything correctly. "So, as I continue on this journey, I first must learn about the group I want to work with, so that I am knowledgeable about the Marines. Then I need to enter into the relationship with them in a loving place of care, respect, responsibility, and humility. It is in this loving place that we are able to dialogue and become more human."

Paulo looked at me with a mixture of concern and approval as he responded, "You make it sound so easy, Athena. And yet, it is a significant journey for all of those involved, including Jamie, the Marines, and even you. The reflective nature of critical pedagogy, which embodies much of what we are talking about here, is 'simple' in explanation and takes a great deal of awareness, engagement, and humility. Whoever teaches learns in the act of teaching, and whoever learns teaches in the act of learning (Freire, 1998, p. 31). The relationship is reciprocal, and incredibly powerful." 
Carl continued the thought, "While I have never called it critical pedagogy, I do believe that reliance on process rather than upon static knowledge, is the only thing that makes any sense as a goal for education in the modern world (Rogers, 1967, p. 304). Just as there are necessary conditions for therapy, the same is true for qualities that facilitate learning, which start when the facilitator is a real person, being what she is, entering into a relationship with the learner without presenting a front or a façade, she is more likely to be effective (ibid., P. 306). The unconditional positive regard allows the prizing of the learner, prizing of her feelings, her opinions, her person. It is a caring for the learner, but a nonpossessive caring. It is an acceptance of this other individual as a separate person, having worth in her own right. It is a basic trust - a belief that this other person is somehow fundamentally trustworthy (ibid., pp. 308-309)."

"Trust is the foundation of a democratic society (Fromm,1969)," Erich added.

"Trusting the people is also the indispensable precondition for revolutionary change (Freire, 2000, p. 60)."

"It is also the basis of all genuine relationships, particularly for folks in leadership, such as parents, teachers, and researchers (Greenleaf, 2008; Patterson, Grenny, McMillan, \& Switzler, 2012). Trust is a key element in creating transformational, not just transactional, leadership (Gill, 2011)." Tallulah added to the conversation, as she had arrived at table at the perfect time, again. "However, to use a music metaphor, a leader does not need a podium; she can be sitting quietly on the edge of any chair, listening passionately and with commitment, fully prepared to take up the baton (Zander \& Zander, 2000, p. 76). It is important to see the leader within each and every person (Greenleaf, 2008). One could even argue that folks are successful because 
they realize and appreciate that other folks matter (Greenleaf, 2008)." We began to soak in the significance of such an idea, as well as the value of such a contribution to our dialogue. She asked if we would like anything more to drink, then went on to care for and talk with the other customers.

After Tallulah left, we continued the conversation about the value of the individual. Everyone had something to say, Carl was relentless in his passion for unconditional positive regard, the need to identify and disregard conditions of worth, and the value of congruence in educator/therapist (Rogers, 1957). Erich listened, and spoke with great eloquence about the need to move to a more loving demeanor, focused on our love for others more than on our being loved (Fromm, 1956). Paulo spoke of knowledge that individuals possesses and the value of working with, not for or on, the people being more impactful and transformative for everyone involved (Freire, 2000). I, too, listened as well as shared my views on the value of authenticity in relationships, so that trust can be formed and safe places can be created. Tallulah, our server, would occasionally add to the conversation about numerous respectable leaders and leadership authors who spoke of the value of respecting others and humility, along with the need to listen to others with empathy and understanding (Cashman, 2008; Greenleaf, 2008; Goleman, 2004; Ferch, 2004; Wheatley, Spears, \& Noble, 2004).

"But the total me, my whole individuality, my suchness that is as unique as my fingerprints are, can never be fully understood, not even by empathy, for no two human beings are entirely alike (Fromm, 1967, p. 75). It is by starting with the value of each individual, which is humanistic, that one can then begin to engage with acknowledging the way things are, so we can ultimately challenge and transform it." Erich said. 
I agreed, "You're right, 'we start from what is, not from what should be; we encompass contradictions, painful feelings, fears, and imaginings... the practice of being with the way things are allows us to alight in a place of openness, where 'the truth' readies us for the next step, and the sky opens up' (Zander \& Zander, 2000, p. 111).”

Paulo responded. "And the next step is challenging! It can sometimes be difficult to acknowledge the historical structures and systems that have such a significant impact on our current realities. Yet, as Henry Giroux (1983) said 'critical thinking becomes a precondition for human freedom' (p. 19). As it is 'freedom through reason' (Peters, Lankshear, \& Olssen, 2003, p. 4) developed by reflection, critical dialogue, and then action that leads to liberations. This really brings us back to critical pedagogy.

"Critical pedagogy can best be described as problem posing with the purpose, described again by Henry (Giroux, 2003), of ‘challenging a society's commonsense assumptions, and for analyzing the interface between their own everyday lives and those broader social formations that bear down on them' (p. 163). The rationale of this process is found in a Native American saying 'the first people had questions and they were free. The second people had answers and they were forever enslaved' (Wind Eagle, Chief). So, it is through self-reflection, consciousness, being openly committed to action, that a critical social citizenship can be developed."

"Yet it is part of the process of "becoming a person." Carl responded immediately, "It means that a person is a fluid process, not a fixed and static entity; a flowing river of change, not a block of solid material; a continually changing constellation of potentialities, not a fixed quantity of traits (Rogers, 1961, p. 122). This process is never done nor is it predetermined. As Shakespeare wrote in Hamlet, 'we 
know what we are, but not what we may be' (as cited in Cashman, 2008, p. 35). As such, we may be in the processes with people, theirs and ours, yet we are never 'done'."

Again, Tallulah had perfect timing. "You know if you keep the grammar of the original text in the Bible, 'it's not 'In the beginning God created the Heavens and the Earth,' it's 'In the beginning God is creating the Heavens and the Earth.' It changes the whole context. Even if you don't have the religious belief, the message is a wonderful reminder. You don't ever get there, wherever there is, it's the journey that is the objective' (Autry et al., 2004, p.69).”

Paulo was nodding and smiling, "Of course it is not a destination!" he exclaimed. "If we reflect on the face that our human condition is one of essential unfinishedness, that, as a consequence, we are incomplete in our being, and in our knowing, then it becomes obvious that we are "programmed" to learn, destined by our very incompleteness to seek completeness, to have a "tomorrow" that adds to our "today." In other words, wherever there are men and women, there is always and inevitably something to be done, to be complete, to be taught, and to be learned (Freire, 1998, p. 79). The process of humanization requires constant reflection and increased consciousness of the world and the understanding of the human person as a maker of history and as one made by history (Freire, 1998, p. 115). As a result, conscientizaçāo or critical consciousness is developed."

"That increased consciousness can lead to feelings of loneliness." Erich added. "Because society, frequently through the media, fights to keep the thinking individual 'defeated' (Horkheimer \& Adorno, 1944, 1947), it can be difficult to embrace a critical consciousness and be in the process of becoming. Paulo speaks of unfinishedness, and it 
is that humility of being that 'enables self-actualization, fulfillment, and abiding peace' (Lankshear, 2003, p. 56) and fights against the having society in which we live. An example of this is to return to our initial topic of education. Our education generally tries to train people to have knowledge as a possession, by and large commensurate with the amount of property or social prestige they are likely to have in later life. The minimum they receive is the amount they will need in order to function properly in their work (Fromm, 1976, p. 36). This is a having perspective of learning; it is in line with the banking theory of education. Yet, from the being perspective, they do not simply acquire knowledge that they can take home and memorize. Each student has been affected and has changed: each is different after the lecture than he or she was before it (ibid., p. 26). As a result, not knowing is an opportunity to engage and learn, instead of evidence of someone's lacking (Lankshear, 2003).

"Yet, we cannot deny that we live in a having society, a society that focuses more on being worthy of love or loveable, rather than that of loving, of one's capacity to love (Fromm, 1956, p. 1). So, if our whole social and economic organization is based on each one seeking his own advantage, if it is governed by the principle of fairness, how can one do business, how can one act within the framework of existing society and at the same time practice love? (Fromm, 1956, p. 121).

Carl responded with a peaceful passion that was at once a call to action and a reassurance of his support. "We must be a small voice of protest against a massive and solid system (Rogers, 1985, p. 10).”

"That is what we hope to do." I replied.

"Then you will be a leader." Tallulah had returned. 
Erich looked at me and smiled, "When it comes to giving, giving of the self is the most important. When someone gives of himself, of the most precious he has, when he gives of his life (Fromm, 1956, p. 23) that communicates a care and love for the other person, or group. You are giving of all that you are to inspire The Unit, Athena. That is an act of love and it can inspire many others to do the same."

Tallulah remained at the table as we continued the conversation about love and leadership. We continued to discuss the crucial nature of being authentic and humble in all relationships, particularly the relationship Jamie would have with The Unit, as the humanizing nature of the work together was instrumental to its success. We discussed value of humanistic theory, particularly Rogerian, as it was the guide to Jamie's current and future relationships, personally and professionally. We talked, at length, about how Jamie would use critical theory and humanistic theory together to work with The Unit. We also talked of the best places to reflect, as both Jamie and I had always been, and continue to be, drawn to the ocean. At the end, we departed from one another refreshed and still unfinished. Erich and Carl left first, together, to go and meet Sigmund Freud at local cigar shop.

As Paulo said goodbye, he held my arm. "Remember, to tell Jamie, that as she continues in her own process of becoming, and engage as a teacher, researcher, and person, I ask that [she] give [herself] to it critically and with ever-expanding curiosity (Freire, 1998, p. 27).” He then hugged me and went to meet his wife for dinner.

I sat and drank my iced tea while I wrote as many notes as I could about the wonderful conversation with Paulo, Erich, Carl, Karl, and Tallulah. It was a wonderfully enriching afternoon. The dialogue, the ideas, the inspiration... I looked forward to 
passing all of it along to Jamie and The Unit. I admitted to myself, that I liked being the muse in this situation. I hoped others would enjoy the process as much as I did. 


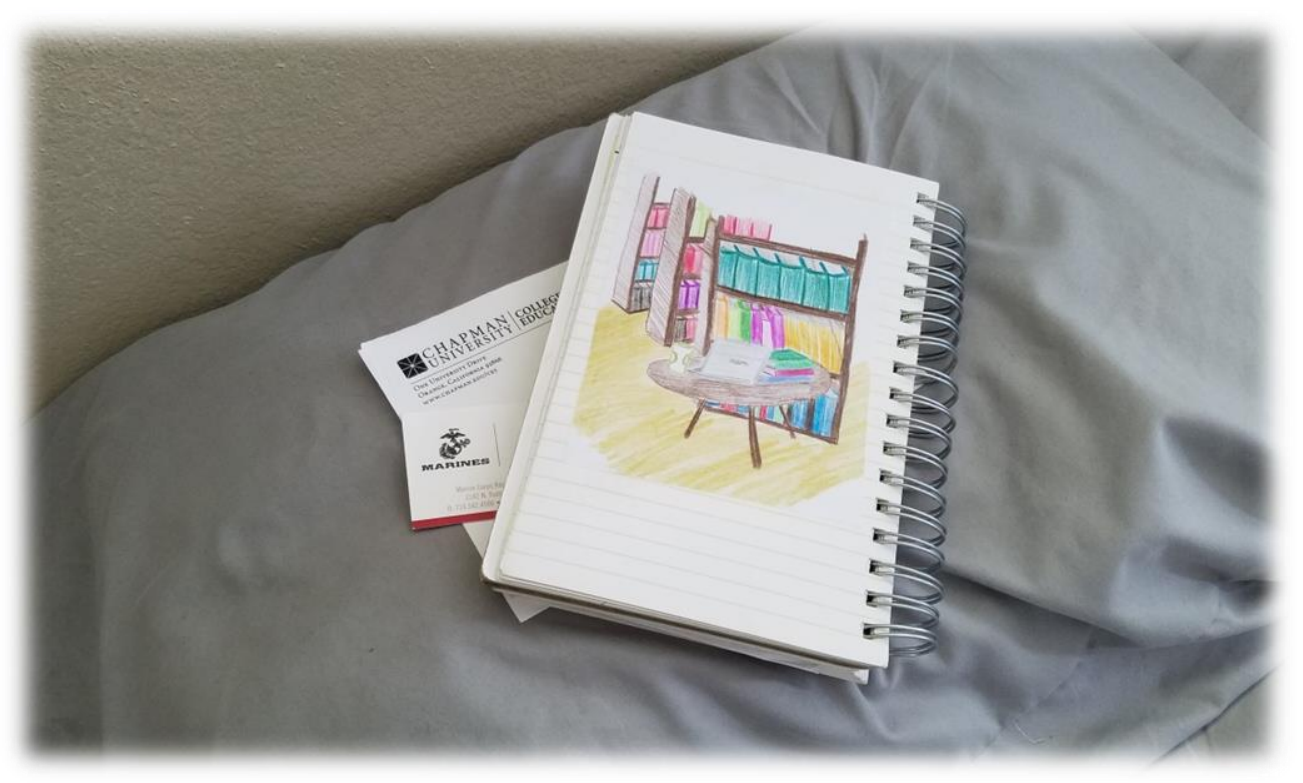

\section{Dreams, Dialogue, and Other Developments}

Jamie woke up that Thursday morning, her head almost spinning with ideas. I

was actually at the cafe, but Jamie needed to get the information somehow. So I figured having her there as a fly on the wall in a dream state was the most efficient way to share the knowledge and wisdom that resulted from the conversation with Paulo, Erich, Carl, Karl, and myself. While it was "only a dream" it greatly impacted Jamie. It was the next piece that she needed for the work with The Unit.

She walked out of the bedroom and began her morning routine. As she showered, she reflected about the oddity of remembering her dream with such detail; she was replaying the conversation we had about her in the dream, over and over again in her head. While she brushed her teeth, she contemplated critical theory in relation to Veterans and higher education. As she woke up her boys, she focueds completely on the chaos of getting a four-year-old and six-year-old dressed, teeth brushed, and to school on time, ready for the day. After she successfully dropped the young eager minds at preschool and kindergarten, respectively, she returned home. Jamie walked into the 
empty house, except for her dog, and slowly closed the front door. After taking 10 steps, she fell into the couch, heavy with an endless and overwhelming conversation within her brain.

Now, I am the goddess of wisdom, and even I was captivated with the focus on Jamie's face and the weight of the thoughts racing in her mind. I sat next to her on the couch, not that she saw me at that moment. If I were to do that, it might lead to Jamie believing she had a psychotic break. Appearing to people with an intellectual and psychology background takes more finesse than materializing out of nothing. As I sat there, Jamie pulled the hood of her sweatshirt over her head, to help her think. I laughed a great belly-laugh; sometime similarities are signs of a great selection.

Jamie began to think about what started this whole process; those two Marines and a Sailor who were the inspiration for the investigation. How could she honor them? What would be the best way to make sure that their stories were heard and understood? She knew that there was no one answer or story about Marines in transition that could be labeled as "The Story." In fact, the possibilities of different individual experiences seemed infinite, yet "each [Marine] has a different 'angle of vision' that touches a common world' (Bach, 2007, p. 282). So together, the task of The Unit was to find some of the common truths that bring Marines in transition together, while adding to the multiplicities and diversity of experiences that are plausible stories (Bowman, 2006; Clandinin, 2013; Chase, 2011; Delgado, 1989; Gilligan, 2015; Leavy, 2015; Sermijn, Devlieget, \& Loots, 2008; Siegesmund \& Cahnmann-Taylor, 2008). Just as Jim Garrison (1997) once wrote, "For even if someone had complete knowledge of the world as it actually is, even if that person could complete the mistaken quest for absolute certainty, 
the moral questions would remain: What should I do? How ought I respond?” (p 1).

Even if there was one story to discover, how would it be created? As the story was one that people needed to hear, how could The Unit tell the story to others?

Jamie continued to think, while she opened her journal and happened upon a found poem from a series of interviews with Marines:

\author{
Rugged, Ruthless \\ Elite, Proud, The Best \\ First ones in \\ President says "I want Marines" - we go \\ Bad boys of the military \\ They panicked every time they saw us
}

Fight

Kill

Kill? Left with no choice

Train

A robot, "sir" "ma'am"

Left hand, left knee, right hand, right knee

If you don't fear pain, then you think straight

Body can do unbelievable things, let it do it

Refusing to quit...

If you quit, you were gonna have a problem

Forced to do it

Not comfortable

Challenge

Doesn't get harder than that

If I do make it, then I'm going to be amazing

They issue you your Eagle, Globe, \& Anchor

You're a Marine

A well-trained, elite fighting machine

She thought about the poem and began making notes in her journal, specifically about The Unit - Jamie and a group of Marines. They were my heroes, my Marines, who I supported then, and in the future, just as I supported Perseus, Odysseus, and Hercules in 
the past (Roberts, 2008; Schwab, 1977). My care for them as individuals increased my desire to ensure the research story was honest and authentic to who they were as Marines and complex human beings.

So, what did Jamie know already? She knew that to be a Marine meant to be part of the iconic brotherhood of the Corps that was evident in the motto Semper Fi, a shortened version of Semper Fidelis, meaning "always faithful” in Latin. "This does not misrepresent the phrase; it simply symbolizes the ability of common people to become part of a brotherhood that demands more of its members than any other comparable group in the world" (Beck, 2005). Certainly, it was more than a motto, it was a core value imbedded into the heart of every Marine. Along with that core value, was the perception that Marines are the finest members of the armed forces; a perception that exists within the Corps, as well as in civilian society. A 2011 Gallup poll found that $46 \%$ of Americans believe that Marines are the most prestigious branch of the military; a distant second was the Army with 22\% (Newport, 2011). The USMC was also known "as one of the world's toughest fighting forces" (David, 2008, p. 5). This concept remained central to the Corps, as they worked on their future vision (officially called the Marine Corps Capstone Concept) where they hoped to build a Corps that remained true to the history while growing and developing to one that "exploits the advantages of being fast, austere, and lethal" (USMC, 2014).

Jamie also realized that the lethal image of a Marine could be accompanied by fear or intimidation, a strategic benefit for the battlefield. Yet, that same impression could be a hurdle for the transition to civilian. In fact, time and time again, one of the most difficult aspects of the transition to civilian was reported to be the loss of the team 
(Ackerman et al., 2009; Bellafiore, 2012; Hinojosa \& Sberna Hinojosa, 2011; Hosek \& Martorell, 2009; Kok, 2015; Lang, 2013; Livingston \& Bauman, 2013; Junger, 2014; Miller, 2013; Rumann \& Hamrick, 2010; Wiliams, 2013). Loss of a team, combined with the Semper Fi mentality, Jamie thought would make the transition out of the Marines even more difficult for members of the Corps, than say the transition of a solider from the Army. General Louis H. Wilson, 26th Commandant of the Corps, added support to her thought with his reminder to Marines of their duty, in 1975, that

What the Marine Corps becomes is what we make of it during our respective watches. And that watch of each Marine is not confined to the time he spends on active duty. It lasts as long as he is "proud to bear the title of United States Marine" (Marines.com, 2014).

The brotherhood embodied in Semper Fi, which was key to the essence of the Corps, also brought with it an endless "watch" or responsibility for the men and women of the USMC, during and after their active duty service. They were never fully "done" with the Marines, as the title "Marine" would follow them for years. Jamie remembered her father telling her that when he was in boot camp, they told all the recruits that once they were a Marine, the title would follow them everywhere. "Look at the newspaper," he said, "if they were a Marine it says so. Hell, they even care that the actor in the new Star Wars movie is a Marine. But they told us, 'If you do something good or bad, for the rest of your life, your name will be preceded with Marine. So, make sure you don't tarnish our beloved Marine Corps” (M. Steponovich, personal communication, 17 December 2014).

It was that title, and all the responsibility it entailed, that often led to Marines living civilian lives with personal expectations that exceeded the average citizen. This 
was particularly true for Marines when they became students on college campuses. It was true for the Marines of The Unit as well. Making The Unit, in a way that honored them as Marines, a qualified group to examine the move of a Marine into life as a civilian and student, acknowledged that one "can't be alive and not be a Marine" (M.

Steponovich, personal communication, 17 December 2014) or the fact that there is "no such damned thing as an ex-Marine" (Mundy, 1998, p 15).

As Jamie continued to think about Marines, she started to get a bit hungry. Intense thinking often increased her appetite, usually for sweets or carbs, or sweet carbs! So, she put her journal on her desk, and headed toward the kitchen. There was nothing that looked good in the pantry or the fridge, so being inspired by her dream, Jamie headed out to Café Intelligentsia for some lunch. It was the perfect opportunity to meet Jamie and talk with her in person. Remember, I had to stay away from the possibility of being viewed as a hallucination. So, my joining her at the cafe were appear as destiny. Jamie grabbed her journal, her purse, and her keys and was out the door in a matter of minutes.

When Jamie arrived at Café Intelligentsia, it was packed. Almost every table was taken, except one in the back with two chairs. She took the chair with the high back and began to think about what she wanted to eat.

"Good afternoon, Jamie" Tallulah greeted her. Jamie had become a regular at the cafe.

"Same to you! Any specials or recommendations for breakfast?"

Tallulah looked at the pensive look on Jamie's face, smiled, and walked toward the kitchen as she yelled "I have just what you need."

A few minutes later, Jamie was thoroughly enjoying a cinnamon roll, fresh from 
the oven, with an iced cold glass of milk. She was happy, and she began to really think about what she needed to do. She pulled out her journal and wrote done one word:

\section{Marines}

Jamie knew that one of the important ways that she was being true to these Marines was by focusing only on Marines. When the members of The Unit were discharged, they left their brotherhood in the Corps for life as individual civilians, sometimes that led to feelings of discomfort (Livingston \& Bauman, 2013). Being away from their former units, and unable to connect with civilians (Cropsey \& Hendrickson, 2013; DiRamio et al., 2008), often led to feelings of isolation and loneliness. She remembered Sebastian Junger's Ted Talk, "Why Veterans Miss War”:

Think about all these soldiers having an experience like that, a bond like that, in a small group, where they loved 20 other people in some ways more than they loved themselves... and then they come home, and they are just back in society like the rest of us are, not knowing who they can count on, not knowing who loves them, who they can love, not knowing exactly what anyone they know would do for them if it came down to it... That's why they miss it, and that's what we have to understand and in some ways fix in our society (Junger, 2014, 11:21).

So, the fact that The Unit was only Marines who experienced combat provided a place for them to connect with each other, to be crude, real, and safe, without inappropriate questioning about those experiences (DiRamio et al., 2008; Rumann \& Hamrick, 2010). The hope was to recreate the prior bonds of brotherhood in some way, as being with other Marines would provide a feeling of safety allowing them to really relax (Ackerman, et al., 2009; Barry, Whiteman, \& Wadsworth, 2014; Bellafiore, 2012; Kok, 2015;

Livingston \& Bauman, 2013; Phelps, 2015; Rumann \& Hamrick, 201; Veteran spouse 
focus group participant, personal communication, 16 August 2014).

Another moment of insight, and another word in the journal:

\section{Culturally Responsive Methodology}

Jamie was working with Marines to examine their transition in a way that did not demean them or ask them what they were lacking. Her plan to "resist superiority and self-interest to promote humility, humanity, and empathy not for individual gain and reputation but to serve the social good as determined by the community" (Berryman, SooHoo, \& Nevin, 2013a, p. 17) was what being a culturally responsive researcher was all about. Culturally responsive methodology came from the blending of critical theory, which had already framed the work so much, and Kaupapa Māori Theory, which focused on challenging the creation and determination of valid knowledge (ibid.). The fact that Veterans, in general, were viewed by civilians as broken or having challenges in transitioning to civilians as result of their deficiencies was an example of the Veteran's powerlessness to construct their own valid knowledge. They were instead forced to live in a society that saw them only as "Heroes" or "wounded warriors," never asking the Veterans what they saw, what they wanted, or what success meant to them in their own words. There was, without a doubt, a culture of Marines, and it was through culturally responsive methodology that Jamie worked with Marines to answer some of the questions about what it meant to transition and how they navigated becoming a civilian and a student, while always remaining a Marine.

One crucial piece of culturally responsive methodology was that "participants and researcher are encouraged to bring their identities and ideologies to the research table so that these authentic selves inform the co-creation of new knowledge in a third space, the empty space between the self and the other" (Berryman et al., 2013a, p. 5). The idea of 
all the members of The Unit bringing their whole selves to the research table meant that Jamie would also bring all of herself. Jamie brought her deep respect and appreciation of the men and women in the military, as well as her affinity, or bias for Marines. She could not deny the impact of her father, a Marine. As a result of her father challenging Jamie to be her own person, while also supporting her with his resources, power, and backing, she was able to pursue opportunities that were not offered to everyone. She was able to grow into an educated, creative, and empowered female who was able to support others, inspire conversation, and add to the overall wisdom of the world. Yet, while she supported the heroes, it was always from a place of safety and privilege. Just as my immortality allowed me to risk nothing in my support, Jamie was never in harm's way. Also, she acknowledged that as the researcher, even though the work was with the Marines, there was privilege and power inherent in that role. Yet, Jamie was a culturally responsive researcher. She was aware of that power dynamic and actively worked to create the dialogue and relationships with The Unit that led to work that was co-created together (Berryman et al., 2013a).

Jamie was excited to use culturally responsive methodology, because it meant she was able to bring herself as a mother into the research. Jamie was a mother before anything else, and it was her mothering care and concern that was core to who she was. As a mother, she was intimately aware of the constant and crucial balance of strength, support, nurturing, and guidance. Nurturer was a role that she could not separate from herself, regardless of where she was or what she was doing. I thought we had that in common, as one scholar summarized me, quite graciously, as "A warrior capable of exhibiting great tenderness, powerful yet surprisingly sensitive and compassionate... one 
of the most interesting and complex of all the Greek gods" (Roberts, 2008, p. 43). I had the honor to inspire The Unit, that Jamie was a part of as herself, with all of her complexities of emotions, politics, interpretations, and ideas (Harrison, MacGibbon, \& Morton, 2001), just as the other members of The Unit brought who they really were. The result of that beautiful reality was that together all of the members of The Unit created a research story that was rich and thick. At the same time, they were all impacted by one another and the relationships formed to co-construct the research story (Ferguson \& Ferguson, 2000). These relationships were based on reciprocity and research through conversations and care (Harrison et al., 2001) and continued beyond the research story. Also, Jamie remained true to the leadership through service values that were core to who she was, as culturally responsive methodology and servant leadership have similar tenets of respect, empowerment, democracy, and collaboration.

Jamie remembered her strange, very detailed dream from the night before and added a few more words to her journal:

\section{Theories - Veteran Critical, Humanistic Critical Pedagogy}

Then she looked up and saw me. Now, I was not in my god-like form; that would have been awkward. Today, I looked like Jamie's friend and mentor, Rose Mary. Rose Mary had moved out of the state, so the possibility of her actually walking into the cafe was almost non-existent. Also, Rose Mary was a former professor, so her ability to speak with Jamie about academic concepts and theory was going to useful in this situation. You see, I was pretending to be Rose Mary to work through some of the concepts for The Unit with Jamie. It is not the first time the gods have taken on human forms to meddle in the affairs of mortals (Rose, 1959). Jamie needed to believe I was Rose Mary for it to 
actually work.

"Rose Mary, fancy meeting you here!" Jamie said as she walked over and gave me a hug.

"I came out for a quick visit, and I have seen that you have been raving about this place on Facebook, so I figured I would give it a try. Running into you here, is an unexpected and wonderful treat." I pointed to Jamie's chair, with her journal opened to her notes. "I see you are working on something."

"I am. And it would be great if you could join me to bounce some ideas, and sort of help me talk through it. I am always better when I can dialogue about an idea or plan." Jamie believed I was Rose Mary, and now we could have the conversation that was crucial for moving along the work with The Unit. Let me have Jamie tell you how it went.

$\begin{array}{lll}* & * & * \\ \text { (Jamie's Voice) }\end{array}$

I could not believe Rose Mary was in town. It was perfect, since Rose Mary was always someone who could help me work through concepts and ideas so they could become real plans and possibilities. I began to talk before she sat down, "I am working on my research with a group of Marines to examine the transition to civilian, and the role higher education plays in their identity formation. I know that I am going to use culturally responsive methodologies so that I can honor the group as Marines, instead of forcing them to examine Marine experiences as civilians and students from a civilian perspective. Beyond that, I am still thinking about how to create the opportunity for the stories to flow freely, as it is through the stories that we will learn so much more and are 
able to create the research story together (SooHoo, 2013)." I couldn't forget that, so I added it to my journal:

\section{Stories - Narrative Inquiry}

Rose Mary looked at me, "What about art? 'The arts, at their best, are known for being emotionally and politically evocative, captivating, statically powerful, and moving. Art can grab people's attention in powerful ways' (Leavy, 2009, p. 12). Also, art provides 'resonance, understanding, multiple meanings, dimensionality, and collaboration' (Leavy, 2009, p. 16) making artsbased research the perfect tool for working with The Unit.”

I knew that arts based research was the magnificent fusion of art and science (McNiff, 2011). Or more accurately, art allowed us to feel what we discover through science (Bruce, et al., 2013; Eisner, 2008). That was because:

The arts are ways to get a natural high. This high is secured largely through our sensory response to the way sound is arranged, as in music; to the way colors are composed, as in visual art; to the ways in which the movement of a human body excites us as we experience its motion in time and space, as in dance. " (Eisner, 2008, p. 4)

Incorporating the arts into the research creation would be a wonderful way to bring both imagination and emotion into the process intentionally (Eisner, 2008).

Indeed, arts would allow for more creativity in the co-construction of the research process and "in the creative process, the most meaningful insights often come by surprise, unexpectedly, and even against the will of the creator" (McNiff, 2008, p. 40). The journey was richer and presented surprising new paths, resulting in greater complexity in "our understanding of some aspect of this world" (Barone \& Eisner, 2012, 
p. 3). The fact that arts are often used for therapeutic processes is proof of the power of arts accessibility and natural ability to form connections between the work and the audience (Leavy, 2009). Also, "through imagery, movement, music and poetry, researchers can holistically represent knowledge and generate emotional as well as cognitive understandings" (Bruce, et al., 2013, p. 24). Those understandings illuminated through art might be lost in the translation to the traditional words of research writing. I was already thinking about what aspects of arts based research The Unit would engage with. I didn't want to forget it, so I added another word to my journal:

ART
I was excited, after all that thinking, I finally responded. "I agree, arts based research is a key element to making the work with The Unit effective. 'Bringing together the systematic and rigorous qualities of conventional qualitative methodologies with the artistic, disciplined, and imaginative qualities of the arts acknowledges the power of art forms to reach diverse audiences and the importance of diverse languages for gaining insights into the complexities of the human condition' (Cole \& Knowles, 2008, p. 59). It also enables us to see what we failed to notice before (Barone \& Eisner, 2012) and to welcome the 'ordinary things with an eye for their unusual and extraordinary qualities' (McNiff, 2008, p. 37). On top of all of that, it opens up the opportunity to be more creative. Yet, there are still some things that I need to consider about using arts based research."

"You are going to tell me that it isn't accepted as 'real' research by some, aren't you?" Rose Mary questioned with just enough distaste to make sure I understood that she thought such a belief was ridiculous. 
"If I know and dispute the arguments against it before anyone else brings them up, then I make my case even stronger. You know, the best defense is a good offense." "You were raised by a Marine!" she laughed. "So, what is the first argument against art?"

"Well not necessarily arguments. Elliot Eisner (2008) came up with five tensions involved in arts based research. The first of which is about the ambiguous nature of art. The beauty of art is that it can represent or illicit a variety of reactions and emotions, so it can be problematic to find the 'common understanding' that is often sought through research (Eisner (2008)."

Immediately, she responded. "Yes, and it is the ability for art to speak directly to each individual that makes it so personal and reflective (McNiff, 2008). Also, the hope to find one Truth is not what you are after, nor it is in line with who you are as an individual, Jamie. You know that there is always another way to look at things. That there is a difference between knowledge of facts, the understanding of ideas, and the different ways of knowing (Eisner, 2008), making the pursuit of one 'ineffable knowledge' futile."

I nodded; she was absolutely right. "I know. The truth that I hope to find uses the definition from Dewey (1934): “"Truth” never signifies correctness of intellectual statements about things, or truth as its meaning is now influenced by science. It denotes the wisdom by which men live' (p. 34). Yet, while it is not a single Truth we seek, I must be cognizant of the fact that if we create a piece of art that is creative and original, yet fails to communicate and relate to the audience, we have failed to create a RESEARCH story (Eisner (2008).” 
"Exactly," Rose Mary was getting just as excited as I was as she spoke, "I also think that the beauty of art is that it is bound only by the imagination (Cole \& Knowles, 2008), thus enabling the creation of stories that are relatable beyond their specific context. The creator, or creators, are able to intentionally relate the work to their intended audience (Cole \& Knowles, 2008), which allows them to reach a larger audience."

At this, I almost jumped out of my seat with glee. I agreed, "Definitely! And that is Eisner's second tension. Research findings need to be 'generalizable' in quantitative terms or applicable beyond a single situation (Eisner, 2008). Arts based research is relatable to situations beyond the one presented. Also, art provides an opportunity for critical thinking skills that 'enable us to peer more deeply into situations that might not be the same as the one that we study' (Eisner, 2008, p. 21); a powerful tool for all realms of life. So, not only is it relatable beyond the context of the story, the method creates beneficial skills for life.

"Honestly, I do not understand why so many people see research as only something that deals with statistics or occurs in a sterile laboratory. Don't they know that 'socially responsible research for and by the people cannot resident inside the lonely walls of academic institutions' (Finley, 2008, p. 74). There are numerous types of research that are all valuable!

"I find that research is anything that expands knowledge (Cole \& Knowles, 2008), or as Elliot Eisner explains 'useful research enlarges our intelligence' (Eisner, 2008, p. 21). Thus, it makes sense that the third tension of arts based research is the importance of keeping the research in the forefront of the arts based research process. Because if 
something is beautiful yet fails to serve the research objective of providing new useful knowledge than it is art and not arts based research (Ibid.)."

"Yes, and equally important is the focus on art." Rose Mary eagerly added. "The aesthetic is the 'science of beauty' (Marcuse, 1955, p. 144). It is the focus to find that new information and do so in a way that provides a 'connection between pleasure, sensuousness, beauty, truth, art, and freedom' (Marcuse, 1955, p. 172). So, one must also pursue utility without sacrificing aesthetics.

"Also, it is important to remember that the arts speak to our senses, and it is through our senses that we experience the world (Cole \& Knowles, 2008). Thus, art allows for a way of knowing that goes beyond normal objective detachment and connects on an intimate, accessible manner (Springgay, 2008). It is art that gives feeling and expression to the unspeakable words and experiences. It was Dewey (1934) who said 'if all meanings could be adequately expressed by words, the arts of painting and music would not exist' (p. 77)." Rose Mary pointed around to the cafe, to the numerous pieces of art that adorned the wall, to the music that played in the background; she was full of a passion for the arts.

I completely agreed with her. The artistic nature of arts based research is equally important to the utility or science of the work. Incorporating arts based research was certainly going to add an additional way of working with The Unit, particularly in accessing difficult thoughts, emotions, and feelings. It would also provide a way to present the research story that was more accessible and relatable to others once we cocreated it.

"You know, you don't have to convince me!"” I said with a sarcastic smile. "My 
hope is to work with The Unit creating new questions and fresh inquiries that lead to potential 'answers' to be applied in the world. The need for useful information is part of Eisner's (2008) fourth tension, "to pursue novelty without sacrificing utility” (p. 24). It is the desire to find new ways to illuminate in all stages of research that can at times obscure the potential useful nature of the research discoveries. So, we, as The Unit, need to create a story that "both finds its inspiration in the arts and leads to progressive forms of social awareness' (Barone, 2008, p. 35).

She smiled back, "I know it can happen!"

I continued, "And, I must also be sure that our creation is not just a collection of my subjective musings (Eisner, 2008). The final tension is about the desire to 'seek what is novel or creative and the need to create work that has verisimilitude to the furniture of the world' (Ibid., p. 25). All members of The Unit need to keep in mind that our need for an authentic story cannot be surpassed by our desire for a new and entertaining story. We do not want our research to be viewed as purely our subjective musings (Ibid.)." I hoped that things would be valuable, I was constantly questioning myself.

Rose Mary gave me a reassuring look. "Remember, Jamie, you are working with a group. It would be difficult for an entire group to agree on one 'subjective musing' story. That is another beautiful part of arts based research, you get to bring all of you into the creation process! To quote Dewey (1934), again,

The painter did not approach the scene with an empty mind, but with a background of experiences long ago funded into capacities and likes, or with a commotion due to more recent experiences He comes with a mind waiting, patient, willing to be impressed and yet not without bias and tendency in vision 
(p. 91).

You, and every other member of The Unit, has to be themselves, use what they know, and embrace their own knowledge, including how they came to know (Jankie, 2013) to construct something that is uniquely of The Unit, colored by the individuals who create the group. That co-creating process builds in less subjectivity on your part."

"True. And that is key to culturally responsive methodology as well." I replied as I took a drink of milk after I finished chewing. I still had half of my cinnamon roll left, and it was too tasty to not finish. "It is important that my work with The Unit incorporates arts based research while remaining true to culturally responsively methodology. This means I enter as humbly and authentically as possible; so that I can listen and learn, and so that we can create connections of mutual respect that will continue beyond the creation of our research story (Valenzuela, 2013). It also means listening to all the stories, not just the stories that I like, agree with, or that support my ideas at the time (Cook-Sather, 2007). It means that we can do more than just create a research story, as we have the opportunity to create a comfortable and safe environment that enables deep and real conversations from an authentic position so The Unit can be a place for social change.

"In that effort to really work together to create social change for Marines, The Unit will engage in 'dialogue as a form of social praxis so that the sharing of experiences is informed by reflection and political action' (Macedo, \& Araújo Freire, 2005, p. xvii). As a group, we will engage in the critical pedagogical activities that are key to culturally responsive methodology as we critically examine of the role of Marines in society today (Burbules \& Berk, 1999). The hope is 'to look at and problematize the lives, 
experiences, or cultures [we are] researching through the eyes of the participants themselves' (Jankie, 2013, p. 101). While it may be uncomfortable at times, with the support of The Unit for each other and with one another, we can challenge our biases and assumptions together (Nodelman, 2013, p. 163). The culturally responsive methodologies will help create a space to discuss 'ideas that will guide us toward the critical road of truth, toward the reappropriation of our endangered dignity, toward the reclaiming of our humanity' (Macedo, \& Araújo Freire, 2005, pp xvii-xviii). Art will help in this process, as Dewey (1934) says:

Art throws off the covers that hide the expressiveness of experienced things; it quickens us from the slackness of routine and enables us to forget ourselves by finding ourselves in the delight of experiencing the world about us in its varied qualities and forms (p. 108).

The Unit will use art and dialogue to work toward critical consciousness that will allow us, as a group, to make changes that are in line with what Marines want, not what civilians think they need. As Valenzuela (2013) says 'An authentic person does not try to superimpose any preconceived agenda on the participants. Instead, they seek to learn from others and to grow with others through mutual trust and respect (p. 82).' Thus, together we will reflect, examine, and make meaning of the world in hope to create a research story that will change the world for Marines, and potentially other Veterans as well (Burbules \& Berk, 1999).”

Rose Mary nodded in approval. "So, what you really want to do is conduct research in a way that is more empowering, democratic, and inclusive so that you can create social change. From what I know about culturally responsive methodologies and 
arts based research they sound like a perfect blend to make that desire a beautiful reality."

"I think they are." I responded with a conviction and satisfaction that I felt to my core. "It is also the fact that 'the desire to give voice to those who are often marginalized through methods that are more inclusive and empowering' (Conrad \& Campbell, 2008, p. 250, as cited in Walsh, Rutherford, \& Crough, 2013, p. 121) that is part of arts based research is also a key element of culturally responsive methodologies. Thus, remaining true to the stories, the interpretations, and the growth of the Marines through the process is enacting the blend of arts based research and culturally responsive methodologies, as well as being true to myself. I agree with Harrison and their colleagues (2001), who stated that 'we are drawn to research approaches that do not dehumanize people - to research approaches that acknowledge the complexity of people's lives, approaches that challenge preconceived notions of what is already known and establish scientific fact' ( $p$ $325)$.

"That means that our work in The Unit will help disrupt the current narratives about Veterans that allow for only two extreme possibilities. 'At one extreme, it's the story of the veteran as the superhero - unstoppable and iconic. At the other extreme, it's a narrative that frames the veteran as 'broken,' whose life course will be defined by posttraumatic stress, domestic violence, suicide, unemployment and homelessness' (Haynie, 2012, para. 9). The Unit, like the entire population of Veterans, will not fit into only those two extremes. They are real, distinct individuals who belong to a group who is often denied the privilege of being 'complicated, internally diverse, or contradictory' (Tuhiwai Smith, 2012, p. 77). I hope that the research story constructed by The Unit will aid in disrupting the narrow and damaging narrative that currently exists in mainstream 
media."

Rose Mary leaned back, "That is no small feat, Jamie!"

I leaned more forward, "Yes, and I am the daughter of a Marine, working with other Marines; we are up for the challenge!"

She laughed. "I believe it was Elliot Eisner (2008) who said that 'The arts are a way of enriching our awareness and expanding our humanity' (p. 11). My goal is that The Unit can provide the civilian world with a bit more humanity!"

"I hope to expand my humanity!" I exclaimed. The Unit provided a great learning experience for all of us that were involved. As we talked about it, Rose Mary and I grew more and more passionate.

I added, "Also, the blend of arts based research and culturally responsive methodology creates a wonderful opportunity to be transformative or healing for those involved. So, using the arts will allow conversation that 'promotes a level of dislocation, disturbance, disruptiveness, disequilibrium that renders it sufficiently - even highlyuseful, and therefore, in this unusual sense of the word, truthful' (Barone \& Eisner, 2012, p. 16). That may be uncomfortable, so the culturally responsive methodology lends itself to the creation of an environment and process that makes the difficult conversations as comfortable as possible. The need to listen, openly and without assumptions, is crucial in culturally responsive methodology, arts based research, and transformational leadership. Those three ideas combined guide The Unit's work and suggest a more casual setting (Livingston \& Bauman, 2013; Rumann \& Hamrick, 2010) away from "the isolated sanctuaries of the laboratory and constructed and bounded environments to places where people meet" (Finley, 2008, p. 74) is the best setting for honest dialogues. The casual 
atmosphere will naturally promote conversation and humor among the group (Macfarlane, 2013). Being the person that I am, I will not judge nor be offended by the crude conversations that might occur. Such comfort and authenticity will provide a place for healing. While a place of healing is not sought by many Marines, yet we all benefit from such an experience, because:

Healing is about reconnecting to your roots and reclaiming for you really are. Without this sense of reconnection to your roots, you would be lost in where you are going... Healing is also about being whole. It does not enhance one's domination over others but promotes harmony and balance not only among human beings but among all beings, including nature, animals, and the supernatural (Mayuzumi, 2006, pp 12-13).

The Unit will be able to serve their brothers once more as they support each other in the healing process."

Rose Mary mused, "I believe it was Schiller (as cited in Marcuse, 1955, p. 187) who said that 'One must pass through the aesthetic, since it is beauty that leads to freedom'. I hope and believe that is what you will do as The Unit."

"Indeed, the co-creation of the artistic research story can be an experience, as defined by Dewey," I responded. "He said that an experience is transformational. Specifically, he said that:

A piece of work is finished in a way that is satisfactory; a problem receives its solution; a game is played through; a situation, whether that of eating a meal, playing a game of chess, carrying on a conversation, writing a book, or taking part in a political campaign, is so rounded out that its close is a consummation and not 
a cessation. Such an experience is a whole and carries with it its own individualizing quality and self-sufficiency. It is an experience (Dewey, 1934, p. $37)$.

The experience is more than just going through the motions, as the use of the arts often creates an energy and investment that delves deeper into the being of those engaged in the research. That added energy will enhance the ability of The Unit to fully participate in the process, and thus be altered by its completion (Dewey, 1934)."

Rose Mary leaned forward, with a bit of concern, reminded me. "Don't forget that the idea of 'completion' will not happen really. Arts based research is just like art, a continuous process that is never finished. 'An engraver, painter or writer is in the process of completing at every stage of his work' (Dewey, 1934, p. 58). There is always a change you could make, an improvement, an adjustment, just one more thing (Garrison, 1997). At some point you as the artist, the writer, or the arts based researcher, has to walk away and be satisfied with the piece as it is. "

"I know." I surrendered to the weighty responsibility of always being in the process. "It is much like Freire's (2000) unfinishedness and the process of becoming. I had a crazy dream last night that Athena, the Greek god, had a conversation about that constant, reflective process with Paulo Freire and Carl Rogers. It is one of the most exciting and intimidating aspects of this journey. It is exciting because it means that there is always work and progress to be made. Yet, it is intimidating since it is reminder that we are never done. Never. The idea of finality is unavailable. While that is daunting, that lack of finality is also comforting. The idea that we, as people, are always in the process of growing and developing is, in many ways, a relief as well as a call for 
continuous growth. We never have to know everything, as there is always something more to know. There is a deep beauty in such a state of being (Fromm, 1976). That same constant process is also true of art. So, while it is a bit unnerving, it is also a wonderful adventure that has no specific end.

"Also, if you think of what Dewey said of the arts, it is never done until it is experienced. Once experienced it is changed, thus it is always in continuous development as 'what is done and what is undergone are thus reciprocally, cumulatively, and continuously instrumental to each other' $(1934$, p. 52). Thus, once the story is written, and even that story is incomplete as The Unit continues to live and write their stories, it is changed by the fact that it is written, and then experienced. It is a work of art, in a constant 'act of reconstructive doing" in a way (Dewey, 1934, p. 54). But that dynamic constant growth and change is life!"

"Jamie, I think what The Unit is going to do is incredibly exciting. You will use the arts to create something together, learn and share wisdom with one another, seek justice for Marines who have a variety of experiences that are often ignored, and build a community that will provide possible healing for all of the members. That is a big undertaking, and it is something that "challenges the comfortable, familiar, dominant master narrative, not by preferring a new totalizing counter-narrative, but by luring an audience into an appreciation of an array of diverse, complex, nuanced images and partial, local portraits of human growth and possibility' (Barone, 2008, p. 39). It will be a wonderful adventure."

I looked down at my journal, and my random assortment of notes: 


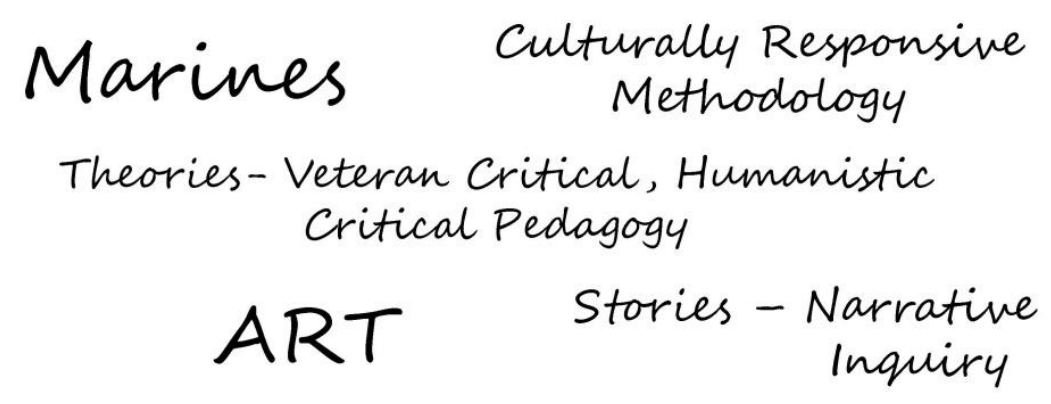

I sat up a bit straighter and smiled "I hope so! And I think the blending of culturally responsive methodology and arts based research will lead us to collaboratively create something that 'politely but powerfully, that is to say, artfully...makes one wonder about what [the world] should and can become' (Barone, 2008, p. 47). I am definitely excited about this journey and ready to begin working with The Unit. We get to create the story together and it will be one that honors their varied experiences and voices."

Rose Mary looked satisfied. "Jamie, it was great talking with you. And I love this little cafe. Although, we were so wrapped up in the conversation, I never ordered."

"I'm sorry about that" I apologized. I had not meant to keep her from the delicious food; I was just so excited to see her I jumped at the opportunity for dialogue with her.

"Not a problem. Although, I do need to get going, as I have lunch plans." We both stood. "Good luck, Jamie. I know that The Unit will do some great work."

“Thanks, Rose Mary!” I hugged her goodbye. "I'll send you the finished piece when I'm done."

"That would be lovely!" She replied. It was such a serendipitous occasion running into Rose Mary, and the conversation was exactly what I needed to continue moving forward with The Unit. I was excited to see what would happen next. 


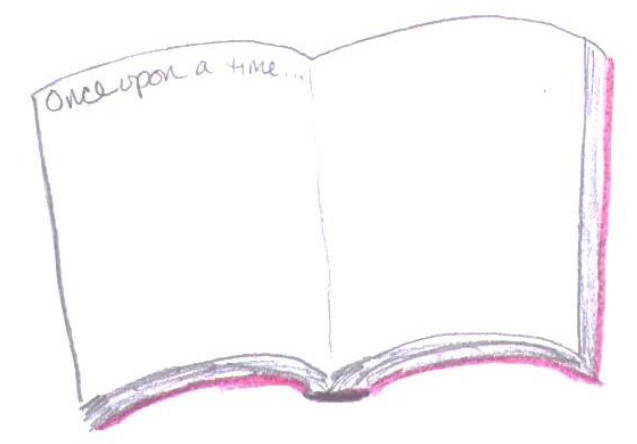

\section{Becoming a Storyteller (Jamie's Voice)}

After Rose Mary left, I headed back home. In the car, I remembered Charlotte's words at the cafe. "Just be sure that before anything else, you listen (Shay, 1995, as cited in Gilligan, 2015). “

If was invited into the story, I had to listen first. Everything within arts based research, culturally responsive methodologies, transformative leadership and leadership through service had already pointed me to the importance of listening first. "True listening builds strength in other people" (Greenleaf, 2008) because a bond is created out of empathy, trust, and love that leads to understanding. Thus I needed to listen toward empathetic understanding with an embodied resonance that connects through multiple senses (Bresler, 2006). I had to listen to what was said, when, and to whom in the story, so that the collaborative investigation could then 'listen under parts of a narrative with an ear to how marginalized and oppressed people negotiate their lives' (Miller, 1976, as cited in Sorsoli \& Tolman, 2013). That was the beauty of narrative inquiry, a valuable method within arts based research, it allowed us to see the change in the hegemonic discourse, or the dominate dialogue that was often taken as truth even though it failed to recognize the varied and diverse experiences and beliefs among people (Bowman, 2006; Clandinin, 2013; Chase, 2011; Delgado, 1989; Gilligan, 2015). As Wayne Bowman 
(2006) said, 'Narratives give us alternative descriptions of things, different truths and realities: they make audible voices that are ignored and silenced by theoretical abstraction and global explanation' (p. 10). As stories were born within culture, there were some life stories that were privileged above others (McAdams \& Janis, 2004), thus the use of narrative inquiry came from a desire to change the limiting story of Veterans and Marines in the media, as either "heroes" or "wounded warriors," to illuminate the plurality of authentic and diverse experiences possible for Marines in transitions.

When I arrived home, I sat back down on the couch and pulled out some books. Immediately, I found a great quote by Richard Delgado (1989): "Storytelling emboldens the hearer, who may have had the same thoughts and experiences the storyteller describes but hesitated to give them voice. Having heard another express them, he or she realizes, I am not alone" (p. 2437). I hoped that the stories of The Unit would help those who shared their experiences, as well as those who had never questioned the limiting stories about Veterans and Marines in the media as possibly being just one of many possibilities.

Yet that was the beautiful thing about stories. As Blayne Smith, Team RWB Podcast once said "Your story, while it might be unique because it is yours. Elements of it are not unique at all. That everyone has a story. They may not have experienced the exact same things you did, but they likely have experienced the same emotions" (Smith \& Junger, 2016). So, the stories of The Unit would have the power to disrupt the one narrative that continued to find traction in the public media, the idea that many Veterans were broken (Haynie, 2012; Smith \& Junger, 2016). I would use narrative inquiry, to add to the possibilities.

I thought about narrative inquiry and how, like all of arts based research, it was 
rhizomatic (Deleuze \& Guattari, 1987). Rhizomes, from the Ancient Greek rhizoma for "a mass of roots," were plants with horizontal roots that amass underground, then plants shoot up from those roots (dictionary.com). I was reminded of the time I tried to remove a rhizomatic plant from my back yard. Tried and ended in defeated. The knotted, intertwined, mass of roots made the complete removal a huge feat; each attempt to remove one root resulted in the discovery of another. Yet, a similar experience existed within arts based research; we would "create and critique, challenge and explain" (Siegesmund \& Cahnmann-Taylor, 2008, p.234), and not discover "the answer," "the truth" or "the real story." The Unit was about possibility, multiplicity, and diversity (Bowman, 2006; Chase, 2011; Sermijn et al., 2008). The rhizome, the plant and the metaphorical investigation, had a plethora of origins and pathways that were not ordered or hierarchical (Deleuze \& Guattari, 1987), and regardless of which to entryway was chosen, it led to a connection and engagement in the "dynamic construction process" (Sermijn et al., 2008, p. 639) of the story. This was certainly true for The Unit.

Part of that interconnection was the reciprocal aspect of the relationships that occurred in The Unit. Each of us had to be able to be vulnerable. Together we would share, each Marine and The Unit as a group, so that all of the stories were shared in 'a process of collaboration involving mutual storytelling and (re)storying as the research proceeds' (Connelly \& Clandinin, 1990). It was through a dialectical nature that 'a rich tapestry of conversation, of stories' would be created, so that we would be able to transcend 'the unthinking convention that our way of seeing the world is the only one' (Delgado, 1989, p. 2439). In fact, there was no "one way," because "not everything is knowable, and that wisdom distinguishes between what we can possibly affect and what 
is beyond our grasp" (Siegesmund \& Cahnmann-Taylor, 2008, p.234). Narrative inquiry was about finding direction through "deliberation, inquiry, and imagination" (Barone \& Eisner, 2012, p. 158), as all of arts based research was in pursuit of possibility, plausibility, plurality, and not certainty (Clandinin, 2013; Leavy, 2015; Siegesmund \& Cahnmann-Taylor, 2008). It was a research journey that presented a sort of pleating, with numerous possibilities all connected, unable to be separated, and thus leading to an even greater amount of potentialities (Irwin \& Springray, 2008).

As I got off the couch and walked to the kitchen I admitted that there was no way to examine all the possibilities. That would be impossible, particularly since even our own stories are ever-changing (Bresler, 2006; Chase, 2011; Connelly \& Clandinin, 1990). I hoped to work with The Unit to create a story, together, that offered a different way to understand the experiences of Marines transitioning to civilian and student. The story was born in collaboration, "over time, in a place or series of places, and in social interaction with milieus. [I enter] ... in the midst and ... conclude the inquiry still in the midst of living and telling, reliving and retelling" (Clandinin \& Connelly,2000, p. 20). I knew that although the final story may appear permanent, it was temporal.

A written document appears to stand still; the narrative appears finished. It has been written, character's lives constructed, social histories recorded, meaning expressed for all to see. Yet, anyone who has written a narrative knows that it, like life, is a continual unfolding where the narrative insights of today are the chronological events of tomorrow' (Connelly \& Clandinin, 1990, p. 9).

Yet, before I could even think about the story that was created with The Unit, I began with a plan to illuminate those stories they had already lived and told, were living and 
telling. This was where the process of narrative inquiry was a method that celebrated stories and was "also an exploration of the social, cultural, familial, linguistic, and institutional narratives within which individual's experiences were, and are, constituted, shaped, expressed, and enacted" (Clandinin, 2013, p. 18). Yet, how was I going to do all of that?

I opened the cupboard to get a cup and filled it with water. I knew that narrative inquiry was all about relationships with a constant, intentional negotiation based on "respect, mutuality and openness to multiple voices" (Clandinin, 2006, p. 52). I knew that through the relationships, we would think narratively about the transitioning experiences of the Marines in The Unit by examining the three commonplaces of temporality, sociality, and place throughout (Bach, 2007; Clandinin, 2013). In the temporal commonplace, we would examine time - the past, present, and future of the Marines and their lives in transition to civilian and student (Ibid.). With the notion of time, it was important that we remembered that "simultaneously participants [were] in, and tellers of, life stories" (Ibid., p 45). In the process of telling a story, we were changed and the story may be changed as well, an "meaning is achieved and enhanced as portions of the world are constructed, organized, and disclosed" (Barone \& Eisner, 2006, p 100). The dynamic and continuous nature of storytelling was part of life and the experiences of those living it, yet it was not the only impact on our life narratives.

The relationships throughout our past had a huge impact on how our stories were told. That was why the sociality was another place we would examine. Together, we would excavate the impact of family, school, political, and culture, both civilian and USMC, of the Marines in The Unit (Ibid.). We were not alone in our experiences, and it 
was often "where lives meet in storied ways, where spaces between open up and create the possibility of world traveling and loving perception" (Lugones, 1987, as cited in Clandinin, 2013, p. 23). The relationships were important in the process of narrative inquiry, as well as in living a storied life. We lived in collaboration with others, and thus an examination of our lived and told stories required an excavation of our relationships as well. While 'our experiences are always our own, they are shaped by the social, cultural, and institutional narratives in which individuals are embedded' (Bach, 2007, p. 282).

Lastly, I knew we would look at the actual places, the physical spaces involved in experiences. Time, place, and relationships in our narratives were all interrelated, and thus were examined in a "metaphorical three-dimension space with participants" (Ibid., p. 41). I found a quote from Jean Clandinin (2013), "Our stories are always in relation, always composed in between, in those spaces between time and people and generations and places" (p. 30). This meant that I was also within the examination of The Unit's stories; I would gather stories through my reflections, notes, and observations to aid the excavation of the essence of the story, one that contained "real, textured, complex, sensory, contextual meanings" (Leavy, 2009, p 32). I acknowledge that observations are selective (Barone \& Eisner, 2006), and I would also examine the relationships between me and the members of The Unit, as intense relationships can develop (Clandinin, 2013; Connelly \& Clandinin, 2006). Throughout the research experience, I would continue to reflect on my own experiences with The Unit and as a researcher (Clandinin, 2006).

I took a drink of water and thought back to Dewey's aesthetic experience, as most art forms tell a story, be it through music, dance, or visual arts (Bresler, 2006). Using arts based research was not just the narrative inquiry; I would use the arts in the gathering of 
the actual stories. Since "the world told is a different world to the world shown" (Kress, 2003, p. 1) the visual would become part of our work together. As individual Marines, they would create art that allowed them to tap into the unexpected, deeper connections and understandings (Barone \& Eisner, 2012; Bruce, et al., 2013; Leavy, 2009; McNiff, 2008). The art would include poetry as 'the power of a poem as a communicative device [was] in its ability to dramatically set a sensory scene fostered by attention to the space in between words, as well as to those that (literally) appear on the page' (Leavy, 2015, p 91). It would also include collage and photography, completed willingly by the members of The Unit.

Because humans are visual beings, there was great power in the image or visual creation. Visual arts are used to maintain a specific belief system or to the challenge us to see things in a new way (Leavy, 2015). Images always surround us, and it was important to note that visual art was not "a window onto the world but rather [a] created perspective... determined not only by the artist but also the viewer and the context of viewing" (Leavy, 2015, p.224)." Each visual art activity was a mixture of what the artist wanted to express, and what the viewer actually experienced.

That meant that I had to use photography. Photography empowered the perspective of the Marines, so I saw what mattered to them, in their social landscapes (Allen, 2012). It was also an opportunity to further examine the societal and temporal elements within narrative inquiry. The pictures themselves would tell a story, as well as inspire deeper and fuller stories by all of the Marines in The Unit (Allen, 2012; Bach, 2007). I would ask each member of The Unit to gather past pictures and take pictures of what made them a Marine, a student, a civilian, and their own unique being. With the 
request, we would discuss the ethics of taking the photographs of other people, as the right to privacy was a valuable and necessary reality (Allen, 2012). Through these photos they would use their voice as they decided when, how, and where to collect the images (Allen, 2012; Bach, 2007). The Marines would document and share the people, places, moments, and experiences that moved them to tell more stories (Bach, 2007), and thus tell me their identities (Banks, 2008; Gardner, 2011). After the photos were collected, I would listen to the stories that made the pictures important. My relationships with them would impact their photo selection and their willingness to share them with me. So I was sure to build a relationship where they knew the photos would "not be damaged, misrepresented, or prejudiced in any way" (Bach, 2007, p. 298). Also, throughout the entire project, the Marines would always be able ask that a piece (artwork or photograph) not be used for research or could be used for research but not for any publications or presentations.

As I sat down at the kitchen table, I asked myself about the photos themselves, beyond the stories they inspired. What would we do with the pictures? We would make collages. It would be the Marines who would create the pieces, a piece of art journaling (Chilton \& Leavy, 2014, as cited in Leavy, 2015). Art journaling would allow the Marines to create a piece on who they are - their identity. We could pull from a variety of materials including that pictures they gathered for their identities and their "I poems" from their first interviews. Also, we would write "I am" poems and they could each create found poems from The Marine's Hymn, The Rifleman's Creed, and a poem titled Semper Fidelis. The last pieces of material would be magazines (including The Marine Corps Gazette and Leatherneck) and colored construction paper that could be cut up for 
words, pictures, and shapes.

In the end, the pieces would combine words, pictures, photographs, colors, and more to present stories that might not have been presented in the interviews (Leavy, 2015). I loved the way visual creations would allow the Marines to access and express stories that would otherwise be unavailable, and the addition of visual field notes (Ibid.). Yet I could not ignore the power of the words in a story. That would include the stories they would tell about their collage.

The conversations and stories I would collect from the Marines and The Unit as a whole would be the most important piece for the creation of the research story. Part of my responsibility to the Marines, was to make "spaces for telling and listening to stories as well as the responsibility for sustaining each other" (Clandinin, 2013, p. 28). All the information gathered from the spoken stories, photographs, other works of art, and other artifacts brought in by the Marines, as well as my notes, reflections, and observations would become the "field text" (Ibid.). "Field texts are co-compositions that are reflective of the experiences of researchers and participants, and they need to be understood as such - that is, as telling and showing those aspects of experience that the relationship allows" (Ibid., p. 46). I had to ensure that we built relationships on trust and through the process I was “awake." Aware and awake, defined by Maxine Greene (1978) as An imaginativeness, an awareness, and a sense of possibility are required, along with the sense of autonomy and agency, of being present to the self. There must be attentiveness to others and to the circumstances of everyday life. There must be efforts made to discover ways of living together justly and pursuing common ends" (p. 51). 
I had to remain awake throughout the process to create the best research story possible, and that would begin with the field texts (conversations, photos, collages made with the group, text messages, email, poetry, found poetry, observations, and my personal reflections).

Once the field texts were gathered and examined in relation to the threedimensional space (temporality, sociality, and place), it would lead to "interim field texts" to be reviewed and approved by the Marines (Clandinin, 2013). It would be crucial to keep the stories together and not dismantle them in a series of codes and themes. That is a completely different type of analysis. I had to look at the stories as "texts in transition," as they would be open to input, correction, elaboration, and more from the Marines, and potentially The Unit as a whole. I began to mentally prepare myself for a time of "tension and uncertainty" (Ibid., p. 47) during the process of cocreating storied meanings and interpretations of the field texts with the members of The Unit.

I took another drink of water, and looked at the numerous books, articles, and notes that were stacked on my desk. Then, I remembered Charlotte's words once more, "Just be sure that before anything else, you listen (Shay, 1995, as cited in Gilligan, 2015)." I would use the Listening Guide to hear the voice of the Marines and get the essence of the stories (Gilligan, 2015; Gilligan, Spencer, Weinberg, \& Bertsch, 2003).

Voice in narrative inquiry was not just the sound of someone talking; the voice was 'a manifestation of the psyche, a way of communicating experience or bringing the inner world out into the open' (Gilligan, 2015, p. 69). Thus the Listening Guide was a fitting way to hear the different voices within one person's story and "is distinctly 
different from traditional methods of coding, in that one listens to, rather than categorizes or quantifies, the text of the interview" (Tolman, 2001, p. 132, as cited in Gilligan, 2003, p. 159). The process would begin with a printed transcription of the conversation with a Marine, with enough room to make notes on the transcript. (This, of course, meant that the conversations were first recorded on my handheld digital recorder.) With the transcript in hand, the Guide work would begin with at least three listenings (as it is more than just a reading) of the transcript and then an analysis (Gilligan, Spencer, Weinberg, \& Bertsch, 2003). Each listening was "intended to guide the listener in tuning into the story being told on multiple levels and to experience, note and draw from his or her resonances to the narrative" (Ibid., p. 159). Thus, each listening created visual markings (in different colors for each reading) to create a record of the analysis, and to support future interpretations.

I stopped myself for a moment and thought about the time it would take to really analyze all of the conversations I would have with the Marines. This was the method that was most aligned with my personal thoughts and beliefs, a method within Narrative Inquiry, which fell under arts based research. The Listening Guide also honored culturally responsive methodologies as it used stories, or narratives. A "narrative is simply the most powerful way to communicate connection, purpose, meaning, and value... We must communicate in stories; it is a fundamental duty of a leader of Marines" (Fleischaker, 2015, p.41). The Listening Guide was worth the work, and I would use it to tell the stories of the Marines. So, I would:

Listen first, for the plot the details in the story the who, what, when, where, why, and how reoccurring words, like love and glory 
Listen to the emotions

those expressed and those kept concealed

Listen to the essence, not just facts

as well as what the story does to me - my own thoughts revealed

(Gilligan, 2015; Gilligan, et al., 2003)

It was important that throughout the process I did not use my privilege as the researcher to persuade the stories to be interpreted to mean what I think or want them to be. Instead, the collaboration within narrative inquiry, in line with culturally responsive methodologies and arts based research, would be about listening to the Marines meanings, as it is always their story to tell. With so much to excavate, I had to always remember it was about listening, as it is being actively engaged with the text, not just reading it (Gilligan et al., 2003).

The next step would be the I Poems. An I Poem:

first-person I

I plus the verb and other important words

create a poem

begin with "I"

new stanza, new direction

begin to hear their voice

rhythm, cadence, feeling, insight

even silence is a choice

(Gilligan, 2015; Gilligan et al., 2003)

connect in ways that play with senses

yet easy to understand

"easy to enter" and engage with

a poem which gives the essence of the man

(Leavy, 2015)

Poetry "expands our understanding of social life, makes an impact on readers, expresses a reality, promotes reflexivity, and is attentive to aesthetics" (Richardson, 2000, as cited in 
Leavy, 2015, p 83).

I took another drink of water and thought about how much of my work with The Unit seemed to clash with what I knew about critical theory (Clandinin \& Rosiek, 2007), which influenced culturally responsive methodology. The idea that each individual's experiences and observations created their reality and an explanation for a phenomenon ignored the oppressive cultural and societal structures, some of the key elements of critical theory. I had struggled with navigating that duality. As I sat at the kitchen table, I realized it was 'both, and'.

It was in the borderland between narrative inquiry and critical theory that I found myself and the work with The Unit (Clandinin \& Rosiek, 2007). I believed that our own experience and knowledge form, or create, our identities and realities. I also believed that there were oppressive structures that maintain the power of the ruling class. I would navigate this complexity by planning to listen to the Marines, their stories told in their words, without any judgment or critique. I would move through the analysis with them to excavate the authentic transition experiences of Marines. I hoped to work with The Unit to examine the structures and cultural stories, previously accepted as truth, by using their stories (the Marine's) to illuminate the oppressiveness that limits plurality and diversity for Veterans. I hoped that we would be able to shine a light on what Richard Delgado (1989) call "intellectual apartheid" (p. 2439). I hoped that by working with, and not on The Unit, that we would enable "individual and collective movements toward social change and social justice" (Fine \& Weis, 2003, p. 4-5, as cited in Clandinin \& Rosiek, 2007, p. 63).

Another drink of water came with thoughts about the next listening; the listening 
for contrapuntal voices.

only one speaker

yet still so many voices

all internalized

(Gilligan et al., 2003; McAdams \& Janis, 2004)

I would listen for the voices that would speak to relationships and our specific research puzzle and highlight the oppressive structures in the stories of the Marines. Then, I would have one more listening to examine the oppressive structural systems (political, social, cultural, and economic) that impact their identity. At times these voices may be in conflict (Sermijn et al., 2008; Gilligan, 2015), and that would be part of the investigation into identity, as identity 'could be many different (and conflicting) things' (McAdams \& Janis, 2004, p. 161). It would also be a way to see identities that may be held, even if they distance the individual from the community that identity belongs to (Gilligan, 2015). It would be a chance to see the whole person, not just one aspect of their identity (Wheatly, Spears, \& Noble, 2004).

Finally, after I completed the multiple active and engaged listenings, I would then create a synthesized and cohesive essence of the story to then present to the Marine (Gilligan et al., 2003). The analysis would include what I learned through the process, as well as my evidence. The analysis would be ongoing, dynamic, and collaborative as we would be co-creating the research story (Clandinin, 2013; Leavy, 2009). After each interview, creation of art work, and photo collection, there would be a period of analysis that would be represented and/or analyzed with each Marine at the next meeting together to ensure the essence is accurate, inspire further stories, and focus on the co-construction of the narrative (Leavy, 2009).

The endless creation of story and analysis would occur throughout the research 
process. We would continue the process, until the point of data saturation, when further storytelling does not add to the illumination and discovery for the research story (Leavy, 2009). Following data saturation, together we would:

Agree on stories and their meaning Ensure they hang together

Write it for the world to hear

A research text endeavor

(Clandinin, 2013)

Tell the stories so more may come And bring out a greater narrative unity With more stories told and heard Transformation is a potential reality

Together "our hope is to create research texts that allow audiences to engage in resonate remembering as they lay their experiences along the inquiry experience, to wonder alongside participants and researchers who were part of the inquiry" (Clandinin, 2013, p. 51). The stories would be to share, to inspire others, and to inspire change and community for Veterans.

I thought I had it, or the formation of a realistic plan. I would begin to listen to the Marines as they shared their stories. From there, we would begin the work together.

Collaborate, create, with, not on Illuminate, discover, now we've begun

Stories, photos, collages, too Marines will lead the journey through

Digging deep and feeling scared Keeping safe, those who dared

Struggle through to find the beauty Freedom, too, that is our duty

Authentic trust and transformation An endless voyage, of our own creation

Together The Unit will create a tale to share 
A story unheard no longer, because they care

My excitement about the adventure that awaited grew. I left the kitchen table, put my water cup in the dishwasher, and headed back out the door. It was time to pick up the boys from school. The work with The Unit would be on hold for the rest of the day, yet the thoughts in my head would be continuous until the stories were finally told. 


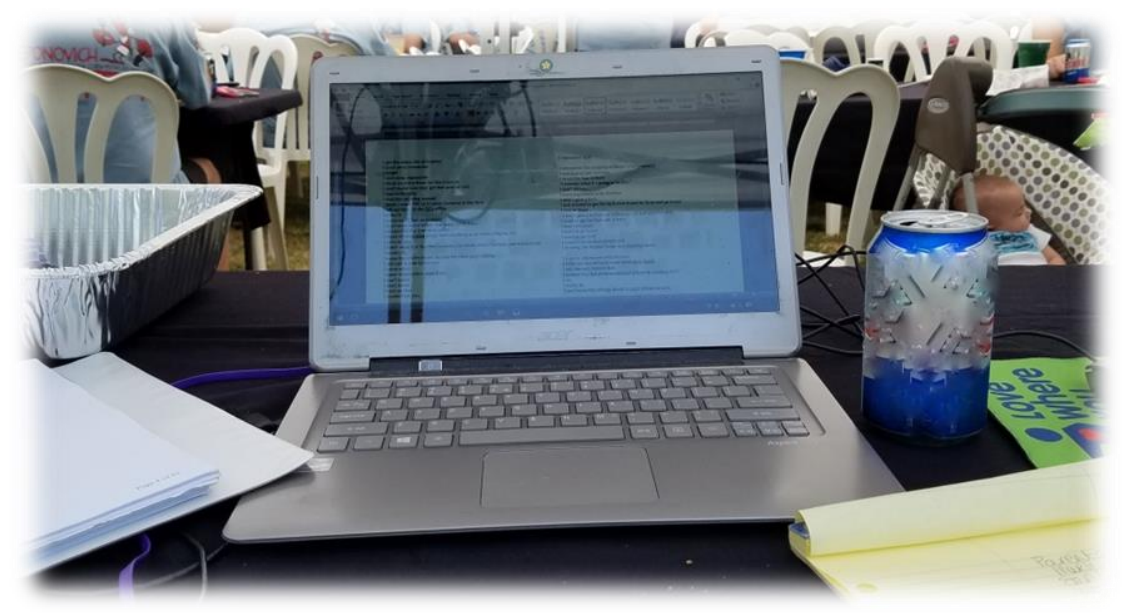

\section{Reconnaissance: The Listening Guide}

Jamie told you about her plans to use the Listening Guide to analyze the data.

Now, I will to show you what it actually looked like through the process. To do this, I will take the first interview Jamie had with Sgt. G. as an example through the full process of the Listening Guide.

Following the interview with Sgt. G, Jamie transcribed the interview then began her analysis using the Listening Guide.

\section{First Listening: Plot}

Recurring words/themes: Pride; Service; Selflessness; Others First; Earned; Elite;

Order; Hierarchy; Control; Fear; Pain; Suffering; Challenge; Transformed;

Other Marines; Comradery; Fun; Constant Vigilance; Longing; Loss

Plot: Joined to become part of something bigger, do something with his life. He deployed soon after he completed Bootcamp and MOS school and deployed often as he had four total deployments. He married first wife before first deployment. First deployment was the invasion, they followed the infantry so when his unit arrived "It was nobody, it was abandoned. It looked like War of 
the Worlds, that movie with Tom Cruise. It was beat up and burning. There was ruble everywhere." The Second deployment was the "worst," as a Marine was KIA the first night in Al Assad. They were mortared once a week, at least, during that deployment. It was also when Sgt. G earned his Combat Action Ribbon (CAR). "The last two deployments were fairly simple.” He discharged after his second deployment because he had "some stuff to take care of." His team deployed shortly after, and during that deployment, some of the guys did not make it home. "Maybe I could have changed something." Sgt. G loves the Corps "I don't regret any of it. Even the adversity, even the negatives, even the cons. It's a learning experience, you know? I think it helped shaped me, helped harden me to where I need to be hard, and given me that ... What's the word I want to use? It's given me the strength, when most people wouldn't have the strength, it's given me that strength, that will to overcome things. And it's also made me humble. And it's given me patience, lots of patience. And sometimes I don't have patience these days, I know when I was in man, I had tons. You have to. “

Key Characters: Other Marines; Patrick Gallagher (KIA April 2, 2006, OIF)

Briefly Mentioned: Dad; Brothers; Friends; First Wife; Wife

Summary: Never seen as a mentor to his younger brothers, the Marines gave Sgt. G an opportunity to be part of something bigger and support the Marines who came after him as a guide and mentor. "I love having Marines. I loved shaping them and helping foster their career... I had a lot of Marines that looked up to me, and I looked up to them too." This has become core to who 
he is - he likes to provide help and joy, to make other's lives better!

\section{Second Listening: I Poem}

I was in the Marine Corps for a total of 8 years

I did 6 months in the National Guard as a reservist

I did 8 years in the Marine Corps. The best time in my life by far

I mean aside from getting married and having children

I think the Marine Corps was one of the biggest highlights of my young adult life.

I would do it all over again in a heartbeat

I saw

I don't regret any of it

I wanted to say out of high school.

I knew

I wanted to join the service

I tried the Army

I couldn't get in for a medical purpose.

I joined the Marine Corps

I looked into the Marine Corps

I started asking questions

I'm glad

I made that choice

I'm glad the Army didn't take me.

I'd be a soldier. But, um, there's nothing wrong with that.

I won't say

I've known

I like to be challenged

I like to be challenged to the point where either

I do it or

I don't

I do it obviously

I'll get to see where my limits are

I went through that

I passed

I could do that

I could be a Marine

I'm sure you probably get that from a lot of the Marines

I felt like a real Marine

I did have that pride, that sense of belonging

I got my EGA

I did have that sense of pride and belonging

I knew

I don't get past this evolution 
I'm not gonna be a Marine

I was a little cautious

I think once they put that EGA in my hand

I was up there

I balled like a baby

I uh, you know, just like everybody else up there

I balled like a baby

I think that was uh, that was the pivotal point for me

I think it's everybody's

I don't know

I know that he (my father) wanted to join, but he didn't finish his high school

I don't know

I was already going

I was just

I'm a teenager

I did

I think my dad was very

I think that changed his mind

I think that um, he treated me a lot better

I think he had a lot of pride too

I think he was very prideful

I enlisted after. (9/11)

I actually went and enlisted

I think uh, no. No

I did sign after

I officially signed documents

I didn't ship until 2002

I was supposed to be a reservist

I signed up to be a reservist

I knew we were gonna get into some conflict

I kinda wanted to

I had a change of heart last minute

I was like, "You know what

I'm just gonna go full time

I might as well just do it all the way."

I switched my contract

I didn't have a ship date

I was a reservist, they were waiting

I did sign up as a full-blown active duty personnel

I am the second oldest

I have an older sister 
I don't think I was a role model to my brothers

I know

I finished boot camp

I went home on leave

I went to boot camp

I don't know

I went home

I just

I came home

I've had two friends

I actually work with (one) right now

I went to school with

I remember

I think one of the guys wanted to join too

I don't know what happened

I think

I see

I think um, putting yourself last, putting your country,

I think that

your community, your family...Um, service first

I wish there were better words I could use

I think that's it

I'd say, to be a Marine

I think you have to have a lot of patience

I think that's what helped me out a lot during boot camp

I'm fine with that

I think having patience

I think having thick skin, and just being the best person you could possibly be

I think

I genuinely want to help people

I was in Iraq ...

I was out there

I know

I think

I would say

I was riding a bike

I was contemplating before that

I was on a bike ride with my buddy

I jumped a curb, face planted, lost my teeth, and got cuts

I think right there and then

I knocked some sense into myself

"I gotta go through with this." 
I did

I was in the recruiter's office

I mean that was the beginning of it

I gave it $110 \%$

I've been in positions where people yelled

I was an Explorer for Santa Ana

I've been through police explorer academy

I remember going through the process

I had patches of hair still

I got a patch right here

I'll probably get yelled at for that

I have no control

I remember we got there

I want to say maybe 7 or 8 . We didn't finish till about 2 or 3

I remember laying down and thinking to myself, "What the hell did you get yourself into?"

I remember hearing people crying

I remember getting woken up by the receiving Drill Instructor

I mean, it was crazy

I remember getting picked up, Black Friday

I remember going in as a diet recruit

I went in

I was at about uh, $205 \mathrm{lbs}$

I was considered a diet recruit

I used to remember lining up for chow

I got burned for it once

I told them

I couldn't have it

I'm gonna get messed up anyway

I might as well just enjoy the pizza

I guess they expected me not to eat it

I ate it

I was squad leader then

I got fired for that

I got re-hired

I was uh, showing leadership abilities, and doing really well

I was really grateful for it

I was really kicking myself

I ate the slice of pizza

I was really hungry

I graduated July 3rd

I knew to expect it to be a different type of animal 
I think that helped me be cautious

I was in the Marine Corps

I was with uh, back then they called it 1st FSSG

I was part of transportation support battalion, TSB

I remember training

I knew all this was getting ready, getting us ready to prepare to deploy

I got in

I deployed

I graduated and got into the fleet from MOS school in September

I was on a plane (by January)

I got married (between the time I graduated school to the time I actually left)

I was gone

I can't imagine the stress on her

I was there for the Invasion

I mean, the sights, the smell

I remember sitting in that fox hole

I know everybody was just stressed out

I remember March $19^{\text {th }}$

I guess they passed it (the signal) down

I happened to be the driver that day

I felt like. (laughs)

I was like, "Ah, shit. Great."

I'm thinking like "We're gonna get resistance, and we're probably gonna get shot

at

I'm hoping I get through this."

I was uh, a little relieved, you know, because we didn't get resistance

I got home

I remember showing up to Al Assad

I left

I left

I left

I remember hearing about it

I was like, "Damn, that could have been us.

That could have been one of my friends.

That could have been me."

I didn't see that

I didn't get to experience it the first time

I heard explosions

I saw the aftermath

I didn't get to actually, physically hear the boom and them see it I heard it

It was a rocket, transrocket 
I mean, you hear the first Initial boom and you're like, "Well, here It comes."

I was a truck driver

I was on the road a lot

I was there for my second month

I mean, we were truck drivers, and a lot of those things were on the road and so we were the biggest target, you know?

I remember going through this traffic circle

I don't remember what it was

I remember they had all stopped to watch the convoy go by

I remember feeling like, there's something about this trip just doesn't sit well

I got that gut feeling

I mean the roads were typically empty.

They were typically, busy, but that day they were kind of empty

I remember seeing a large cloud go off

I had a gunner in my truck

I remember hearing him shoot

I remember hearing the guys

I had a, what is it, about 12 guys in the back

I don't want to say the Iraqis, the Insurgents took casualties

I didn't get to see it firsthand

I know that the MP's, the military police that were with us did a reconnaissance

I returned fire

I was like doing a drive by

I know there was a vehicle off in the distance

I saw

I'm not the only one that saw it

I remember one of my colleagues

I drove through the smoke

I was the last vehicle

I was the last vehicle to get out of there

I went through that smoke

I was going pretty fast

I'm like shaking out of my pants

I'm like, "Fuck man

I'm just glad

I made it out of there."

I remember that whole incident

I think that it was more manageable

I had been through the worst

I was a seasoned veteran

I think, my experiences

I was able to bring comfort to them

I've noticed 
I've been through

I love having Marines

I loved shaping them and helping foster their career

I had a lot of Marines that looked up to me

I looked up to them too

I think it was a two-way street

I took care of them

I remember

I was getting out

I was getting out

I gotta get out

I've got some stuff to take care of

I'll try to visit every now and then

I'm getting out

I don't live that far away

I'll come up on base

I got out, he deployed

I remember getting a call from one of my friends

I mean, that, to that day, to today

I think back about it

I feel bad

I didn't go with him.

I could have changed something

I think back about him every now and then

I think overall

I think my deployments, my career in the Marine Corps

I don't regret any of it

I think it helped shaped me

I don't have patience these days

I know when I was in

I had tons. You have to

\section{Additional Second Listening: We (Marines) Poem}

We could either sulk about it and, you know, be miserable.

Or, you know, have fun with it

We did.

We played a lot of jokes.

We were like the show Jackass

We played and messed around 
We actually take it to heart

We do the best we can

We do that (honor, courage, commitment)

We follow those in our daily routines

We saw a family

We got there around, I want to say maybe 7 or 8

We didn't finish till about 2 or 3 in the morning

We'll separate you

We got special attention

We had the nickname fat-body

We had little tabs that we kept on our uniform that says, "Diet recruit"

We'd have to literally go in front of the drill instructor and show them our plate

We were considered

We were formally, before I got there, Bravo Company

We called them bar-b-que bravo

We're leaving in a month

We're leaving in the next month

We're leaving...

We did our first deployment

We saw

We're gonna go there any day now, any hour, any minute

We're gonna go

We're joking around

We're having fun

We're laughing

We want to know what it is

We're going

We're getting resistance on the driver's side

We actually went

We crossed the line of departure into Iraq

We get into our first

We're gonna get resistance

We're probably gonna get shot at

We get there, and it was nobody, it was abandoned

We followed Seventh Marines

We pretty much followed suit

We got to see the aftermath

We got to see all that

We didn't get resistance 
We didn't get resistance

We didn't get shot at

We, that entire deployment

We were expecting to be in actual combat

We got there

We got there, first night

We got there, they got mortared

We got mortared at least once a week

We meet up, and then, just go about our life

We were on the road pretty much 6 to 7 days a week

We were on the road for hours on end

We were sleeping there

We would drive out, sleep there, and then drive back

We got a lot of resistance on this one, with IED's

We started hearing about it

We were truck drivers, and a lot of those things were on the road

We were the biggest target, you know? Supply line

We saw people working on this hut

We had about 20 vehicles

We were like "Ooh."

We get our supply dropped

We're starting to get ready to leave

We get our accountability, and everybody's good,

We push on out

We get to that traffic circle

We're getting small arms fire

We're getting shot at

We're like, "Where the hell's it coming from?"

We just have them back there

We could

We were getting fire

We're also engaging that vehicle

We did

We never got shot at after

We've always had attempts for IED's

We passed by another convoy

We used an alternate route

We used

We're gonna deploy again

\section{Third Listening: Voices}


In the World: Always a Marine; a husband (to Holly) and a father (to his girls); a Mentor, Leader ("My Marines”)

Within: Desire to do something, lost since the Marines; Responsible for others when he left - but it could have been him; Always serving or being of service (active duty or not)

\section{Fourth Listening: Politics \& Power}

Political: Hierarchy within Marines, rules, control, and punishment within the Corps;

War, invasion, combat, "Iraqis" v "insurgents," us v them; Heroes in battle Social: "diet recruit" also known as a "fat body"; Hatred for recruits; Perception of Dress Blues with women; Comradery among Marines; Heroes in battle; Look cool, when nervous

Cultural: Honor, Courage, Commitment - constant, lifetime service to others; Marines the best branch of the armed forces; Comradery among Marines; Heroes in battle

Economic: Ended the conversation so he could return to work (only one hour for lunch) 


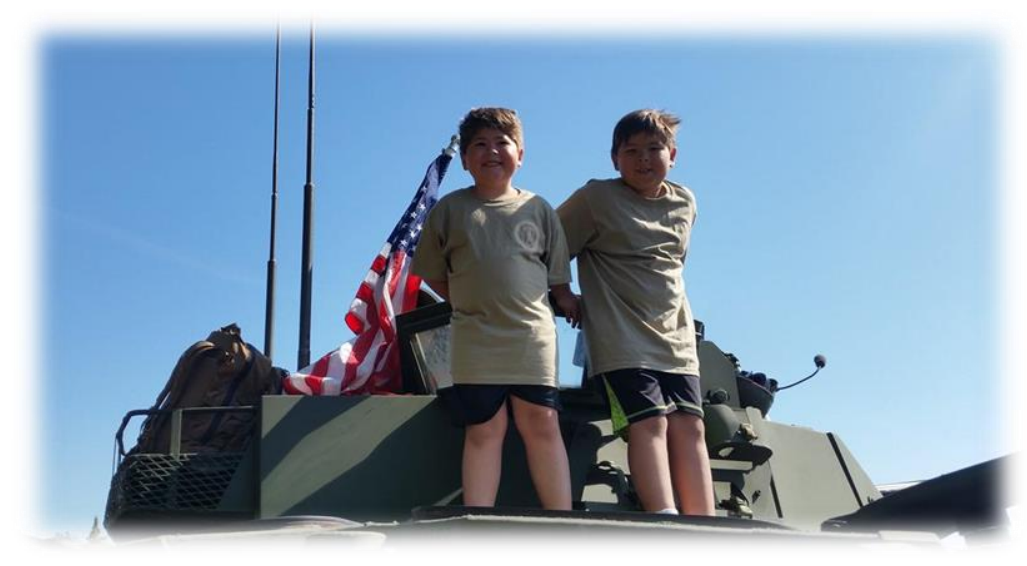

\section{What are you doing, Mom? (Jamie's Voice)}

"MOM!” Danny yelled from his playroom. As I walked back there to see what he needed, he called for me two more times.

"Yes, Danny. What do you need?" I stuck my head through the playroom door.

“Have you seen my Marine necklace?” Apparently, he was going to pretend to be a Marine for a while.

"You mean the dog tags?" I asked. Having a grandfather in the Marines, and a mom working with Veterans meant that he knew more about the military than other nonmilitary connected civilian children.

"Yeah!” He replied. "Hey, do your Marines have dog tags?" He asked, then without waiting for an answer, he added, "What are you doing with the Marines, anyway?" Often, it is the children who ask the most difficult questions.

"Well, honey, how much detail do you want to know?" I asked. At four years old, Danny was naturally curious and intelligent, and I had a habit of over-answering and losing his attention.

He turned around, put down his superhero action figure, looked me right in the eyes, and said "Everything!" 
"Okay then," I replied, as I took a seat on the floor in the playroom. "I am going to write a story with them about what it was like when they left the Marines, came back home, and went to college."

"But how are you going to get the stories?" He asked as he took a seat in my lap. "I'm going to ask, then listen." I replied.

"No, like where are you gonna go? What are you gonna do? Can't you just read some books?" He pointed to his bookshelf packed with books.

"Well, not exactly. I am trying to get at the diversity in the experience of Marines in transition. So, I need to talk with actual people. I figured I could meet them over food to talk about it. What do you think of that idea?" I knew that conversations were always easier over food. It would be easier to talk about their overall experiences in The Corps, their transitions, and even to engage in critical critique about society, the military, and Veterans, if we were also eating.

"When?" He asked as he played with my ponytail.

"Sunday mornings." It was the first time that came to mind. "They will be Brotherhood Breakfasts, here at the house, so it can be more casual and comfortable. The one on one conversations," the more vulnerable and intimate ones, I thought to myself, "can be over lunch, wherever they want to go."

"Like Panda?" Danny was a big fan of the chow mein at Panda Express.

"If they want to, baby." I smiled.

"Can I come?"

“No, honey. It would be a grown-up conversation, so you wouldn't have any fun." I knew these breakfasts would be an opportunity to engage in critical dialogue and 
record the conversations to be analyzed in the same three-dimensional space as the individual stories. bell hooks (1994) said that 'to engage in dialogue is one of the simplest ways we can begin as teachers, scholars, and critical thinkers to cross boundaries, the barriers that may or may not be erected by race, gender, class, professional standing, and a host of other differences' ( p. 130). So above all else, I hoped to engage in honest and critical dialogue with all the members of The Unit.

"Okay." Danny was satisfied; he got up out of my lap and went back to playing with his superheroes. He had forgotten all about "playing Marines." I got up as well, gave him a kiss on his forehead, and headed back to the front room, to find Mikey, my six-year-old, drawing a picture.

I sat down at the table, next to Mikey, and thought more about what it was exactly that I was going to do with the Marines. In many ways the word "dialogue" did not come near to the depth of the conversations and community that I hoped to build among The Unit. I hoped, in the words of Paulo, that "founding itself upon love, humility, and faith, dialogue becomes a horizontal relationship of which mutual trust between the dialoguers is the logical consequence" (Freire, 2000, p. 91). The respect and care that would be my foundation for the work with The Unit was essential to deep and treasured learning (hooks, 1994). More than anything I would enter into my work with The Unit from a place that honored and respected their knowledge, even if it was from a different source than mine, so that together we could create new knowledge (Aronowitz, 1998). Also, it was through the use of critical pedagogy that I would acknowledge that 'I cannot think for others or without others, nor can others think for me' (Freire, 2000, p. 108). The Unit would create an opportunity for us to all work together to examine the transition of 
Marines to civilian and students in a way that illuminates the issues that are the most important to them. It is insensitive and arrogant to think that I knew what their reality was, or that I had answers they did not. We would work together and come into the discussions as equals, even if we entered from a variety of places.

There was great value in recognizing that everyone who entered the conversation had value, it would allow them to share their experiences and use their voice. It created a situation where "there are neither utter ignoramuses nor perfect sages; there are only people who are attempting, together, to learn more than they now know" (Freire, 2000, p. 90). It was one of the most inspiring events in the world, real dialogue. It was the dialogue that occurred in those situations that played an integral role, in the beginning and the continuation, of liberation (Freire, 2000).

The act of dialogue would also allow me to learn as well as share my knowledge. I hoped that together we could create a community. Then, that "communion in turn elicits cooperation... This fusion can exist only if revolutionary action is really human, empathetic, loving, communicative, and humble, in order to be liberating" (Freire, 2000, p. 171). I truly believed the first crucial piece for the research with The Unit was a foundation of humility, respect, and love. Love and care would be the foundational to the genuine desire to continue learning and searching. In fact, it was Paulo who said Curiosity as a restless questioning, as movement toward the revelation of something hidden, as a question verbalized or not, as search for clarity, as a moment of attention, suggestion, and vigilance, constitutes an integral part of the phenomenon of being alive. There would be no creativity without the curiosity that moves us and sets us patiently impatient before a world that we did not make, 
to add to it something of our own making (Freire, 1998, pp. 37-38).

That curiosity was nurtured by the care that existed in my dream with Paulo, Erich, Carl, Karl, and Athena. That care did not mean that their conversation was not heated at times, or that all opinions were in agreement, just that there was a genuine desire to think critically, to dig deeper, and to learn more. I wanted the work with The Unit to have a similar feeling. It would be together that a group of Marines and I would embrace that same care and curiosity that I experienced in my dream at Café Intelligentsia.

To have that deep dialogue, we would first have to develop trust and community with each other. I hoped we would build a unit that supported one another, so that we could investigate the role of Marines in the world together; a potentially difficult and intimidating dialogue. We could not ignore the value of the connections among The Unit, as it would be through connections with others - past, present, future - that positioned us in the world and enabled us to make other connections (Mayuzumi, 2006). Through the bonds forged within The Unit, I hoped that we would be able to discuss "ideas that will guide us toward the critical road of truth, toward the reappropriation of our endangered dignity, toward the reclaiming of our humanity" (Macedo, \& Araújo Freire, 2005, pp xvii-xviii). Also, Henry Giroux (1983) said, “critical thinking becomes a precondition for human freedom" (p. 19). So, the use of critical dialogue would aid in the growth and liberation for every member of The Unit, and could possibly change the world!

"Mom?" I looked up at Mikey and thought that I probably heard the word Mom at least 100 times a day.

"Yes, honey?" I replied. 
"Why are you staring at the TV? It's not on." I had not even noticed I was thinking that hard.

"I was thinking, baby. How is your picture coming along?" I may get caught in my thoughts, yet I was always Mom before anything else. Always Mom - at least 100 times a day!

"Good. So, what are you thinking about?"

"What I am going to do with the Marines; just getting some of my thoughts together."

"You should just listen to their stories, Mom." I smiled, "Have you been talking to Charlotte?"

"No" he answered surprised as he put down his pencil. "But stories tell you a lot about people. Do you think they'll trust you enough to tell you their stories?" What was it with my kids asking the big questions?

"Well," I began, "I hope so! I don't plan on doing the research in a in a sterile environment, like a lab, with objective measurements and statistics, instead it will be happening in this big messy world we have. 'In a methodology where knowledge and meaning are constructed through social interaction and understanding, the relationships that occur between researchers and participants are critical... Good examples of interpretivist research engage the participants in helping to define the questions to be asked and the way in which the answers are communicated' (Ferguson \& Ferguson, 2000, p. 183). So, I hope to build trust, and the trustworthiness of our work by being real and doing the work in real places, like here at home and other places the Marines will be comfortable. I hope the work is valid and trustworthy within the realm of qualitative 
research as it values people and stories instead of objective numbers and standardized measurements."

"You lost me at met-hood-ology, Mom."

"Meth-od-ology, baby. It means the ideas that guide how Mama is going to work with the Marines." I told you, I sometimes over-answer. Yet, Mikey also knows how to hold his own in big conversations most of the time.

"Okay. You can go back to thinking. Can I watch the iPad?"

"Sure, baby. But, only one show, and then you need to read." He was satisfied with that answer and headed to the bedroom to get the iPad. As he walked down that hall, I began to think about the element of trust in my work with The Unit. I knew we would meet at my home. It would be another way that I would be vulnerable and open to them. I knew that it meant that my house would receive a deep clean before each meeting. Marines, interestingly enough, have a very high standard of cleanliness (although, I was lucky enough to have learned how to clean a bathroom from Sgt. Stepo, my Dad). Acknowledging the sexist standards and expectations in the world, I knew that their entrance into my home would accompany a judgement of my cleanliness and order. I was willing to take on this judgment, as it meant I could also play the role of a host, not a hero (Wheatley, et al., 2004).

The job of a host would be to prepare everything, to coordinate and orchestrate. Throughout the process, I would have to remain conscious of my role. I needed to think about the Marines and their stories above all else. To remain trustworthy, the voices and critical stories that were shared bring with them a responsibility that I must have "faithfulness to participants and truth" (Moss, 2004, p. 366). This faithfulness extended 
beyond the conversations with The Unit, to all social action as a result of our work together (Moss, 2004). It was a large responsibility, yet one that was worthy of claiming if the work of The Unit would create social change for Marines and other Veterans."

Also, I was not alone; far from it. The members of The Unit would all be empowered to make things happen in an environment co-created to foster conversation.

All of that was accomplished through trust in others, because one person cannot do everything. The building of trust with others was crucial to effective leadership (Wheatley, et al., 2004). It was about making them leaders in the group themselves (Greenleaf, 2008). Part of building people and trust was using acknowledgment and gratitude. I had tremendous faith in these Marines and The Unit. It was a good sign as our team success would be greatly impacted by the "leader's' confidence in the team and ability to make the team an "us"” (Fransen et al., 2015). As the "leader," or the one who would be gathering us together, my belief in our ability would aid in our success.

I started to think more about leadership, I would have to embody transformational leadership and leadership through service within all my interactions with The Unit. To start, I would build community among The Unit by focusing on the Marines within (Cashman; 2008; Ferch; 2004; Spears, 2004). By showing genuine care for The Unit, their thoughts, beliefs, and opinions I could build community, as a transformational leader (Goleman, 2004). It is through emotional intelligence and empathy (Cashman, 2008; Gill, 2011) that I would be able to build relationships based on trust, love, and acceptance (Cashman; 2008; Ferch; 2004). By coming to each meeting, conversation, and breakfast open to the experience and being present in the moment while I was there (Cashman, 2008), I would be able to listen to the members and respond to their needs. 
The act of authentically listening would lead to stronger relationships with The Unit (Autry et al, 2004; Bach, 2007; Bresler, 2007; Cashman, 2008; Ferch, 2004; Greenleaf, 2008; Spears, 2004). Also, together we would create a space where different opinions and ideas would be added to the pool of meaning in an honest and respectful manner (Patterson et al., 2012).

I admitted I had no control! Meg Wheatley was spot on when she said that we can "prepare, but there is no control" (Wheatley et al., 2004, p. 244). I have accepted my lack of control with the Mom role. I would use that humility and care as I would engage with the Marines in The Unit to build community and focus on the research project, as they will be more involved if they are part of the creation (Wheatley et al., 2004). I would guide by asking the best possible questions, and listening to the answers, (Autry et al., 2004) and hoped that the conversation was rich, and that the members themselves wanted to stay on topic. I would use my powers of persuasion as a leader, and my desire to help others, to create an atmosphere of community (Spears, 2004). Yet, ultimately, it would be the group's responsibility to be committed to the task at hand. These are Marines, accustomed to focusing on mission completion; I knew that any off-topic conversations might still be insightful for further illumination and discovery. Also, as an educator with years of experience in the classroom, I was comfortable bringing a conversation that strayed too far from the topic to be useful back on track in a respectful and sensitive manner that would remain open and welcoming to additional conversation and engagement. I would use everything that I was and had learned to create work with The Unit that was useful, liberating, and informative, thus giving the creation multiple purposes and utility (Ferguson \& Ferguson, 2000). 
Yet, in all ways, it was not about me. The work was about the people who live the realities, who struggle, and who know. It was with the Marines that the depth of wisdom dwelled. Yet, even the Marines were unable to know everything, as 'knowing requires not knowing; a state of being lost in order to find. It also suggests that not everything is knowable, and that wisdom distinguishes between what we can possibly affect and what is beyond our grasp' (Siegesmund \& Cahnmann-Taylor, 2008, p.234). As a result, we would all embrace our unfinishedness, celebrate our becoming with the help of critical pedagogy, and together create something that will lead to social change.

Indeed, I hoped the conversations would be about "issues of work and economics, but also about questions of justice, social freedom, and the capacity for democratic agency, action, and change, as well as the related issues of power, exclusion, and citizenship" (Giroux, 2011, p. 101). The dialogue would be part of critical pedagogy; related to both critical theory and culturally responsive methodology. Thus, the fact that I planned to use critical pedagogy in the work with The Unit was not only wise, it was integral to our journey to critical consciousness. It was critical pedagogy that emboldened us "to act on the knowledge, values, and social relations [we] acquire by being responsive to the deepest and most important problems of our time" (Giroux, 2011, p. 14).

The use of critical conversations and critical thought would allow us to challenge assumptions and examine our personal lives within the larger societal structures (Giroux, 2003, p. 163). As we examined together, we would be able to identify and name the powers, within history and politics, that impacted our daily lives and our realities (Freire, 2000; Giroux, 2014). It would also be an opportunity for all of us to see ourselves in 
constant transformation. As Paulo said,

People develop their power to perceive critically by the way they exist in the world with which and in which they find themselves; they come to see the world not as a static reality, but as a reality in process, in transformation" (Freire, 2000, p. 83).

Such a discovery would empower all of the members of The Unit "to question the deepseated assumptions and myths that legitimate the archaic and disempowering social practices structuring every aspect of society and then to take responsibility for intervening in the world they inhabit" (Giroux, 2011, p. 158). Certainly the use of arts based research as well would align perfectly with the critical, revolutionary spirit within critical pedagogy, as "radicalization, nourished by a critical spirit, is always creative" (Freire, 2000, p. 37). So, my plan of work with The Unit would be both critical and creative.

I smiled as I thought about the beautiful synergy that could come from creative and critical. It embraced everything I wanted in the research process and it acknowledged the art in life. Paulo Freire, much like Dewey (1934), noticed that and even pointed out the constant interaction with life and art when he said:

Women and men by the mere fact of being in the world are also necessarily with the world. Our being is a being with. So, to be in the world, without making history, without being made by it, without creating culture, without a sensibility toward one's own presence in the world, without a dream, without song, music, or painting, without caring for the earth or the water, without using one's hands, without sculpting or philosophizing, without any opinion about the world, without 
doing science or theology, without awe in the face of mystery, without learning, instruction, teaching, without ideas on education, without being political, is a total impossibility" (Freire, 1998, pp. 57-58).

Mikey was back in the kitchen, with the iPad, watching some cartoon. So much of my work was influenced by his presence, not because he was military (obviously, he was six years old). It was because I tried to parent like I taught, and how I hoped to build community in the group.

It was my own constant acknowledgement and understanding of my unfinishedness that I would begin the work of critical pedagogy with The Unit (Freire, 2000). That idea of unfinishedness in critical pedagogy brought with it the beauty of possibility, or as Giroux (2014) said 'making the impossible, once again, all the more possible' (Giroux, 2014, para 21). We would be encouraged to imagine beyond the current reality and would try to make an 'untested-feasibility' possible (Araujo Freire, 2014). It would be hope that emboldened and empowered us to imagine. As Hope for Freire was a practice of witnessing, an act of moral imagination that enabled progressive educators and others to think otherwise in order to act otherwise. Hope demanded an anchoring in transformative practices, and one of the tasks of the progressive educator was to "unveil opportunities for hope, no matter what obstacles maybe"' (Giroux, 2011, p. 161).

Hope changed the traditional examination of Marines, and all Veterans, in transition from "objects to be analyzed and (based on the analysis) presented with prescriptions for behavior" (Freire, 2000, p. 133) to one that respects and values the individual beings and listens to their voice and experiences (Freire, 2000; Giroux, 2011; hooks, 1994). 
Hope would allow us all to really listen to each other. Again, Charlotte and Mikey's voices were in my head. Listening was so crucial to the process. Yet the act of listening would not result in blind agreement.

True listening does not diminish in me the exercise of my right to disagree, to oppose, to take a position. On the contrary, it is in knowing how to listen well that I better prepare myself to speak or to situate myself vis-à-vis the ideas being discussed as a subject capable of presence, of listening "connectedly" ad without prejudices to what the other is saying. In their turn, good listener can speak engagedly and passionately about their own ideas and conditions precisely because they are able to listen" (Freire, 1998, p. 107).

Often it was the simple act of real listening that built strong bonds among people, based on trust and respect, thus forming the foundations for a democratic society (Fromm, 1969). So, too, would it be through listening, critical thinking, and dialogue that we, The Unit, would illuminate the issues that are the most oppressive and inequitable for Marines or Veterans in higher education and in general. We would use their stories, their artwork (with their permission of course) as well as other prompts from the media, be it the news (i.e. \#BlackLiveMatter) or movies (i.e. American Sniper) or other sources for our discussions and dialogues. However, "being aware of the conditions that cause human suffering and deep inequalities that generate dreadfully undemocratic and unethical contradictions for many people is not the same as resolving them" (Giroux, 2011, p. 126). I hoped we would be able to move from awareness to action. Throughout the process, we would not lose sight that critical thought AND action must be combined. The work "cannot be purely intellectual but must involve action; nor can it be limited to mere 
activism but must include serious reflection: only then will it be praxis" (Freire, 2000, p. 65). Praxis "is transformation of the world" through the collaborative and dynamic dance of "theory and practice; it is reflection and action" (Freire, 2000, p. 125). Again, the importance of listening remained as it empowered The Unit to share their own answers; it was often the people engaged in the situation that were able to create some of the best possible solutions (DeGraff, Tilley, \& Neal, 2004; Goleman, 2004).

"Mom? Are you still thinking?" Mikey had a look that was a mixture of intrigue and concern.

"Yes, baby. What do you need?" I asked, a layer of annoyance in my voice.

"Can I have a snack?"

"What do you want, sweetheart?"

“Spaghetti?" I had to appreciate the optimism in his voice.

"For a snack? No. Want to share an apple and a string cheese?"

"Sure!" At least he was easily satisfied.

I got up to prepare our snack. As I cut the apple, my thoughts returned to the work with The Unit. The plan engaged the people who knew best, as they were the individuals who lived it. The Unit was comprised of Marines, so the conversation would definitely include the most important stakeholders. While other stakeholders (families, Veteran support organizations, higher education administrations, etc.) were not members of The Unit, they could certainly join the conversation in the future. The Unit was formed to ensure that the most important voices were heard first, the voices of Marines who were, and continue to be, the most greatly impacted by the research topic; which added to the democratic validity (Anderson \& Herr, 1999). Also, as I believed that 
Marines have the greatest difficulty transitioning to civilians, working with them would provide greater insight for all Veterans.

The Unit's ability to embrace critical pedagogy within the dialogue would also add to the catalytic validity, or the personal transformations or reenergizing of The Unit to make change (Anderson \& Herr, 1999). I hoped that each member of The Unit found growth and greater understanding, personally and as a community, as a result of our work together. Furthermore, our goal as The Unit was not in search of one Truth, but instead we hoped to add to the possibilities and to deepen the current knowledge: our process validity (Anderson \& Herr, 1999). Overall, I hoped that the work with The Unit resulted in social change, with the societal perception of Marine Veterans as well as with the policies, programs, and procedures that impacted Veterans in higher education. If successful in our goal to make social change happen, we would be able to add outcome validity to the research (Anderson \& Herr, 1999).

I walked back to the table with the cut apple and a string cheese to share with Mikey. Mikey had returned to drawing while he watched the iPad. So, I made sure to set the plate down to the side. That was when I saw the picture Mikey had drawn before he went to get the iPad. 


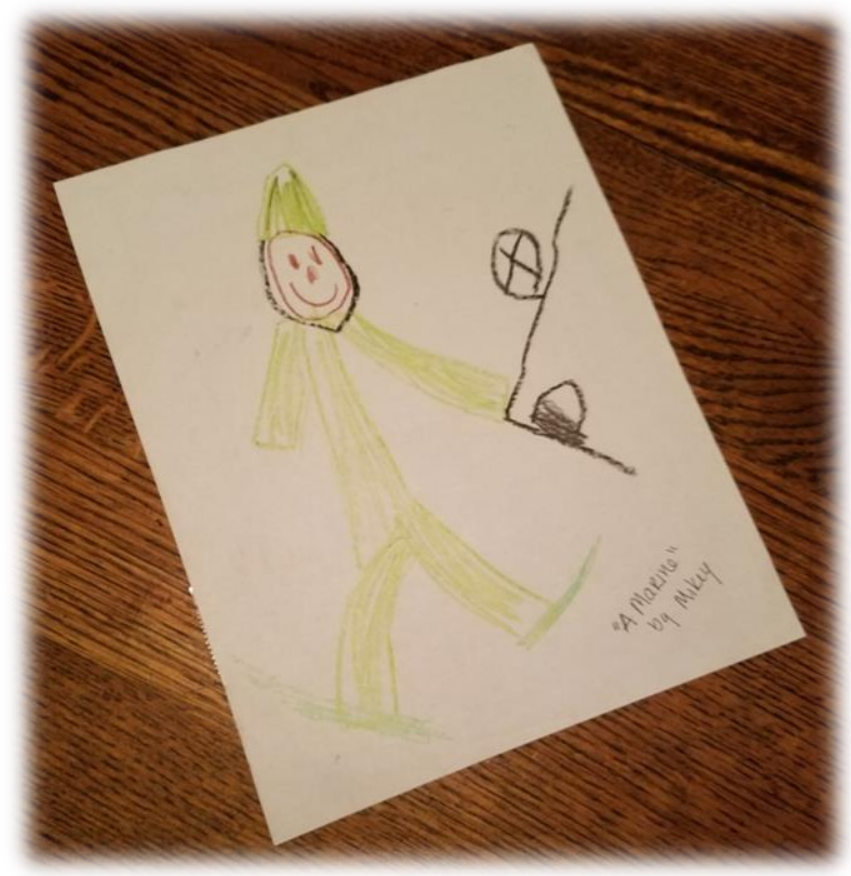

He did not see Marines as broken! I knew the adventure ahead would be full of dialogue, creativity, and challenges to make myself and others see things in new ways. I was excited and nervous, yet ready for the task. 


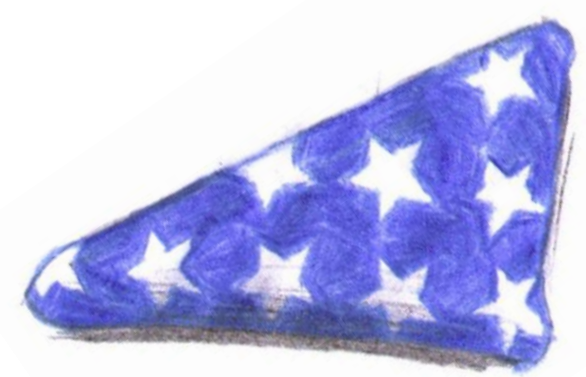

\section{Freedom Isn't Free}

Jamie and Tony/Beaver were grabbing a coffee at Café Intelligentsia in between classes. He was no longer a student in her class, and they had become friends. While they were drinking their tea and smoothies (Beaver was not into coffee in the afternoon), Jamie decided to ask Beaver if he had ever heard of the military-industrial complex.

“The what?” Beaver raised one eyebrow in a request for clarity.

"I think the full term is 'military-industrial-technological-entertainmentacademic-scientific-media-intelligence-homeland security-surveillance-national securitycorporate complex' (Turse, 2008, p. 25)." Jamie spoke slowly to make sure she remembered each piece of the puzzle. "Yet, since that is too much of a mouthful, 'the Complex' is often enough (Ibid., p. 26).”

"Damn, that is a mouthful. So, what exactly is it?"

"Well," Jamie began, "I've never heard so many industries added into the mix before, yet it is the idea that war is often manufactured for the benefit of industry. In essence, war is another capitalistic venture that includes the 'Iron Triangle,' which is Congress, arms manufacturers, and the Pentagon, and the 'Golden Triangle,' formed by military agencies, high tech industries, and academic research (Turse, 2008). Or 'a gigantic labor process' (Ernst Jünger quoted in Klay, 2016, para 57). Using the term 'The Complex' seems much easier to say, yet far less telling of how big the interrelations 
really are."

"Well, I had never heard it called that before. Unfortunately, it is far bigger than just arms manufacturers. The number of DoD contractors each year is huge. I get why organizations want to work with the DoD, VA, Pentagon, and various branches of the military; it's good money. However, some of the practices pursued by the parties for those financial benefits make me question their authentic motivations."

"What do you mean by that?" Jamie was intrigued to find out more about his experiences with The Complex in relation to the Marines.

“They don't care about the people serving and fighting; they just care about the money that they are going to get. It is all one big cluster-fuck of money making. That is all that they care about." Beaver replied, with a mixture of frustration and hopelessness. "It was Gen. Smedley Butler who said that:

War is a racket. Is always has been. It is possibly the oldest, easily the most profitable, surely the most vicious. It is the only one international in scope. It is the only one in which the profits are reckoned in dollar and the losses in lives.

A racket is best described, I believe, as something that is not what it seems to the majority of people. Only a small "inside" group knows what it is about. It is conducted for the benefit of the very few, at the expense of the very many. Out of war a few people make huge fortunes' (2003, p. 23).

And that was in fucking 1935. Some things don't change!”

Jamie shared his frustration. "I know. I think that is the worst part. You know as well as the fact that 'The human costs of war are now and have perhaps always been hugely borne by young people' (Pollard, 2015, para. 9). It is more than oppression, it is 
exploitation! With little effort, you can find research reports from the RAND Corporation about how to 'attract college-bound youth into the military' (Asch, Kilburn, \& Klerman, 1999), complete with suggestions to increase the military pay to be competitive. Or even more disconcerting is the assessment of the traditional educationmilitary tracks, or the ways that individuals attend college and serve in the military, and the statement that when Veterans go to college AFTER service, 'the military does not reap an active duty return on the most important college program it offers' (Ibid, p. xv.). I have a difficult time thinking of education for Veterans as something that needs to be a benefit to the service branch. It is far too capitalistic an idea for me.

"The treatment of the service men and women after service, as Veterans, would be aligned with such a belief system. In many ways, in the eyes of the highest public officials, the military service members are not people, but cannon fodder (M. Steponovich, personal communication, 17 December 2014). I read in another RAND report about recruiting minorities, a line that referred to Black and Latino 'enlistment supply' (Asch, Heaton, \& Savych, 2009, p. xvii).”

“They were actively recruiting minorities?” Beaver said, with a bit of distaste. “"Diversity of enlistments has been an area of concern among policymakers since the end of conscription' or the draft (Ibid., p. xv). As of 2007, Black representation within the Army was $11.8 \%$, and 9.7\% for Latinos (Ibid, p. xv-xvi). The U. S. Census Bureau (2015) reports 13.2\% Black or African American alone and 17.1\% for Hispanic or Latino for 2013. So, the focused recruiting could be viewed as an attempt at a diverse military, representative of the overall population of the United States, or as targeting already marginalized groups. Either way, the reference to human beings as 'supply' 
denotes a lack of humanity." Jamie stated.

"No shit." Beaver declared. "After 9/11, some guys joined. But overall, times of war make military recruitment a bit difficult. That whole possibility of actually dying stops some people from signing up. Then, on top of that, if you want any job above working at McDonald's, you have to have a college degree, so military recruitment has been even lower (Asch, Du, \& Schonlau, 2004). The military response has been to increase their pay, as well as introduce some new educational benefits, like the Post-9/11 GI Bill. That doesn't even touch the added incentives for the recruiters themselves (Ibid.). Notwithstanding, we are getting away from original Complex you asked about. So, who all is supposed to benefit from war, or The Complex?"

Jamie leaned back. I could tell her chest hurt when she talked about this. "I feel sick when I think or read about how many companies, politicians, and corporations see dollar signs not people. It genuinely makes my heart hurt that there are companies that see growth in war or military conflicts, and thus use their political influence to maintain their necessity. They are at least partially responsible for the endless funds allocated for defense (Turse, 2013). Yet, there is a lack of adequate funding and resources for Veterans, who suffer homelessness, unemployment, and high rates of suicide ideation (Castro et al., 2015). I have to admit that the most surprising discovery I found, when I started to look at all the people or organizations in the Complex, was that a piece of the puzzle was academic. I know that academic research is a major player in the advancement of knowledge, but I never connected it with the military."

Beaver look at Jamie, a bit surprised. "Really, have you ever heard of DARPA?" He asked. "The Defense Advanced Research Projects Agency certainly helps to ensure 
that the advancement of knowledge includes information of strategic technologies and warfare (Turse, 2008). DARPA was created to:

be the initiator and not the victim of strategic technological surprises... DARPA explicitly reaches for transformational change instead of incremental advances. But it does not perform its engineering alchemy in isolation. It works within an innovation ecosystem that includes academic, corporate and governmental partners, with a constant focus on the Nation's military Services, which work with DARPA to create new strategic opportunities and novel tactical options' (DARPA, 2015, para. 2-3).

While it is beneficial to both the school and the military, there is a question about the amount of 'critical patriotism' that is occurring (McLaren, 2013). Are the universities researching and creating in a hope to make service members and civilians safer? Are they asking the difficult questions about democracy? Are they just doing it to get the grant money?"

"Is it another piece of a political agenda and imperialism?" Jamie added. "Politics and war are often bedfellows. You know, I recently read a book by a service member who examined the relationship of politics and war, from the battlefield up (Simpson, 2013). The book is actually called, From the Ground Up. He found that modern day war is very different from the perceived 'us versus them" polarization of opposing forces of the past. The violent battle resulting in a 'clear' winner doesn't really happen anymore. In reality, politics on a national, as well as local, level play a critical role in war. The fact that the "military now tends to speak of "battlespaces" rather than "battlefields" acknowledges the expansion of the traditional, apolitical, military domain beyond the 
physical clash of armed forces to include its political, social and economic contest even at the local level'( Simpson, 2013, p.19). The long-term investment in a 'war' involving counter-insurgency often fails to deliver the short-term and decisive results that are often expected and associated with the idea of war (Simpson, 2013).”

"You don't have to tell me. I lived that shit!" Beaver sat back in his chair as he acknowledged that accuracy of the statement.

"Well, in the book, Simpson (2013) describes a language of war that communicates meanings through actions that are interpreted through a pre-existing lens, for example a particular religion or culture. Just like any sort of argument, each statement can be made in a manner that is offensive or defensive with the ultimate goal 'to convince a set of audiences of a given political "narrative", (p. 88). As a result, war is much more than combat, or the traditional form of war. It is a political extension of policy, an 'armed politics' to be used as an instrument to reach a decision. That decision is created and is only temporary, as the victorious and defeated parties may trade places as the "war" continues.

"The idea that success or failure is determined by the relationship to the enemy is not enough in the political realm of today's world. Instead war is all about interpretations, making war a back and forth, or dialectical, endeavor. It is, once again, like an argument or conversation about desires. Yet those desires must remain grounded in possibility (Ibid.). It is the grounding in real possibility that requires the involvement of the men and women in the field, at the local level. Those who are engaged in the tribal issues, religious dialogues, and community politics, need to be able to communicate the 'ground truth' (Ibid., p 130). In so doing, the military service members should contribute 
to and not just execute policy (Ibid., p. 126)." Jamie looked to Beaver, who was leaned back in his chair.

"Well, my 'ground truth' is that there is no realistic solution. It's a fucking religious war, and no way to 'win'. Sometimes I wish we could just wipe out the whole Middle East.” Beaver didn’t even look at Jamie as he said it.

"The location or the people?" Jamie questioned. She knew Beaver too well to think he really wanted to wipe out millions of people with a push of a button.

“The situation! I don't have a preference for one side or another with the religious stuff. They just can't get along. Obviously, Al Qaeda, ISIS, the Taliban, those fuckers can go. But it isn't that easy. Just like the Klan here, for some reason they seem to be able to recruit new members. Even if they are all fucking nut jobs!"

Beaver took a breath; he was getting heated thinking about it. Part of his frustration was the complex feelings of being proud of his service and sometimes wondering if it really made a difference over there. He knew he had made some sort of impact; he has the stories and memories as proof. He brought himself back to the conversation with Jamie.

"Anyway, what does all that have to do with The Complex?" Beaver asked. Jamie took a minute to collect her thoughts. "Well, I am intrigued by the military industrial complex, yet find it difficult to talk about as I feel that when it is brought up, there is a strong negative military connotation. When I think about the Complex, I think of the huge political monster that is all about money and world domination. I feel that it is another example of how the men and women who serve in the armed forces are marginalized and treated as less than civilians. It seems to me that they become a 
commodity, their only values being their ability to risk. If they survive or die, it doesn't matter to those at the top. Those in power only want to achieve their political desires. I think that we sometimes forget that the men and women with the boots on the ground are often the greatest victims of the Complex as they are frequently treated as nothing more than pawns on a chess board."

“Ain't that the fucking truth.” Beaver scoffed. "Gen. Butler said that 'The bankers collected their profits. But the soldier pays the biggest part of the bill' (2003 p. 28). The Marines do whatever is in the politicians' best interests, they use us as bullies. We're the biggest bullies in the whole fucking world.

“But you know what? We all volunteered to join. We didn't volunteer to be pawns or bullies. We joined to fight for something valuable and righteous; that is true for most Marines I knew or know. We want the fight to be unnecessary. Some Marine, I think his name was Sgt May or something, once said:

The Warrior, the way I have made the word to mean in my own mind, is one of the elite caste of mankind who do something that no other profession does... they seek to make their jobs disappear. The Warrior is one who desires nothing more than to lay down his sword (or rifle, whatever) and never do harm again. The Warrior, whose sole reason for existence is War, is the seeker of Peace" (Sergeant Kenneth May in Larson, 2010).

I'll admit that our role in the Complex isn't really acknowledged until we're out. I never noticed that shit when I was in. But, man, did I feel the difference in treatment once I was discharged and no longer 'needed' to fight and therefore no longer valuable. That's when it started to sink in. When I was in, I thought about the mission, and my fellow 
Marines. Fuck we were a cohesive Unit, working and suffering together because we had developed 'an intricate web of friendships of character' (Desgrosseilliers, 2014, p. 64).”

"You really miss it, don't you?" Jamie asked, a hint of sadness in her tone.

"Every fucking day! I mean I used to be part of something bigger than myself, something with a rich history and tradition (Moore, 2014). I had leaders, like Mad Dog Mattis..."

"Who?" Jamie asked.

“General Mattis. You would get along with him. He once told the 1st Division 'You are part of the world's most feared and trusted force. Engage your brain before you engage your weapon.' (Mattis, 2003). Anyway, he was the type of leader we all trusted because he was a real role model. There were other NCOs, Staff NCOs, and Officers that were also role models. They had the ability to see and respond to the future enough to keeps us alive, and working as a cohesive unit (Goleman, Boyatzis, \& McKee, 2004)."

Jamie smiled at Beaver, "You know, some call foresight 'the central ethic to leadership' (Kim, 2004, p. 25). The ability to see and respond to the future before it happens is one of the most valuable elements of a leader, as it allows for crises to be averted, successes to be achieved, and the growth of people to be continuous (Greenleaf, 2008). It sounds like the Marines like to embody transformative leadership as a part of their culture as they promote leaders serving other leaders (Goleman, et al., 2004) It sounds like, within the units, among the divisions, and even up with General Mattis, they realize that people matter most (Cashman, 2008; Goleman, 2004; Greenleaf, 2008).”

Beaver half laughed, half scoffed. "People certainly matter, yes." Then he grew more serious as he continued. “Chesty Puller's first principle of leadership was 'know 
and understand your people... because unlike standard uniforms, standard equipment, and standard weapons, standard Marines are unique despite their common grounding in the Corps' ethos and spirit.' (Schick, 2015, p 9). The 'Officers think for themselves; they are not robotically programmed' (Simpson, 2013, p. 126). That is how they help the men and women in their care develop and grow as Marines. I know that leadership is about empowering people to do what they are capable of, allowing them to discover their own strengths and supporting them to make it happen. While the tactics of the Marines are not what one would consider typical for leadership development, you can't ignore that every Marine is acutely aware that they are much more capable than they first believed. It is the leadership goal of the Corps for every individual Marine to be agile, resilient, capable, and ethical (Desgrosseilliers, 2014). It may include some brainwashing and indoctrination, yet the result is, more often than not, a transformation. Marines are developed to have great confidence in part due to the realization that physically, and emotionally, the limits we think limit us are far below what we are truly capable of (M. Steponovich, personal communication, 17 December 2014; all members of The Unit). That understanding, when used for good, is a force that can change the world. Remember, General Mattis said that 'The most important six inches on the battlefield is between your ears' because it is intelligent Marines that make choices at all levels, not robots who simply await orders." 


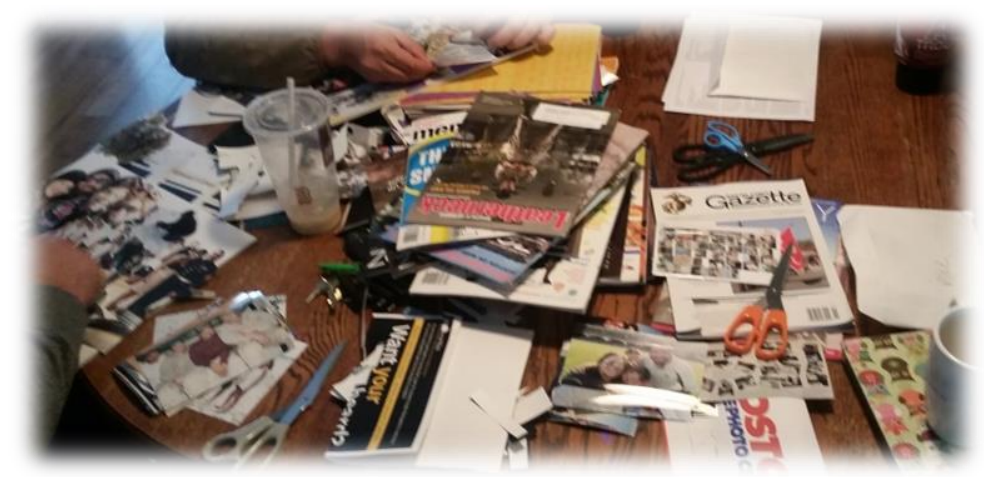

\section{Breakfast with The Unit (Jamie's Voice)}

Our first meeting was on a Sunday morning at "zero eight hundred (0800)," or 8:00am for me. They all were at that time, so it would allow them to have the rest of their Sunday with their families. I had spent several hours on Saturday cleaning. My bathroom, kitchen, and front room were the cleanest they had been in the five months we had lived there. Being raised by a Marine, I knew the sticklers they were about cleanliness. I was up at 6:00am to shower, set out the fruit and pastries, and mentally prepare myself for the first group meeting.

When I saw the first truck drive up, at 7:40am, I was ready to open the door. No one came in. By 7:55am four large trucks of various colors, makes, and models were parked near my house. Each truck had some Marine identifier on it - an Eagle, Globe, and Anchor front plate, USMC California plates, a Marine sticker. At 7:59am, a group of four Marines walked up to my front door, with Beaver in the front to knock. I thought it was interesting that they all waited.

They came in and each selected a seat at my kitchen table. Those seats would be their seat for every Sunday morning breakfast conversation. Everyone made themselves a cup of coffee with a Keurig, and a few grabbed some fruit. There were polite requests for sugar and milk as needed. There was the formality of a new group coming together 
and getting to know one another; we were in the forming or orientation stage (Tuckman, 1965; Tuckman \& Jensen, 1977).

As we sat down to "begin" they all looked at me, in awkward silence. I smiled and offered to an icebreaker. They laughed, and we started the conversation. There was an unofficial reporting of their rank, MOS, unit, and bases they visited during the service. I noticed the subtly in their comparisons with each other later, as they would occasionally mention each other in their individual interviews. It was all part of the forming phase of group development (Tuckman, 1965). At the breakfasts, they all talked, they all shared, and they began to slowly become a group.

At that first meeting, every silence came with four sets of eyes on me, waiting for the next question, the prompt, or approval to talk. They began to loosen up a little, and Beaver was, I think, a critical part of that result. It was because of the relationship and comfort level Beaver already had with me, that I believe the other three Marines relaxed a bit faster with me than they might have if he wasn't there. In many ways, he was my "in" to the group. He had vetted this "nasty civilian" to be acceptable (he even wrote one of my letters of recommendation for the Professor of Counseling - Veterans position). It was his support of my place that allowed me to start this work; he acknowledged my place at that table and empowered my position in the group (Gill, 2011). His ease was communicated to the other Marines at the table that morning, and as a group we quickly moved through the forming stage (Tuckman, 1965).

In many ways, The Unit was not a group that was coming together for the first time, since they were all Marines. They had already been through a very intense group formation process in boot camp. So this reformation, with a new group of individuals, 
was in part revisiting an older group, much like Veterans on campus finding each other (Bellafiore, 2012; DiRamio et al., 2008; Hammond, 2015; Kok, 2015; Livingston \& Bauman, 2013; Olsen et al., 2014; Phelps, 2015; Rumann \& Hamrick, 2010; Summerlot, Green, \& Parker, 2009). In these meetings they were able to support each other, share with each other, and look for each other (Hoge, 2010).

The meeting was productive. I learned a lot as we began some great conversations about what it meant to transition to a civilian, although not a single Marine at that table thought of themselves as one. I noticed that each one of them had some form of Marine wallpaper on their phone, which may have been related to the $240^{\text {th }}$ Marine Corps Birthday (November 10, 2015) and Veterans Day (November 11), since our meeting was at the end of November. I noticed it, but I didn't point it out to the group.

I also noticed they didn't move in their chairs as much as I did. I have squeaky kitchen chairs, so it is noticeable when someone readjusts for comfort. They didn't readjust much at all. Maybe I fidget more than average person, although I don't think so. They were very still in their body positions, although they did talk with their hands and such as they spoke. It was not an observation for the future meetings, so I think it may have been part of the initial meeting formality (Tuckman, 1965). Also, they all did their own dishes before they left. Even though I asked them to just leave the dishes in the sink. Every single cup, spoon, glass, and plate was washed and placed in the drying rack. It was a little thing, and a behavior that would continue at every breakfast meeting that happened.

The last interesting thing about the first meeting, was that there was significantly more swearing than I heard during the individual meetings. We heard the word fuck 386 
times in the 166 minutes that we were together, shit 152 times, and ass 106 times; that was an average of 3.88 swear words a minute (Group Meeting \#1, 11/29/15). Yet, that was part of being with Marines, and my ability to be in that space without being offended enabled the group to continue our work together - I had to know and understand my group (Autry, Spears, \& Lawrence, 2004; Goleman, Boyatzis, \& McKee, 2004; Schick, 2015).

After they left that first meeting, I began to make notes to prepare for the next meeting. What would we do? What discussions would we have? Was my house clean enough for them? It wouldn't be too long until I saw them again, as our next meeting was only two weeks later, since they had agreed that they were more comfortable in the private space.

Again, I deep cleaned my house, well the parts they would see, in preparation for the breakfast. The morning of, I awoke again at 6:00am to start making three pounds of bacon and a dozen scrambled eggs. Lance was unable to make it to the meeting that time, as he was volunteering at a welcome home barbeque for his old unit. However, Beaver, V, and Sgt. G were all willing to have some great conversations, write I am... poems, and even create some found poetry from The Marines Hymn, the Rifleman's Creed, and a poem Semper Fidelis (included in their respective Recon Reports) that they would be able to use for the collages at the third meeting (Lance completed this at an individual meeting). They all enjoyed the bacon and eggs but mentioned they all felt guilty about me always buying all the food. After the meeting, the three Marines spent another 10 minutes talking together on the sidewalk. While I have no idea what they were talking about, it made me smile that they had made a connection. 
At the third meeting, I intentionally left the recorder in my bag while we worked on our Identity Collages. The only instructions were to make a collage that represented them. We had all the pictures that they gathered or took for their Marine, student, civilian, and their unique identities, a variety of magazines (including Leatherneck and Marine Corps Gazette: Professional Journal of U.S. Marines), their I am... poems and found poetry from the last meeting, as well as the I Poems from their first individual meeting (although no one use the words from any of the poetry in their pieces). Throughout the three hours that we were together I heard even more stories, more swearing, and a lot more teasing one another, about anything and everything.

Each Marine created a very different Identity Collage, and the Marine Corps was a big piece of every single one. Sgt. G had most of his piece dedicated to his family, with three pictures about being a student, and the remainder of the photos of his time in the Marine Corps (he mentioned he felt rushed, as he was the last one working). All of V's pictures and words were about the Marines, except the one photo of his mother; even the background design was like a Marine award. Beaver had seven pictures - one of his East Forrest College diploma and the rest were from his time in the Marines, or in uniform. Lance used a mixture of pictures from magazines that represented animals and water, with pictures of him. His pictures represented his time in the Marines, as law enforcement, his role as the face of his school (marketing material), and then one that combined his love of the water, service, and Veteran from a Team RWB event, the Waves of Valor Veteran Surf Camp. Mine, was the most chaotic, a mixture of pictures of people and things, and words from magazines. The design was an accurate representation of my identities (mom, student, teacher, researcher, friend, daughter). 
At the end of the meeting, with more bacon and eggs, they acknowledge that there was a connection to the group. The stories we shared with each other about our collages helped strengthen that bond even more. We had moved to the norming phase of group development, but more importantly the saw themselves as a group (Tuckman, 1965). I think that was one of the most exciting moments for me. They all had other things they could have been doing on a Sunday morning. Yet they were in my kitchen, sharing time and their stories with each other, with me. I was very honored in that moment, as we were all "working together for something bigger than just ourselves" (Goleman, Boyatzis, \& McKee, 2004).

The fourth meeting brought with it a noticeable change in behavior. To begin, no one knocked or rang the doorbell. Each Marine arrived and walked right in. They didn't ask for anything in the kitchen, as they knew where everything was, and they helped themselves. Sgt. G even brought tortillas to the breakfast, as we had previously decided to do eggs and chorizo, instead of bacon, for variety. It was my first time making chorizo. They ate it, so it must have been okay. They still all did their dishes, but there was a feeling of comfort in the kitchen during that meeting, which had been missing at the first breakfast. These were not strangers in my kitchen, they were my Marines. Our conversations were able to get deeper and the topics a bit riskier. As a group, we were performing (Tuckman, 1965).

These four Marines changed my life. Just the process of becoming a group was an experience that I will always appreciate being part of. I believe that the relationship with these gentlemen is not done now that the research project has concluded. They have become part of the story of my life, and I imagine they will continue to be my friend as 
we add to our own individual stories for years to come. That was just the group experience; I haven't even touched on the actual conversations! 


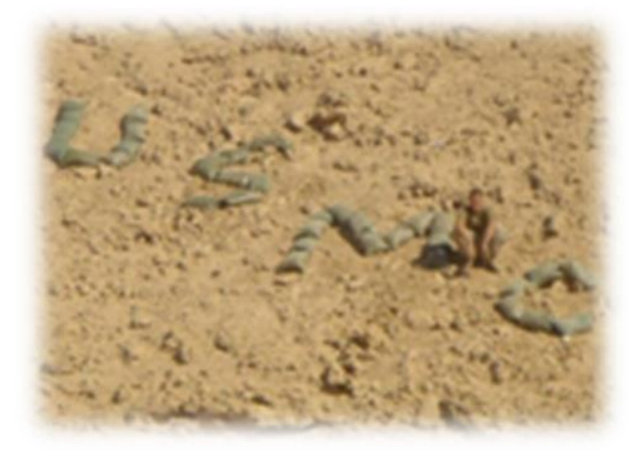

Photo courtesy of Beaver

\section{The Few}

Sometimes, being a god was infuriating. Sometimes it was invigorating. My time in Jamie's kitchen with The Unit was most certainly the latter. On those Sunday mornings, they would walk into Jamie's kitchen, grab a plate, fill it with whatever item she made for breakfast, and put it at their place at the table. The kitchen table was the table Jamie had as a child. She had numerous dinners, hours of homework, and thousands of conversations with her dad at that table. Now, that table was the place where four Marines shared their stories of transition, hope, hopelessness, and healing. It wasn't a fancy table, but it served its purpose. They were comfortable there.

Jamie may have told you about how they came together as a group, yet their conversations were incredibly powerful as well. As they walked in and out of the kitchen, to refill their coffee or grab another piece of bacon, they also talked about a variety of topics, from life in the Marines to blenders. They talked about their experiences and their frustrations. They shared stories about their time at Camp Pendleton, the bases they called home, the other Marines they served with, and their lives after leaving the Corps. Through it all the prevailing theme and the reoccurring conversation was about the intense feeling of loss and longing that came with leaving the Marines. 
Even though you hated the Marine Corps

Every fucking day

You loved it

No matter what you loved it

Fuck, you love

You love hanging out with your boys

Your friends

You miss your boys

Miss certain guys that you've grown up with.

Hanging out with the guys

Deployments

I'm not going to lie though I miss that

At least parts of it

I fucking miss it

You love going to the field

Everything else

Start missing that little shit

Even the fuck-fuck games

Just miss certain things

Miss the Marine Corps

Found Poem from Group Meeting \#1, 11/29/15

After the intensity of life in the Corps, which included all of the structure, the tradition, the ritual, and the significant relationships with the other Marines, life in the civilian world seemed a bit less fulfilling and meaningful. In many ways, the Marines were part of a tribe - a group of individuals who lived, fought, ate, slept, and believed together (Smith \& Junger, 2016). They were part of a family with their battle buddies (Bellafiore, 2012; Hinojosa \& Sberna Hinojosa, 2011; Hosek \& Martorell, 2009; Kok, 2015; Livingston \& Bauman, 2013). The level of unit cohesion was part of how they acted and looked (Naphan \& Elliott, 2015). Marines "are discouraged from looking unique, because that would encourage them to feel unique, to feel unique like an individual. The problem with individuals is that they think for themselves and of 
themselves, rather than for and of their unit" (Roach, 2016, p 32). Thinking for and of their unit meant that other people, the mission, and the bigger picture were more important than what they wanted. It meant that they were willing to die for each other (DiRamio \& Jarvis, 2011; Junger, 2014). In that willingness, these Marines discovered Fromm's (1956) definition of love. They may not have called it love, yet they discovered their capacity to love (being willing to make the ultimate sacrifice), more than to be loved (ask others to sacrifice for them). They experienced a love for each other with "unlimited liability"; they were in real community with each other (Greenleaf, 2008, p 39). The loss of such a connected group into a civilian society unable to fill the gap pointed to the loss of community in society at large (Junger, 2014; Junger, 2016; Smith \& Junger, 2016;

Wood, 2014).

It's not the experience

It's the people

It's the people that make it

You're just never going to feel that

Or see that again

It's the people that make the difference

That camaraderie in the Marine Corps

You're just never going to feel that again

Found Poem from Group Meeting \#2, 12/13/15

It was no wonder that Veterans sought each other out, consciously or unconsciously, as it was with other Veterans that they were able to be themselves again (Ackerman et al., 2009; Bellafiore, 2012; Kok, 2015; Livingston \& Bauman, 2013;

Phelps, 2015; Rumann \& Hamrick, 2010; Summerlot et al., 2009). Indeed, frequently, it didn't matter if the Veterans were the same age or from the same era.

Whatever generation of military 
Together we served

Regardless of whether or not you were by my side during deployment

Together we served

I never served with you,

Never went on deployments together

Always hold that commonality

Together we served

We never served together

Started talking

So many things in common

Together we served

Fucking boot camp stories

Always boot camp

Fucking fleet stories

Together we served

Found Poem from Group Meeting \#1, 11/29/15

"I didn't realize until now, what they told us in boot camp. It really is for life!" Beaver admitted to the group.

"Hell, yeah it is!" Lance agreed. "I mean, you know in a few years we're gonna be those old guys in the red jacket with the EGA on the back, going all moto. You may want a break for a bit when you first get out. But not too much of a break, because the Corps is in your blood."

"Fucking old guys, man. Have you ever listened to some of their stories? I mean these guys, and I laugh at their hats with Korean War or Vietnam Vet, but these mother fuckers are badass. The stories they tell with the gear, or the lack of gear, that they had. They did some amazing shit and survived. But they tell it like, it's all nonchalant. They are hard core. They have every right to wear that fucking hat every goddamn day." Beaver was laughing as he spoke.

"It's true. Our gear kept getting better and better. They told us 'If you wake up 
after getting hit, you'll survive' because the trauma meds are so good.” Sgt. G added. "Hell, I even heard that there is a sniper that uses his fake leg downrange as a bipod for his rifle."

At this, V interrupted, "But going back to the old moto Marines; it is the responsibility of every Marine to continue the standards and traditions of all the Marines who came before, as well as for those who will follow us. So, for the guys who went into battle with nothing more than a helmet and a uniform, we have to continue bravely and honorably. Even beyond our active duty service." At this every Marine at the table nodded in agreement.

Lance put down his coffee mug as he spoke. "And every time you put on the uniform, you are representing every Marine in history and in the future. You are in a high-level competition with those who came before you, and they have done great things. So, as a Marine, we are just walking in the footsteps of these great names. That's why Marines are so confident or cocky. That is where they have to be. It's what keeps us accountable to and for every other Marine."

"Exactly!" Beaver agreed. "Before boot camp it didn't really sink is that I was becoming part of the most fucking noteworthy fucking branch that ever walked the fucking Earth, and I was about to embark on this little journey of mine. It never hit me; the gravity of the Marine Corps' role in any conflict, war, battle, whatever you want to call it. It wasn't until the history lessons in boot camp that I started to take in the emotional and the physical, the whole gamut of the Marine Corps in its entirety. That's when that kind of shit set in. What the Marine Corps had done in American history and the responsibility of being a United States Marine.” 
"It is also what makes leaving so fucking hard." V leaned in a bit as he spoke, "I have not found a single thing that made me feel that same sense of purpose or accomplishment as when I was in. All the shit I deal with now is just to fucking make money, pay bills. I miss it so much, man."

It's hard not having a job with a purpose

That fulfillment

It is such an accomplishment Doing stuff for a greater purpose I haven't felt that in awhile

Found Poem from Group Meeting \#1, 11/29/15 (Junger, 2016; Naphan \& Elliott, 2015; Wood, 2014)

Being a Marine was so much more than just wearing the uniform, and every Marine at that table knew how important that uniform was. Being a Marine meant being part of a culture of honor, courage, and commitment; one that prompted respect among civilians and other military service members. It was also one of the tenets of VCT (Phillips \& Lincoln, in press). The notions of honor, courage, and respect became part of their identity, and thus part of their expectation about how they would be treated (Burke, 1991; Stryker \& Burke, 2000).

The transition to such elevated standards for themselves and others began in boot camp. The main goal of boot camp was to transform recruits, test their limits, and build United States Marines (Chenoweth \& Nihart, 2005). It was about making Marine part of the identity of each man and woman in the uniform. As they came with multiple identities, including numerous social identities they had been given to them by others (Abes, Jones, \& McEwen, 2007; DiRamio \& Jarvis, 2011). And while three of the Marines of The Unit were Men of Color, the topic of race was only a very minimal part of the discussions. This might be a result of the indoctrination of the Marines that 
encourages Marines, beginning in boot camp, to see only "green Marines and dark green Marines" in the members of their units (Harada et al., 2002). Marines work to mission completion!

The Marines performed their identities daily for at least four years, and the more one performs an identity the stronger it becomes (Butler, 1991). As such, the Marine identity was core to each one of the Marines at the table ( Abes, Jones, \& McEwen, 2007; Hammond, 2015). While each Marine had multiple identities, another tenet of VCT (Phillips \& Lincoln, in press), when they were together their Marine identity was by far their most significant identity. It was that sense of community and comfort that they had with each other that they also sought out when there were in school. Once they found each other, they would create wolf packs reminiscent of their active duty units (DiRamio et al., 2008; Livingston \& Bauman, 2013; Naphan \& Elliott, 2015). If you were the accepted civilian in the group, like Jamie, you were able to experience a piece of the unbridled love and affectionate "shit giving" and inappropriate humor that would occur.

Beating off jokes

Dead people jokes

We laugh about it

Most people....

Found Poem from Group Meeting \#1, 11/29/15

Most people would be disturbed by our humor.

A video on Facebook

Some insurgent getting dusted

"Goddamn, all right"

This dude wants to kill you

That's fucking sad.

He just got served

Whatever

You're scaring me

That's funny shit

I'm pretty sure there are a lot of people 
Don't see the point

Don't think it's funny

For us, you've got to lighten up while we're out there

You cannot be that serious

Found Poem from Group Meeting \#4, 4/10/16

Jamie was even lucky enough to get to participate in an entire conversation about

"port-a-shitters"

When you've shit in an oven

You get to be picky where your next shit is going to be

I trained my whole life to hold it

Because I was deployed

That is the sole reason why I get to be picky

You have to go to the restroom

You're going to walk down there

It's a mile walk

All of us are going to throw rocks at you when you go by

"Oh, they got to take a shit"

Then when you're in the head

"Hey what's taking you so long?"

When you're in a mini oven

And you're worried about some asshole

Coming and tipping it over

"Don't tip it over on the door"

It's a microwave

100 degrees out here

It's like 150,170 in there

Flies up your ass

These aren't like US flies

They don't get cleaned either

There's like piss all over the fucking place

That's disgusting

When you shit overseas...

Civilians dude

They just don't fucking get it

Found Poem from Group Meeting \#1, 11/29/15 
While a conversation about port-a-potties may seem odd, it speaks to two important points concerning Marines. First, the level of comfort and crudeness that can occur among Veterans (or in active duty military), that can be inappropriate for civilized conversation. Second, there is an assumption (reinforced by metanarratives) that Marines are tougher than anything and remain unfazed by any discomfort or struggle. However, as Jamie learned, it was their previous suffering and endurance that has led to their increased standards of comfort whenever possible.

Part of that desired comfort was being completely who they were. When the Marines got together, what they were was even more Marine. There was a lot of potentially offensive language, as Marines are not known for their delicate and pure demeanor.

We don't say it to offend anybody It's just part of our lingo

Our language

When we curse, we don't curse at you, we...

I'm just trying to explain

It's just part of our language

Just part of our lingo

We've heard it all

Found Poem from Group Meeting \#2, 12/13/15

The absence of judgement made them comfortable, both in The Unit and with other Veterans on campus. It was the other Veterans on campus that got them through school, helped them actually connect to the campus, and supported their transition (Ackerman et al., 2009; Barry, Whiteman, \& Wadsworth, 2014; Kok, 2015; Livingston \& Bauman, 2013; Olsen et al., 2014; Summerlot et al., 2009). Yet, each Marine would tell you that they could never be a civilian (a point I will discuss more in depth later). Interestingly enough, Veterans who pursue higher education are found to have 
more pride in their military service (Aikins, Golub, \& Bennett, 2015). This might have been a result of the civilian privilege that exists in higher education, which was one of the tenets of VCT (Phillips \& Lincoln, in press). Because of experiences that reminded the Marines that the world is designed for civilians, including some class discussions, they would cling tighter to their Marine identity which they suffered in boot camp to earn. It was certainly true for the Marines in The Unit, as it was their experience that generally only faculty and staff who were Veterans had realistic expectations. Some civilian faculty would look to Veterans as lazy drones incapable of thinking for themselves, to the point that it was believed that they were "beyond help."

Such deficit thinking, exists even in research on Veterans when it inappropriately references a desire by Veterans to "just do pushups" for class (Arminio, Kudo Grabosky, \& Lang, 2015) or a change to critical thinking (Arminio \& Kudo Grabosky, 2013) and reflection (DeSawal, 2013; DiRamio \& Jarvis, 2011; Phelps, 2015), as a significant, dramatic shift from military functioning. Deficit thinking is another one of the tenets of VCT (Phillips \& Lincoln, in press) and, unfortunately, it exists well beyond higher education, as it is a part of the metanarrative for Veterans of the Wounded Warrior (McAdams \& Janis, 2004; Moore, 2014).

Notably, certain faculty members would view student Veterans differently. Jamie found that the Veterans in her classrooms were more mature and disciplined with their educational pursuits (Bellafiore, 2012; Brown \& Gross, 2013; Cropsey \& Hendrickson, 2013; DiRamio et al., 2008; Glasser et al., 2009; Hassan, Jackson, Lindsay, McCabe, \& Sanders, 2010; Olsen et al., 2014; Osborne, 2013; Rumann \& Hamrick, 2010; Schiavone \& Gentry, 2014; Street, 2014), although they often teased each other in class, much like 
the Marines in The Unit. She also found that her Veterans often drew on their leadership experience (Olsen et al., 2014) for class group work, discussions, and presentations. Often, it was the faculty who the Veterans bonded with, as their life experience was more equitable than compared to the other students.

At times, other students found the Veterans' confidence to be intimidating. When Veterans would come into class, they came with many experiences the other students didn't have. During their time in the service, they had met a variety of people from all over the country, or around the world if they deployed (DiRamio et al., 2008; Hassan et al., 2010; Osborne, 2013; Osborne, 2014; Reynolds, 2013; Schiavone \& Gentry, 2014). Veterans walked into the classroom with a greater appreciation for the world at large (Cropsey \& Hendrickson, (2013; Olsen et al., 2014; Reynolds, 2013). So, Jamie always appreciated their ability to add to the class discussion (DiRamio et al., 2008; Osborne, 2013; Phelps, 2015; Rumann et al., 2011; Vacchi, 2012), so much that it altered the course of her life within her education and research. 


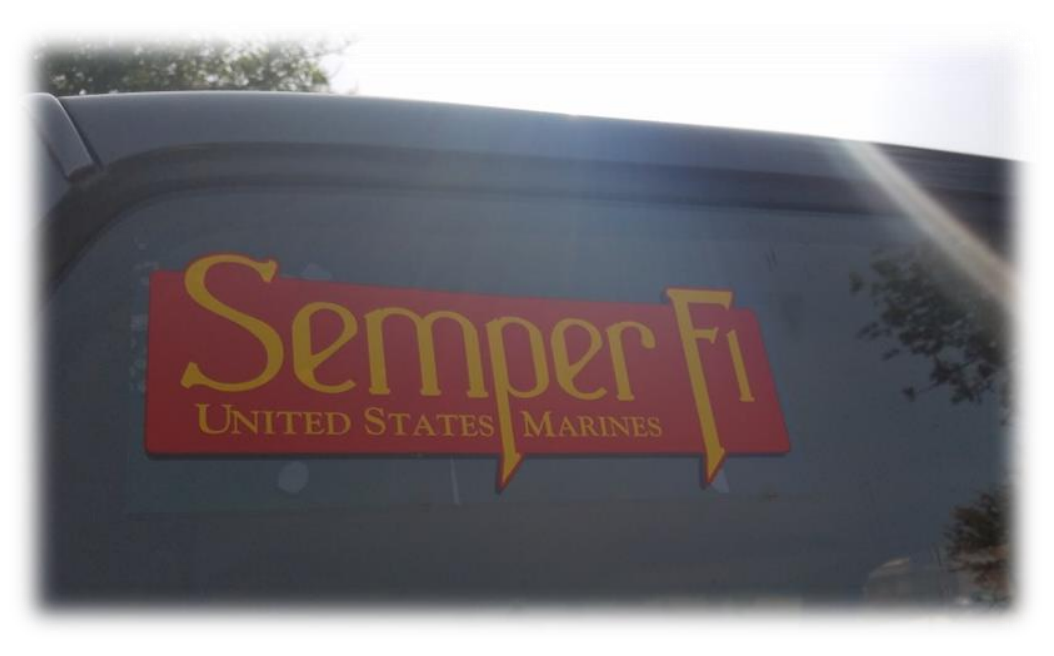

\section{The Proud}

For the Marines in the Unit, education did not start as a path to greater learning or engagement in discussions. It was a job (Naphan \& Elliott, 2015), the next mission to complete. Because society has made it clear to the Marines that even with an extensive, honorable, and impressive military career, a college education is what made someone valuable. So, if they wanted to compete with the civilians in the job market, they had to become equal. That meant they had to obtain a college degree.

Just a piece of paper

End of the day

That's all I need

A necessary evil

I enjoy education but....

Without that piece of paper

Necessary evil

May not need a piece of paper to be educated

I don't think school made me any smarter

This day and age

Everybody wants

That stupid square piece of paper

Just another piece of paper

To really achieve anything now 
To get somewhere

Promotion

Pay raise

Just the getting in the door

Found Poem from Group Meeting \#1, 11/29/15

(Arminio, Kudo Grabosky, \& Lang, 2015)

Since school was a mission, and they were all trained for mission completion, they completed their degrees. Every Marine in The Unit acknowledged that going to college after the Marine Corps greatly impacted their success level in the endeavor. It also, occasionally, negatively impacted their relationships with the civilian students.

I think the problem is people don't understand

What we're used to, like

We have a certain way of doing it

Anybody that has not served

They don't understand the importance

Of being punctual

Of getting shit done

When it's supposed to be done

We train to mission accomplishment

The result of not getting that mission done

Losing half your damn unit.

Losing this many pieces of assets

Just losing the fight in general.

We take that same mindset to school with us

To everything

Assignment due this day

If it's not done by this time

We're shit out of luck

There's not catastrophic results in school

It's just a grade

It's so ingrained in our head

Meet a deadline

Meet a deadline

Mission accomplishment

Don't meet a mission, 
Dead in the water.

In the Marine Corps

Don't get A, B,C,D,

Get pass or fail

Pass or fail

Go or no go

Go or no go

Found Poem from Group Meeting \#2, 12/13/15

Sometimes, the Marines would try to explain these differences to the civilians.

Often in group projects, the Marines would try to "handle civilians" by identifying strengths and weaknesses of the group, delegating tasks, and just "take charge and get it done." As the group leader, sometimes they had to lead their group with some tough love. While some civilians thought that "take charge attitude" was a bit harsh, for the Veterans, they were much softer than they used to be.

V had explained "As shitty as we may look when we're correcting a civilian, it would blow your mind to realize how soft we are in comparison to being in the Marines. I feel like I toned it down a lot.”

Civilian students may not have understood, but other Veterans did. So, again, they sought out other Veterans on campus (Bellafiore, 2012; DiRamio et al., 2008; Hammond, 2015; Kok, 2015; Livingston \& Bauman, 2013; Olsen et al., 2014; Phelps, 2015; Rumann \& Hamrick, 2010; Summerlot, Green, \& Parker, 2009). Of note, when the Marines in The Unit reflected on their educational experiences, they saw that is was more than just a piece of paper.

"I think it helped soften me, so that I could communicate with civilians again. It made me more mindful of other people's feelings." V acknowledged his personal transformation. 
Beaver agreed, "Yeah, you can't expect civilians to understand or relate or be on the same level as you. You have to bring yourself to their level. It's kind of tricky to say, it's not about intelligence. It's more about not getting irritated with the fact that they're not picking up what you're putting down. You know, that's not their fault. They'll never understand it; they've never heard it before. You have to sort of dumb it down, I guess.

"But, at the same time, you cannot expect to get out of the Marines and expect the whole fucking world to understand everything that you're talking about. I tell Marines just out, that you've had a real-life experience here. Being in the Marines is a life changing, life altering decision. Civilians don't have that, because they chose not to go through that. You chose to go through it. You have to find somewhere in the middle to compromise. You cannot hold it against them because they didn't want to go. They're not holding it against you because you volunteered to go. If anything, most people I've found, most people thank you for your service. Even if it's fucking fake I don't give a shit. 'You're welcome."'

Sgt. G didn't really hear Beaver, as he was thinking about his educational experience. "You know, I think education was the next best thing to the service. It gave me some sense of accomplishment again. Don't get me wrong, it wasn't the same as being in, but it was closer to most things I've done since getting out."

"And no education is ever wasted." Lance added. "I started in environmental science. I learned how to sail. I did the liberal arts classes. I love art and stuff like that. So, it was neat for me to expand my knowledge, and not just talk about weapons and things like that. But that process took a while, and I went back to Veterans. I am always 
the Veteran guy - at work, in school, and in the community. I gave a speech about PTSD last week."

“Oh fuck, don't get me started on PTSD!” Beaver threw his hands in the air as he spoke. "I cannot tell you how many fucking people think that just because I am a Marine, I must immediately have PTSD. That included some of the goddamn instructors at East Forrest College, too.”

"Really?" Jamie was genuinely surprised. She knew the symptoms of PTSD, and knew that more symptomology translated to poor academic effort and self-efficacy (Ness, Middleton, \& Hildebrandt, 2015). That was not what she saw in Beaver. However, Jamie was also keenly aware that a large percentage of the population experienced and viewed Veterans through the lens of the media. She thought back to the conversation with Jim, Pete, and Randy, concerning the media's portrayal of Veterans, and acknowledged that another tenet of the VCT was in action. Veterans were often presented as deviants, by civilian authors (Phillips \& Lincoln, in press). Many media consumers never stopped to question the accuracy of the narrative, so Veterans often suffered microaggressions in everyday life (another tenet of VCT; Phillips \& Lincoln, in press).

"Yes! Fucking really!" Beaver sat up as he began his rant. "And with the backgrounds for police departments, too, dude. I cannot tell you how many times they asked me if I ever hit my ex-wife or girlfriends. They called my ex-wife to ask her about it, multiple times. Are you telling me, that it was a standard practice to ask every past partner of a potential candidate and the candidate about domestic violence 10, 15, 20 times? No, that shit was because they assumed as a combat Veteran, I had to be abusive. 
Bullshit, bro! Fucking bullshit!”

"Oh, it's bigger than that!" Lance added. "I went to a community meeting last week in Newport Beach because they were all upset that Vets with PTSD were going to move in and start hurting their neighbors. I fucking went through the roof."

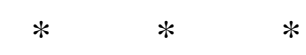

It just happened the week before and Lance had received the phone call at the last minute. There was a town hall meeting as a result of a federal affordable house grant project that was passed without much community knowledge or buy in. However, it was the fear and concern from the Newport Beach that bothered Lance.

When Lance stepped up to the microphone to speak he was poised, but pissed as hell. "It's like you might as well just say we don't want a bunch of black people being here, but you won't say that because you're educated people. That would make you racist."

A few members of the audience looked shocked. One of the community members stood up and defended her fear. "I took my daughter to the park when she was a child. Now, I take my granddaughters to the park. I don't want some weird Veteran sitting on the bench, thinking about who knows what. Accidently mistake her for the enemy, or, I can't even imagine..."

"With all due respect, ma'am, we're not going to be sitting on a bench. But if we want to, we can, as it is a PUBLIC bench. I think your bigger concern should be the number of sex offenders in your neighborhood. I did a quick search online on the way over, and did you know 571 sex offenders live within a mile of your precious park? And here you are worried about eight Veterans who are more likely to have combat scars?" 
Lance finished telling The Unit about the meeting in Newport Beach, and none of them looked surprised at all. It hurt Jamie's heart that they all dealt with this negative perception as part of their daily experience. It was another reminder of the deficit thinking that followed Veterans (Phillips \& Lincoln, in press).

Sgt. G knew too well the impact of negative perceptions of Veterans and PTSD. "I got disqualified from LA Sherriff's because of my PTSD." He shared. "I have a 10\% rating. Fucking 10\%, that's it! I even paid for a second evaluation. The psychologist did another full assessment, it took forever. She submitted the appeal to the department and assured them that my PTSD would not inhibit my ability to function. She said that I should be a police officer. But, nope! Those four fucking letters, P T S D, they kept me from law enforcement."

Everyone at the table was aware of the damage a PTSD diagnosis could have on potential careers in law enforcement, government, or other positions requiring security clearances (Zoroya, 2016). It was at times why many Veterans would not seek help. Other times, it was due to the fact that they had been trained in the military to work through pain (Ackerman et al., 2009; Livingston \& Bauman, 2013; O’Herrin, 2011; Osborne, 2013; Phelps, 2015; Vance \& Miller, 2009; Vacchi, 2012). Or, they just didn't see themselves as needing any help (Arminio \& Kudo Grabosky, 2013; DiRamio et al., 2008; Ford et al., 2009; Smith-Osborne, 2012). Another piece of the PTSD puzzle is that the DSM 5 diagnosis for PTSD is not the most fitting label for combat Veterans. Their reaction to combat is normal, and pathologizing that response does not help their return to civilian life for themselves or those around them (Hoge, 2010; Smith \& Junger 2015). 
Instead of working through their experiences and acknowledging that much of the symptomology might also be a result of training, not trauma, they are labeled or categorized (Hoge, 2010). The result is civilian fear and a negative self-perception, and change in physiology, for Veterans (Hoge, 2010).

"Law enforcement isn't a second military though." Lance continued the conversation about law enforcement and tried to reassure the other Marines that not being a cop might be positive. "You think it might be similar brotherhood idea, that they would respect your military service. But they don't give a shit. Once you're in the department, you have to re-earn everything."

“That would be another example of civilian privilege, wouldn't it?" Jamie asked the group. As they thought about what civilian privilege might mean, Jamie continued. "You know Critical Theory is all about power, privilege, and oppression (Freire, 1994; Freire, 1998; Freire, 2000; Fromm, 1955; Fromm, 1969; Fromm, 1973; Fromm, 1976; Giroux, 1983; Giroux, 2011; McLaren, 2009; McLaren, 2013). Who is in power, who is oppressed, and so on. Marx speaks of use value to define how much something or someone is worth (1887). It appears that, after you are discharged, the actual experience from the Marines has no recognized use value. It is a perception in our capitalistic society that keeps Veterans at the mercy of the privileged civilians who are able to write their stories and homogenize them or make all Veterans the same. Both of those ideas are part of Veteran Critical Theory (Phillips \& Lincoln, in press), and y'all seem to be confirming the various tenets of the theory."

"Well, good for us!” Beaver replied. Everyone chuckled a bit, and then he continued. "You know, when I got out, I was ready to start my life. At least I thought I 
was ready! I went through TAPs. Now granted it was only two days, but when I left, I thought I was ready to be a civilian again. It wasn't until later I realized I should have fucking stayed in. Maybe the General knew something I didn't when he kept asking me if I wanted to reenlist."

When the Marines in The Unit went through the Transition Assistance Programs (TAP) it was far from what would be genuinely helpful for anyone transitioning out of the Marine Corps. It has changed since Sgt. Stepo was in; he was told, "You are now prepared for one of two careers: Law Enforcement or the mafia” (M. Steponovich, personal communication, 17 December 2014). Yet, the use of active duty Marines to communicate the expectations of Marines transitioning out of the Corps was not effective. Also, the focus was more on mental health and finding employment (Ackerman et al., 2009). So returning, starting school, and the actual transition to civilian life often resulted in being more difficult than expected (Miller, J., 2013; Phelps, 2015).

There was also some inconsistency in some of the procedures: Lance \& V wore their normal camouflage uniforms (cammies) in 2011, Sgt. G wore civilian business attire in 2011, and Beaver was in civilian clothes (civvies) in 2008. Yet, while they may have worn different clothes, every single Marine reported that all other formalities and rituals of the Marine Corps remained.

“So, should TAPs change?” Jamie asked The Unit.

“Absolutely!" Sgt. G answered as Beaver and V nodded their heads. "It needs to happen within the Marines, since that is where we are."

Interestingly, the Marine Corps has made improvements to the transition 
resources available to all Marines. The Marine Corps Gazette has highlighted that issue, as it is one that will impact every Marine that does not die during their active duty service. From articles that suggested Marines need to plan their exit, just like in the field (Timmerman, Hepler, \& Orient, 2014) to articles about advise on the procedural piece of leaving the Corps (Ray, 2013), there was a variety of information, yet all that information may not have gotten all the way down within the troops. Anyone who planned for a career change needed to think about the necessary education and start networking to make the career transition easier. The same was true for Marines, as they should have begun that process about a year before their EAS (Expiration of Active Service) date (Timmerman, Hepler, \& Orient, 2014). The American Corporate Partners (ACP) even created a mentor program to assist Veterans in transition with networking by conducting assessments that aid both the mentor and mentee in the transition process (Swope, 2014). The relationship between the mentor and mentee is reminiscent of the relationships many NCOs have with their Marines, full of duty and obligation for the NCO/mentor to help the Marine/mentee succeed (Ibid.). This mentorship is important because for many Marines transitioning to a civilian career they must also deal with assumptions that may hinder their opportunities so they need to "civilianize" their resume and interview style as a crucial piece of their professional civilian success (Timmerman, Hepler, \& Orient, 2014).

Indeed, as a result of the personnel drawdown that began in 2009, the transition services in the Marine Corps were forced to improve. Taking from the model of participation in a Personal Readiness Seminar (PRS) at the first assigned duty station, the Corps created the Transitional Readiness Seminar (TRS) for departing Marines, to begin 
12-14 months before their EAS (Gaddo, 2015). The five-day TRS allows Marines to create individualized transition plans and receive their Verification of Military Experience and Training (VMET), which documented their military career (Ibid.) It is also during this seminar that Marines can join the Marines for Life (M4L) network that will offer support beyond their separation from the Marine Corps (Forkin, 2015; Gaddo, 2015). TRS began in fiscal year 2014 (FY14) as part of the Marine Corps Transition Readiness Program (TRP), as a replacement for TAP (Forkin, 2015), which is what the members of The Unit went through. With the introduction of career assistance from the Department of Labor (DOL), an entitlement brief from the VS, and individual transition plans (Ibid.), Marines transitioning out in 2015 had significantly more resources available to them than the Marines from The Unit. The TRS was mandatory, while the two-day pathway seminars focused on college/university education, career/technical training, employment, or entrepreneurship were optional (Ibid). Unfortunately, since it was optional, less than $25 \%$ of those who qualified attended (Forkin, 2015, p. 28). In 2013, a Capstone was added, to ensure that Marines met Career Readiness Standards (CRS), which required Marines, at least 90 days before separation or retirement, to:

- Complete a 12-month post-separation budget;

- document requirements and eligibility for certification, licensure, and apprenticeship;

- evaluate the transferability of military skills to the civilian workforce and a gap analysis;

- register on the e-benefits website;

- complete an individual transition plan; 
- complete a Continuum of Military Service Opportunity counseling;

- complete a job application package or present a job offer letter;

- complete the assessment tool to identify personal interests concerning career selection; and

- receive a DOL Gold Card and understand that post-9/11 veterans have priority for six months at DOL American Job Centers.” (Forkin, 2015, p. 29).

The Capstone was part of the M4L cycle that would follow a Marine from the yellow footprints to their return to civilian society with seven different touch points over their Marine career (Ibid.). Unfortunately, as of September 2015, there was no case management system to assess the effectiveness of the M4L cycle (Ibid.). Instead, the plan was to find data from other databases, and to rely on locally managed data for compliance rates (Ibid.). As a result, a great plan floundered as it did not have a realistic method of assessing the effectiveness of the program, and no Marine Corps Orders (MCO) or formalized training requirements had been on the TRP and the M4L cycle (Ibid.).

Not all of the Marines in The Unit thought the responsibility to transition Veterans to civilian society was with the military.

"I don't think so." Lance offered a different perspective. "The job of the Marines is to fight and win wars. They are not there to tell you how to become a banker. Once you're out, they don't give a fuck about you." Everyone looked at Lance for a moment, as they took in the gravity of his statement.

"So," Jamie began, "should the transition support happen within higher 
education?"

Immediately, Beaver spoke up. "Nope. Because if you tried to have the schools make changes, make these little things different, and maybe easier, or whatever the fuck the case is, it won't work. Because you're going to have all these little whiny crybabies who have never done shit with their life, "How come they get that?" Their voice matters. I guess that is that civilian privilege shit you were talking about (Phillips \& Lincoln, in press)."

Throughout this story you have heard about some of the resources available to Veterans at different campuses. Things like Veteran Resource Centers (Brown \& Gross, 2013; Caspers, 2013;Community College Times, 2012; DeSawal, 2013; DiRamio \& Jarvis, 2011; Ford et al., 2009; Griffin \& Gilbert, 2015; Jackson et al, 2013Osborne, 2013; Persky \& Oliver, 2011; Sander, 2012b) and Veteran Student Organizations (Cook Francis \& Kraus, 2012; Cropsey \& Hendrickson, 2013; DeSawal, 2013; Hawthorne, Bauman, \& Ewing Ross, 2013; Mikelson \& Saunders, 2013; Osborne, 2013) where part of the experiences of the Marines in The Unit. Many institutions are trying to identify themselves as military friendly or veteran friendly (Brown \& Gross, 2013; Lokken et al., 2009), as they often turn to the 8 Keys (listed below) to guide their programs and policies:

1. Create a culture of trust and connectedness across the campus community to promote well-being and success for veterans.

2. Ensure consistent and sustained support from campus leadership.

3. Implement an early alert system to ensure all veterans receive academic, career, and financial advice before challenges become overwhelming. 
4. Coordinate and centralize campus efforts for all veterans, together with the creation of a designated space (even if limited in size).

5. Collaborate with local communities and organizations, including government agencies, to align and coordinate services for veterans.

6. Utilize a uniform set of data tools to collect and track information on veterans, including demographics, retention and degree completion.

7. Provide comprehensive professional development for faculty and staff on issues and challenges unique to veterans.

8. Develop systems that ensure sustainability of effective practices for veterans. (Baker, 2013, para. 2).

Those 8 Keys have led to the creation of numerous resources that the Marines in The Unit might not have had, or taken, the opportunity to utilize. However, as institutions are trying to bridge the gap between military and civilian, I think it is important to at least list some of the campus resources that are available:

- Veteran only orientation prior to the start of the school year, creating an opportunity for Veterans to gather together, meet each other, and learn about the specific resources and benefits available to them (Cropsey \& Hendrickson, 2013; DeSawal, 2013; O’Herrin, 2011; Osborne, 2013; Persky \& Oliver, 2011);

- Transition coaches who makes contact with Veterans prior to the start of classes to answer any questions and serve as a guide for navigating all of the procedures at school (DiRamio et al., 2008);

- Veteran specific study skills course that highlights the resources available on 
campus for Veterans, while supporting their transition to student and civilian (Minnis, Bondi, \& Rumann, 2013; Smith-Osborne, 2012);

- Veteran only cohorts for general education courses, so Veterans are able to support each other throughout their academic journeys (Minnis et al., 2013; O’Herrin, 2011);

- Veteran Resource Center with campus services just for Veterans (Jackson et al, 2013; McBain et al., 2012);

- Veteran contacts in student services, such as Financial Aid, Registrar, etc. (Muckenfuss, 2013; O’Herrin, 2011);

- Veteran Services Professional or Office that includes all the resources and benefits as a VRC, without the physical location (Arminio \& Kudo Grabosky, 2013);

- VetSuccess on Campus (VSOC), which is basically a two-person VA office on campus. The campus must meet certain requirements and be approved by the VA for this program (Veteran Benefits Administration, 2011);

- Mentoring programs, with faculty and staff (Moon \& Schma, 2011) or other student Veterans (Glasser et al., 2009; Griffin \& Gilbert, 2015; Mikelson \& Saunders, 2013; Moon \& Schma, 2011; O’Herrin, 2011);

- Military tuition discounts or military scholarships (McBain et al., 2012);

- Bachelor's degree programs specifically matched with a particular military occupational specialty (MOS) (Brown \& Gross, 2013)

- Priority registrations for Veterans allows Post-9/11 GI Bill processing earlier and greater potential to meet school funding deadlines (Cook Francis \& 
Kraus, 2012; Moon \& Schma, 2011; Vacchi, 2012).

- Tuition assistance programs to provide financial aid for Veterans until the GI Bill is processed, so they do not have to pay out of pocket (Moon \& Schma, 2011)

- For Reservists/National Guard Service Members:

- Full tuition refund and full withdrawal if a deployment occurs early in the term for a Veterans (DiRamio \& Jarvis, 2011);

- Maintenance of in-state tuition status even when deployment is extended beyond the time allowed for residency (Brown \& Gross, 2013; McBain et al., 2012);

- Extended access to school email and other technological resources to deployed students so that faculty can work with them and they can complete coursework (while deployed or upon returning) and continue their academic progress (Moon \& Schma, 2011);

- Streamlined the reenrollment processes so Veterans can return to class with less paperwork and fewer inconveniences (Abel et al., 2013);

- Online courses to complete during deployment (DiRamiro \& Spires, 2009; Ford et al., 2009).

A VA Certifying Official on campus is a minimum requirement for schools that have students utilizing the GI Bill. Such an individual's assistance is crucial as navigating the financial processes of both the VA and a Veteran's school can be challenging (Ackerman et al., 2009; DiRamio \& Jarvis, 2011; Reynolds, 2013; Rumann et al., 2011; Vacchi, 2012). There are other federal resources available to Veterans, in 
addition to the Post-9/11 GI Bill:

- The Yellow Ribbon Program is a process established between degree granting institutions and the government in which the school provides funds for tuition, for an agreed upon number of Veterans. The funds are then matched, to a certain amount, by the VA, and the money is not taken from the Veteran's GI Bill entitlement (U.S. Department of Veteran Affairs, 2013a);

- Joint Services Transcript helps Veterans obtain college credit for military service as a consistent tool, across military branches and academic institutions, that documents the America Council on Education (ACE) recommended (and standardized) college credit for various military experiences (Cropsey \& Hendrickson, 2013; DiRamio et al., 2008; Persky \& Oliver, 2011; Sander, 2012b; Voluntary Education Programs, 2013);

- The Defense Activity for Non-Traditional Education Support (DANTES) is available to help Veterans and institutions of higher education work together to assure that prior learning, even in the flexible and non-traditional format, is recognized (Cropsey \& Hendrickson, 2013; Ford et al., 2009; Persky \& Oliver, 2011).

The various financial programs were created for Veterans, to increase their access to higher education. Many of the other programs for Veterans mentioned are already utilized in general student support for other students, or specific populations of students (i.e. international students). As there is no "one way" to serve all international students, there is no single program that will provide for the needs of all Veterans (Griffin \& Gilbert, 2015). Considered by some to be the 'greatest untapped American resource' 
(Lighthall, 2012, p. 88), Veterans are a benefit to any college campus (Ackerman et al., 2009; Arminio \& Kudo Grabosky, 2013; Bellafiore, 2012; Brown \& Gross, 2011;

Cropsey \& Hendrickson, 2013; Glover-Graf et al., 2010; Jackson et al, 2013; O’Herrin, 2011; Osborne, 2013; Ostovary, \& Dapprich, 2011; Persky \& Oliver, 2011; Reynolds, 2013; Rumann \& Hamrick, 2010; Sander, 2012; Vacchi, 2012; Vance, \& Miller, 2009; Whiteman et al., 2013) and should be treated with the same care and attention as other students.

It is also important to note, part of the benefit of being military friendly or veteran friendly (Brown \& Gross, 2013; Lokken et al., 2009), is the increased enrollment of Veterans at the institution. Recognizing that the Veteran is part of a fully funded group, as a result of the Post-9/11 GI Bill, the institution's desire to be Veteran friendly may come first from a place of financial benefit (Phillips \& Lincoln, in press; Sander, 2012). The motivation to serve the Veteran is a secondary benefit. These factors support another tenet of VCT, as the services appear to benefit Veterans, when it is actually interest convergence, as it first benefits the civilian institutions.

Sgt. G's own history vividly illustrates the difference in the benefits he personally received due to the instructional management of Veteran funding:

At University of Phoenix, we got taken for a ride with our benefits Something to do with the way the class is set up Prorate the amount

Our benefits were supposed to be $\$ 2293$ a month We only got $\$ 1600$ or $\$ 1700$

"Well, you only went to school for five weeks, and you started on this day of the month." What about the rest?

I moved over to Argosy, another private for profit We got our full amount 
Full time, Full benefits

We had the same schedule

Same scheduling for classes as Phoenix

Same shit, 5-week courses

Phoenix we only got two thirds

What the hell!

Where's the rest of that money going?

Who's getting it?

What's going on with it?

They definitely made money off us,

I know that's an issue now... legally

Found Poem from Group Meeting \#4, 4/10/16

$* \quad * \quad *$

"You know," Lance began, "this is why so many Veteran service organizations were created, to help Vets transition. Whether it is to help connect with other Veterans and civilians or help with the transition from MOS to a civilian career. Unfortunately, many Veterans remain unaware of the number of great resources available."

Beaver looked at Lance, with an equal amount of frustration and hope, as he spoke. "I'm not looking for a job that is given to me just because I'm a Veteran. I don't need an acknowledgement of my experience. I just want them to recognize that I have the technical expertise and leadership skills for the job. I'm not asking for a job that pays really well, or that I don't know shit about. I'm just asking for a job that I know I can do. One that I am qualified for.”

"Getting a job when I got out was tough." Sgt. G agreed. "It took me almost two years to find something. I wanted to be in law enforcement, but we all know how that turned out. I finally got into the Orange County Park System. I like my job, but I still miss that sense of purpose I had in the Marines."

V was nodding as the spoke, "Took me about 9 months, and it was East College 
that helped me get in with Boeing. I worked the entire time I was at school. I didn't want a gap in my job history, and it paid off with my new job. I feel valued and appreciated, but I don't feel like that job that I have is as valuable as when I was in."

"I was lucky, because I had something lined up when I got out." Lance shared, "It was as a bartender, but it paid the bills."

Beaver was shaking his head, "I just... I get so frustrated. I left my job with San Gabriel to go to school, thinking that would help me. But I feel like ever since I left the Marines, I have been going backwards. I feel like all the places who say they are hiring Vets, just put that shit on their website to make people feel good."

Jamie agreed, “A lot of civilians like to 'support' Veterans, even if they don't actually do anything actively to support them. So, it would be an example of interest convergence, or where something is marketed to look like it helps an oppressed group yet is valued or supported by the privileged because it helps them. Starbucks has published a book about supporting Veterans, yet I do not honestly know how many Veterans work in their company, which is another of the tenets of Veteran Critical Theory (Phillips \& Lincoln, in press; Sander, 2012).”

“Okay, you keep talking about that. What else does the theory say?” Lance asked as he leaned in slightly. 


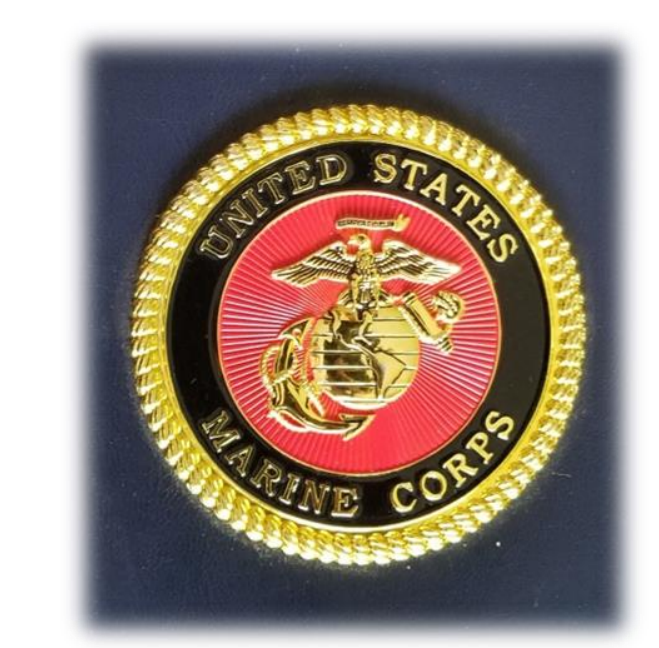

Photo of The Marines (Simmons \& Moskin, Eds. 1998)

\section{The Marines}

"One of the tenets that we have touched on, which is also a focus in my research, is the metanarratives, or the pervasive and limiting stories that civilians hear about Veterans. A civilian group who includes employers, strangers on the street, faculty, and higher education administrators, believing that all Veterans are wounded combat warriors, merciless killers, or heroes (Haynie, 2012; McAdams \& Janis, 2004; Moore, 2014). While all three of those perceptions certainly exist, in limited numbers, among Veterans, so do a great variety of other experiences and narratives. Veteran Critical Theory acknowledged that both the narratives and counternarratives exist, or that all of those stories are possible (Phillips \& Lincoln, in press).”

"Well of course all those possibilities exist. People need a fucking theory for that?!" Beaver asked rhetorically.

"No but think about how people treat you. Do you think people try to put you in one of those boxes (Hammond, 2015)?" Jamie responded to Beaver, and the rest of the group, with an inquisitive and caring look in her eyes.

Every Marine at that table was quite for a moment, and then Lance spoke. 
"Well, people always want to know if you've killed somebody. It's a morbid curiosity, but at the same time it is a major religious and moral line. People want to know, did this guy kill somebody? Could he kill somebody again? It's a big deal in our society, because normally if you kill somebody, you did something bad. For us it's different, because it was part of our job. It was what we did to protect ourselves instantly, without thinking about it usually. But that's a big thing that we're struggling with and people want to know. It's that divide, that unspoken, or sometimes spoken, question, that seems to come up. 'Thank you for your service,' but then, 'Fuck, did this dude kill a bunch of people? Did I just shake the hand of a killer?"

The perception that they are "killers" was often how they were viewed by civilian students (Hammond, 2015). Such a pervasive opinion about Veterans can begin to color an individual Veteran's self-perception, which can be harmful physiologically (Hoge, 2010) or can lead to isolation or nondisclosure (Hammond, 2015; Lang, 2013; Rumann \& Hamrick, 2010). It also impacts their identity, as it becomes part of the decision to openly share the identity, or keep in hidden, due to the perception and response from others (Abes, Jones, \& McEwen, 2007; Arminio, Kudo Grabosky, \& Lang, 2015). "You know," Beaver began. "Civilians say they want to get to know us, but I don't want them to judge me or change how they look at me. I think that is the issue for a lot of Vets. Civilians try to listen, but we're just not fucking talking. At the same time, we wish they understood more (Castro, Kintzle, \& Hassan, 2015b). I think it's going to be like that forever. Even my mom doesn't know half the shit that happened, and I'm super close with my mom. In reality, I don't want my mom knowing everything. She knows how many times I deployed and how many times I came back. That's pretty much 
all she needed to know."

"Seriously, most guys with a ton of war stories never left the base, never even went outside the wire." V added.

"Right, you find out they did supply or some shit." Beaver laughed as he spoke, so did the other three Marines.

"So," Jamie gave them a moment to focus, "If you could keep your military time, but take away your combat, would you?"

Without hesitation, four voices responded with absolute conviction, almost in unison, "No."

"Some of my best times in the Marine Corps were when I was deployed. Some of the funniest times," V added.

"You can be deployed and not see combat. So, you all still would keep it?" Jamie asked, intrigued but not surprised.

Again, in almost perfect unison, as if they were responding to a DI in boot camp, they all replied, "Yes."

Jamie continued with her questions, "Do you think you need to have something you love or need to protect, or something you hate to be able to pull the trigger?" At this, everyone at the table leaned back in their chairs to think.

Sgt. G spoke first. "I don't know if you necessarily need someone or need to love something or hate something to pull the trigger. I think it's more of a necessity to survive. It's instinct. You go through training; it's ingrained in us. I've been in a firefight. It wasn't that long, but I've been in a firefight, and I didn't think about anything. I didn't think about my daughter at home. I didn't think about my girlfriend or family. It just clicked. 
I'm getting shot. I'm going to shoot back."

Beaver added, "You don't think about it. The minute you're getting shot, you instantly, instinctively react the way you've been taught. It's like second nature. You don't really think about anything. If you have that privilege to come out of it, then you're like, 'Holy shit."”

"You're just so amped up on adrenaline and everything in the moment is just happening really quick, but really slow." V leaned slightly forward as he explained his experience.

Sgt. G began again, "I think the situations where you actually have time to think of shit is when there is no escalation of force. There's a show of force, somebody pointing a weapon at you or having a weapon present, but not necessarily engaging. I've had it happen, too. It was a little kid, holding an AK-47, going towards a convoy. I'm like, Oh shit. I'm on the guns. I'm expecting a daughter. Here I am, possibly going to shoot this kid. I don't want to, but you have time to reflect. Like, Fuck. There's a little kid coming at me, what do I do? I don't want to shoot him. He's got a gun, though. He can't possibly be that much of a threat."

As he spoke, the Marines at the table were with him on that gun. "He's not friendly, for sure." V confirmed.

Sgt. G continued "He can't possibly be that much of a threat with a gun. He doesn't know how to really use it, but if he pulls that trigger... all it takes is one shot. One driver gets hit and that causes a catastrophic chain reaction. Let's say that driver is hauling ammunition. Rockets, bullets and HE, he gets hit. It might be something, nonlive threatening, but it causes him to veer off the road. There goes the whole convoy. 
"Luckily, the kid got slapped in the head by some elder and he got pulled away. I was sweating bullets, fucking pounding chest. Just like, holy shit, thank God. Even then, in that instance, you're worrying about the situation ahead." Sgt. G breathed a sigh of relief, just telling the story. It was a powerful moment.

"But that isn't everyone's experience." Lance stated. "Not every single person in the military is kicking in the door. That's the Navy Seal bullshit movie crap. It was like the majority of the time we sat on the base beating off and throwing rocks. And then you had that one couple days like, fuck this sucks. Fucking get some. Contact left, contact right."

Jamie added, "That is getting back to one of the other metanarratives, the super heroic Veteran who single handedly saves an entire unit. But there is a danger in believing that all Veterans fall in one or those categories or are the same."

"We're not all the same" Beaver agreed.

"That is what I hope to share with people in the retelling of your stories. This work is in part about disrupting the limited stories that exist for Veterans." Jamie explained.

"Well, you should have had a few more Vets here, then Fenton." Beaver said to Jamie. He felt comfortable giving her a hard time, and had no problem honestly pointing out the small group at the table.

“Thank you, Captain Obvious." Jamie responded with a slightly defensive tone. "I also know that you are all Marines. The group at this table will start the conversation, it won't finish it." Jamie was very aware of the limitations of the work with The Unit. In addition to the small group, although Jamie went for depth not breadth, it was 
also only one military service branch. Jamie acknowledged that she selected Marines for two reasons; 1) her admitted bias because of her father, and 2) she felt that the esprit de corps that existed in the Marines made it harder to transition to civilian. As a result, she felt the while this was a group of Marines, it could serve as an example for other Veterans, because Marines probably had one of hardest times transitioning (Castro, et al., 2015a). Also, this group only included Marines who had successfully completed, or were about to complete, their bachelor's degree. That meant that there was no one in the group who had unsuccessfully attempted to obtain a degree and failed; that was another population that could add to the stories of transition. Also, as already addressed, The Unit consisted of only males, so the stories of female Veterans needed to be added. As far as the other diversities, all of the Marines in The Unit were heterosexuals from middle to low socio-economic class, two were Latino, one was Latino/Caucasian, and one was Asian/Caucasian. Thus, while there was variety, there was not representation from all of the different diversities.

Another characteristic about the Marines in The Unit is that they were all enlisted Marines, with a rank of E-5, Sergeant, and below. The E notes the enlisted status, $\mathrm{O}$ is for Officer, W is for Warrant Officer, and the number is the rank within the group. So, an E-5 would be in charge of Marines at a level of E-4, Corporal and below. Also, Corporals (E-4) and Sergeants (E-5) are NCOs, or Non-Commissioned Officers. While there is diversity in the ranks of the Marines, the fact that they were all equitable enabled the conversations and group formation that occurred. As Marines tend to always "measure up" in any way possible, the idea of having a great variety in the ranks in this type of study would have hindered the ability to have open, honest dialogue in the group. 
Also, no commissioned officers were included as the great majority of officers obtain their bachelor's degree prior to or during military service, not after (Marines.com, 2016a).

Jamie continued her defense to the group of Marines at her kitchen table. "My intention in gathering your stories was never to put every story possible out in the world. It was to move the conversation forward about the variety of possibilities in the stories of Veterans, particularly when it came to the role of higher education. And while you each have stories that are uniquely similar to other Veterans, there are thousands of stories not yet told, including more of your own. Just the act of listening to each other and listening to your own story represented to you might change how you experience the story (Banks, 2008; Barone \& Eisner, 2012). While you have many things in common, you are all different enough to represent another tenet of Veteran Critical Theory that Veterans have multiple identities that merge together to make you who you are. That is the idea of intersectionality (Phillips \& Lincoln, in press). Really you are more than just 'Green Marines and Dark Green Marines."”

V laughed at that. "Yeah, they used to say "Hey, V, you're the Mexican. Go 'acquire' some mounts for the MRAPs. So, I would go over there at night and steal it from a Humvee that was down. We tactically acquired it." An MRAP is a MineResistant Ambush Protected vehicle built to withstand an IED explosion.

"You just borrowed it, that's all!" Beaver said as he laughed, knowing that was a common occurrence during deployment.

"We gave it back." V was still laughing at the memory while he spoke.

"Not exactly what I was getting at," Jamie started to explain. "While you are all 
Marines, you also walk into every situation with other identities as well (ASHE, 2011a; McAdams \& Janis, 2004; Stryker, 1968; Stryker \& Burke, 2000). For example, none of you are Black Men, one of you identifies as White, two as Latino, and one as 'Hapa'. So, when you walk into a room, most people will see that first, before they see other Marine behaviors or identifiers. You are all men, so you can walk in this world very differently than I, as a female, am able to, safely. So, you have a variety of identities, many of which the world 'gives' to you (McAdams \& Janis, 2004)."

"I see what you're getting at. We are more than just Marines," Sgt. G summarized. "Because we are also college educated men, some of us are fathers, and so on. And sometimes it is a result of how other people see us, not just how we see ourselves."

“Exactly!” Jamie confirmed. "And as your collages all clearly showed, Marine is a core identity for each one of you (Hammond, 2015; Jones \& McEwen, 2000)! So, in many ways, that fact has altered how you see all of your other identities. The Marine Corps has become part of the lens through which you make meaning of all your other identities (Abes, Jones, \& McEwen, 2007).”

Interestingly, Jamie then had several inquisitive and reflective faces at her kitchen table, so she continued. "Think about it. How you view everything in the world today is colored by your time in the Marines. \#BlackLivesMatter is viewed not by two Men of Color, but by men in uniforms. It is neither good nor bad, it is just an observation about the power and permanency of the Marine identity."

"There is a reason that Semper Fi is the motto." V declared as he leaned back.

“Once a Marine, Always a Marine.” Lance agreed. 
Jamie replied, "And yet, you are not active duty anymore. So, you all are forced to live on what Anzaldúa (1987) refers to as the borderlands. That third space between Marine and civilian; that place where you are neither fully one or the other, and always both." As they were thinking, Jamie slipped in, "this is another one of the tenets of Veteran Critical Theory (Phillips \& Lincoln, in press).

"But, more importantly," Jamie continued, "You are NEVER not a Marine. So, you have to shift your identities to what you are focused on at the time, but Marine is always core to who you are and how you move in this world (Hammond, 2015; Jones \& McEwen, 2000), which might make it harder to be in this world than if you were a civilian.”

"Fuck yeah it does. Marines have different standards, dude. Just different standards," Beaver admitted with both frustration and pride.

Sgt. G added, "I've been told that I'm not in the Marine Corps anymore, that I need to calm down a little bit. I was like, 'You serious?'"

At this, Lance leaned onto the table, and began to share, "It's way easier to be a civilian than a veteran. You don't necessarily expect anything, but as a veteran, you hold yourself to a fucking higher standard. You try to be good, for yourself and every Marine who came before you. As a civilian, you're just trying to make it, pay the bills, and look good on Facebook."

"I think it also impacts your self-worth as a Veteran," V revealed. "We know we're worth more than what we're doing. Beaver knows he's worth something more than where he is right now. Fuck, even I knew I was worth more than where I was. I'm not anywhere better now that I'm with Immigration, but the job is so simple. Anybody could 
fucking do it. I know I'm worth more than that. Same thing with him. If he was just a regular civilian, he wouldn't even have those thoughts in his head. He'd be like, got out of high school, went to college, and now I'm working here."

"And add Marine on top of that Veteran standard." Lance jumped back into the conversation. "We are Marines, always. It's so ingrained and instilled in you. You'll see alumni plates on civilian cars and that was four years of going to a school. When it's something that's such an integral part of your life, like the Corps, it is more than license plates. Whether you want it to or not, the Marine Corps becomes a part of you. You're going to hate the Marine Corps, but that's all you live and breathe. You will do physical harm to your body if you're not doing everything right. It is comparable to being a professional athlete because there is such a high standard that you have to maintain, and we do it through straight peer pressure. One ounce of body fat, one second slower, and you're going to get it from everybody. They do a really good job of building us versus them.

"So, you get that, you're a Marine. You're a Marine. You're a Marine. You're not a nasty civilian puke anymore. You're not a nasty civilian puke. Every week I tell my guys, 'You're a United States Marine. Go out there, drink the beer, screw the women, have a good time. End of the day, you're a Marine. Don't be one of those nasty little pigs, get back here Monday morning, ready to rock and roll.

"I was in the Marines. Now I'm a civilian piece... so it's hard to identify with that person that I always said I don't want to ... I was taught not to be. I can never let go of the Marines, because it's such a big part of my life. This is all I've known. I may have been out for a while, but I'm still a Marine. I live being a Veteran every day.” 
As Lance spoke, the other Marines at the table were nodding their heads in agreement. They would all always be Marines, as it was an identity down to their core (Hammond, 2015; Jones \& McEwen, 2000).

Fromm pointed out that civilians live in a world of having, not being (1976). To lose the title of United States Marine would be even more destructive than discharging from the Corps. Yet, listening to the Marines in The Unit, it was clear that "Marine" was something they would always be (1976). Even if no one knew of their service, they did. As a result, they held themselves to a higher standard that was worthy of other Marines, both those from history and their actual brothers in arms (Fromm, 1956). The esprit de corps of the Marine Corps had altered them at boot camp, to the point that they would always see themselves as a Marine in all situations. A Marine father, like Sgt. Stepo. A Marine student, like everyone at the table. A Marine employee; a Marine friend - the Marine would always be there to describe that they were more than just a father, a student, an employee, or a friend (Abes, Jones, \& McEwen, 2007)). This was in part because the Marines:

Instill in their people that if you have ever been a Marine, you will always be a Marine. ... if you're the chairman of the board at a giant corporation; the fact that you were a Marine comes first. If the other services could capture only 10 percent of that, it would help them immensely" (Shelton, Levinson, \& McConnell, 2010). These Marines believed that they would be more reliable, more honorable, more committed, and more limitless in their care because they were United States Marines. The Corps had done one hell of a job convincing every Marine that they were unmatched in the world of mortals (Shelton, Levinson, \& McConnell, 2010). Yet, when some of the 
world looked at Veterans they saw weakness, trauma, or danger.

“And sometimes that being a Veteran, a Marine, means that civilians don't want to give you a job." Beaver began to vent. "Because they are fucking assuming, incorrectly, that everyone of has fucking gnarly-assed PTSD, and we're going to blow up buildings, and shoot up hostages and shit. Don't. Everybody is different. You don't know their story. Get to know them.” Beaver was so frustrated with his lack of purposeful employment. Working graveyard at Home Depot helped with the bills but not with his self-perception. It did not match how he felt a Marine should be treated, or what they should be doing (Burke, 1991; Stryker \& Burke, 2000).

"I think you hit the nail on the head. Every Marine, every Veteran is different;" Jamie agreed with Beaver. "Or, to go back to Veteran Critical Theory... I know I keep talking about it. Is to say that Veterans are unknowable (Hammond, 2015; (Phillips \& Lincoln, in press)."

"We aren’t unknowable, it just takes time." V responded with a slight tone of defensiveness.

"Not unknowable in that you can never be known," Jamie began to explain further. "Unknowable in that I cannot assume that there is one type of Veteran, or one type of Marine. So much of the histories of oppressed groups are being victim to the stories others tell about them, and those stories being unquestioned by society (Delgado, 1989). For Veterans it is the stories of wounded warriors, heartless killers, or superheroes (Gardner, 2011; Merry, 2015; Moore, 2014). Together, I hope we can break up those stories with others that are more representative of the diversity that exists in the Veteran population. And in so doing, help people change their perception of Veterans!" 
Beaver laughed, "Ha! Ah, good luck there! As they say in the Corps, 'Good initiative, bad judgement.' I don't want to burst your bubble, but ... You're scratching a cinder block wall, not just a bubble."

Jamie looked at Beaver, and thought of all the Marines at the table, and the numerous Veterans who had been in her classrooms. Then she spoke, with all seriousness, "But it's a start. If no one starts scratching, what happens?"

"Well," Lance answered, "Your biggest problem is going to be trying to change people's perception, and that's very hard to do."

"You're Marines! Since when has the fact that something may be hard stopped you?" Jamie half-jokingly, half-seriously challenged the table. "As Veterans, YOU are the most qualified to inform the policies and procedures that impact you." This was the final tenet of VCT (Phillips \& Lincoln, in press).

Jamie continued, "Since the focus on this work is on higher education, you have an opportunity to potentially impact the experience for current and future Veterans. You know, Carl Rogers always believe that the role of the therapist was to guide the client to the answers that they, the client, already knew within themselves (Rogers, 1951; Rogers, 1959; Rogers, 1961; Rogers, 1967; Rogers, 1980; Rogers, 1985). You have the answers in you. You know how the systems and structures can be better, based on your personal experiences and knowledge."

As the Marines sat at her kitchen, taking in the weight of Jamie's statement, she continued. "Then, it was Paulo Freire who said that the oppressor cannot free the oppressed. That would be patronizing and would maintain the power structure. So, it must be the oppressed that rise up and free themselves (Freire, 1998; Freire, 2000). As 
Veterans are living in a civilian privileged world, you must work, with allies, to change those systems. In part, that is why you went to school, to complete with civilians.

"While being in higher education did not change your Marine identity, as you will forever and always be a Marine (Marines.com, 2014; M. Steponovich, personal communication, 17 December 2014; Shelton, Levinson, \& McConnell, 2010), it did change how you view yourself intellectually. Each one of you spoke of how you learned, gained knowledge and confidence in your abilities, and improved your ability to adapt to civilian society. In some ways, higher education increased your identity as a Marine, as you see that as a higher standard and code of living than the other students (Hammond, 2015).

"The awareness of that difference is not helpful. Awareness never is! Awareness, be it about yourself or of the injustices of the world, is uncomfortable. 'Awareness is not a giver of solace - it is just the opposite. It is a disturber and an awakener. Able leaders are usually sharply awake and reasonably disturbed' (Greenleaf, 2008, p. 29). As you are now aware, and most likely troubled by the awareness, you are in the perfect place to help enact change for future.

"Now that I have gone on for long enough, what do you think should be done? What do we suggest for higher education? What advice do we give to Veterans?" Jamie looked to the group, those with the knowing, to give guidance about what should happen next. 


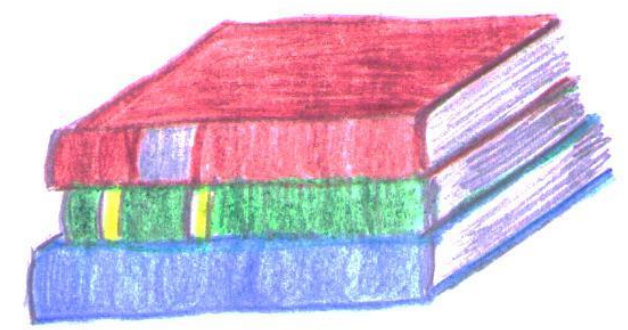

\section{The Stories (Jamie's Voice)}

I asked them the big questions. I had my own ideas, but I entered into this whole experience with humility to listen first. I had most certainly learned so much on this walk with The Unit, but I knew it was far from over. My desire to support Marines, and all Veterans, in their transition was “a never-ending path. You don't ever get there but the journey is the objective" (Autry, Spears, \& Noble, 2004, p. 69). New issues would arise, new stories would be presented, new solutions would be presented; it was an endless cycle. However, at that moment, I was with The Unit, thinking of how we could make tomorrow better for those Veterans going into higher education.

"Well," Beaver started the discussion after a few moments of silence. "I said it before, and I will say it again. Stop with the fucking assumptions. Don't assume that you know what I did, that I have PTSD, that I killed people, just stop fucking assuming."

"I agree," Sgt. G added. "You keep talking about a civilian privileged society, but I don't think this society is better. I miss the guys who I knew had my back. Even the shit bags who couldn't get their shit together always came through when it mattered. I miss that feeling of being able to really count on someone."

$\mathrm{V}$ joined in, "Yeah, man. If there is one thing that I want faculty and college staff to know, it's that we are not all the same. We all have our own stories to tell. I mean, just that fact that you gave us a voice is great. Hearing other stories has been cool." 
It kept coming back to the stories. Stories help us humanize others, to walk with them in their journey (Clandinin, 2013). I had already planned to help Team RWB plan a Town Hall for Veterans Day, and that too was all about stories (Smith \& Junger, 2016; Junger, 2016). The Town Hall idea was presented by Sebastian Junger (2016) to help build community among Veterans and civilians. The event consisted of Veterans sharing their stories and civilians listening. Not asking questions, just listening as each Veteran spoke of 10 minutes or less. The success of the event was evident of the power of stories. And I had heard of colleges and universities that had done similar events on campus with Veteran Panels (Osborne, 2014). Again, it was through listening to stories that Veterans were humanized and civilians' misconceptions were cleared up (Ibid.). However, the stories needed to go both ways.

"And we, as Veterans, need to listen to their stories, too." Lance added to the conversation. "Fuck, I get it. We only want to hang with Marines or other Veterans sometimes. But we also have to learn how to adapt to the civilian world, since that is where we are now. Spending time in the Vet Center is great, but you have to get out to the rest of the campus, too."

"Yeah, but before we can listen to them or engage with them; they have to stop fearing us!" Sgt. G declared.

"I think," I began cautiously, "that both the Marines and higher education, or academia, tend to look at themselves as the best there is. They view themselves, respectively, as the path to value. The idea that you are not valuable without a college degree is equally as damaging as the endless competition about who is better, or you are only worthy if you are a Marine. Both sides need to come together and listen to one 
another.

“"We humanize ourselves through dialogue with others' (Roberts, 2003, p. 176), but we must first find the humility to engage in the dialogue ready to listen and really understand. If we continue to only give lip service to Veterans, nothing will improve. While nothing in the capitalistic world, in which most civilians reside, will match the comradery and commitment in the Corps, if you never try anything else life will be full of loss and longing.

"I know each of you would go back in a heartbeat. I know each of you misses the Corps every day you aren't in. I know that each of you longs to do more than you are doing today. So, what is it that educators can do to support that goal? Even General Mattis believed in learning. He spoke about seeing 'The Killing Fields' in Cambodia, and how they targeted the teachers first. He is attributed to having said that 'They wanted to extinguish free thought, and the spark of questioning and dissent. Because, to a Totalitarian dictator, an open and inquisitive mind is more dangerous even than a Marine with a rifle.' So, what are your recommendations for higher education?"

Sgt. G was the first to speak, "Give us a place to be with other Veterans. Don't fear us. Don't assume we are all the same, as Beaver said. Listen to our stories, even if it is hard. Listen and authentically respond to them, from a place of respect and care. Welcome us throughout the campus, without making us feel like we are nothing more than Veterans."

"And to the Veterans," Lance added, "Give civilians a chance. Not all of them are nasty pigs!" He smiled at me when he said this, and all of the Marines laughed. "In the end, most faculty and staff are there to support you through the education. And as 
Marines, we know, just like 'Every good leader knows, he is nothing without people who support him' (Bridge, 2015, DE2).”

There was so much work still that needed to be done. While the stories of the Marines in The Unit were powerful, there are still so many other stories that need to be heard. Campus administrators need to sit down and listen to their Veterans, discover what their stories were, and provide the space and place for them to move into becoming part of the community on campus. The stories of the Veterans who left campus need to he heard. The tales of female Veterans need an audience. The accounts of LGBTQ+ Veterans need a voice for the public. The experiences of other service branches need space in the dialogue as well. Veterans, too, need to give civilians, particularly academics, a chance to learn and understand their stories. It was in that place of humility and understanding that dialogue and change began or could begin. Lastly, Veterans need to also listen to the stories of civilians, as everyone lives different lives.

It cannot go unrecognized the incredible importance that stories had in this work. Indeed, it was the use of stories that made the work real for people. Stories were so powerful, and they were what made the work with The Unit possible (Gardner, 2011). Stories provided us with:

Innumerable truths, limitless tales, and untouched possibility. There is love, if we would have it. And hate, if we choose it. There is likewise wonder, hope, peace, strife, anger, beauty, goodness, disgust...as we wish to see them and give them meaning. We are beautiful creatures in a marvelous world of beautiful creatures. In this world, I think I have always known that my job is to tell stories...new stories...good stories...stories of light in dark places" (K. Stockbridge, personal 
communication, 23 July 2016).

I hope I was able to challenge some assumptions (Connelly \& Clandinin, 2006), to present at variety of stories that are among the possible truths for Veterans (Cole, 1989; Hammond, 2015; Phillips \& Lincoln, In Press). And I hope that because this was a story, it was accessible (Connelly \& Clandinin, 2006) and thus, would lead to better policies and practices, and thus improved communities on college campuses and beyond. I hope the stories within the pages will lead to more questions, more investigation, and a greater respectful curiosity for each other, instead of limiting assumptions that brake down the possibility for healthy relationships. I hope that those in academic systems will take the time to sit with their Veterans to listen to their stories, learn their histories, and build a better campus culture for all in attendance. I hope that civilians on college and university campuses begin to look to Veterans as people who have their own individual stories to share, and that they come to them willing to listen, and share in return.

More than anything, I hope that I honored the Marines who shared so much with me. As they continued to live their stories, I hope their service through The Unit will make a difference for other Veterans becoming students, and civilians. And I hope they know that it wasn't just an obligatory statement when I said Thank you! THANK YOU for your service to the Marines, to The Unit, and to me.

listen to the words the honest portrayals listen to the diversity these stories from those who experienced it not from a privileged outsider more than heroes, killers, or wounded warriors stories of comradery \& loss lived, survived, longed for the brotherhood, duty, \& love these are the Marines of The Unit 


\section{Bibliography}

Abel, S. G., Bright, R., J., \& Cooper, R. M. (2013). Offices of Veterans and Military Services. In F. A. Hamrick \& C. B. Rumann (Eds.), Called to Serve (pp. 167-197). San Francisco, CA: Jossey-Bass.

Abes, E. S., Jones, S. R., \& McEwen, M. K. (2007). Reconceptualizing the Model of Multiple Dimension of identity: The role of meaning-making capacity in the construction of multiple identities. Journal of College Student Development, 48(1), 1-22.

ACCT (2011). The Vow to Hire Heroes Act of 2011. The association of community college trustees. Retrieved from http://www.acct.org/files/Advocacy/Factsheets\%20and\%20Summaries/vow\%20act\%20summary. pdf

Ackerman, R., DiRamio, D., \& Garza Mitchell, R. L. (2009). Transitions: Combat veterans as college students. New Directions for Student Services, 126, 5-14. doi:10.1002/ss.311

Aikins, R. D., Golub, A., \& Bennett, A. S. (2015). Readjustment of urban Veterans: A mental health and substance use profile of Iraq and Afghanistan Veterans in higher education. Journal of American college health, 63(7), 482-494. doi:10.1080/07448481.2015.1068173

Allen, P. (1995). Art is a way of knowing (eBook). Boston, MA: Shambhala Publications.

Allen, P. (2005). Art is a spiritual path: Engaging the sacred through the practice of art and writing (eBook). Boston, MA: Shambhala Publications.

Allen, Q. (2012). Photographs and stories: Ethics, benefits and dilemmas of using participant photography with Black middle-class male youth. Qualitative research, 12(4), 443-458.

American Psychiatric Association. (2013). Diagnostic and statistical manual of mental disorders (5th ed.). Arlington, VA: American Psychiatric Publishing.

Anderson, G. L., \& Herr, K. (1999). The new paradigm wars: Is there room for rigorous practitioner knowledge in schools and universities. Educational Researcher, 28(5), 12-21, 40.

Anzaldúa, G. (1987). Borderland/LaFrontera: The new Mestiza. San Francisco, CA: Spinsters/Aunt Lute. Araujo Freire, A. M. (2014 October 25). “The Presence of Paulo Freire at Chapman University” presented at The Teaching Critically and Democratically Symposium and Re-Dedication of the Paulo Freire Critical Pedagogy Archives. Orange, CA: Chapman University. 
Arminio, J., \& Kudo Grabosky, T. (2013). Promoting organizational change to create a veteran-friendly campus: A case study. In F. A. Hamrick \& C. B. Rumann (Eds.), Called to Serve (pp. 278-300). San Francisco: Jossey-Bass.

Arminio, J., Kudo Grabosky, T., \& Lang, J. (2015). Student Veterans and Service Members in Higher Education. New York, NY: Routledge.

Aronowitz, S. (1998). Introduction: Prologue. In P. Freire, Pedagogy of freedom: Ethics, democracy, and civic courage (pp. 1-19). London, UK: Rowman \& Littlefield Publishers, Inc.

Asch, B. J., Headton, P., \& Savych, B. (2009). Recruiting minorities: What explains recent trends in the Army and Navy? Santa Monica, CA: RAND Corporation.

Asch, B. J., Kilburn, M. R., \& Klerman, J. A. (1999). Attracting college-bound youth into the military: Toward development of new recruiting policy options. Santa Monica, CA: RAND Corporation.

Asch, B. J., Romley, J. A., \& Totten, M. E. (2005). The quality of personnel in the enlisted ranks. Santa Monica, CA: RAND Corporation.

Asch, B., Du, C., \& Schonlau, M. (2004). Policy options for military recruiting in the college market: Results from a national survey. Santa Monica, CA: RAND Corporation.

Astor, R. A. (2015, 16 March). PhD Research Forum about community-based research, the publication process, and large-scale funding. Orange, CA: Chapman University.

Athena. (2006). Encyclopedia Britannica Online. Retrieved from http://www.britannica.com/EBchecked/topic/40681/Athena

Autry, J. A., Spears, L., \& Noble, J. (2004). Love and work. In Spears, L., \& Lawrence, M. (Eds.), Practicing servant-leadership: Succeeding through trust, bravery and forgiveness (pp. 47-69). San Francisco: Jossey-Bass.

Avolio, B. J. (2010). Pursuing authentic leadership development. In Nohria, N. (Ed.), Handbook of Leadership Theory and Practice (pp. 721-750). Boston: Harvard Business Review Press.

Bach, H. (2007). Composing a visual narrative inquiry. In D. J. Clandinin (Ed) Handbook of Narrative Inquiry: Mapping a Methodology (pp. 280-302). Thousand Oaks, CA: SAGE Publications. doi: $10.4135 / 9781452226552 . n 11$

Baker, S. (2013, August 13). 8 Keys to success: Supporting veterans, military and military families on 
campus. The White House: President Barack Obama. Retrieved from

http://www.whitehouse.gov/blog/2013/08/13/8-keys-success-supporting-veterans-military-andmilitary-families-campus

Balfour, M., \& Stewart, D. (2015). Perspectives and contexts of arts, social health and the military. Arts \& Health: International Journal for Research, Policy \& Practice, 7(2), 87-95.

Balfour, M., Westwood, M., \& Buchanan, M. (2014). Protecting into emotion: therapeutic enactments with military veterans transitioning back into civilian life. Research in Drama Education, 19(2), 165181. doi: $10.1080 / 13569783.2014 .911806$

Banks, S. (2008). Writing as theory: In defense of fiction. In J. G. Knowles \& A. L. Cole (Eds.), Handbook of the arts in qualitative research: Perspectives, methodologies, examples, and issue (pp. 155164). Los Angeles, CA: SAGE Publications.

Barone, T. (2000). Aesthetics, politics, and educational inquiry: Essays and examples. New York, NY: Peter Lang.

Barone, T. (2001). Touching eternity: the enduring outcomes of teaching. New York, NY: Teachers College Press.

Barone, T. (2008). How arts-based research can change minds. In M. Cahnmann-Taylor \& R. Siegesmund (Eds.), Arts-based research in education: Foundations for practice (pp. 28-49). New York, NY: Routledge.

Barone, T., \& Eisner, E. (2006). Arts-Based Educational Research. In J. L. Green, G. Camilli, P.B. Elmore, \& A. Skukauskaite, \& E. Green (Eds), Handbook of complementary methods in education research, (pp.95-109). Washington, D.C.: American Educational Research Association.

Barone, T., \& Eisner, E. (2012). Arts-based research. Los Angeles, CA: SAGE Publications.

Barry, A.., Whiteman, S. D., \& MacDermid Wadsworth, S. (2014). Student service members/Veterans in higher education: A systematic review. Journal of Student Affairs Research and Practice, (51)1, 30-42. doi:10.1515/jsarp-2014-0003

Beauchamp, S. (13 March 2016). What Daredevil's depiction of the Punishers gets right about War Vets. Vulture. Retried from http://www.vulture.com/2016/03/what-daredevils-punisher-gets-right-aboutvets.html 
Beck, C. (2005). From the Halls: The meaning of Semper Fidelis. OO-RAH: The Marine Corps

Community. Retrieved from: http://www.oo-rah.com/store/editorial/edi52.asp

Behar, R. (2008). Between poetry and anthropology: Searching for languages of home. In M. Cahnmann-

Taylor \& R. Siegesmund (Eds.), Arts-based research in education: Foundations for practice (pp. 55-71). New York, NY: Routledge.

Bellafiore, M. (2012). From combat tocampus. Academe, 98(5), 33-36. Retrieved from http://www.aaup.org/AAUP/pubsres/academe/2012/SO/Feat/bell.htm

Berryman, M., SooHoo, S., \& Nevin, A. (2013a). Culturally responsive methodologies from the margins. In M. Berryman, S. SooHoo, \& A. Nevin (Eds.), Culturally Responsive Methodologies (pp. 1-31). Bingley, UK: Emerald Group Publishing Limited.

Berryman, M., SooHoo, S., \& Nevin, A. (2013b). The confluence. In M. Berryman, S. SooHoo, \& A. Nevin (Eds.), Culturally Responsive Methodologies (pp. 389-408). Bingley, UK: Emerald Group Publishing Limited.

Bowman, W. D. (2007). Why Narrative? Why Now? Research Studies in Music Education, 27(1), 5-20. doi:10.1177/1321103X060270010101

Bresler, L. (2007). Embodied Narrative Inquiry: A Methodology of Connection. Research Studies in Music Education, 27(1), 21-43.doi:10.1177/1321103X060270010201

Bridge, J. (2015). For love of civilians: Is your perspective warped? Marine Corps Gazette, 99(9) Digital Edition, DE1-2.

Brown, P. A., \& Gross, C. (2011). Serving those who have served: Managing veteran and military student best practices. Journal of Continuing Higher Education, 59(1), 45-49. doi:10.1080/07377363.2011.544982

Bruce, A., Schick Makaroff, K. L., Sheilds, L., Beuthin, R., Molzahn, A., \& Shermak, S. (2013). Lessons learned about arts-based approaches for disseminating knowledge. Nurse Researcher, 21(1), 2328.

Bruner, J. (1987). Life as narrative. Social Research, 54(1), 11-32.

Bruner, J. (2004). The narrative creation of self. In L. E. Angus \& J. McLeod (Eds.), The handbook of narrative and psychotherapy: Practice, theory, and research, (pp. 3-14). Thousand Oaks, CA: 
SAGE Publications. doi: 10.4135/9781412973496.d13

Burbules, N.C., \& Berk, R. (1999). Critical Thinking and Critical Pedagogy:

Relations, Differences, and Limits. In T. S. Popkewitz \& L. Fendler (Eds.), Critical theories in education: Changing terrains of knowledge and politics (pp. 45-65). New York, NY: Routledge.

Burke, P. J. (1991). Identity processes and social stress. American Sociological Review, 56(6), 836-849.

Burkhart, L., \& Hogan, N. (2015). Being a Female Veteran: A Grounded Theory of Coping with Transitions. Social Work in Mental Health, 13(2), 108-127. doi: 10.1080/15332985.2013.870102

Butler, J. (1990). Gender trouble: Feminism and the subversion of identity. New York, NY: Routledge.

Butler, J. (1991). Imitation and gender subordination. In D. Fuss (Ed.) Inside/out: Lesbian theories, gay theories (pp. 13-31). New York, NY: Routledge.

Butler, S. (1935, 2003). War is a racket. Los Angeles, CA: Feral House.

Cahnmann-Taylor, M. (2008). Arts-based research: Histories and new directions. In M. Cahnmann-Taylor \& R. Siegesmund (Eds.), Arts-based research in education: Foundations for practice (pp. 3-15). New York, NY: Routledge.

Campbell R., \& Riggs, S. A. (2015). The role of psychological symptomatology and social support in the academic adjustment of previously deployed student Veterans Journal of American college health, 63(7), 473-481. doi:10.1080/07448481.2015.1040408

Canfield, J. (2014). Traumatic Stress and Affect Management in Military Families. Social Work in Mental Health, 12 (5/6), p544-559. doi: 10.1080/15332985.2014.899296

Carey, B. (30 May 2016). After thriving in combat tours, Veterans are struggling at home. The New York Times, pp. A1 \& A3.

Casey, J. A. (21 August 2014) Searching for the right metaphor: Veterans in popular culture. John A Casey $J r$. Retrieved from https://johnacaseyjr.com/2014/08/21/searching-for-the-right-metaphorveterans-in-popular-culture/

Cashman, K. (2008). Leadership from the inside out (2 ${ }^{\text {nd }}$ ed.). San Francisco: Berrett-Koehler.

Casper, S. (2013). Vignette. In F. A. Hamrick \& C. B. Rumann (Eds.), Called to Serve (pp. 87-88). San Francisco: Jossey-Bass.

Castro, C. A., Kintzle, S., \& Hassan A. M. (2015b). The Combat Veteran Paradox: Paradoxes and 
dilemmas encountered with reintegrating combat Veterans and the agencies that support them. Traumatology, 21(4), 299-310.

Castro, C. A., Kintzle, S., \& Hassan, A. (2015a). The state of the American veteran: The Orange County veterans study. Los Angeles, CA: USC CIR.

Cate, C.A. (2014). Million Records Project: Research from Student Veterans of America. Student Veterans of America, Washington, DC.

Chase, S. (2011). Narrative Inquiry. In N. K. Denzin \& Y. S. Lincoln (Eds.), The SAGE Handbook of Qualitative Research (pp. 421-434). Los Angeles, CA: SAGE Publications.

Chenowrth, H. A., \& Nihart, B. (2005). Semper Fi: The definitive illustrated history of the U. S. Marines. New Your, NY: Sterling Publishing Co., Inc.

Clandinin, D. J. (2007). Narrative Inquiry: A Methodology for Studying Lived Experience. Research Studies in Music Education, 27(1), 44-54. doi:10.1177/1321103X060270010301

Clandinin, D. J. (2013). Engaging in narrative Inquiry. Walnut Creek, CA: Left Coast Press, Inc.

Clandinin, D. J., \& Rosiek, J. (2007). Mapping a landscape of narrative inquiry: Borderland spaces and tensions. In D. J. Clandinin (Ed) Handbook of Narrative Inquiry: Mapping a Methodology (pp. 35-72). Thousand Oaks, CA: SAGE Publications. doi: 10.4135/9781452226552.n2

Cole, A. L., \& Knowles, J. G. (2008). Arts-informed research. In J. G. Knowles \& A. L. Cole (Eds.), Handbook of the arts in qualitative research: Perspectives, methodologies, examples, and issue (pp. 55-70). Los Angeles, CA: SAGE Publications.

Coles, R. (1989). The Call of Stories: Teaching and the Moral Imagination. Boston, MA: Houghton Mifflin Company

Community College Times. (2012, July 17). Building services for military veterans. Community College Times. Retrieved from http://www.communitycollegetimes.com/Pages/Campus-Issues/Buildingservices-for-military-veterans.aspx

Connelly, F. M., \& Clandinin, D. J. (1990). Stories of experience and narrative inquiry. Educational Researcher, 19(5), 2-14.

Connelly, F. M., \& Clandinin, D. J. (2006). Narrative Inquiry. In J. L. Green, G. Camilli, P.B. Elmore, \& A. Skukauskaitè, \& E. Green (Eds), Handbook of complementary methods in education research, 
(pp. 477-487). Washington, D.C.: American Educational Research Association.

Cook Francis, L., \& Kraus A. (2012). Developing a student veterans center: The confluence of academic and military cultures. About Campus, 17(4), 11-14. doi:10.1002/abc.21087

Cook-Sather, A. (2007) Resisting the impositional potential of student voice work: Lessons for liberatory educational research from poststructuralist feminist critiques of critical pedagogy. Discourse: Studies in the cultural politics of education, 28(3), 389-403.

Cropsey, J., \& Hendrickson, J. (2013). Report of the APSCU Blue Ribbon Taskforce. Washington, DC: Association of Private Sector Colleges \& Universities.

Darder, A., Baltodano, M. O., \& Torres, R. D. (2009). Critical pedagogy: An introduction. In A. Darder, M. P. Balrodano, \& R. D. Torres (Eds.), The critical pedagogy reader (2 $2^{\text {nd }}$ ed.) (pp. 1-20). New York, NY: Routledge.

DARPA (2015). About DARPA. Defense Advanced Research Projects Agency. Retrieved from http://www.darpa.mil/about-us/about-darpa

David, J. (2008). Armed Forces: United States Marine Corps. Minneapolis, MN: Bellwether Media, Inc.

Defense Manpower Data Center. (2013a, September 19). Overseas contingency operation deployments by operation/location country and service as of July 31, 2013. Retrieved from https://www.dmdc.osd.mil/appj/dwp/reports.do?category=reports\&subCat=milAct DutReg

Defense Manpower Data Center. (2013b). Welcome to SCRA. Retrieved from https://www.dmdc.osd.mil/appj/scra/welcome.xhtml

DeGraff, D., Tilley, C., \& Neal, L. (2004) Servant-leadership characteristics in organizational life. In Spears, L., \& Lawrence, M. (Eds.), Practicing servant-leadership: Succeeding through trust, bravery and forgiveness (pp. 133-165). San Francisco: Jossey-Bass.

Deleuze, G., \& Guattari, F. (1987). A thousand plateaus: Capitalism and schizophrenia. (B. Massumi, Trans.) Minneapolis, MN: University of Minnesota Press.

Delgao, R. (1989). Legal storytelling: Storytelling for oppositionists and others: A plea for narrative. Michigan Law Review, 87(8), 2411-2441.

Demers, A. L. (2013). From death to life: Female veterans, identity, negotiation, and reintegration into 
society. Journal Humanistic Psychology, 53(4), 489-515.

DeSawal, D. M. (2013). Contemporary student veterans and service members: Enrollment patterns and student engagement. In F. A. Hamrick \& C. B. Rumann (Eds.), Called to Serve (pp. 71-86). San Francisco: Jossey-Bass.

Desgrosseilliers, T. (2014). Character and the warrior ethos. Marine Corps Gazette, 98(9), 62-64.

Dewey, J. (1954). Art as experience. New York, NY: Perigee Books.

Di Ramio, D., Ackerman, R., \& Mitchell, R. (2008). From combat to campus: Voices of student veterans. NASPA Journal, 45(1), 73-102. doi:10.2202/1949-6605.1908,

DiRamio, D., \& Jarvis, K. (2011). Veterans in higher education: When Johnny and Jane come marching to campus. ASHE Higher Education Report, 37(3).

DiRamio, D., \& Spires, M. (2009). Partnering to assist disabled veterans in transition. New Directions for Student Services, 126, 81-88. Retrieved from http://www.blackwellsynergy.com/doi/abs/10.1002/ss.319

Dunayevskaya, R. (1958) Marxism and freedom ... from 1776 until today. New York, NY: Bookman Associates.

Dunayevskaya, R. (1992). The Marxist-Humanist theory and state-capitalism. Chicago, IL: News and Letters.

Editors of Cook's Illustrated Magazine (1999). The Best Recipe Cookbook. Brookline, MA: Boston Common Press.

Einser, E. (2008). Art and knowledge. In J. G. Knowles \& A. L. Cole (Eds.), Handbook of the arts in qualitative research: Perspectives, methodologies, examples, and issue (pp. 3-12). Los Angeles, CA: SAGE Publications.

Eisner, E. (2008). Persistent tensions in arts-based research. In M. Cahnmann-Taylor \& R. Siegesmund (Eds.), Arts-based research in education: Foundations for practice (pp. 16-27). New York, NY: Routledge.

Evans, J. (2009). Inspirational Presence. New York: Morgan James Publishing LLC.

Evans, J. J., Pellegrino, L., \& Hoggan, C. (2015). Supporting Veterans at the Community College: A Review of the Literature. Community College Enterprise, 21(1), 47-65. 
Executive Order No. 13607, 77 (85) Fed. Reg., 25861-25864 (2013, April 27).

Ferch, S. R. (2004) Servant-leadership, forgiveness, and social justice. In Spears, L., \& Lawrence, M. (Eds.), Practicing servant-leadership: Succeeding through trust, bravery and forgiveness (pp. 225-239). San Francisco: Jossey-Bass.

Ferguson, D., \& Ferguson, P. (2000). Qualitative research in Special Education: Notes toward an open inquiry instead of a new orthodoxy? The Journal of the Association for Persons with Severe Handicaps, 25(3), 180-185

Finley, S. (2008). Art-based research. In J. G. Knowles \& A. L. Cole (Eds.), Handbook of the arts in qualitative research: Perspectives, methodologies, examples, and issue (pp. 71-81). Los Angeles, CA: SAGE Publications.

Fleischaker, N. A. (2015). Military leadership and narrative. Marine Corps Gazette, 99(11), pp. 37-41.

Ford, D., Northrup, P., \& Wiley, L. (2009). Connections, partnerships, opportunities, and programs to enhance success for military students. New Directions for Student Services, 126, 61-69.

Doi:10.1002/ss.317

Forkin, K. A. (2015). Transition Assistance: Being proactive in the $21^{\text {st }}$ Century. Marine Corps Gazette, 99(9), 27-34.

Fransen, K., Haslam, S. A., Steffens, N. K., Vanbeselaere, N., De Cuyper, B., \& Boen, F. (2015). Believing in "Us": Exploring leaders' capacity to enhance team confidence and performance by building a sense of shared social identity. Journal of Experimental Psychology: Applied, 21(1), 89-100. doi: 10.1037/xap0000033

Freire Institute (2015). Paulo Freire. Retrieved from http://www.freire.org/paulo-freire

Freire, P. (1994). Pedagogy of hope. London, UK: Bloomsbury.

Freire, P. (1998). Pedagogy of freedom: Ethics, democracy, and civic courage. London, UK: Rowman \& Littlefield Publishers, Inc.

Freire, P. (2000). Pedagogy of the oppressed. New York, NY: Bloomsbury.

Freud, S. (1922). Psycho-analysis. (J. Strachey, Trans.). In R. D. Parker (Ed.), Critical theory: A reader for literacy and cultural studies (2012). (pp. 181-194). New York, NY: Oxford University Press.

Freud, S. (1955). Beyond the Pleasure Principle. In The Standard Edition of the Complete Psychological 
Works of Sigmund Freud, Volume XVIII (1920-1922): Beyond the Pleasure Principle, Group Psychology and Other Works (J. Strachey Trans. Ed.), (pp. 1-64). Great Britain: The Hogarth Press.

Fromm, E. (1955). The sane society. New York, NY: Henry Holt and Company.

Fromm, E. (1956). The art of loving. New York, NY: Harper Perennial Modern Classics.

Fromm, E. (1969). Escape from freedom (eBook). New York, NY: Open Road.

Fromm, E. (1973). The anatomy of human destructiveness. New York, NY: Picador.

Fromm, E. (1976). To have or to be? London, UK: Bloomsbury.

Gaddo, R. (2015). Marine for life: Veterans reach out to transitioning Marines. Leatherneck, 98(6), 43-45.

Gardner, H. (2011). Leading minds: An Anatomy of Leadership. New York, NY: Basic Books.

Garrison, J. (1997) Dewey and Eros: Wisdom and desire in the art of teaching. New York, NY: Teachers College Press.

Geerts, R. (2015). Netherlands Ministry of Defence, Centre of Excellence for Leadership Development. ILA Member Connector, May 2015, 21.

George, B., Sims, P., McLean, A. N., \& Mayer, D. (2007). Discovering your authentic leadership. Harvard Business Review, 85(2), 129-138.

Gill, R. (2011). Theory and Practice of Leadership (2nd ed.). London: SAGE Publications.

Gilligan, C. (2015). The Listening Guide method of psychological inquiry. Qualitative Psychology, 2(1), 69-77.

Gilligan, C., Spencer, R., Weinberg, M. K., \& Bertsch, T. (2003). On the Listening Guide: A voicecentered relational method. In P. M. Camic, J. E. Rhodes, \& L. Yardley (Eds.), Qualitative research in psychology: Expanding perspectives in methodology and design (pp. 157-172).

Washington, DC, US: American Psychological Association. doi: 10.1037/10595-009

Giroux, H. (1983). Theory and resistance in education: A pedagogy for the opposition. South Hadley, MA: Bergin \& Garvey.

Giroux, H. (2011). On critical pedagogy. New York, NY: Continuum.

Giroux, H. A. (2003). Pedagogy of the depressed: Beyond the new politics of cynicism. In M. Peters, C. Lankshear, \& M. Olssen (Eds.), Critical Theory and the human condition: Founders and praxis 
(pp. 143-168). New York, NY: Peter Lang.

Glasser, I., Powers, J. T., \& Zywiak, W. H. (2009). Military veterans at universities: A case of culture clash. Anthropology News, 50(5), 33.

Glover-Graf, N. M., Miller, E., \& Freeman, S. (2010). Accommodating veterans with posttraumatic stress disorder symptoms in the academic setting. Rehabilitation Education, 24(1-2), 43-56.

Glynn, S. M. (2013). Family-Centered Care to Promote Successful Community Reintegration After War: It Takes a Nation. Clinical Child \& Family Psychology Review, 16 (4), 410-414. doi: $10.1007 / \mathrm{s} 10567-013-0153-\mathrm{z}$

Goleman, D., Boyatzis, R., \& McKee, A. (2004). Primal leadership: Learning to lead with emotional intelligence. Boston: Harvard Business School Press.

Greene, M. (1978). Landscapes of Learning. New York, NY: Teachers College Press.

Greenleaf, R. K. (2008). The servant as leader. Westfield: The Greenleaf Center.

Griffeth, E., \& Jackson, B. (2010). The portrait as leader: Commissioned portraits and the power of tradition. Leadership, 6(2), 133-157.

Griffin, K. A., \& Gilbert, C. K. (2015). Better Transitions for Troops: An Application of Schlossberg's Transition Framework to Analyses of Barriers and Institutional support structures for student veterans. Journal of Higher Education, 86 (1), 71-97.

Gur-Ze'ev, I. (2003). Critical theory, critical pedagogy and the possibility of counter-education. In M. Peters, C. Lankshear, \& M. Olssen (Eds.), Critical Theory and the human condition: Founders and praxis (pp. 17-35). New York, NY: Peter Lang.

Hammond, S. P. (2015). Complex perceptions of identity: The experience of student combat Veterans in community college. Community college journal of research and practice, 1-17. doi:10.1080/10668926.2015.1017891

Harada, H. D., Damron-Rodriguez, J., Villa, V. M., Washington, D. L., Dhanani, S., Shon, H., Chattopadhyay, M., Fishbein, H., Lee, M., Makinodan, T. , \& Andersen, R. (2002). Veteran identity and race/ethnicity: Influence on VA outpatient care utilization. National Center for Biotechnology Information. Retrieved from http://www.ncbi.nlm.nih.gov/pubmed/11789624

Harrison, J., MacGibbon, L., \& Morton, M. (2001). Regimes of trustworthiness 
in qualitative research: The rigors of reciprocity. Qualitative Inquiry, 7(3), 323-345.

Hassan, A. M., Jackson, R., Lindsay, D. R., McCabe, D. G., \& Sanders, J. (2010). The veteran student in 2010. About Campus, 15(2), 30-32.

Hawn, H. (2011). Veterans and Veteran Families in General Education. JGE: The Journal of General Education, 60(4), p248-264.

Hawthorne, B. A., Bauman, M. C., \& Ewing Ross, L. (2013). Student veteran organizations and student self-advocacy. In F. A. Hamrick \& C. B. Rumann (Eds.), Called to Serve (pp. 221-252). San Francisco: Jossey-Bass.

Haynie, M. (2012, July 2). As attitudes shift on PTSD, media slow to remove stigma. New York Times: At War. Retrieved from http://atwar.blogs.nytimes.com/2012/07/02/as-attitudes-shift-on-p-t-s-dmedia-slow-to-remove-stigma/?_php=true\&_type=blogs\&_r=0

Herrmann, T., \& Kohan, J. (Writers), \& Bernstein, A. (Director). (June 17, 2016). Toast can never be bread again (Season 4, Episode 13). In T. Herman, S. Hess, \& J. Kohna (Producers), Orange is the New Black. New York, NY: Netflix.

Herspring, D. R. (2011). Creating shared responsibility through respect for military culture: The Russian and American cases. Public Administration Review, July-August, 519-529.

Hess, S. (Writer), \& Makris, C. (Director). (18 March 2016). Power Suits (Season 4, Episode 2). In T. Herman, S. Hess, \& J. Kohna (Producers), Orange is the New Black. New York, NY: Netflix.

Hinojosa, R., \& Sberna Hinojosa, M. (2011). Using military friendships to optimize postdeployment reintegration for male Operation Iraqi Freedom/Operation Enduring Freedom veterans. Journal of Rehabilitation Research \& Development, 48(10), 1145-1158. doi:10.1682/jrrd.2010.08.0151

History vs Hollywood (2016). Reel Faces: 300 (2007). History vs Hollywood. Retrieved from http://www.historyvshollywood.com/reelfaces/300spartans.php

Hoffman, J. T. (1998). The Iwo Jima Flag-Raising and the Monument. In E. H. Simmons \& J. R. Moskin (Eds.), The Marines (pp. 112-127). Quantico, VA: Marine Corps Heritage Foundation.

Hoge, C. (2010). Once a warrior, always a warrior: Navigating the transition from combat to home. Guilford, CT: Lyons Press. Homer (1997). The Odyssey (R. Fagles, Trans.). New York, NY: Penguin Publishing Group. 
hooks, b. (1994). Teaching to transgress: Education as the practice of freedom. New York, NY: Routledge. Horkheimer, M., \& Adorno, T. W. (1944, 1947). The cultural identity: Enlightenment as mass deception. (E. Jephcott, Trans.). In R. D. Parker (Ed.), Critical theory: A reader for literacy and cultural studies (2012). (pp. 415-442). New York, NY: Oxford University Press.

Hosek, J. R., \& Martorell, F. (2009). How have deployments during the war on terrorism affected reenlistment? Santa Monica, CA: RAND Corporation.

Howard, G. S. (1991). Culture Tales: A narrative approach to thinking, cross-cultural psychology, and psychotherapy. American Psychologist, 46(3), 187-197.

Hudis, T. (1992). Introduction. In R. Dunayevskaya, The Marxist-Humanist theory and state-capitalism. Chicago, IL: News and Letters.

Irwin, R. L., \& Springgay, S. (2008). A/r/tography as practice-based research. In M. Cahnmann-Taylor \& R. Siegesmund (Eds.), Arts-based research in education: Foundations for practice (pp. 103-124). New York, NY: Routledge.

Jackson, T., Jr., Fey, C. J., \& Ewing Ross, L. (2013). Institutional leadership on serving student veterans and service members. In F. A. Hamrick \& C. B. Rumann (Eds.), Called to Serve (pp. 255-275). San Francisco: Jossey-Bass.

Janesick, V. J. (2008). Art and experience: Lessons from Dewey and Hawkins. In J. G. Knowles \& A. L. Cole (Eds.), Handbook of the arts in qualitative research: Perspectives, methodologies, examples, and issue (pp. 477-483). Los Angeles, CA: SAGE Publications.

Jankie, D. (2013). “Tell me who you are”: Problematizing the construction and positionalities of "Insider/Outside" of a "Native" ethnographer in a postcolonial context. In K. Mutua \& B. B. Swadener (Eds.), Decolonizing research in cross-cultural context: Critical personal narratives (pp. 87-104). Albany, NY: State University of New York Press.

Johansen, R. B., Laberg, J. C. \& Martinussen, M. (2013). Measuring military identity: scale development and psychometric evaluations. Social behavior and personality, 41(5), 861-880.

Jones, S. R. \& McEwen, M. K. (2000). A conceptual model of multiple dimensions of identity. Journal of College Student Development, 41(4), 405-414.

Jones, S. R., \& Abes, E. S. (2013). Identity development of college students: Advancing frameworks for 
multiple dimensions of identity. San Francisco, CA: Jossey-Bass.

Jongeward, C. (2015). Visual portraits: Integrating artistic process into qualitative research. In P. Leavy, Method meets Art: Arts-based research practice ( $2^{\text {nd }}$ ed) (pp. 253-265). New York, NY: The Guilford Press.

Junger, S. (2014, January). Sebastian Junger: Why veterans miss war [Video file]. Retrieved from https://www.ted.com/talks/sebastian_junger_why_veterans_miss_war

Junger, S. (2016). Tribe. New York, NY: Twelve.

Kalteux, L. (Writer), \& Girotti, K, (Director). (18 March 2016). Semper Fidelis (Season 2, Episode 7). In Johnston, K. (Producer), Daredevil. Burbank, CA: ABC Studios.

Kehle, S. M., Reddy, M.K., Ferrier-Auerbach, A.G., Erbes, C.R., Arbisi, P.A., \& Polusny, M.A. (2011). Psychiatric diagnoses, comorbidity, and functioning in National Guard troops deployed to Iraq. Journal of Psychiatric Research, 45(1), 126-32. doi: 10.1016/j.jpsychires.2010.05.013.

Kellner, D. (2003). Marcuse and the quest for radical subjectivity. In M. Peters, C. Lankshear, \& M. Olssen (Eds.), Critical Theory and the human condition: Founders and praxis (pp. 67-83). New York, NY: Peter Lang.

Kerenyi, C. (1979). The gods of the Greeks. New York, NY: Thames \& Hudson.

Kim, D. H. (2004) Foresight as the central ethic of leadership. In Spears, L., \& Lawrence, M. (Eds.), Practicing servant-leadership: Succeeding through trust, bravery and forgiveness (pp. 201-224). San Francisco: Jossey-Bass.

Kimble, M. O., Fleming, K., \& Bennion, K. A. (2013). Contributors to Hypervigilance in a Military and Civilian Sample. Journal of Interpersonal Violence, 28(8), p1672-1692. doi: $10.1177 / 0886260512468319$

King, T. (2008). The art of indigenous knowledge: A million porcupines crying in the dark. In J. G. Knowles \& A. L. Cole (Eds.), Handbook of the arts in qualitative research: Perspectives, methodologies, examples, and issue (pp. 13-25). Los Angeles, CA: SAGE Publications.

Kirschenbaum, H., \& Henderson, V. L. (1989). Introduction. In H. Kirschenbaum, \& V. L. Henderson (Eds). The Carl Rogers Reader (pp. xi-xvi). Boston, MA: Houghton Mifflin Company.

Klay, P. (24 May 2016). The Citizen-Soldier: Moral Risk and the Modern Military. The Brookings Essay. 
Retrieved from http://www.brookings.edu/research/essays/2016/the-citizen-

soldier?utm_source=FB\&utm_medium=BPIAds\&utm_campaign=TBESoldier\&utm_term=MNFTBESoldier_NoNoCtyUS-34

Klein, J. (2015). Charlie Mike: A true story of heroes who brought the mission home. New York, NY Simon \& Schuster.

Knowles, J. G., \& Promislow, S. (2008). Using an arts methodology to create a thesis or dissertation. In J. G. Knowles \& A. L. Cole (Eds.), Handbook of the arts in qualitative research: Perspectives, methodologies, examples, and issue (pp. 511-525). Los Angeles, CA: SAGE Publications.

Koenig, C. J., Maguen, S., Monroy, J. D., Mayott, L., \& Seal, K. H. (2014). Facilitating culture-centered communication between health care providers and veterans transitioning from military deployment to civilian life. Patient Education \& Counseling, 95(3), 414-420. doi: 10.1016/j.pec.2014.03.016

Kok, D. (2015). From combat to ceramics: A unique phase transformation. American Ceramic Society Bulletin, 94(1), 48.

Kress, G. (2003). Literacy in the new media age. New York: Routledge.

Kyle, C. (2013). America Sniper: Memorial Edition. New York, NY: Harper Collins.

Lang W. A., \& Powers, J. T. (2011). Completing the mission: A pilot study of veteran students' progress toward degree attainment in the post-9/11 era. Operation College Promise and The Pat Tillman Foundation. Retrieved from http://www.operationpromiseforservice members.com/Completing_the_Mission_Nov2011.pdf

Lang, J. (2013). Vignette. In F. A. Hamrick \& C. B. Rumann (Eds.), Called to Serve (pp. 39-40). San Francisco: Jossey-Bass.

Lankshear, C, (2003). On having and being: The humanism of Erich Fromm. In M. Peters, C. Lankshear, \& M. Olssen (Eds.), Critical Theory and the human condition: Founders and praxis (pp. 54-66). New York, NY: Peter Lang.

Larson, J. L. (2010 May 15). Sgt. Kenneth May Killed in Afghanistan. Kilgore News Herald. Retrieved from http://www.kilgorenewsherald.com/news/2010-05-15/front_page

Leavy, P. (2009). Method meets Art: Arts-based research practice. New York, NY: The Guilford Press. Leavy, P. (2015). Method meets Art: Arts-based research practice ( $2^{\text {nd }}$ ed). New York, NY: The Guilford 
Press.

Leggo, C. (2008). The ecology of personal and professional experience: A poet's view. In M. CahnmannTaylor \& R. Siegesmund (Eds.), Arts-based research in education: Foundations for practice (pp. 89-97). New York, NY: Routledge.

Lighthall, A. (2012). Ten things you should know about today's student Veteran. Thought \& Action, Fall 2012, 80-89.

Lincoln, A. (1865, March 4). Second Inaugural Address of Abraham Lincoln. Retrieved from http://avalon.law.yale.edu/19th_century/lincoln2.asp

Litwack, L., \& Foster, C. L. (1981). Isolation and identity: Loss in the military. The Personnel and Guidance Journal, 59(6), 386-388.

Livingston, W. G., \& Bauman, M. C. (2013). Activations, deployments, and returns. In F. A. Hamrick \& C. B. Rumann (Eds.), Called to Serve (pp. 41-68). San Francisco: Jossey-Bass.

Lokken, J. M., Pfeffer, D. S., McAuley, J., \& Strong, C. (2009). A statewide approach to creating veteranfriendly campuses. New Directions for Student Services, 126, 45-54. doi:10.1002/ss.315

Luttrell, M. (2013). The Lone Survivor. Boston, MA: Little, Brown and Company.

Lyon, K. (2008). Understanding and writing the world. In M. Cahnmann-Taylor \& R. Siegesmund (Eds.), Arts-based research in education: Foundations for practice (pp. 79-82). New York, NY: Routledge.

Macedo, D., \& Araújo Freire, A. (2005). Foreword. In P. Freire, Teachers as Cultural Workers: Those who dare to teach (vii-xxvi). Boulder, CO: Westview Press.

Macey, D. (2000). Dictionary of Critical Theory. London, UK: Penguin Reference.

Macfarlane, S. (2013). To acquiesce and to coalesce: Achieving alignment and unity for Māori through culturally responsive and socially responsible research. In M. Berryman, S. SooHoo, \& A. Nevin (Eds.), Culturally Responsive Methodologies (pp. 129-147). Bingley, UK: Emerald Group Publishing Limited.

MacLean, M. B., Van Til, L., Thompson, J. M., Sweet, J., Poirier, A., Sudom, K., Pedlar, D. J. (2014). Postmilitary adjustment to civilian life: Potential risks and protective factors. Physical Therapy, 94(8), 1189-1195. 
Mair, M. (1988). Psychology as storytelling. International Journal of Personal Construct Psychology, 1, 125-138.

Marcuse, H. (1955). Eros and civilization: A philosophical inquiry into Freud. Boston, MA: Beacon Press. MarineParents.com (2016). The Crucible During Marine Corps Recruit Training. Recruit Parents.com. Retrieved from: http://recruitparents.com/bootcamp/crucible.asp

Marines.com (2014). Our Purpose. U.S. Marine Corps. Retrieved from: http://www.marines.com/historyheritage/our-purpose

Marines.com (2016a). Commissioning Programs. U.S. Marine Corps. Retrieved from: http://www.marines.com/becoming-a-marine/commissioning-programs

Marines.com (2016b). Recruit Training - Week 1: Receiving. U.S. Marine Corps. Retrieved from: http://www.marines.com/becoming-a-marine/recruit-training/-/twelve-weeks/week/1

Marines.mil (2016). 1st Air Naval Gunfire Liaison Company. Marines: The Official website of the United State Marine Corps. Retrieved from http://www.imef.marines.mil/Units/I-MHG/1ST-ANGLICO/

Marx, K. (1859). Preface to a Contribution to the critique of political economy. (N. I. Stone, Trans.). In R. D. Parker (Ed.), Critical theory: A reader for literacy and cultural studies (2012). (pp. 380-381). New York, NY: Oxford University Press.

Marx, K. (1867a). The fetishism of commodities and the secret thereof. (S. Moore \& E. Aveling, Trans.). In R. D. Parker (Ed.), Critical theory: A reader for literacy and cultural studies (2012). (pp. 381388). New York, NY: Oxford University Press.

Marx, K. (1867b). The working day. In R. D. Parker (Ed.), Critical theory: A reader for literacy and cultural studies (2012). (pp. 388-394). New York, NY: Oxford University Press.

Marx, K. (1887). Capital: A critique of political economy. (Vol 1, Bk 1). (S. Moore \& E. Aveling, Trans.). Moscow, USSR: Progress Publishers. (Retrieved from https://www.marxists.org/archive/marx/works/download/pdf/Capital-Volume-I.pdf).

Mattis, J. N. (2003). $1^{\text {st }}$ Marnie Division (REIN): Commanding General's message to all hands. Retrieved from https://upload.wikimedia.org/wikipedia/commons/4/4b/Genmattisltr.jpg

Mayuzumi, K. (2006). The Tea Ceremony as a decolonizing methodology: Healing and Japanese women. Journal of transformative education, 4(1), 8-26 
McAdams, D. P. (1993). The stories we live by: Personal myths and the making of the self. New York, NY: William Morrow.

McAdams, D. P. (2006). The role of narrative in personality psychology today. Narrative inquiry, 16(1), $11-18$.

McAdams, D. P., \& Janis, L. (2004). Narrative Identity and Narrative Therapy. In L. E. Angus \& J. McLeod (Eds.), The handbook of narrative and psychotherapy: Practice, theory, and research, (pp. 159-173). Thousand Oaks, CA: SAGE Publications. doi: 10.4135/9781412973496.d13

McBain, L., Kim, Y. M., Cook, B. J., \& Snead, K. M. (2012). From Soldier to Student II: Assessing Campus Programs for Veterans and Service Members. Washington, D.C.: American Council on Education.

McLaren, P. (2009). Critical Pedagogy: A look at the major concepts. In A. Darder, M. P. Balrodano, \& R. D. Torres (Eds.), The critical pedagogy reader (2 ${ }^{\text {nd }}$ ed.) (pp. 61-83). New York, NY: Routledge.

McLaren, P. (2013), A critical patriotism for urban schooling: A call for a pedagogy against fear and denial and for democracy. Texas Education Review, 1, 234-253.

McNiff, S. (2008). Art-based research. In J. G. Knowles \& A. L. Cole (Eds.), Handbook of the arts in qualitative research: Perspectives, methodologies, examples, and issue (pp. 29-40). Los Angeles, CA: SAGE Publications.

McNiff, S. (2011). Artistic expressions as primary modes of inquiry. British journal of guidance \& counseling, 39(5), 385-396.

McRuer, R. (2002) Compulsory able-bodiedness and queer/disabled existence. In S. L. Snyder, B. J. Brueggemann, \& R. Garland-Thomson (Eds.), Disability studies: Enabling the Humanities (pp. 88-99). New York, NY: MLA.

Medalia, A. (2010). Ask the experts: What is cognitive remediation and for whom is it helpful? Columbia Psychiatry. Retrieved from http://asp.cumc.columbia.edu/psych/asktheexperts/ ask_the_experts_inquiry.asp?SI=300

Meo, A. (2010). Picturing students' habitus: The advantages and disadvantages of photo-elicitation interviewing in a qualitative study in the city of Buenos Aires. International Journal of Qualitative Methods, 9(2), 149-171. 
Merry, S. (18 May 2015). There's a divide between civilians and soldiers, partly because of Hollywood. The Washington Post. Retrieved from https://www.washingtonpost.com/lifestyle/style/theres-adivide-between-civilians-and-soldiers-hollywood-is-partly-to-blame/2015/05/17/ea1332f0-f81911e4-a13c-193b1241d51a_story.html

Mikalson, J. D. (2005). Ancient Greek religion. Malden, MA: Blackwell Publishing.

Mikelson, J. D., \& Saunders, K. P. (2013). Enrollment, transfers, and degree completion for veterans. In F. A. Hamrick \& C. B. Rumann (Eds.), Called to Serve (pp. 140-164). San Francisco: Jossey-Bass. Military.com (2014). Poll: America values vets but stereotypes them. Miliatry.com News. Retrieved from http://www.military.com/daily-news/2012/06/14/poll-america-values-vets-but-stereotypesthem.html?ESRC=navy-a.nl

Miller, J. (2013). Vinegette. In F. A. Hamrick \& C. B. Rumann (Eds.), Called to Serve (pp. 165-166). San Francisco: Jossey-Bass.

Miller, K. (2013, August 24). War is loud: Hearing loss most common veteran injury. News21. Retrieved from http://backhome.news21.com/article/hearing/

Minnis, S., Bondi, S., \& Rumann, C. B. (2013). Focused learning environments for student veterans. In F. A. Hamrick \& C. B. Rumann (Eds.), Called to Serve (pp. 201-217). San Francisco: Jossey-Bass. Molina, D. \& Morse, A. (2015). Military-connected undergraduates: Exploring difference between National Guard, reserve, active duty, and Veterans in higher education. Washington, DC: American Council on Education.

Moon, T. L., \& Schma, G. A. (2011). A proactive approach to serving military and veteran students. New Directions for Higher Education, 153, p53-60. Retrieved from http://dx.doi.org.libproxy.chapman.edu/10.1002/he.426

Moore, W. (2014, January). Wes Moore: How to talk to veterans about the war [Video file]. Retrieved from https://www.ted.com/talks/wes_moore_how_to_talk_to_veterans_about_the_war

Moss, G. (2004). Provisions of trustworthiness in critical narrative research: Bridging intersubjectivity and fidelity. The Qualitative Report, 9(2), 359-374.

Muckenfuss, M. (2013, November 5). Veterans' educational needs addressed at hearing. The PressEnterprise, p A4. 
Mulvey, L. (1975). Visual pleasure and narrative cinema. Screen, 16(3), 6-18.

Mundy, C. E. (1998). The Marine Corps Experience. In E. H. Simmons \& J. R. Moskin (Eds.), The Marines (pp. 14-31). Quantico, VA: Marine Corps Heritage Foundation.

Mustakove-Possardt, E. (2003). Critical consciousness: A study of morality in global, historical context. Westpoint, CT: Praeger.

Naphan, D. \& Elliot, M. (2015). Role exit from the military: Student Veterans' perceptions of transitioning from the U.S. military to higher education. The Qualitative Report, 20(2), 36-48. Retrieved from http://www.nova.edu/ssss/QR/QR20/2/naphan3.pdf

National Council on Disability (2009). Invisible wounds: Serving service members and veterans with PTSD and TBI. Washington, DC: Author.

Ness, B. M., Middleton, M. J., \& Hildebrandt, M. J. (2015). Examining the effects of self-reported Posttraumatic Stress Disorder symptoms and positive relations with others on self-regulated learning for student service members/Veterans. Journal of American college health, 63(7), 448458. doi:10.1080/07448481.2014.975719

Newport, K. (2011, July 21). Americans see Army, Marines as most important to defense: Americans say Marines are most prestigious. Gallup: Politics. Retrieved from: http://www.gallup.com/poll/148127/americans-army-marines-important-defense.aspx

Nichols-Casebolt, A. (2012). The Green Zone--A program to support military students on campus. About Campus, 17(1), 26-29. doi:10.1002/abc.21070

Nodelman, D. J. (2013). Culturally responseive methodology within an aesthetic framework. In M. Berryman, S. SooHoo, \& A. Nevin (Eds.), Culturally Responsive Methodologies (pp. 149-173). Bingley, UK: Emerald Group Publishing Limited.

O’Herrin, E. (2011). Enhancing veteran success in higher education. Peer Review, 13(1), 15-18.

Obama, B. (23 August 2013). Remarks by the President in Town Hall at Binghamton University. The White House: Office of the Press Secretary. Retried from https://www.whitehouse.gov/the-pressoffice/2013/08/23/remarks-president-town-hall-binghamton-university

Olsen, T., Badger, K., \& McCuddy, M. D. (2014). Understanding the student veterans' college experience: An exploratory study. U.S. Army Medical Department Journal, Oct-Dec 2014, 101-108. 
Osborne, N. J. (2013). Veteran ally: Practical strategies for closing the military-civilian gap on campus. Innovative Higher Education. doi:10.1007/s10755-013-9274-z

Osborne, N. J. (2014). Student Veteran discussion panels: Deconstructing the traumatized Veteran stigma on campus. About Campus, 19(2), pp. 24-29. doi: 10.1002/abc.21153

Ostovary, F., \& Dapprich, J. (2011). Challenges and opportunities of Operation Enduring Freedom/Operation Iraqi Freedom veterans with disabilities transitioning into learning and workplace environments. New Directions for Adult \& Continuing Education, 132, 63-73. doi:10.1002/ace.432

Paquette, M. (2008). The aftermath of war: Spiritual distress. Perspectives in Psychiatric Care, 44(3), 143145.

Parker, L. (2003). Critical race theory in education: Possibilities and problems. In M. Peters, C. Lankshear, \& M. Olssen (Eds.), Critical Theory and the human condition: Founders and praxis (pp. 184198). New York, NY: Peter Lang.

Pasupathi, M., Mansour, E., \& Brubaker, J. R. (2007). Developing a life story: Constructing relationship between seld and experience in autobiographical narrative. Human Development, 50, 85-110. doi: $10.1159 / 000100939$

Pasupathi, M., Weeks, T., \& Rice, C. (2006). Reflecting on life: Remembering as a major process in adult development. Journal of Language and Social Psychology, 25(3), 244-263.

Patterson, K., Grenny, J., McMillan, R., \& Switzler, A. (2012). Crucial Conversations: Tools for Talking When Stakes Are High (2nd ed.). New York: McGraw Hill.

Persky, K. R., \& Oliver, D. E. (2011). Veterans coming home to the community college: Linking research to practice. Community College Journal of Research and Practice, 35(1-2), 111-120. doi: $10.1080 / 10668926.2011 .525184$

Peters, M., Lankshear, C., \& Olssen, M., (2003). Introduction: Critical theory and the human condition. In M. Peters, C. Lankshear, \& M. Olssen (Eds.), Critical Theory and the human condition: Founders and praxis (pp. 1-14). New York, NY: Peter Lang.

Phelps, S. F. (2015). The Veteran Student Experience and the Academic Librarian. Journal of Academic Librarianship, 41(3), p236-240. doi: 10.1016/j.acalib.2015.04.001 
Phillips, G. A. \& Lincoln, Y. S. (In Press). Introducing Veteran Critical Theory.

Pollard, T. J. (2015 May 27). The Canadian University and the War Against Omar Khadr. The Public Iintellecturals Project. Retrieved from http://www.truth-out.org/news/item/30997-the-canadianuniversity-and-the-war-against-omar-khadr

Radford, A. W. (2009). Military service members and veterans in higher education: What the new G.I. Bill may mean for postsecondary institutions. Washington, D. C.: American Council on Education.

Rafool Bidwell, L. (2012). On the forefront of military trauma research. Colleague, 29(2), 18-22.

Ray, S. L. (2013). On leaving the Corps: Be prepared. Marine Corps Gazette, 97(7), 55-56.

Reynolds, C. V. (2013, March 8). From combat to campus. Chronicle of Higher Education, Convergence: Diversity \& Inclusion, 21-26.

rhizome. (n.d.). Dictionary.com Unabridged. Retrieved May 18, 2015, from Dictionary.com website: http://dictionary.reference.com/browse/rhizome

Roach, M. (2016). Grunt: The Curious Science of Humans at War. New York, NY: W. W. Norton \& Company

Roberts, P. (2003). Knowledge, dialogue, and humanization: Exploring Freire’s philosophy. In M. Peters, C. Lankshear, \& M. Olssen (Eds.), Critical Theory and the human condition: Founders and praxis (pp. 169-183). New York, NY: Peter Lang.

Roberts, R. (2008). Profiles in Greek \& Roman Mythology: Athena. Hockessin, DE: Mitchell Lane Publishing.

Rogers, C. (1951). Client centered therapy. New York, NY: Houghton Mifflin Company.

Rogers, C. (1957). The necessary and sufficient conditions of therapeutic personality change. Journal of Consulting Psychology, 21(2), 95-103.

Rogers, C. (1959). A theory of therapy, personality, and interpersonal relationships, as developed in the client-centered framework. In S. Koch (Ed.), Psychology: a study of a science, Vol. 3, (pp. 184256). New York, NY: McGraw-Hill.

Rogers, C. (1961). On becoming a person. New York, NY: Houghton Mifflin Company.

Rogers, C. (1964). Toward a modern approach to values: The valuing process in the mature person. Journal of abnormal and social psychology, 68(2), 160-167. 
Rogers, C. (1967). The interpersonal relationship in the facilitation of learning. In H. Kirschenbaum \& V.L Henderson (Eds.), The Carl Rogers Reader: Selections for the lifetime work of America's preeminent psychologist, author of One Becoming a Person and A Way of Being (pp. 304-322). Boston, MA: Houghton Mifflin Company.

Rogers, C. (1969). Freedom to learn. Columbus, OH: Charles E. Merrill Publishing Company.

Rogers, C. (1980). A way of being. New York, NY: Houghton Mifflin Company.

Rogers, C. (1985). Toward a more human science of the person. Journal of Humanistic Psychology, 25(4), $7-24$.

Rose, H. J. (1959). A handbook of Greek mythology: Including its extension to Rome. New York, NY: Dutton.

Rumann, C. B., \& Hamrick, F. A. (2009). Supporting student veterans in transition. New Directions for Student Services, 126, 25-34. Retrieved from http://www.blackwellsynergy.com/doi/abs/10.1002/ss.313

Rumann, C. B., \& Hamrick, F. A. (2010). Student veterans in transition: Re-enrolling after war zone deployments. Journal of Higher Education, 81(4), 431-458. Retrieved from http://dx.doi.org/10.1353/jhe.0.0103

Rumann, C., Rivera, M., \& Hernandez, I. (2011). Student veterans and community colleges. New Directions for Community Colleges, 155, 51-58. Retrieved from http://dx.doi.org/10.1002/cc.457

Saldaňa, J. (2008). The drama and poetry of qualitative method. In M. Cahnmann-Taylor \& R. Siegesmund (Eds.), Arts-based research in education: Foundations for practice (pp. 220-227). New York, NY: Routledge.

Sammons, M. T. (2005). Psychology in the public sector: Addressing the psychological effects of combat in the U.S. Navy. American Psychologist, 60(8), 899-909.

Sander, L. (2012a). Colleges go off campus to bridge the military-civilian divide. Chronicle of Higher Education, 59(4), 21.

Sander, L. (2012b, May 4). With GI Bill's billions at stake, colleges compete to lure veterans. Chronicle of Higher Education, 58(35), A1-A8.

Schiavone, V., \& Gentry, D. (2014). Veteran-Students in Transition at a Midwestern University. Journal of 
Continuing Higher Education, 62(1), p29-38.

Schick, W. (2015). Three principles for leadership success: Knowing and understanding your people. Marine Corps Gazette, 99(9), pp. 66-68.

Schonfeld, L., Braue, L.A., Stir, S., Gum, A. M., Cross, B. L., \& Brown, L. M. (2015). Behavioral health and adjustment to college life for student service members/Veterans. Journal of American college health, 63(7), 428-436. doi:10.1080/07448481.2014.963106

Schultz, H., \& Chandrasekaran, R. (2014). For love of country: What our Veterans can teach us about citizenship, heroism, and sacrifice. New York, NY: Alfred A. Knopf.

Schwab, G. (1977). Gods \& heroes: Myths and epics of ancient Greece. New York, NY: Pantheon Books.

Schwandt, T. A. (2007). The SAGE dictionary of qualitative inquiry. Los Angeles, CA: SAGE Publications.

Selber, K., Chavkin, N. F., \& Biggs, M. J. G. (2015). Dual Mission: An Innovative Field Model for Training Social Work Students for Work with Veterans. Journal of Social Work Education, 51, S59-S75. doi: 10.1080/10437797.2015.1001286

Senge, P. M., Scharmer, C. O., Jaworski, J., \& Flowers, B. S. (2008). Presence: Human Purpose and the Field of the Future. New York: Currency Doubleday.

Sermijn, J., Devlieget, P., \& Loots, G. (2008). The Narratice construction of the self: Selfhood as a Rhizomatic Story. Qualitative Inquiry, 14(4), 632-650. doi: 10.1177/1077800408314356

Shane, I. (2016 July 10). VA disability backlog tops 70,000 - 7 months after it was supposed to be zero. Military Times. Retrieved from http://www.marinecorpstimes.com/story/veterans/2016/07/10/vadisability-claims-backlog-veterans-affairs/86862716/.

Shelton, H., Levinson, R., \& McConnell, M. (2010). Without hesitation: The odyssey of an American warrior. New York, NY: St. Martin's Griffin.

Siegesmund, R. \& Cahnmann-Taylor, M. (2008). The tensions of arts-based research in education reconsidered. In M. Cahnmann-Taylor \& R. Siegesmund (Eds.), Arts-based research in education: Foundations for practice (pp. 231-246). New York, NY: Routledge.

Simon, J. (2011). Legal issues in serving students with disabilities in postsecondary education. New Directions for Student Services, 134, 95-107.

Simpson, E. (2013). War from the ground up: Twenty-first-century combat as politic (Nook version). New 
York, NY: Oxford University Press.

Smith, B., \& Junger, S. (2016, June 9). Sebastian Junger on Veterans, modern society, and finding a tribe. Team RWB Eagle Nation Podcast. Podcast retrieved from http://www.teamrwb.org/blog/specialedition-podcast-with-sebastian-junger-best-selling-author-and-oscar-nominatedfilmmaker/?utm_source=newsletter\&utm_medium=email\&utm_content=http\%3A//d31hzlhk6di2 h5.cloudfront.net/20160609/3b/9a/50/34/3c2a954d5c980cd115bda70e_1182x618.jpg\&utm_camp aign=Special\%20Edition\%20Podcast\%20with\%20Sebastian\%20Junger

Smith, J. A. (8 June 2106). The science of the story. Greater Good: The science of a meaningful life. Retrieved from http://greatergood.berkeley.edu/article/item/science_of_the_story

Smith-Osborne, A. (2012). Supported education for returning veterans with PTSD and other mental disorders. Journal of Rehabilitation, 78(2), 4-12.

SooHoo, S. (2013). Humility within culturally responsive methodologies. In M. Berryman, S. SooHoo, \& A. Nevin (Eds.), Culturally Responsive Methodologies (pp. 201-217). Bingley, UK: Emerald Group Publishing Limited.

Sorsoli, L., \& Tolman, D. L. (2013). Hearing Voices: Listening for multiplicity and movement in interview data. In S. Hesse-Biber \& P. Leavy (Ed.) Handbook of Emergent Methods, (pp. 495-515). New York, NY: Guilford Publications, Inc.

Spears, L. (2004) The understanding and practice of servant-leadership. In Spears, L., \& Lawrence, M. (Eds.), Practicing servant-leadership: Succeeding through trust, bravery and forgiveness (pp. 924). San Francisco: Jossey-Bass.

Springgay, S. (2008). Nurse-in: Breastfeeding and a/r/tographical research. In M. Cahnmann-Taylor \& R. Siegesmund (Eds.), Arts-based research in education: Foundations for practice (pp. 137-141). New York, NY: Routledge.

Stewart, K. J. (2015). Observations in Command: Leadership is continuous. Marine Corps Gazette, 99(10), $50-52$.

Stewart, R. L. (2014 September 23). Onward and Upward Bound: Military Veterans Charge Toward Higher Education. New England Journal of Higher Education, 1.

Stone, S. J. (2013). Ana Maria Araujo Freire: Scholar, HUmanitatarian, and Carrying on Paulo Freire's 
Legacy. In J. D. Kirylo (Ed) A Critical Pedagogy of Resistance: 34 Pedagogues We Need to Know (pp. 45-48). Rotterdam, The Netherlands: Sense Publishers

Street, M. (2014). Military Veterans bring value to the classroom. Chronicle of Higher Education, 60(32),

30.

Strong, J., Ray, K., Findley, P. A., Torres, R., Pickett, L., \& Byrne, R. J. (2014). Psychosocial Concerns of Veterans of Operation Enduring Freedom/Operation Iraqi Freedom. Health \& Social Work, 39(1), p17-24.

Stryker, S. (1968). Identity salience and role performance. Journal of Marriage and Family, 30(4), 558564.

Stryker, S., \& Burke, P. J. (2000). The past, present and future of Identity Theory. Social Psychology Quarterly, 63(4), 284-297.

Sue, D. W. (2010). Microaggressions, marginality, and oppression: An introduction. In (D. W. Sue, Ed.), Microaggressions and Marginality: Manifestation, Dynamics, and Impact (pp 3-22). Hoboken, NJ: John Wiley \& Sons, Inc.

Summerlot, J., Green, S., \& Parker, D. (2009). Student veterans organizations. New Directions for Student Services, 126, 71-79.

Swope, C. N. (2014). Marines and mentors: Planning for the transition. Leatherneck, 97(10), 14-16.

Tajfel, H. (1978). Differentiation between social groups: Studies in the social psychology of intergroup relations. London, UK: Academic Press.

Tamas, S. E. (2010). Walking the lines: Art, research, and unknowing. Creative approaches to research, $3(2), 5-20$.

Tanielian, T., \& Jaycox, L. H. (Eds.). (2008). Invisible wounds of war: Psychological and cognitive injuries, their consequences, and services to assist recovery. Santa Monica, CA: RAND Corporation.

Team RWB (2016). Our Approach: Our Mission. Team RWB. Retrieved from: https://www.teamrwb.org/our-approach/mission

Tillman, L. (2002). Culturally sensitive research approaches: An African-American perspective. Educational Researcher, 31(9), 3-12. 
Timmerman, T., Hepler, R., \& Orient, E. (2014). Corps to Career. Marine Corps Gazette, 98(4), 71-74.

Torreon, B. S. (2015). U. S Periods of war and dates of recent conflicts (CRS Report No. RS21405). Washington, DC: Congressional Research Service.

Tuckman, B. W. \& Jensen, M. A. C. (1977). Stages of small-group development revisited. Group Organization Management, 2(4), 419-427. doi:10.1177/105960117700200404

Tuhiwai Smith, L. (2012). Decolonizing Methodologies: Research and Indigenous Peoples. London: Zed Books.

Turse, N. (2008). The Complex: How the military invades our everyday lives (Nook version). New York, NY: Henry Holt \& Company.

Tyson, L. (2006). Critical theory today: A user-friendly guide (2nd ed.). New York, NY: Routledge.

U.S. Census Bureau (2015 June 8 revision) State and County QuickFacts. Data derived from Population Estimates, American Community Survey, Census of Population and Housing, State and County Housing Unit Estimates, County Business Patterns, Nonemployer Statistics, Economic Census, Survey of Business Owners, Building Permits. Retrieved from http://quickfacts.census.gov/qfd/states/00000.html

U.S. Department of Defense. (2015). Operation Freedom's Sentinel Qualifies for Campaign Medal.

Retrieved from http://www.defense.gov/News-Article-View/Article/604135/operation-freedomssentinel-qualifies-for-campaign-medal

U.S. Department of Education. (2015). 8 keys to Veteran's Success Sites. Retrieved from http://www.ed.gov/veterans-and-military-families/8-keys-success-sites

U.S. Department of Veteran Affairs. (2013a). Benefits of the Yellow Ribbon Program. Retrieved from http://www.gibill.va.gov/benefits/post_911_gibill/yellow_ribbon_program.html

U.S. Department of Veteran Affairs. (2013b). Factors to consider when choosing a school: A guide before using the GI Bill. Retrieved from http://www.gibill.va.gov/student_tools/choose/index.html\#_Toc361303015

U.S. Department of Veteran Affairs. (2013c). The Post-9/11 GI-Bill. Retrieved from http://www.gibill.va.gov/benefits/post_911_gibill/index.html

U.S. Department of Veteran Affairs. (2016). Military Songs Inspire Troops, Preserve Tradition. Retrieved 
from http://www.va.gov/opa/publications/celebrate/militarysongs.pdf

USMC (2014). EF-21: Shaping the Future Marine Corps. U.S. Marine Corps Concepts and Programs.

Retrieved from https://marinecorpsconceptsandprograms.com/concepts/expeditionary-force-21/ef21-shaping-future-marine-corps

Vacchi, D. T. (2012). Considering Student Veterans on the Twenty-First-Century College Campus. About Campus, 17(2), 15-21.

Valenzuela, N. (2013). Finding clarity amidst murky waters: Beginnings of a culturally responsive researcher. In M. Berryman, S. SooHoo, \& A. Nevin (Eds.), Culturally Responsive Methodologies (pp. 69-85). Bingley, UK: Emerald Group Publishing Limited.

Vance, M. L., \& Miller, W. K. (2009). Serving wounded warriors: Current practices in postsecondary education. Journal of Postsecondary Education and Disability, 22(1), 18-35.

Veteran Benefits Administration. (2011). VetSuccess on Campus Information. Washington, D.C.: U.S. Department of Veteran Affairs. Retrieved from https://www.vetsuccess.va.gov/public/vetsuccess_on_campus.html

Voluntary Education Programs, 78 (157) Fed. Reg. $49382-49400$ (2013, April 9).

Wallace, M. \& Fromm, E (1958, May 25). The Mike Wallace Interview: Erich Fromm [Television broadcast]. Austin, TX: Harry Ransom Center, University of Texas at Austin. Retrieved from http://www.hrc.utexas.edu/multimedia/video/2008/wallace/fromm_erich.html

Walsh, C. A., Rutherford, G., \& Crough, M. (2013). Arts-based research: Creating social change for incarcerated women. Creative approaches to research, 6(1), 119-139.

Wheatley, M. J., Spears, L., \& Noble, J. (2004) The servant-leader: From hero to host. In Spears, L., \& Lawrence, M. (Eds.), Practicing servant-leadership: Succeeding through trust, bravery and forgiveness (pp. 241-268). San Francisco: Jossey-Bass.

Whiteman, S. D., Barry, A. E., Mroczek, D. K., \& MacErmid Wadsworth, S. (2013). The development and implications of peer emotional support for student service members/veterans and civilian college students. Journal of Counseling Psychology, 60(2), 265-278. doi:10.1037/a0031650

Widome, R., Kehle, S. M., Carlson, K. F., Laska, M., Gulden, A., \& Lust, K. (2011). Post-traumatic stress disorder and health risk behaviors among Afghanistan and Iraq War veterans attending 
college. American Journal of Health Behavior, 35(4), 387-392.

Williams, J. (2013). From inclusion to diversity: A Marine's perspective. Orange County Lawyer, 55(11), 20-21.

Wilson, K. B. (2014). Thank you for your service: Military initiatives on college campuses. New Horizons in Adult Education \& Human Resource Development, 26(3), 54-60.

Wittig, M. (1980). The straight and other essays. Boston, MA: Beacon.

Woff, R. (2003). A pocket dictionary of Greek and Roman Gods \& Goddesses. Los Angeles, CA: Getty Publications.

Wong, F. R. (2005). Leave no man behind: Recovering America's fallen warriors. Armed forces \& society, 31(4), 599-622. doi:10.1177/0095327X0503100408

Wood, J. (2011, December). Jake Wood: A new mission for veterans - disaster relief [Video file]. Retrieved from https://www.ted.com/talks/jake_wood_a_new_mission_for_veterans_disaster_relief

Wounded Warrior Project. (2013). TRACK Program Details. Retrieved from http://www.woundedwarriorproject.org/programs/track/program-details.aspx

Wurster, K. G., Rinaldi, A. P., Woods, T. S., \& Ming Lui, W. (2013). First generation student veterans: Implications of poverty for psychotherapy. Journal of clinical psychology, 62(2), 127-137. doi: $10.1002 /$ jclp. 21952

Zander, R. S., \& Zander, B. (2000). The art of possibility: Transforming professional and personal life. New York, NY: Penguin Books.

Zoroya, G. (2016 May 5). Pentagon perpetuates stigma of mental health counseling, study says. USA Today. Retrieved from http://www.usatoday.com/story/news/nation/2016/05/05/study-slamspentagon-failing-end-stigma-mental-health-counseling/83922456/ 


\section{Research Timeline}

\begin{tabular}{|c|c|c|c|c|c|c|c|}
\hline$\frac{8}{3}$ & $\frac{\Xi}{2}$ & 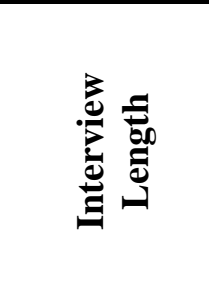 & 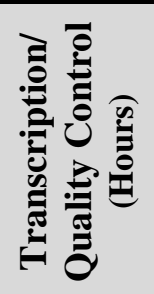 & 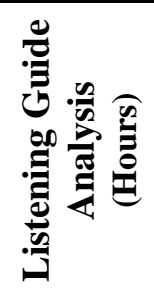 & 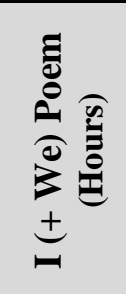 & 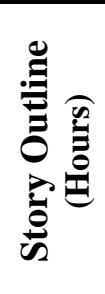 & 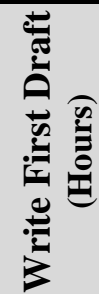 \\
\hline Beaver & $10 / 14 / 2015$ & $1: 51$ & 4 & 4.5 & 1.5 & \multirow{5}{*}{4} & \multirow{5}{*}{6} \\
\hline Beaver & $10 / 20 / 2015$ & $2: 33$ & 2.5 & 4.75 & 1.5 & & \\
\hline Beaver & $11 / 9 / 2015$ & $(2: 45)$ & & & & & \\
\hline Beaver & $11 / 23 / 2015$ & $2: 05$ & 2 & 5 & 1.5 & & \\
\hline Beaver & $12 / 15 / 2015$ & $1: 52$ & 2 & 4.5 & 1.5 & & \\
\hline Lance & $11 / 19 / 2015$ & $1: 19$ & 1.25 & 5.25 & 1 & \multirow{4}{*}{4} & \multirow{4}{*}{6} \\
\hline Lance & $12 / 28 / 2015$ & $0: 51$ & 1 & 4.5 & 1 & & \\
\hline Lance & $1 / 5 / 2016$ & $1: 06$ & 1 & 4.5 & 1 & & \\
\hline Lance & $7 / 2 / 2016$ & $(2: 15)$ & & & & & \\
\hline Sgt. G & $10 / 12 / 2015$ & $: 44$ & 1 & 3.5 & 1.5 & \multirow{3}{*}{4} & \multirow{3}{*}{7} \\
\hline Sgt. G & $11 / 23 / 2015$ & $: 47$ & 1 & 3.5 & 1.5 & & \\
\hline Sgt. G & $12 / 15 / 2015$ & $: 47$ & 1 & 3.5 & 1.5 & & \\
\hline $\mathrm{V}$ & $10 / 25 / 2015$ & $1: 00(+: 30)$ & 1 & 4.5 & 1 & \multirow{4}{*}{4} & \multirow{4}{*}{7} \\
\hline $\mathrm{V}$ & $11 / 22 / 2015$ & $: 45(+: 30)$ & 0.75 & 3.5 & 0.75 & & \\
\hline $\mathrm{V}$ & $12 / 19 / 2015$ & $: 58(+1: 15)$ & 1 & 4.25 & 1 & & \\
\hline \multirow[t]{2}{*}{$\mathrm{V}$} & $6 / 5 / 2016$ & $(2: 00)$ & & & & & \\
\hline & Total & 24:53:00 & 19.5 & 55.75 & 16.25 & 16 & 26 \\
\hline
\end{tabular}

It's 4:00 am

"Drink me" says my coffee

And down the rabbit hole I go

A quick review of an article

That leads to another source

That source to another

And that one...

It's 7:00am

No new words

A million new ideas

And down the rabbit hole I go 


\begin{tabular}{|c|c|c|c|c|}
\hline Who & When & $\begin{array}{c}\text { Interview } \\
\text { Length }\end{array}$ & $\begin{array}{c}\text { Story Outline } \\
\text { (Hours) }\end{array}$ & $\begin{array}{c}\text { Write } \\
\text { First Draft } \\
\text { (Hours) }\end{array}$ \\
\hline The Unit & $11 / 29 / 2015$ & $2: 46$ & \multicolumn{2}{|c|}{} \\
\hline The Unit & $12 / 13 / 2015$ & $2: 20$ & \multicolumn{2}{|c|}{45} \\
\hline The Unit & $1 / 31 / 2016$ & $3: 00$ & \\
\hline The Unit & $4 / 10 / 2016$ & $3: 15$ & \\
\hline
\end{tabular}




\section{Sgt. G. Recon Report}

\section{$\underline{\text { Individual Meeting \#1, 10/12/15 }}$}

\section{First Listening: Plot}

Recurring words/themes: Pride; Service; Selflessness; Others First; Earned; Elite;

Order; Hierarchy; Control; Fear; Pain; Suffering; Challenge; Transformed;

Other Marines; Comradery; Fun; Constant Vigilance; Longing; Loss

Plot: Joined to become part of something bigger, do something with his life. He deployed soon after he completed Bootcamp and MOS school and deployed often as he had four total deployments. He married first wife before first deployment. First deployment was the invasion, they followed the infantry so when his unit arrived "It was nobody, it was abandoned. It looked like War of the Worlds, that movie with Tom Cruise. It was beat up and burning. There was ruble everywhere." The Second deployment was the "worst," as a Marine was KIA the first night in Al Assad. They were mortared once a week, at least, during that deployment. It was also when Sgt. G earned his Combat Action Ribbon (CAR). "The last two deployments were fairly simple.” He discharged after his second deployment because he had "some stuff to take care of." His team deployed shortly after, and during that deployment, some of the guys did not make it home. "Maybe I could have changed something." Sgt. G loves the Corps "I don't regret any of it. Even the adversity, even the negatives, even the cons. It's a learning experience, you know? I think it helped shaped me, helped harden me to where I need to be hard, and given me that ... What's the word I want to use? It's given me the strength, when most 
people wouldn't have the strength; it's given me that strength that will to overcome things. And it's also made me humble. And it's given me patience, lots of patience. And sometimes I don't have patience these days, I know when I was in man, I had tons. You have to. “

Key Characters: Other Marines; Patrick Gallagher (KIA April 2, 2006, OIF)

Briefly Mentioned: Dad; Brothers; Friends; First Wife; Wife

Summary: Never seen as a mentor to his younger brothers, the Marines gave Sgt. G an opportunity to be part of something bigger and support the Marines who came after him as a guide and mentor. "I love having Marines. I loved shaping them and helping foster their career... I had a lot of Marines that looked up to me, and I looked up to them too." This has become core to who he is - he likes to provide help and joy, to make other's lives better!

\section{Second Listening: I Poem}

I was in the Marine Corps for a total of 8 years

I did 6 months in the National Guard as a reservist

I did 8 years in the Marine Corps. The best time in my life by far

I mean aside from getting married and having children

I think the Marine Corps was one of the biggest highlights of my young adult life.

I would do it all over again in a heartbeat

I saw

I don't regret any of it

I wanted to say out of high school.

I knew

I wanted to join the service

I tried the Army

I couldn't get in for a medical purpose.

I joined the Marine Corps

I looked into the Marine Corps

I started asking questions

I'm glad

I made that choice

I'm glad the Army didn't take me. 
I'd be a soldier. But, um, there's nothing wrong with that.

I won't say

I've known

I like to be challenged

I like to be challenged to the point where either

I do it or

I don't

I do it obviously

I'll get to see where my limits are

I went through that

I passed

I could do that

I could be a Marine

I'm sure you probably get that from a lot of the Marines

I felt like a real Marine

I did have that pride, that sense of belonging

I got my EGA

I did have that sense of pride and belonging, $\mathrm{b}$

I knew

I don't get past this evolution

I'm not gonna be a Marine

I was a little cautious

I think once they put that EGA in my hand

I was up there

I balled like a baby

I uh, you know, just like everybody else up there

I balled like a baby

I think that was uh, that was the pivotal point for me

I think it's everybody's

I don't know

I know that he (my father) wanted to join, but he didn't finish his high school

I don't know

I was already going

I was just

I'm a teenager

I did

I think my dad was very ...

I think that changed his mind

I think that um, he treated me a lot better

I think he had a lot of pride too

I think he was very prideful

I enlisted after. (9/11) 
I actually went and enlisted

I think uh, no. No

I did sign after

I officially signed documents

I didn't ship until 2002

I was supposed to be a reservist

I signed up to be a reservist

I knew we were gonna get into some conflict

I kinda wanted to

I had a change of heart last minute

I was like, "You know what

I'm just gonna go full time

I might as well just do it all the way."

I switched my contract

I didn't have a ship date

I was a reservist, they were waiting

I did sign up as a full-blown active duty personnel

I am the second oldest

I have an older sister

I don't think I was a role model to my brothers

I know

I finished boot camp

I went home on leave

I went to boot camp

I don't know

I went home

I just

I came home

I've had two friends

I actually work with (one) right now

I went to school with

I remember

I think one of the guys wanted to join too

I don't know what happened

I think

I see

I think um, putting yourself last, putting your country, your community, your family ... Um, service first

I think that

I wish there were better words I could use

I think that's it 
I'd say, to be a Marine

I think you have to have a lot of patience

I think that's what helped me out a lot during boot camp

I'm fine with that

I think having patience

I think having thick skin, and just being the best person you could possibly be

I think

I genuinely want to help people

I was in Iraq ...

I was out there

I know

I think

I would say

I was riding a bike

I was contemplating before that

I was on a bike ride with my buddy

I jumped a curb, face planted, lost my teeth, and got cuts

I think right there and then

I knocked some sense into myself

"I gotta go through with this."

I did

I was in the recruiter's office

I mean that was the beginning of it

I gave it $110 \%$

I've been in positions where people yelled

I was an Explorer for Santa Ana

I've been through police explorer academy

I remember going through the process

I had patches of hair still

I got a patch right here

I'll probably get yelled at for that

I have no control

I remember we got there

I want to say maybe 7 or 8 . We didn't finish till about 2 or 3

I remember laying down and thinking to myself, "What the hell did you get yourself into?"

I remember hearing people crying

I remember getting woken up by the receiving Drill Instructor

I mean, it was crazy

I remember getting picked up, Black Friday

I remember going in as a diet recruit 
I went in

I was at about uh, $205 \mathrm{lbs}$

I was considered a diet recruit

I used to remember lining up for chow

I got burned for it once

I told them

I couldn't have it

I'm gonna get messed up anyway

I might as well just enjoy the pizza

I guess they expected me not to eat it

I ate it

I was squad leader then

I got fired for that

I got re-hired

I was uh, showing leadership abilities, and doing really well

I was really grateful for it

I was really kicking myself

I ate the slice of pizza

I was really hungry

I graduated July 3rd

I knew to expect it to be a different type of animal

I think that helped me be cautious

I was in the Marine Corps

I was with uh, back then they called it 1st FSSG

I was part of transportation support battalion, TSB

I remember training

I knew all this was getting ready, getting us ready to prepare to deploy

I got in

I deployed

I graduated and got into the fleet from MOS school in September

I was on a plane (by January)

I got married (between the time I graduated school to the time I actually left)

I was gone

I can't imagine the stress on her

I was there for the Invasion

I mean, the sights, the smell

I remember sitting in that fox hole

I know everybody was just stressed out

I remember March $19^{\text {th }}$

I guess they passed it (the signal) down

I happened to be the driver that day

I felt like. (laughs) 
I was like, "Ah, shit. Great."

I'm thinking like "We're gonna get resistance, and we're probably gonna get shot at

I'm hoping I get through this."

I was uh, a little relieved, you know, because we didn't get resistance

I got home

I remember showing up to Al Assad

I left

I left

I left

I remember hearing about it

I was like, "Damn, that could have been us.

That could have been one of my friends.

That could have been me."

I didn't see that

I didn't get to experience it the first time

I heard explosions

I saw the aftermath

I didn't get to actually, physically hear the boom and them see it

I heard it

It was a rocket, transrocket

I mean, you hear the first Initial boom and you're like, "Well, here It comes."

I was a truck driver

I was on the road a lot

I was there for my second month

I mean, we were truck drivers, and a lot of those things were on the road and so we were the biggest target, you know?

I remember going through this traffic circle

I don't remember what it was

I remember they had all stopped to watch the convoy go by

I remember feeling like, there's something about this trip just doesn't sit well

I got that gut feeling

I mean the roads were typically empty.

They were typically, busy, but that day they were kind of empty

I remember seeing a large cloud go off

I had a gunner in my truck

I remember hearing him shoot

I remember hearing the guys

I had a, what is it, about 12 guys in the back

I don't want to say the Iraqis, the Insurgents took casualties

I didn't get to see it firsthand

I know that the MP's, the military police that were with us did a reconnaissance I returned fire 
I was like doing a drive by

I know there was a vehicle off in the distance

I saw

I'm not the only one that saw it

I remember one of my colleagues

I drove through the smoke

I was the last vehicle

I was the last vehicle to get out of there

I went through that smoke

I was going pretty fast

I'm like shaking out of my pants

I'm like, "Fuck man

I'm just glad

I made it out of there."

I remember that whole incident

I think that it was more manageable

I had been through the worst

I was a seasoned veteran

I think, my experiences

I was able to bring comfort to them

I've noticed

I've been through

I love having Marines

I loved shaping them and helping foster their career

I had a lot of Marines that looked up to me

I looked up to them too

I think it was a two-way street

I took care of them

I remember

I was getting out

I was getting out

I gotta get out

I've got some stuff to take care of

I'll try to visit every now and then

I'm getting out

I don't live that far away

I'll come up on base

I got out, he deployed

I remember getting a call from one of my friends

I mean, that, to that day, to today

I think back about it

I feel bad 
I didn't go with him.

I could have changed something

I think back about him every now and then

I think overall

I think my deployments, my career in the Marine Corps

I don't regret any of it

I think it helped shaped me

I don't have patience these days

I know when I was in

I had tons. You have to

\section{Additional Second Listening: We (Marines) Poem}

We could either sulk about it and, you know, be miserable.

Or, you know, have fun with it

We did.

We played a lot of jokes.

We were like the show Jackass

We played and messed around

We actually take it to heart

We do the best we can

We do that (honor, courage, commitment)

We follow those in our daily routines

We saw a family

We got there around, I want to say maybe 7 or 8

We didn't finish till about 2 or 3 in the morning

We'll separate you

We got special attention

We had the nickname fat-body, or just...

We had little tabs that we kept on our uniform that says, "Diet recruit"

We'd have to literally go in front of the drill instructor and show them our plate

We were considered

We were formally, before I got there, Bravo Company

We called them bar-b-que bravo

We're leaving in a month

We're leaving in the next month

We're leaving...

We did our first deployment 
We saw

We're gonna go there any day now, any hour, any minute

We're gonna go

We're joking around

We're having fun

We're laughing

We want to know what it is

We're going

We're getting resistance on the driver's side

We actually went

We crossed the line of departure into Iraq

We get into our first

We're gonna get resistance

We're probably gonna get shot at

We get there, and it was nobody, it was abandoned

We followed Seventh Marines

We pretty much followed suit

We got to see the aftermath

We got to see all that

We didn't get resistance

We didn't get resistance

We didn't get shot at

We, that entire deployment

We were expecting to be in actual combat

We got there

We got there, first night

We got there, they got mortared

We got mortared at least once a week

We meet up, and then, just go about our life

We were on the road pretty much 6 to 7 days a week

We were on the road for hours on end

We were sleeping there

We would drive out, sleep there, and then drive back

We got a lot of resistance on this one, with IED's

We started hearing about it

We were truck drivers, and a lot of those things were on the road

We were the biggest target, you know? Supply line

We saw people working on this hut

We had about 20 vehicles

We were like "Ooh."

We get our supply dropped 
We're starting to get ready to leave

We get our accountability, and everybody's good,

We push on out

We get to that traffic circle

We're getting small arms fire

We're getting shot at

We're like, "Where the hell's it coming from?"

We just have them back there

We could

We were getting fire

We're also engaging that vehicle

We did

We never got shot at after

We've always had attempts for IED's

We passed by another convoy

We used an alternate route

We used

We're gonna deploy again

\section{Third Listening: Voices}

In the World: Always a Marine; a husband (to Holly) and a father (to his girls); a

Mentor, Leader ("My Marines")

Within: Desire to do something, lost since the Marines; Responsible for others when he left - but it could have been him; Always serving or being of service (active duty or not)

\section{Fourth Listening: Politics \& Power}

Political: Hierarchy within Marines, rules, control, and punishment within the Corps;

War, invasion, combat, "Iraqis" v "insurgents," us v them; Heroes in battle

Social: "diet recruit" also known as a "fat body"; Hatred for recruits; Perception of

Dress Blues with women; Comradery among Marines; Heroes in battle; Look cool, when nervous

Cultural: Honor, Courage, Commitment - constant, lifetime service to others; 
Marines the best branch of the armed forces; Comradery among Marines; Heroes in battle

Economic: Ended the conversation so he could return to work (only one hour for lunch)

\section{$\underline{\text { Individual Meeting \#2, 11/23/15 }}$}

\section{First Listening: Plot}

Recurring words/themes: Purpose; Responsible; Mentor; Family; Impact; Marine; Help people; No control (as a civilian); Do something important; Capable of more

Plot: After his second deployment, Sgt. G discharged so he could take care of his divorce from his first wife. During that joined the Reserves with the National Guard, but only did that for less than a year. He re-enlisted with the Marines, but there was no space for him with his old MOS. He received a new MOS, more training, and a new GySgt who was not a good leader. After commiserating with his SSgt, he was called into a four-hour meeting with the SSgt and GySgt. Returning home after that deployment led to isolation and a desire to be back with his Marines. "I got to know my Marines in general, especially like when we got this gunny on our asses about them not doing good enough work and it's nice to be that person in the middle, that buffer for them because, you know, without anybody like that there's no advocate for them. They feel like they're getting taken advantage of over there. Just getting worked and not being appreciated." He volunteered for his fourth 
deployment, a small training team to work with the Iraqi Border Patrol.

During that deployment, he met Holly. When he came home, they got married and had a baby. In order to focus on his family, he discharged. He started school, discovered he was a good student, and completed his BA and MA. At the same time, he tried to get into law enforcement. However, a misunderstanding about a few questions required he change his answers, which hurt his screening. Then his 10\% PTSD rating kept him out of law enforcement. He became dad to two little girls, a job harder than being a Marine, and spoils them whenever he can.

Key Characters: GySgt; Marines; Holly; His children or "his girls"

Briefly Mentioned: Mom \& Dad; Iraqi Border Patrol; Translator

Summary: Sgt G felt like he had a purpose advising and mentoring his Marines. He loved the Marine Corps, but he loved his family more. So, after leaving the Corps, and missing it every day, he still tries to find something that matches his capabilities and desire to help others. While he is a family man, definitely, he is also still a Marine (and will always be).

\section{Second Listening: I Poem}

I don't know

I haven't really ...

I've been gone

I think my second (deployment)

I went through that whole, uh, divorce thing

I kind of got adjusted to that.

I think that's why

I'm pretty sure my ex-wife probably would agree

I think

I learned a lot though.

I learned a lot of patience 
I get, I get um, flustered really easy

I just kind of remember take a breath, step back

I was on base most of the time.

I was on base.

I don't

I came in

I left to go to a different base.

I was on the road every day for like my - my first two deployments.

I got out

I stayed as a reservist for the National Guard.

I came back in

I reenlisted

I couldn't reenlist in that same, uh, MOS anymore

I had to reenlist in a different occupation

I came back in as a mechanic

I was breaking them before

I was fixing them.

I got back, I got back in

I went to school for eight months in North Carolina

I went back as a mechanic

I got my first shop.

I didn't know anything in the mechanical realm

I got there and was like you can sink or swim.

I learned at school.

I did really well.

I also had a gunnery sergeant that was in charge of me who had just got off the drill field

I was able to handle it.

I remember his direction and his leadership was very contradicting.

I mean ...

I think that right there was the cherry on top for me

I came home from that deployment

I didn't want to be around anybody.

I didn't want to ... They had a party for me.

I showed up to the party. Hi and bye within, like, 30 minutes.

I didn't know my dad set it up

I talked to him

I told my mom not to make anything for me.

I didn't want to do anything.

I found out that it was my dad that made that party

I had told him

I don't want any of that.

I made him feel bad. 
I know

I did.

I felt bad afterwards

I didn't want to be near anybody.

I was, um,

I was stressed out

I mean

I was away from home for the holidays

I'd spent Christmas, Thanksgiving all the major calendar holidays out there.

I have this guy riding me for more than half of the deployment.

I was okay.

I did what I was supposed to do and then some, he still rode me to

I don't know

I guess make me better in his mind

I kinda caught on and it's just like okay.

I remember one time

I remember venting to my staff sergeant

I remember venting to him

I get called in the office

I'm like "I don't have a problem with you.

I just ...

I don't-

I don't like the way things are going.

I'm like "I don't get it.

I'm like "But

I don't-

I don't get what you're saying at all."

I was in there for like four hours

I remember getting out sometime after lunch.

I was sweating and everything.

I mean, that right there was the straw that broke the camel's back.

I came back home from that

I just for- for at least a good month or two, no contact with anybody.

I didn't go to the mall,

I didn't want to be out at the movie theater, didn't want to go to a bar.

I just wanted to be at home,

I was back to normal

I was like all right, cool

I mean, that was- that was pretty much the third deployment.

I did a lot of maintenance work.

I ran the shop.

I got to learn how to run the shop. 
I had to deal with budgeting, ordering uh, overhead stock, just getting to know my Marines in general,

I make sure that, be like at the end of the day everybody does a good job.

I might tell them, you messed up on this, you guys still got to do that

I always try to end on a good note.

I volunteered. Couldn't help being away

I'm pretty sure you'll hear this from a lot of people.

I think it's just the comradery that I had with my- my group of men and women.

I was out there for my third deployment,

I got to speak to some of those team members

I went out there.

I deployed

I was just working at the shop.

I was still in charge of the maintenance shop

I was with out there.

I did the best I could do; you know.

I got out there.

I was the only the mechanic on the team

I took care of all the vehicles we had

I would go out there and ... We- we'd all as a whole teach them some tactical um, aspects of their job.

I'd go check out the Motor T

I showed him how to do like a basic oil change on their vehicle

I taught some of their guys

I had an interpreter with me of course

I could speak some of the language, it was always helpful to have that interpreter

I'd be like tell him this, this and that

I'm like "What did they really say?"

I don't even know what happened to them now

I was a Motor T operator

I'm like driving like "Oh shit, when's our number, when's our number up and so ..."

I don't think we got any contact.

I came back

I met Holly. And we got married

I got out

I get it, you know

I can feel my back, my knees and I couldn't run like I used to

I figured,

I'm already falling apart now. You might as well get out and get it taken care of

I really want to do in terms of career and then, uh, you know just raise the family 
I was uh ...

I actually got on terminal leave in January,

I think, so sometime in early January

I burned up like 30 days of leave.

I had a lot of it on the books.

I sold most of them back

I just took a 30-day vacation.

I actually took terminal leave and never went back?

I cried all the way home.

I did.

I looked back in the rear-view mirror

I get to see Pendleton.

I haven't been back since.

I have ...

I'm not obligated to go back anymore.

I've always told Holly,

I'm want to go back and visit.

I just can't find the time for it

I don't have a need to go back,

I mean, there's no need for me to go over there

I definitely do want to go visit.

I don't care.

I'll just go to a unit and be like "Hey. How you doing? I was deployed with this unit before," or "Hey, I was a part of this unit."

I ended up going somewhere local.

I want to do it next year.

I didn't go out anywhere far just because

I knew that Holly was going to be busy.

I didn't want to be out too late

I stayed close.

I did.

I don't want to overdo it.

I'm not retired

I didn't tell her.

I kept it.

I still have it.

I mean they said congratulations.

I'm not going to have to wake up tomorrow so early.

I was just like thank goodness.

I'm just like oh yeah.

I was really considering like ... 
I was over-thinking

I already made my decision.

I can't go back.

I was good at what I did

I felt accomplished

I did a lot of uh ... Especially with Marines

I like to have that ...

I like to be that- that type of mentor type person.

I've had a few of them,

I like to be there and kind of like help them through

I like to be that like "Hey, I've been there. I've done that."

I left when my wife was pregnant

I just-I just felt like there

I was serving a- a purpose

I like what I do.

I love what do.

I don't think I'm-I'm doing what I should be doing.

I don't think I'm like just the-

I'm not operating to my fullest potential.

I just graduated school and-

I like wanna go that route.

I want to break off and get into psychology.

I don't have the experience

I already got the master's

I mean,

I love what I do at the parks but

I think that ...

I think

I'm ... There's something out there else

I could be doing that would make a bigger impact on other people lives you know.

I chose that route

I wanted to be in law enforcement.

I actually ... That was like my biggest aspiration growing up

I kinda cut my- my uh, losses

I've uh, applied and been denied or disqualified.

I went all the way to the very last step which was the psych eval.

I'd already signed my letter of conditional employment and everything

I passed my MMPI.

I passed them both

I did my actual sit down with the psych um, she failed me.

She disqualified me because PTSD.

I was able to provide letters 
I got it

I'm able to operate

I think she might was biased and

I say this because the minute that she asked me

I know

I was done

I was like this isn't going to end well.

I got that DQ letter.

I was like "Wh- What the hell?"

I got to hire a separate psychologist to evaluate, reevaluate.

I went through the MMPI again.

I went through a whole uh, uh, what was it? Uh ... The intake interview all over

I was still disqualified

I sat down with the actual psychologist for the county

I would talk about it

I was like very excite

I got that letter

I was like calling like "Why?" And he was like "You still have PTSD."

I'm like "It's a small ... It's a 10\% rating.

I'm like well if it's like this there

I'm probably going to get DQ from other places.

I don't have a background that's bad.

I don't have a dirty record.

I've never been arrested.

I guess lack of work experience.

I have two cousins or an uncle and a cousin who are both felons.

I remember, uh,

I'd put in my first background.

I'd filled out some stuff

I'd said yes to so the questions that I didn't understand

I thought I did.

I was young

I answered yes

I thought I knew what they were, but she explained them to me.

I said what I thought it meant.

I don't know what to tell you. Everything on there is truthful.

I was like three classes away, three classes away from getting it.

I get these two things that you're gonna give me a job?

I was like "You're just fucking with me.

I get it.

I started school in, officially in December of 2010.

I was still in .... 
I was still in the Marine Corp.

I started at the time; it was like an orientation class.

I took my first course in January, got an A in that and was like "All right."

I can double up.

I doubled up.

I had two classes

I was going to where at University of Phoenix you take one class, your full time I graduated

I was officially done and graduated in August of 2013.

I could have double up on that one.

I could have, but I didn't want to.

I've always wanted to go back to school.

I did

I was um, right out of high school.

I went to college

I didn't appreciate it.

I was young.

I figured

I'd go to school. More time to party and hanging out

I'm actually going to do something important.

I did the first two

I didn't do the something important

I had some pretty bad grades.

I'm talking about withdrawals and Fs.

I joined the military, did my thing.

I got out of my first enlistment

I took another course,

I took another semester.

I took competitive debate, don't know why, for communications and psychology.

I passed them both with like Cs

I was just like that was the top of the world for me

I'd never had a C, in college at least.

I want to finish school.

I want to finish school.

I want to have a house and want to have my bachelor's degree by the age of 28 .

I wanted to do psychology at first ...that class that was a pain in the ass.

I want to go that route anyway.

I went to Phoenix, for my uh, for my Bachelors.

I mean that was like ...

I actually did really well in school for the first time in my life

I was getting As.

I've never had As in high school.

I was a $\mathrm{C}$ average student. 
I graduated with like a 2.0.

I was like terrible, the beginning stages of it.

I got that first A

I was like okay, that's a challenge to myself.

I finished off with all As and two Bs. It was like a 3.87, my GPA.

I was-

I was getting it.

I want to go back to school

I want to get those good grades again

I also want what's different.

I figured, you know, I've- I-I kinda shied off or wanted to step away from going the law enforcement route

I still want to be somewhat tied to law enforcement, criminal justice in general.

I'll just do forensic psychology.

I started feeling like a student

I was telling myself "Man you sold yourself short"

I think

I was just

I was really distracted

I was in high school

I had scholarships. Well not scholarships but programs for first-time students

I took advantage of that.

I earned it (GI Bill)

I don't pass a class I have to repay that.

I'm like ... It's almost like it's coming out of my pocket

I stayed focused.

I think Holly was my motivation because she had her master's already

I don't want to look like a dummy with my kids

I need to get some sort of, some sort of degree even if it's an associates.

I need to get some sort of degree

I can tell my kids like "Hey, I went to college too and I think you guys should."

I wanted to go back

I didn't ever foresee me going past the Bachelors.

I'd even told myself a couple times like "You're not going to get a master's or anything like that."

I want to get a Doctoral degree.

I say why not

I could totally do this Doctoral degree, the PsyD especially.

I don't want to do is get caught up on research.

I do.

I want to say.

I do.

I do feel like a civilian.

I think 
I started feeling a civilian once I started working for the county.

I'm ...I'm not all civilian...

I'm in there. My foot's in the door but I'm not completely in you know.

I, I feel like I'm still, even though I'm not,

I still feel like I'm still part of the service like- like my membership hasn't expired yet.

I don't think so. It will never go away.

I know that for sure.

I don't think I-I don't think I want to let it go either.

I don't-I don't blame it, you know.

I remember having a- another baby ....

I was gone when my first daughter was born.

I was gone for the pregnancy, most of the pregnancy and the actual birth

I got to see it all.

I was there from- you know for ... from conception up until like the- the bulging baby belly and- and the sitting in the chair next to her while he's getting her C-section.

I'm like "Oh geez."

I actually got to hold my baby

I'd say Ma- not Marine.

I'd say dad. It's just, you know, the whole fact that you got a little person relying on you

I try to keep the cussing down and stuff like that.

I mean it doesn't really hit you until you actually hear one of your kids say "shit" I said that.

I mean that- that's just a small thing.

I mean, you know, just being a father in general

I think everything about being a father, or parent, is- is much harder than being a Marine.

I like ... I- I- I-

I want to make sure

I spoil those girls.

I'll get it for them.

I want to ...

I like to get them things that I wasn't able to have when I was little

I'm sure a lot of people do that.

I'm like "I'm sorry. They wanted it.

I wanted to shut them up, so I got them it."

I took cupcakes this morning

I dropped her off so they could sing happy birthday

I can't wait until the other one's five so she can sleep in her own bed 


\section{Third Listening: Voices}

In the World: Always a Marine; Dad (to his girls); Husband (to Holly); Mentor; Student; Police Officer Candidate/Hopeful; Combat Vet with PTSD

Within: Capable of doing more; Dad (a big job); Husband; Not living up to his potential

\section{Fourth Listening: Politics \& Power}

Political: Poor leadership in the Corps, but can serve a buffer in the middle; PTSD Stigma; High GPA/good student

Social: Life is better in the Corps, and best when deployed; Comradery among Marines; Importance of family

Cultural: Translations with Iraqi Border Patrol (What did he really say?); Other Vets at UoPx helped; Marine culture is full of comradery and commitment Economic: School paid for (Post -9/11GI Bill); Ended the conversation so he could return to work (only one hour for lunch)

\section{$\underline{\text { Individual Meeting \#3, 12/15/15 }}$}

\section{First Listening: Plot}

Recurring words/themes: Unsatisfied; Health; Searching; Love; Family; Marines; Thankful; Mentor; VA

Plot: Being deployed greatly impacted Sgt. G. It was on deployment that he missed the birth of his daughter, and that forever (he feels) impacted his relationship with her, even as she is now a teenager. It was also during a deployment that his wife began to cheat, thus leading to his divorce (after his first discharge). 
After reenlisting, it was during a deployment that he met Holly, his wife now. Before Holly, Sgt. G felt empty after nights of partying. But after reaching out to her on Facebook, to ask about her brother (who was a friend from high school), they connected. "'How's your brother?' And that was it. And then from that point on, it just, it grew into something. A distant relationship, of course, but it was nice. It felt right, you know and especially finding out that she's been in the same situation that I'd been in. Um, it was, it was like, dude. Let's get married. (laughs) I don't know how the hell that came up, but sure enough, by the time we get back, when I came back, we already knew we were gonna get married. I was like, holy fuck. That escalated quick, but I think in that moment, when we were both, you know, spilling our guts to each other about our plans, our life, whatever, I think in that moment, I think that was the truest moment we'd both had. I, I truly feel lucky to be with her, and I really love her. I enjoy her. It's not perfect, you know, what marriage is perfect? But we make it work, we find a way to make it work." Sgt. G decided that his family was more important than his Marine family and discharged. He went to school and is looking for a position to use his education. He missed mentoring his Marines and continues to search for something that allows him to provide for his family while he feels that he has a purpose.

Key Characters: Ex-wife; Holly (wife now); Daughters (all three) Briefly Mentioned: VA Staff (nurses, doctors, receptionists)

Summary: Being a Marine was, and remains, a major part of Sgt. G. "I felt more 
accomplished when I was in uniform." His family and his education are also important, although it is a very close placement for his family and the Corps. And now he continues to look for purpose, “ I don't feel like uh, I don't feel like, I don't feel what I do now is significant enough, in terms of like doing my part for my country, my family, community, whatever you want to call it. And so, if there's a way to get in, I definitely want to go back. I don't know how that's going to work with the family... “

\section{Second Listening: I Poem}

I know what I do makes a difference $\mathrm{i}$

I want to do much more

I want to help people

I want to make a difference

I think that's why

I'm pursuing with the psychology field

I want to see

I had a muscle test

I still got to do a cat scan

I told them it's been going on since 2008

I was deployed

I could still feel it

I would have to shake out my hands

I wake up in the middle of the night

I got no circulation, um, and, and it hurts.

I can't sleep

I can't go back to sleep

I don't go back to sleep at all.

I decided to go look

I walked,

I wandered around,

I didn't find the spot

I ended up

I walked into the room.

I might be

I told him

I actually shook his hand.

I was in my work uniform 
I just came from work,

I have an appointment,

I figured I'd stop by,

I intend to

I finished school

I got my degree

I want to pursue a goal in psychology

I can't really do so

I'm lacking experience

I don't have

I want to see

I'm still waiting

I went out there

I want to do it

I think

I got sent to one office

I went to the mental health

I just wandered

I wandered

I could find the right spot

I go and ask

I saw her

I think it was worth it,

I think that was the best

I did

I wasn't going to come back to work

I was done,

I'm going to this,

I'm going to wander

I've been asking,

I've been talking

I want to,

I don't feel-

I'm not happy.

I enjoy what I do now

I'm not happy.

I'm not content.

I'm going to wander

I'm already here,

I might as well stay

I did it. 
I can't wait

I could

I already have one

I did

I sent stuff

I'm just fortunate

I wasn't there

I bring that up

I get it

I almost feel like

I'm not around.

I don't know

I was there

I don't know.

I could sense

I missed her birth

I tried everything $\mathrm{t}$

I could have

I could have

I missed an important, once in a lifetime opportunity

I hope

I'm doing what I can

I'm hoping that I can

I don't know

I live

I don't know

I don't know

I was deployed.

I was gone

I came back

I don't know

I started getting the PTSD symptoms

I obviously have some fault

I was doing something

I don't know

I was confused

I went out for my second deployment

I would wait

I was like holy shit

I went through it

I didn't have

I noticed 
I confronted her

I think that might have exacerbated the whole PTSD thing

I might have gotten worse

I don't know.

I was only,

I might have been 22

I never thought in my entire life

I think that, that's changed me

I didn't get in trouble.

I never got an NGP,

I never got a page 11

I was right on the line.

I was right on the cusp

I drank a lot.

I showed up to work

I was there on time

I was pushing it.

I, I, I did that so many times

I got out

I acknowledged it

I did that.

I was finally able to accept it

I'd say...

I've got to

I genuinely mean it

I'd say yes, being married

I had little relationships

I had fun.

I felt empty.

I felt like, there's got to be more

I still am not satisfied.

I was deployed

I met Audrey

I was, you know,

I wasn't into talking to girls.

I was a shy guy.

I was deployed

I was like, "How's your brother?"

I don't know how $\mathrm{t}$

I came back

I was like, holy fuck 
I think in that moment

I think in that moment

I think that was the truest moment we'd both had.

I truly feel lucky to be with her

I really love her.

I enjoy her.

I think that was one of the most positive and critical, critical but positive, times in my life

I've uh, obviously my ways have changed

I drank,

I drink less.

I only have drinks when I'm at a social gathering.

I still smoke

I don't think she likes i.

I'm trying.

I've slowed down a lot.

I've slowed down a lot.

I chose them as my fourth

I actually got to see them both be born.

I chose them

I actually got to see them

I was like, holy crap.

I actually was there

I'm sure anybody that's a father could tell you

I didn't have a child,

I had a child

I hadn't dealt with

I was like, holy shit

I really didn't get to raise my daughter

I got to see her

I got to see her when I got back

I got back in August

I got back in September

I left again in September

I got to see her for four months

I came back

I came back she was already over a year

I was beside myself.

I was over the moon.

I cried.

I did. 
I was always messing with Audrey,

I'm going to be right next to you in bed

I'm going to faint or some shit.

I actually did well

I'm very mixed

I feel accomplished,

I feel like I could have stayed in

I started

I became um, what do they call it, Limited duty.

I was on limited duty

I wasn't running

I talked about having more kids

I feel like if I stay in, I'm being selfish

I tell you, anything that girl wants

I usually bend backwards

I usually give into it.

I kick myself in the ass for doing it

I definitely,

I love her

I want to make her happy.

I got out

I wanted it to be better

I kind of blame my service for my first deploy- or my first divorce

I was gone

I came back

I was gone again

I was here for four months

I was training again

I wasn't

I wasn't there

I don't know if that caused her to

I don't know.

I didn't want that to be a repeat.

I weighed my options

I kind of looked at what's going on

I wasn't,

I wasn't

I was in the below zone

I was there, but

I was kind of pissed off

I don't

I'd been in, but 
I was like you know, whatever.

I zeroed out

I didn't get to do a lot

I didn't,

I asked so many times

I asked so many times

I did recruitment

I reenlisted

I came in as a Sergeant

I did everything that a recruiter would

I never went to school for it

I didn't write the contract

I'd go up and speak

I wouldn't write the contract

I wasn't supposed to

I asked the recruiter

I felt like I wasn't given the opportunity

I want to feel like I made the right choice,

I've decided to just go head and cut my losses

I feel like I should have stayed in

I just,

I felt more accomplished

I felt like I could do that every day

I could be there to help them

I was leaving

I was mentoring them

I wouldn't get too attached

I knew I was getting out

I was leaving,

I was like, damn man. Who's gonna take care of these guys?

I used to mentor

I would mentor

I always think about them,

I don't know

I kind of kick myself

I'm not in

I miss it.

I miss the hurry up and wait,

I miss the rifle range

I miss the free camping trips,

I miss all that

I got out 
I drove home,

I knew that was going to be my last

I would pass those gates

I was leaving

I miss it

I don't feel like,

I don't feel like,

I don't feel what I do now is significant enough

I definitely want to go back.

I don't know how -

I can't.

I think so.

I would have to

I mean,

I could,

I would have to

I could go in,

I might lose a rank,

I might not.

I don't know.

I have my degree

I don't know

I thought about it,

I wanted to stay reserve

I got sixty percent disability,

I would have to give up,

I would have to give up my benefits

I give them up

I could give them up,

I'm stuck having to reinstate

I'll never lose them

I lose that,

I've always thought about them

I want to work with veterans

I want to work at the VA

I mean,

I might not serve

I help those that are serving

I could vicariously enjoy

I want to help

I could make it

I'll be doing my job

I'm helping out someone 
I'm good right now. (laughs)

I was doing my, uh, comp exam,

I had,

I had to

I took those.

I couldn't walk

I felt like

I went to the VA twice

I went at nighttime

I went in the morning

I get there

I wait

I sit

I get up

I've been here for a while

I've been downstairs

I sat there

I don't have,

I don't need medicine.

I need something else.

I need a doctor

I'm walking

I can't even walk

I'm fine, it doesn't even hurt.

I needed it

I could show somebody,

I couldn't keep

I couldn't keep that

I had to reschedule.

\section{Third Listening: Voices}

In the World: Veteran; Father; Husband; Provider; Psychology student;

Inexperienced; Mentor

Within: Marine; Father; Husband; Provider; Willing and capable of serving others;

Torn between family and Marines- loves both dearly

\section{Fourth Listening: Politics \& Power}

Political: VA services have significant delays, ineffective communication, and tend to medicate symptoms instead of treating causes/disorders; Health services 
better while in, compared to after separation from the Corps; USMC policies kept him from being there for the birth of his first daughter; Re-enlistment also zeroed out his time in grade, impacting his ability to promote up

Social: Pressure from family to discharge; Getting a job is all about who, not what, you know; Single life felt empty

Cultural: High standards of service in the Corps spill over into civilian life; Deployed before smartphones, so pictures of service not on his phone

Economic: VA disability rating equates to specific amounts of money; Ate at Taco Bell (because it is cheaper); Limited time for conversation because Sgt. G is only allowed one hour for lunch

\section{Found Poetry from Group Meeting \#2, 12/13/15}

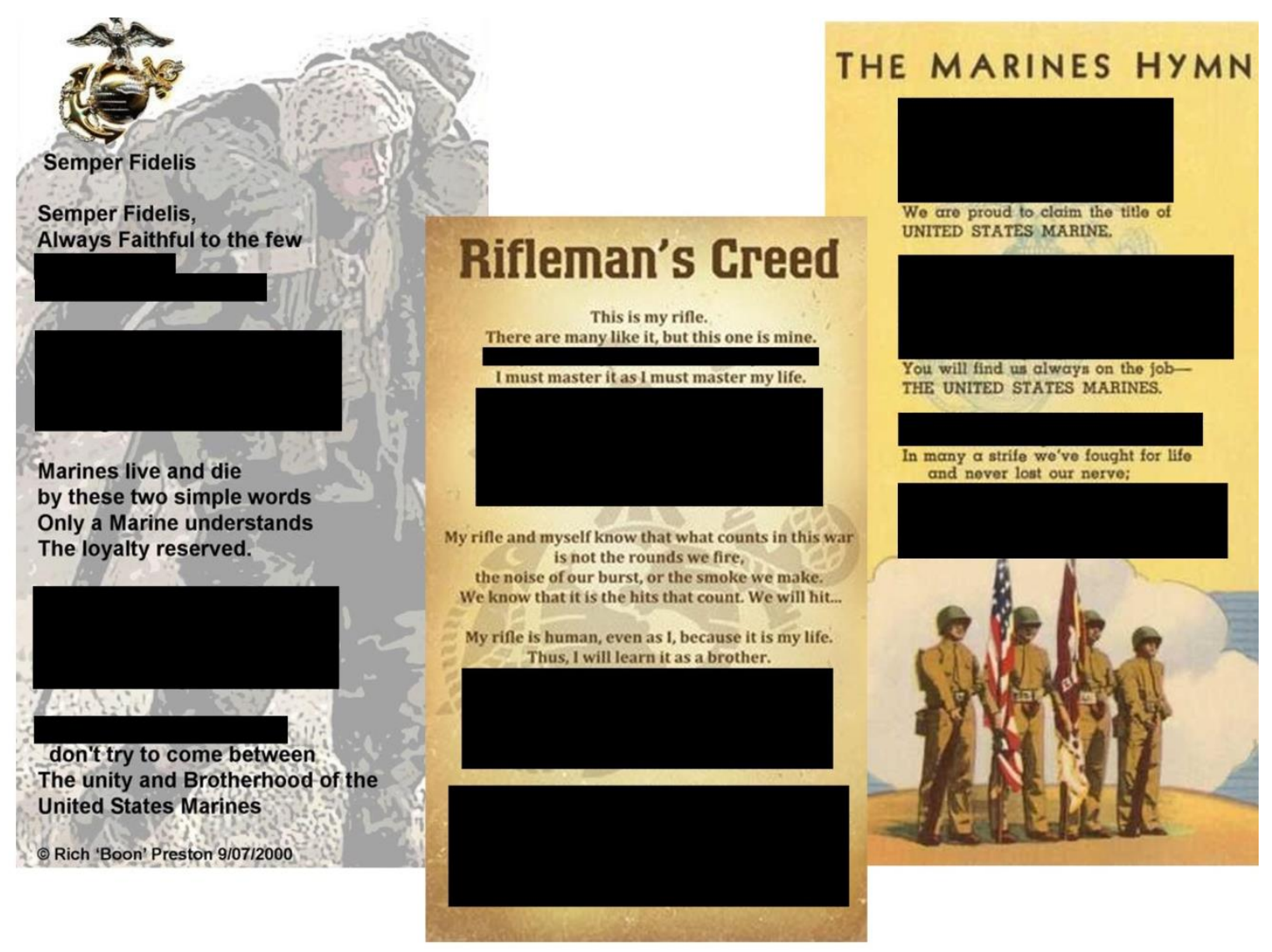




\section{Recon Record}

\section{Individual Meeting \#1, 10/25/15}

\section{First Listening: Plot}

Recurring words/themes: Time in the Marines is simple, civilian life is complicated; Misses the Marines; Need to do something, have purpose (Marines did this, still looking for something in civilian world); Preparation for future (career); Earned; Suffering, enduring, and surviving; Physical abilities/limitations; Private/guarded

Plot: Growing up without a male role model, and being endlessly teased by his sisters, led V to enlist. He briefly tried college to satisfy his mother, but he wanted to "do something" to prove his sisters wrong and become a "man." So, he enlisted, with his Brother-in-Law as one of the DIs (a series ahead of him), making boot camp a significantly difficult experience. It was in the Marines that V "grew up" and was able to connect with his physical abilities. "I ran an 18:45 three mile and I just felt great for me. Just cause I ... My Dad was a marathon runner. So, to me, that meant something for me being able to run like my Dad did." He went to MOS school for Artillery, met Oakland and has remained close to him since. After deployment, he was put on a Body Composition Program (BCP) to lose weight, because of poor leadership from 1stSgt. Mulligan (he still performed/tested well). As a result of the poor leadership and lack of support to continue in the Marines, he discharged. “That experience really ruined it for me. That's why I said, 'Okay maybe, maybe it's time for me to get out." It was about that time of he decided to 
discharge that his back began to bother him, as he has a degenerative back condition that will one day be fixed when some of his vertebrae are fused together. After discharging, V knew he needed to get a job, but had difficulty as his professionalism was viewed as too formal. So, he decided to use his GI Bill to attend East Forrest College, where he could complete his degree in three years. However, he found the students to be incredibly immature and connected more with the professors or other Veterans on campus. He tends to keep to himself, as he is private and guarded. So only the Marines he served with know about what happened with them, and only talk about it among themselves; and his high school friends know about his high school/civilian life and talk about it among themselves. He tries not to bother other people who have families, as he is single without kids. And while he is now too old to re-enlist, he will always be a Marine. The order, situational awareness, and type A nature that was instilled in him, will never go away.

Key Characters: Oakland; Ex-girlfriend; Sisters; 1stSgt. Mulligan; Dad; Brother-in-

\section{Law/DI}

\section{Briefly Mentioned: Students and professors at East Forrest College}

Summary: The Marines was the "worst best time of my life." It is something that V misses every day, as life as a civilian is all about making money, paying bills, and trying to get established. He misses the simplicity and the purpose of the Corps, and keeps trying to do whatever he can to find that value again, while also trying to find a way to make everything else (gym, free time, work, etc) happen in the day. Also, everything in the civilian realm is about supporting 
his family and getting his career established.

\section{Second Listening: I Poem}

I got to meet good people.

I still keep in touch with some

I came back for two weeks

I was there for 9 months

I came back for two weeks

I went back for another 5

I was a Marine,

I agree with it, once you get the Eagle, Globe \& Anchor

I still didn't feel like I accomplished much.

I wanted to do my part.

I actually hit the fleet,

I actually experienced of how a Marine uh, lives life.

I actually felt like,

I was a Marine.

I actually hit the fleet,

I was done with all my schooling and actually was stationed somewhere

I felt independent.

I felt grown up.

I've been the youngest

I'm the youngest in my family, out of three, I actually felt like grown up.,

I was on my own.

I just felt proud of myself

I really just wanted to be a man

I always felt like a boy

I was still a kid even at 18, 19

I joined

I actually felt like a man

I was on my own.

I didn't, you know,

I didn't have to report to Mommy and Daddy

I was actually ...

I felt like a man

I told him to finalize it

I could sign it 
I had gone back to the recruiting station

I went to the Marine Corp recruiter

I took it.

I just

I want to go.

I ended up going that route

I didn't ...

I never cried.

I never bitched and complained.

I don't know

I've never bitched and complained,

I just went along with it

I ended up pushing through and making it on my own.

I still, you know

I still talk to my ex-brother-in-law.

I mean boot camp was bad

I mean,

I used to get picked on,

I used to get asked to dumb crap or dumb shit

I remember for graduation

I'm looking at him, and they're looking at me and they're like, "What the fuck you doing here"

I mean looking back at it, it was freaking hilarious now

I should have joined in

I am family so

I think my, my best story is

I've always been a bigger kid,

I didn't grow until after high school

I've always been round and fat and everything

I joined the Marine Corp and everything else and then um, doing my first PFT,

I think that was the best moment ever

I did okay,

I got a ...

I barely got a first class

I was always uh, thought to be slow just

I'm a big

I'm a big guy.

I was skinny

I'm 6'1

I'm kind of lanky and kind of accident prone

I ran an 18:45 three mile

I just felt great for me 
I don't remember much

I know he ran the LA marathon

I think it was like 6 years in a row

I was born

I've always been like the male figure of the house

I always took care of my family

I grew up and then they didn't tease me or anything, they just kind of let me be.

I don't know it was, it was a good experience.

I met my best friend.

I still talk to him now

I met a lot of good people there

I have stories

I'd seen guys who show up to formation that are 21 and drunk as shit I don't know, it's just dumb shit Marines do.

I didn't really have any

I just wanted to do my job

I hit the fleet

I thought

I guess.

I was.

I don't know

I just ...

I tried to do my best

I knew

I fail

I knew

I could be recycled or get somewhere else where

I didn't want to be.

I didn't want to do artillery at all,

I wanted to do tanks

I went in open contract.

I ended up loving artillery

I brought my best friend over every other weekend

I had my girlfriend and she would bring over random friends for my friend-

I actually met him as a Staff Sergeant.

I still talk to him now.

I haven't kept in touch with many, many of the guys.

I'm not into that so. Um, 
I wanted to reenlist

I got out in 2010

I wanted to go there

I didn't have enough time on my contract.

I tried to,

I tried to extend

I didn't know if I wanted to reenlist at the time,

I wasn't sure about it.

I asked them

I didn't know at the time

I got out.

I kind of got the, the crabby ...

I left

I didn't know if I was going to stay with that unit, if I were to reenlist.

I didn't know that whole process.

I tried talking to, we call our career planner

I was getting out, or my 6-month period.

I got out

I didn't to learn that, that much about where I could go.

I wanted to do a B-Billet.

I kind of want to do that but there wasn't really anything open that interested me.,

I couldn't do that.

I really wanted to go on deployment cause all my friends were going

I couldn't go

I got out

I had, I think 30 days of terminal leave,

I have enough leave saved up

I got out,

I got 30 days free

I had to go back and get my discharge papers

I went home for a month

I felt good not doing anything

I was still on the government dime

I didn't have to work

I didn't have to worry about other things.

I got out it's like "Oh fuck,

I got to get a job". You know, get an apartment.

I got to you know, buy my own food and cook.

I didn't mind, but it's kind of hard to do when you can't get a job

I started applying a few months before I got out but uh, nothing really panned out.

I tried going back to school.

I went back to Santa Ana College, 
I got there

I remembered why I left the first time

I'm not saying I'm mature

I'm more mature then them

I just don't like doing the stupid shit.

I've kept my nose clean for a reason

I want to get a good job.

I want to uh, make enough money to support my family

I still provide for them

I am trying to do the right thing.

I don't mess up or doing anything wrong and keep my nose clean, essentially

I should get a good job.

I mean maybe I just haven't gotten the right opportunity

I'm sure it will work out for me in the long run,

I was getting out

I got put on BCP, Body Composition Program

I left,

I left to Iraq, I would say 190 pounds,

I came back 225 .

I was lifting a lot.

I wasn't sleeping well

I went to the gym a lot

I'm supposed to be 215 and

I was at 225.

I was 10 pounds over.

I still performed right

I ran the first class of PFT

I ended up dropping 6 more pounds

I was still 3 pounds over and he still got on me.

I was put on a body composition program,

I finally dropped the weight, and it was three pounds and it was a hard three pounds

I was checking out my Sergeant Major remembered me a

I stayed outside and he called me back in

I just went home.

I live close by

I'd come home every weekend or whenever

I can

I just went home and collected my things

I maybe had fun for a good week

I didn't do anything at all.

I did.,

I ended up going up North 
I didn't do shit,

I just hung out with my best friend,

I would,

I would have told him to at least stay in the reserves.,

I could have gone to the reserves

I was discharged but my experience was not well with my old unit

I kinda just didn't want to do it anymore.

I still miss it.

I still miss something about it

I mean you can just tell.

I mean-They're just very up front, type A personality.

I got a lot,

I got along with a lot of other veterans from school

I'd just tell him to stay in the reserves

I was working out

I felt something in my back slip

I was like, "Damn, I slipped a disk".

I stopped working out, went home, laid down for a bit.

I woke up and I couldn't walk for a while so

I realized

I can't do this job anymore

I had the option to go back in-

I was off work when that happened

I probably can't do this job anymore

I love it and miss it sometimes.

I just wouldn't,

I wouldn't be able to do it with my condition

I'm going to have to get my back...

I've been going to the VA and um, getting MRIs done a

I'm still in constant pain.

I mean it's, it's not bad it hurts but, it always hurts

I just kinda, just go through it

I walk right now

I drop enough weight

I feel comfortable to run

I'll, I'll get back into it

I wish

I eventually have to get my fuse, my back fused

I got to think about it once the day comes

I won't have any (flexibility)

I also messed up my shoulder. 
I tore my upper labrum on my shoulder

I went with it so long

I just ... it healed that way

I don't know

I'm looking at other options

I joined school

I was fine.

I was uh,

I was perfectly fine.

I wasn't this big,

I was actually still kind of in decent shape

I just got progressively worse

I'm just looking at other options

I stuck with this job

I can live off of it

I don't really want it as a career

I'll take what I can get

I just spent a lot of time with my family

I was young

I was dating someone

I didn't spend that much time with them,

I spent time with her and it kind of all went to shit when I deployed

I drank myself to sleep a lot of times

I wanted support but my family doesn't really understand

I don't talk about certain things

I don't

I don't get really emotional about anything

I don't know

I'm just

I'm just closed off ever since

I knew her for a long time as a friend

I actually opened to her a lot

I haven't done that in a while with you know, with a partner, with a female partner, so it was just kind of a weird ...

I don't know,

I'd rather get my career established first because financially uh, my family cannot help me

I still help them sometimes

I don't know it's ...

I'm just trying to save up money and get out of debt. 
I forget,

I think it's Trans Union

I forget what it was called.

I mean fuck, he's got a life too

I can't really call him and say, "What's up dude?", in the middle of the night

I text him a lot. We talk a lot, uh, we talk once in a while just to catch up and see how everybody's doing.

I know his family.

I know his twin brother.

I know his sisters and everything

I haven't seen him in like ... Physically seen him in like 2 years, 3 years

I mean

I get it we all have lives.

I tell some of my buddies now, like from high school

I reconnected with after I got out

I told them

I just

I don't have time

I didn't forget about you guys

I wasn't married or had kids

I had a family to support

I already went through that as a young kid

I'm just

I'm actually doing well in my life financially.

I'm trying to reconnect with everybody

I have to focus on finding a career.

I mean they (laughs) they're married obviously

I mean they see life differently.

I know their wives, their kids and everything

I'm very private

I don't really tell my high school friends anything that I've done, you know, in the Marine Corps

I don't really tell them (Marines) anything that I've done in my personal life

I don't know

I'm just private

I was like in 5th grade-Fourth grade

I still talk to him

I trust him with it, with anything

I've always been private

I'm the youngest of three

I've been teased growing up 
I got made fun of

I'm,

I'm ... When

I was skinny and at this height and fit,

I was very clumsy and lanky and all this shit

I wasn't really um,

I wasn't really looked at

I actually proved myself

I mean

I've always been private

I'm the only male in my family.

I really didn't have anyone else to talk to

I work all the time

I'm constantly worrying about bills

I still feel like a Marine

I am a Marine

I just ... It's never, it's never, it's never gotten to that point

I always have moments

I miss it.

I think about it.

I think about all the good times, the bad times.

I don't want to think about it anymore

I still have,

I still have my structure

I like order,

I like doing things.

I like ...

I enjoy working.

I enjoy being busy and earning a paycheck and having some sort of a, I guess meaning in life.

I shave every time

I get a haircut, every Sunday ... Every Monday morning

I still do that

I'm a lot more mellow then before.

I used to be kind of loud, obnoxious, kind of stupid about, about shit

I just kind of didn't really

I was always angry sometimes

I never knew why

I was just always angry

I guess, maybe it was from growing up 
I'd take action on anybody or myself or anything

I still like structure,

I still like being here on time like ...

I was here like 20 minutes early.

I saw you pull up and get out

I made sure it was you

I like being here early

I don't know, that's just the way I've always been.

I'm always here 20 minutes, 30 minutes early, even for work

I came in 20 minutes early

I was looking for your SUV, the Pontiac, right?

I remember that.

I remember details like that

I still feel like I'm military

I can remember things at the top of my head

I observe

I walk into a room

I look at the exits

I look at the cameras

I look at people

I like sitting

I like sitting with a wall behind my back

I like to get a whole view of everything

I'm always looking around

I don't know if you've noticed that (laughs)

I like my freedom

I'm a very structured person

I mean

I like,

I liked what the military had offered

I think the cutoff date for the Marine Corps is 27

I'm already past that.

I just had my birthday last month

I'm 28 now

I can't do that

I don't see myself in any other uniform

I wanted to do my education

I wasn't working for a long time.

I was looking for school where I could learn what I needed to learn

I went to SAC

I didn't like it. 
I thought about going back to Cal State Fullerton

I didn't want to be ...

I didn't want to be jerked around

I wanted to focus on my general ed first and then move on

I went to Westwood

I was like, Okay. I can get everything done, it's accredited, it, it's structured, it gives me all the classes that I need.

I'm able to collect like on my GI bill

I'm looking for a job cause

I can live on my own and look for a job

I was trying to find a way to survive

I live in Tustin

I got in

I actually enjoyed the teachers.

I enjoyed you, Doctor Clark just cause he's a veteran. Same thing with Mr.

Anderson, he's another veteran, LAPD.

I related to those people

I got there,

I enjoyed it a lot.

I met a few other veterans and we got along.

I really did enjoy it.

I'm, to be completely honest, now it's really hard to, it's really hard to put down my diploma, coming from Westwood, on a resume

I did like it but now

I wish

I had gone to the regular route

I'm gonna,

I'm gonna to use it

I can get a better job with it, good

I'll see what else

I can do

I've got to survive right now

I've applied to different departments

I have ... Never been arrested, don't have anything on my driving record, got good credit, honorably discharged, everything, all the above and a college degree I get passed on it every single time.

I do.

I don't....

I get an email

I didn't even apply anywhere just cause it's ... It got to the point

I remember,

I remember 
I first uh, went to school.

I was still trying to look for a job.

I went to go apply at a regular 24-Hour Fitness for a front desk attendant

I'm very profession, very stern and um, talking loudly.

I'm assertive and everything

I didn't have enough personality.

I went up to him

I told him, "This is an interview.

I'm not going to act immature or act, act like you know in an unprofessional manner in an interview".

I mean they're like greeters

I realized

I got,

I gotta find something.

I gotta find a way to live.

I still support,

I still help support my parents.

I'm just kind of stuck in this place

I don't

I live in Tustin

I first went to college, or right after high school,

I was very quiet, timid and you know just went along with everything

I was that kid that was cracking ... Like texting or whatever

I was young.

I didn't have any fucking structure or anything

I got out, going back to school ... Fuck,

I remember yelling at kids for fucking being on the phone

I'm paying for my education

I used to see and hear.

I remember

I had this girl, this girl get mad because she's, she's calling her Mom a bitch or something like that and she's like, "Yeah she wouldn't let me use the car, cause I wanted to go out and go clubbing"

I'm like, "What the fuck".

I just,

I didn't get that. Like,

I went there in '06.,

I was there for a short period time.

I wasn't a veteran at the time.

I was there in '06,

I went to boot camp in October

I originally went to Cal State

I dropped out of there because it was really expensive.

I dropped out before anything 
I ended up going to Santa Ana College.

I went there ...

I don't even think I finished a semester

I just dropped out.

I started working and I enlisted

I remember graduating.

I was 17 ,

I was still 17.

I went to apply at Sports Authority,

I got the job.

I was still under 18

I got screwed on that.,

I tried going to school. It was really expensive.

I dropped out of Fullerton.

I went to Santa Ana College, and

I got there and it wasn't what I expected.

I got to do something with myself

I do just cause life just kind of consumes you with bills and all the little shit going on at work, but a lot of time it's my pride that keeps me going. Not really my civilian pride, it's more my Marine Corps pride, just-Uh, knowing what

I did, what

I experienced, knowing the people that I do and, that's what keeps me going.

I never really saw myself as a student.

I related more to the teachers

I related to him as far as you know, tactics. Military, police tactics and everything else

I got along better with the teachers then I did, I did with the students. Well, except for the veteran group

I mean,

I didn't feel like a student.

I felt like

I was just oddly in class

I joined in and we talked crap to one another.

I'm Marine

I didn't really ever feel like a student

I did my work,

I turned it on-time, even with me working graveyard and going to school right after.

I still got everything done.,

I didn't really feel like a student.

I just,

I kind of learned to approach people differently

I would confront people about it.

I do confront them 
I confront them in a nicer way.

I'm a little bit nicer with the, people and individuals

I open my eyes to different things

I had to

I approach people

I'm not angry about it

I tell em ...

I ask them nicely. (

I did learn a lot from school.

I think a little bit of both.

I get the real upfront point of view

I didn't really get any leniency

I told them,

I'm okay with it,

I'm not a kid.

I mean school really did help out.

I'm still trying to find purpose

I worked 40 plus hours a week

I went to school

I did everything.

I've done the Marine Corps thing

I still think about the Marine Corps to this day.

I don't know where I'm at.

I guess, it's never really a complete transition and that's what most people don't understand. It's never a complete transition.,

I can't really speak on other branches

I really can't say

I can define myself in any other way.

I don't know.

I'm in a limbo.

I am a good person.

I am a male.

I am smart.

I am kind.

I am a Marine, definitely.

I am a Marine.

\section{Additional Second Listening: We (Marines) Poem}

We ended up being there for almost 14 months

We came back ... I came back for two weeks

We were related so boot camp was not fun for me

We're, we're good friends.

We had that bond, you know

We could always relate to one another

We were done with everything 
We ended up going to the fleet together

We um, guys sneak out,

We call it a section

We get call for fire or other orders to shoot

We shoot

We have an ammo crew,

We have a loading crew,

We have a gunner, who'll elevate or lower the, the tube and the other person

traverses left to right.

We're supposed to know everything

We had a little recorder

We get an order to shoot or call fire, he's supposed to record everything.

We can verify everything

We actually shoot.

We verify the coordinates

We verify the traversity of the cannon

We have to know our role

We have to know the ammo nomenclatures uh, combinations, what combinations

We're not to shoot with, as ... It's actually a lot of work.

We get a call, a call for fire

We get you know Winchester, ... Winchester is pretty much an expenditure of all rounds.

We're supposed to wait

We actually get the command of fire

We um, the way our artillery works

We get,

We get pushed in the back, behind our infantry and tanks.,

We have to make sure they're out of the way or out of the kill blocks

We have to verify

We have to get the call first,

We call our FDC, Firing Direction Center

We have to make sure

We get the call, the okay from them, before we actually shoot

We'll say, "Welcome back, let's get shit faced".

We don't see it at first but there is always an after effect of everything

We call our career planner

We reenlist.

We have CIF issued gear

We get issued at the fleet like, flap jacket, kevlar, and anything else

We have to return them and that's a long process 
We call it a Battery in Artillery.

We have.... You know, you can tell a Marine from far away just by the way they stand, by the way they talk

We don't realize how good we have it until we get out

We don't realize how good

We have it because

We have the barracks,

We have housing,

We have food,

We have everything and it's all mixed into one.

We don't really,

We don't really see how hard it is to be a civilian

We got along perfectly fine

We were kind of loud

We talked crap to one another

We do and, it's all in good fun

We call them, boots

\section{Third Listening: Voices}

In the World: Marine; Brother; Son; Boyfriend (ex); Protector; Team member; Private/guarded

Within: Drinker; Provider (for family); Pained (physically), but doesn't complain

\section{Fourth Listening: Politics \& Power}

Political: Clean background, "good kid" should help him get a job in law enforcement; Not supported by 1stSgt, so didn't connect with career counselor for options and as a result didn't re-enlist; BMI put him on a Body Composition Program (BCP), even though he still performed/tested well

Social: Felt he needed to learn how to be a "man" so he enlisted; Civilians don't understand what it means to be a Marine; there is a drug problem among the enlisted, but it is often unrecognized until it is too late; He won't bother 
people with family, even if they are his friend

Cultural: Definition of the "man of the family" means to protect and provide, even if it is the son; Didn't earn the title of Marine until he was actually serving in the fleet, not just in MOS school; Family is always the most important; Keep things within the group, don't talk about combat with civilians or stuff from high school with people who weren't there

Economic: Civilians are all about money; When you are in, everything is taken care of, but you have to find a way to make it all work (housing, utilities, etc) when you get out; He saved enough to pay off his truck, then sent the rest of his money to his family when he was enlisted; Post-9/11 GI Bill paid for college; Has to have a good job to prepare for his career (support himself \& his family)

\section{$\underline{\text { Individual Meeting \#2, 11/22/15 }}$}

\section{First Listening: Plot}

Recurring words/themes: Order; Being like his Dad; Marines; Tradition; Civilians are lazy; High standards; Order; Respect; Situational Awareness; Adaptability

Plot: $\mathrm{V}$ father used to be a runner, before his accident when $\mathrm{V}$ was 5 . He was in a coma for several months and has had a lifetime of recovery. When $\mathrm{V}$ was enlisted, he too was a runner (like Dad). He was part of a 15-man team while on deployment, and they conducted $\mathrm{V}$ sweeps when on patrol. He also had the opportunity to serve as the head of security for a Colonel, when his sergeants when away. Also, on deployment, $\mathrm{V}$ got his first tattoo- a full back piece for his mother. After discharge, V started school at East Forrest College where he learned better writing skills and also added a few books to his 
reference library for his professional life. It was while he was at East Forrest that he met David, who had been one of his instructors while he was in the Corps. He and David became friends, V often helped David with school or with making ends meet financially at times. When David got really sick (cancer), V was often stuck working and unable to visit. V does, however, visit David's grave occasionally and makes sure it is clean and presentable. V is working on mending his relationship with his sister, and continues to support his family, and himself, financially. That is why he is somewhat of a workaholic. He continues to live many of his trained behaviors from the Marine Corps- weekly haircuts, cleanliness, order, etiquette- as they have become habits. However, he acknowledges that since he is out, it is optional. He celebrated the $240^{\text {th }}$ USMC Birthday at Bastard's in Downey with approximately 200 other Marines. He also went back to Camp Pendleton for a Marine buddy's friend's retirement; it ended up being one of his former DIs. He remembered him, $\mathrm{V}$, because of all the torment that he suffered because his Brother-in-Law had been a DI.

Key Characters: Dad; Mom; Sisters; Nephews; Marines

Briefly Mentioned: Marines in his Unit; Specific Marine buddies

Summary: The Marine Corps had a huge impact on V, as it allowed him to connect with his father (running) and provided some great relationships (with other Marines). Other than the Corps, the most important thing in V's life is his family. He works to help support himself, and his family. And whenever his family (Mom, Dad, sisters, nephews) need him, he does whatever he can to 
take care of them.

\section{Second Listening: I Poem}

I don't know.

I don't know

I ended up

I have that hanging

I didn't want to show my closet

I have boxes

I really don't take anything out

I just keep everything in boxes.

I put it up there

I have all my Marine Corps

I'm missing three.

I'm missing an army achievement medal

I'm missing two other ones

I have

I really don't

I mean

I have a picture of my dad.

I have this picture of my dad

I was in

I used to be a good runner

I hurt my back

I can't run

I always remember him like that

I have a glimpse

I just know him

I know him now

I was,

I was 5 years old

I have

I can find a picture

I have small memories here and there

I got out of boot camp

I have like

I don't have

I have my safe

I don't have really anything on top 
I found

I took a picture

I'm not a very good creative writer

I can write reports

I'm not very good

I kept that to help me out

I first started

I kept it

I've had it

I kept it

I have like two more

I need

I use.

I used to

I guess

I know

I went,

I don't know

I said

I didn't say old

I said he's older than me

I don't know

I'm like, "Yeah"

I ran into him

I was one of your recruits,

I don't know if you remember me

I saw the Major

I'm like,

I told him, "I'm SSgt L's ex brother-in-law."

I got picked on

I was in boot camp

I had a relative that was a Drill Instructor.

I took it

I think it was

I haven't been in camp Pendleton since

I got out in 2010

I went to go visit him

I took

I took for

I went there in May

I went there for Memorial Day 
I have pictures from after his funeral

I have pictures after the Marine Corps birthday

I took

I met him,

I met him in school

I remember him

I saw his car

I saw it

I couldn't remember

I'd seen it before

I went through boot camp

I was going through boot camp

I remember that car

I used to go visit

I know,

I knew the beast,

I knew the cars

I just, it stuck with me

I saw him

I'm like, "Dude, like, you're a Marine right?"

I'm like, "Dude,

I think you were one of my instructors,"

I always helped him out when he needed it

I always helped him out

I helped him out.

I guess

I lose track

I'm always constantly working.

I mean

I hope he knew that

I was working, going to school

I got paid

I was still working

I didn't want

I didn't want to

I worked

I lost track of people

I didn't want

I got- ...

I got bills to pay,

I got a life too,

I got,

I got my family to take care of 
I went, uh, for the Marine Corps birthday

I'm planning to go again

I go with my buddy

I still go see him.

I still talk to his ex-girlfriend, uh,

I still talk to his girlfriend

I just check up on her

I'll go to the burial spot

I wish

I could do more

I can't right now

I'm checking up on, on her

I do go visit

I pick it up

I make it nice

I'll show you

I have

I'm trying to

I don't have

I'm trying to

I've been keeping in touch

I go shooting

I wanted to start collecting,

I wanted to start collecting

I've always wanted that gun

I loved it.

I don't really have pictures of my mom

I don't like taking pictures

I do

I save them

I don't know

I think it's just funny

I do take pictures of her

I just keep them now

I do now

I bought a 135-gallon fish tank

I sit there sometimes

I turn on the light

I just watch them

I do now just to calm me down

I bought it second hand. 
I like fish.

I wanted to have a dog

I didn't have the time

I was going to work

I was going to school

I bought a fish tank

I don't go to school any more

I work all the time

I kind of want to buy a dog

I don't want the responsibility yet

I had, uh, a had a boxer

I was taking care of for my buddy

I almost

I brought her in

I took her in

I let her stay at my apartment

I didn't want to give her back

I kind of had to.

I just don't have the time

I work morning shift

I never had the time

I'm tired from traffi

I'm sitting in traffic

I have a fish tank

I like exotic fish

I saw

I got out of boot camp in January '07

I promise that's me

I actually got that in Iraq

I got that like, two weeks before coming back home

I forgot his name

I forgot his first name

I was there

I'm looking at him

I went up to him

I kind of want to get a tattoo

I don't know where to go

I liked it

I told him what I wanted

I just didn't have the time

I didn't have the time at all

I still had bunch more time left

I gave him a tip 
I gave him like a $\$ 100$ tip

I've had it for so long now

I'm trying to get more

I wanted to get...

I wanted a- ...

I wanted to get my whole, my whole calf

I am now

I'm more focused on family now.

I'm trying to at least

I'm more focused on my family

I kept this picture

I got for, um, my work as a team.

I was the operations chief

I handled

I helped

I was also head of security

I was the head of security

I was deployed

I'm going to

I got the damn picture upside down

I still talk to my Gunny

I talk to Oakland, obviously.

I talk to Beech,

I talk to him

I kind of still keep in touch

I'm on top

I'm on top because

I just came out of the gun

I don't have kids

I like it

I was goof ball

I don't really tell people I'm a Marine

I know

I don'

I don't tell

I don't,

I meet someone

I just tell them, "I do security"

I tell them

I was in 
I never told people

"I'm a Marine"

I don't know

I'd rather just not say

I mean

I have all my memorabilia

I look at it every once in a while.

I still have my uniforms

I'm still neat

I wake up early

I take a shower

I do my bed

I put my dirty clothes in the hamper

I still, like even for work

I still have to polish them every other day

I get a haircut every Monday

I gotta get a haircut

I wear my sunglasses

I see hair going past the frame

I gotta cut my hair

I'm respectful towards everybody

I say, "Good morning sir, good morning, good morning ma'am."

I'll open up the door

I give them proper greeting of the day

I still do that

I always carry things in my left hand

I rarely carry anything in my right hand 'cause you salute

I'm drinking or smoking,

I never,

I never hold anything in my right hand

I'm so used to it

I always carry something in my left hand

I'm drinking,

I'm drinking from my left

I just took it out actually.

I took it out

I was in my truck

I had it

I actually ripped

I had it

I had it in the back

I took it out just as a precaution

I've got to go buy new jeans 
I think my approach

I read something

I do a report at work

I learn

I learned a lot

I don't know

I'll research it,

I'll research it correctly

I'll look it up and everything

I mean that's my approach now

I'm just more relaxed

I'm trying to be more relaxed

I still stress over finances and

I told you about my, my uncle passing away

I think

I might have to end up paying for it

I'm not, they're not necessarily broke

I'm a little bit better off

I'm going to be stuck with that bill

I don't know how to describe myself

I'm a little bit of everything

I'm shy

I'm loud

I'm loud

I have to be

I'm respectful,

I'm also an asshole

I have to be

I'm clean

I'm messy sometimes

I'm a little bit of everything

I don't think there's, um, just one thing that defines me

I've adapted to everything that's been thrown on me

I'm overcoming

I think

I'm still, like, affects me, and changes me

I kind of

I first started school

I first started school

I didn't consider it

I didn't consider it school.

I considered it more like a job,

I just get it done and then get it over with. 
I did learn.

I tried, and I,

I do

I didn't get to see anyone

I went back home for two weeks

I think it went well

I don't then, okay.

I'm still going to be here

I do get it, great

I have to adapt

I learned

I got older

I eventually learned, and grew up

I'll just take it day by day

I'll wait for it to happen,

I'll deal with it.

I'm glad

I definitely need to

I hope so,

I'm just,

I'm just thinking about it.

I mean

I have

I mean,

I'm going to do that

I don't know

I talked,

I wish

I would have gone

I know they

I know they can

I mean

I don't even have that many

I just

I'm very

I try to be very organized

I'm out and about

I'm always aware of my surroundings

I want to

I don't know if you

I mean like, that's just, it's just a bad habit

I'm driving

I'm always looking at the rear, my side mirrors 
I don't think so

I hope not.

I mean if they ask

I mean that's the truth

I'm going to give them

I don't know

I turned and made sure it wasn't anything

I think me

I'm going to wear

I do wear a uniform for work

I'm off of work

I don't have to worry

I decide not to shave one day

I don't have to worry

I never really let it grow out

I let my beard grow out

I first got out

I had an interview,

I had to go to job interviews

I had to shave it

I haven't been allowed to

I'm fine, to grow it out

I'm thinking.

\section{Third Listening: Voices}

In the World: College graduate; Marine; Organized and neat; Caretaker, mentor,

friend; Worker; Loyal; Son; Brother; Uncle; Team member; Educator (always explains terms and processes); Work to mission completion and live day by day; Adaptable

Within: Insecure about physical appearance; Complex- shy \& loud, respectful \& an asshole

\section{Fourth Listening: Politics \& Power}

Political: Uniform rules and traditions; USMC Birthday Cake Cutting Ceremonyoldest Marine cuts it \& serves the youngest Marine; Guarded/private because he works in security 
Social: Takes care of his family, always; Supports friends (even financially at times); His unit was a 15-man team, so there was a strong bond; Doesn't tell people he is a Marine

Cultural: Traditions and comradery of the Corps; Respect for the Uniform (when and how to where it is very important); Marine behaviors become a habit, but are optional when a civilian (shaving, polishing shoes, etc)

Economic: Supports family (and sometimes friends); Works to pay his bills; Civilian life equals stressing about money

\section{$\underline{\text { Individual Meeting \#3, 12/19/15 }}$}

\section{First Listening: Plot}

Recurring words/themes: Workaholic; Taking care of others; Protecting others (especially family) - situational awareness; Shy as a child; Marines; Misses the Corps; Can be mean if needed, usually gentle; Family; Survivor; Being "a man"

Plot: V's father was in a bad accident on Christmas Eve, when V was 5 years old. As a result of the damage, V's father had amnesia and forgot about V. V's father continued to suffer from memory problems, and often behaved like a toddler. Since his mom was working two or three jobs to support the family, and his sisters would head off to school, V was often left home to take care of his father. The situation led to $V$ being endlessly teased by his sisters, and embarrassed by his father, making $\mathrm{V}$ even shyer as an adolescent. V felt he grew up without a male role model and needed to care for his family. He began working for his neighbor, a local attorney, to help his family 
financially. And he continued his education; in fact, he and his sisters were the first in his extended family to complete high school. After high school, he tried to get a job at Sports Authority (to support his family), but he was only 17, so he was limited on his number of workable hours. So, he decided to enlist. "I was going to join and take care of them essentially. So, I joined for me. I joined for me to learn how to be a person, how to be an adult, and get out of that funk. If I would have been in that situation, I would have essentially just been that, that son, that typical son or daughter who takes care of their parents who never goes out, never dates, none ... and I've seen that happen already with my dad's sister. With my mom's sister. They've taken care of their parents all their lives. I'm not saying it's a bad thing, but I didn't want that for me. I wanted to experience something different, that's why. I saved up enough money to pay off my ... I bought a truck, an SUV. So, I saved up enough money to where I can pay for it for up to 6 months with insurance and then also pay all my bills and then have my mom keep whatever is left over." One of his uncles made V feel guilty him about the decision, then later tried to show V off. This really bothered V. When he went to boot camp, it was hell because his Brother-in-Law was a DI in the same group. So, all of the DIs knew V and gave him extra time to suffer and" improve." Then he went on his deployment. "So many things happened with my deployment that, you know, it just changed me." His girlfriend was pregnant when he left, and they had planned to get married. However, while he was gone, she miscarried and found another man. She told V in a Dear John letter. But 
"There's worst things in life, you know, than a break up. Than feeling like this, I'll get over it. I realized, you know, there's worse things in life. I'm still alive. I'm still breathing." After he got back, and discharged, he tried to find a job- more accurately a career, with a purpose. He hoped for Diplomatic Security (but he still has to work to do before he can apply). He went to school, but it was a job. He ended up having to help some of the students that fell behind in class and that bothered him. And he hated the immaturity of the other students, so he played the numbers games to ensure he did well, without doing everything (i.e. he didn't complete all of the assignments, but he tested well).

Key Characters: Dad; Mom; Sisters; Ex-girlfriend; Neighbor (attorney); Nana;

Oakland

Briefly Mentioned: Professor and students at East Forrest College

Summary: V was forever impacted by his dad's accident, the how it impacted how he grew up with his sisters and mom. He was also forever changed by the Marines and continues to be a Marine. Since discharging, he has been looking for something that can give him the same sort of purpose he felt in the Corps as a career.

\section{Second Listening: I Poem}

I said

I'm there

I've been there

I know pretty much the entire site

I already know

I have

I already know

I know 
I get along with

I don't get along with

I know it's them

I'll pick up

I don't think ...

I don't know

I've just ...

I've been used to it

I don't know

I've always had that mind set

I'm a Virgo

I changed a little bit

I need to be an asshole

I can be an asshole

I'm going to try ...

I'm just trying ...

I'm trying to find a better job

I'm trying to

I just,

I'm sorry

I got ...

I know

I gotta

I just notice.

I have wondering eyes

I just want to make sure everything's okay.

I really do

I can tell you about it

I was 5 years old

I can't think of what else

I call my nana

I had a brother

I remember ...

I remember him waking up and he wasn't talking I think

I've shown you pictures

I want to say

I see

I don't know

I was like ...

I was a kid

I didn't know any better

I knew then was that my dad didn't recognize me 
I kind of knew

I didn't

I don't know

I was the little one, so they protected me

I didn't really like catch on

I finally found out exactly what happened.

I was the only male

I was $19 . .$.

I don't know

I just couldn't, you know

I couldn't ...

I know that was the weird part

I was like the Cinderella of the story

I mean?

I wasn't allowed

I was pretty much, not a servant

I was kept away from all the options

I was still in middle school.

I had to go home to take care of my dad

I would go home and hang out with my dad

I'd still remember my dad like how he was before

I mean

I don't know

I don't know.

I don't know

I used to be embarrassed

I grew out of that

I understand it's a medical condition

I like, around 13 or 14 ,

I grew out of that

I was just trying to find myself

I guess, not being seen as the man of the family

I'm also taking care of my dad, taking care of my mom

I was working with my neighbor

I would do all his paperwork, clean his office

I cut the grass, take care of his garden

I was just like an assistant to the house

I didn't care,

I was making good money

I mean, he paid me well

I was making good money

I listened

I can be mean 
I have it in me

I can be angry and react

I guess

I was pretty timid and quiet

I like being alone

I mean,

I was going to go to college but money's tight.

I was still 17

I graduated

I couldn't work past 9:00

I still had

I think it was

I turned ... July

I would turn 18

I was able to work past 10:00

I was going to do

I was going to go to the Marine Corps

I was going to go to the Army

I happened to walk back

I was very timid, very quiet

I remember my senior year

I dropped 50 pounds just to make weight to go

I begged my mom to sign the contract

I tried,

I tried going to Fullerton

I went there for orientation...

I was going to start

I was going to start

I tried summer there

I dropped out.

I ended up dropping out

I enrolled in Santa Ana College

I didn't even finish semester

I dropped out of there

I ...

I was still working,

I worried

I was going to join, and take care of them essentially

I joined for me

I joined for me to

I would have been 
I would have

I've seen that happen

I'm not saying it's a bad thing

I didn't want that for me.

I wanted to experience something

I saved up enough money.

I bought a truck

I saved up enough money

I can pay for it

I did that

I joined almost a year later

I joined.

I spent

I loved it

I still miss it

I wouldn't change

I wouldn't change anything about it.

I still remember everything about it.

I mean

I told you

I got tortured

I watched him graduate

I was messing with his friends

I was like oh have fun

I got to boot camp

I happened to say

I was like you fucking asshole

I can't believe ...

Yeah, we technically are drinking buddies

I was actually a Marine

I gave her a chance

I told her

I come back whatever happens

I'm not married to you

I went on with our relationship.

I ended up deploying

I'm like all right we're doing fine

I started noticing little things

"I'm busy right now"

"I can't talk right now"

I get it

I just started noticing different

I'm pretty strong by myself

I don't need somebody. 
I knew this girl from high

I felt like dying

I just could not exist anymore

I was over there

I couldn't do anything about it

I was angry, angry, angry, angry

I talked to him about it and he calmed me down,

I was just rambling

I've had one after that, but it didn't end, it didn't end too well.

I don't know,

I guess

I'm just not

I was

I'm busy

I'm at work

I'm like yeah

I'm fucking busy

I get that

I'm all about that

I've got bills to pay

I think they're just used to having this free

I've been working most of my life

I don't have time for it,

I don't have time for it

I guess

I'm at right now

I used to

I tell these guys

I don't mean

I tell them

I don't mean to

I've learned to drop that ego

I'm out

I'm proud of what I did

I know what I did

I haven't had that yet

I still made it

I'm still here

I haven't cracked

I haven't broken down

I just keep on going

I've seen that.

I had a buddy 


\section{I don't know}

I would love to have him get my back and cover me

I want to go back to who I was but

I'm just trying to be physically, mentally, who I was before

I've been through worse

I've realized

I had that mental breakdown

I realized that this is nothing,

I'm not missing a leg

I'm not missing an arm

I'm not handicapped in any way, shape, or form

I'm just hurting and it's going to eventually go away

I'm very passive now

I get angry, it takes a lot for me to get angry

I do get angry

I get angry

I do get angry

I react

I do dumb shit

I've done certain things

I'm not proud of

I'm still in the process,

I'm still in the process of changing

I'm getting there slowly

I have a good job

I make good money

I spend more time with my family

I spend more time with my dad

I told you

I've just been spending a lot of time with him

I'm like you've got to take care of yourself

I'm like

I'm going to miss you if you ever die

I'm going to miss the hell out of you

I love you

I remember after my dad's accident

I haven't seen my grandparents in like 15 years

I'm helping my siblings

I don't get along with my uncle

I don't

I'm really cool

I'm close with 
I left my one uncle

I come back from boot camp

I come back from Iraq

I grabbed him

I was like

I know you're my uncle

I said look man you fucking gave me shit when I left.

I made for myself

I was going to leave my mom

I wasn't leaving.

I was just going to do something

I was still going to come back

I was still going to keep in the picture

I honestly hated myself for that

I realized that this guys just being a fucking asshole.

I told him don't fucking talk to me and

I saw him at my uncle's funeral

I'm fucking, no.

I had to put my hands on him.

I just tell him look dude, don't fucking, don't mess with my family

I work

I work

I think

I'm just so caught up with everything else

I missed out on so much

I came back

I dove into the whole family situation

I realized it wasn't for me

I shouldn't help them

I limit my time with them

I'm trying to work, save money

I want to start my career already

I want to find that job already

I want to find that fulfillment again

I've been missing for

I want to do

I feel like

I feel like

I just want to

I want to do

I don't know.

I'm good at taking care of people.

I was healthy 
I think

I'd go back in

I was healthy

I'd be able

I did before

I was in the same physical state

I would go back

I essentially want to do

I don't know.

I thought about ...

I, honestly

I don't think so

I think

I just don't want to ...

I don't know

I do want kids

I don't

I know

I want to find somebody

I'm like no

I don't want to deal

You know that girl, the one that cheated on me when I was in Iraq

I came back. We're supposed to be ... she had a miscarriage

I like

I left she told me

I don't ...

I told you like how they tried to protect me

I was so scared to do anything

I was a kid

I was a

I'm doing this wrong.

I was always shy.

I wasn't active.

I didn't want to go out

That's why

I had to stick around.

I get what you're feeling

I've been through or experienced,

I'll essentially get over it

I'll get over it.

I realized, you know, there's worse things in life

I'm still alive

I'm still breathing 
I have a job

I'm not a screw up

I'm not a felon or some shit

I actually have a fucking great background

I'm so pissed

I apply and places don't want to hire me

I know we talked

I agree, but what can I do?

I get mad.

I get really upset and angry

I get over it eventually

I haven't been able

I've been so busy with work

I try to go to the gym

I'll go.

I'll be there for an hour

I hate my life, fuck

I have to go back to work

I got ...

I get here ...

I go to places

I get there early

I got to be in at 6

I wake up around 4:30

I leave my house by 5

I get to work by 5:30

I'm always

I go to the gym

I'm like god damn

I'm not going to get enough sleep

I don't get at least 6 or 7 hours

I can't function at all

I used to go like 4 or 5 hours

I was used to that schedule

I'm still trying to get used to the morning schedule

I want to be, not necessarily thin,

I used to

I want to be able to perform

I used to

I essentially,

I want to be able to fit back into my Dress Blues

I mean with me

I know 
I don't do much for me

I'm not out on the street

I'm not living out of my car

I'm working

I'm making money

I'm happy.

I know it may not seem like it

I'm happy.

I treated it as a job

I needed to

I mean

I'd learn

I enjoyed it

I always go back this,

I met the other veterans

I just

I need to find a purpose

I need to get

I need to develop a job history

I didn't have anyone

I needed help

I help them

I never put myself in that position

I went back to work,

I went to school,

I like Clark

I met Clark

I saw Clark at the VA

I didn't like him that much

I was good at it

I was actually great at it

I got put in a group

I ended up doing all the work

I'm good at math

I took calculus in high school

I've been out of school for 4 years.

I don't know

I had to take Comp and statistics

I had Clark

I did my work

I'm part of that now

I'm kind of part of that generation where they should have failed me, but they didn't 
I grew up

I was stuck in school

I'm okay with it

I'm not that smart

I'm smart but not that ...

I understand math you know what

I mean? It's simple.

I understand it

I would get off work at 7:00

I have to be at school

I gotta freaking sit there

It wasn't a hard test

I think

I got like the second highest

I wouldn't do my homework

I did my tests or my exams

I'd ace them

I'd get a $b$ plus or A minus

I didn't do my homework

I did very well on the tests.

I had a work at night

I was curious

I would be outside

I was busy all the time

I was

I didn't really have time

I would rather honestly sleep

I was tired.

He knew about it

I told him

I did the test

I didn't ...

I would go down and not show my work

I would just put the answer

I'm like look

I started everything,

I got the answer

I did it in my fucking head

I don't have time for this shit

I just got off work

I have to deal with your fucking dumb ass

I just got into it with him.

I had to do 
I got placed with 3 individuals

I want to get a good grade

I'm not going to fucking do it

I'll do my part

I'll expect you to do your part

I ended up getting done early

I was like here's my work

I'm going to go

I'm already done

I have to come and take my final exam

I'm still going to get a B, why does it matter?

I'm like no

I walked out.

I didn't like math

I like it, to a certain extent

I just got off an 8- or 12-hour shift,

I don't want to deal with this bull shit.

I want to go to sleep.

I would leave a lot to go smoke

I was smoking just to stay awake.

I smoke

I as chewing seeds

I've got the craving

I was like

I don't

I make sure I don't smell like

I bet you

I had a family,

I would still want to like do my own thing

I'm like fuck

I don't want to do it

\section{Third Listening: Voices}

In the World: Caretaker; Protector; Son of a disabled father; Brother; Asshole (when necessary); Marine; Survivor; Son; Brother; Friend; Provider

Within: Unfulfilled; Tired from always supporting his family; Smoker; Constant transition \& growth 


\section{Fourth Listening: Politics \& Power}

Political: His Brother-in-Law made sure all the DIs knew who V was, and when the DIs know you exist in Boot Camp, life is hell; He had a great background, but getting a job is tough because it is all about who you know, not what you know

Social: Having a dad with a disability, led to $\mathrm{V}$ being embarrassed and shy as an adolescent; Fake people (like his uncle) are unworthy of his (\& his family's) time

Cultural: He is his family's caretaker, they are the most important thing; Don't whine, even if you are in pain or suffering

Economic: School is expensive, so he left Cal State for a community college, then dropped out to enlist; His mom has no formal education, so she struggled with work; Money has brought out the nasty in his extended family at times; Has to make money to survive and support his family 


\section{Found Poetry from Group Meeting \#2, 12/13/15}

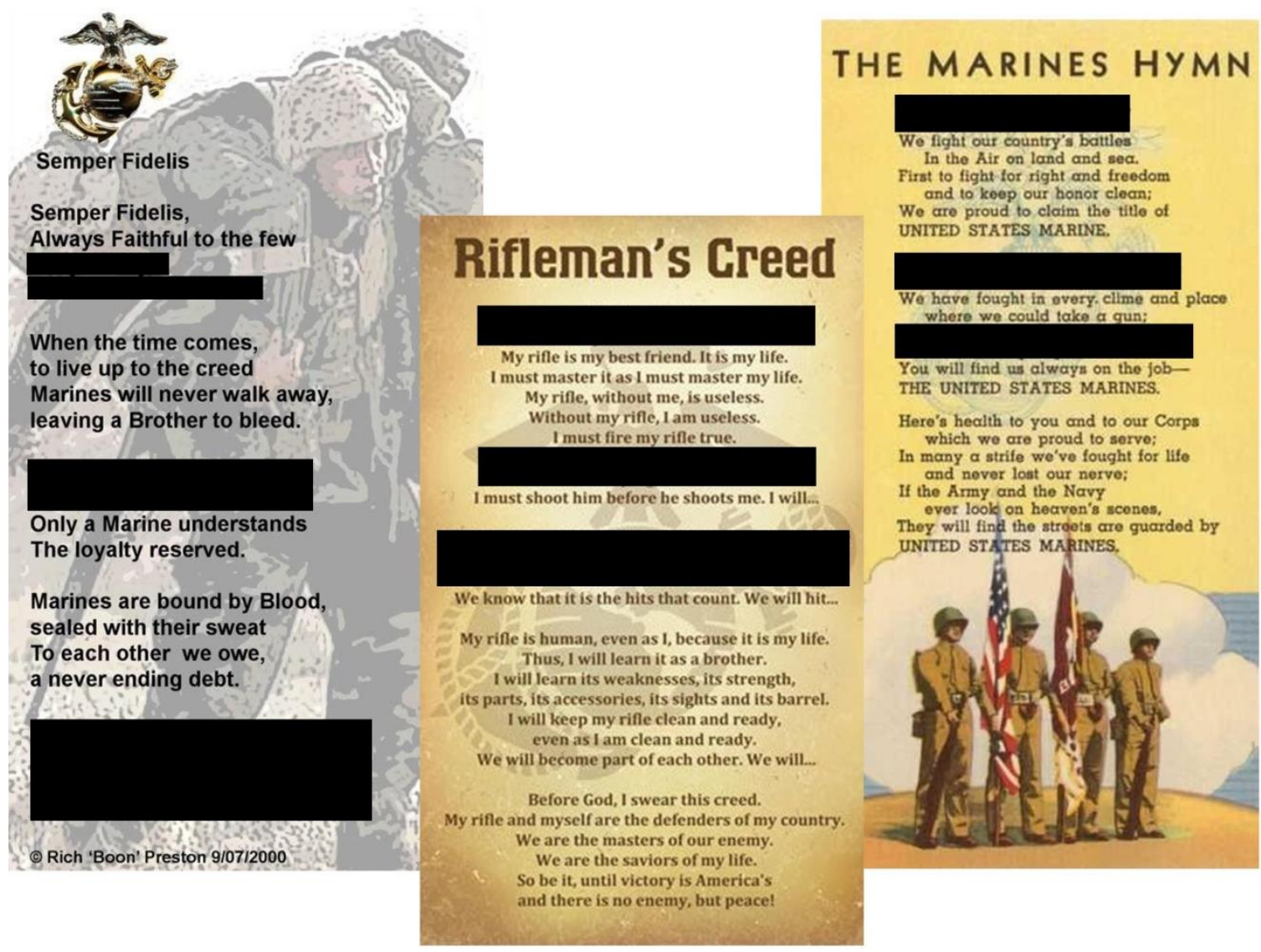




\section{Lance Recon Report}

\section{Individual Meeting \#1, 11/19/15}

\section{First Listening: Plot}

Recurring words/themes: "Ghetto" street smarts; Loves women (or sex); Marines; Marines work better together; The Hierarchy: Civilian < Veteran < Marine POG (Person other than Grunt) < Marine Grunt < Combat Marine; Service and volunteering; Atonement; Humanizing Veterans; Fighter; Kill; High Standards; Tradition

Plot: Lance was born in Oakland and grew up in "the hood." He grew up fighting, and it got worse when his father died. He wanted to kill everyone, and the Marine recruiter said that he had a place for him. He served 10 years and had a 4 day "anticlimactic" was in Desert Storm. He also had a contract marriage to a woman 15 years his senior. Since there was no war, he was bored, even if he was serving as an instructor, so he discharged and went into law enforcement with Las Angeles County Sherriff Department. He worked the graveyard in South Central. And was always on! When 9/11 happened, he wanted to go back in, had to. So, he -enlisted. And served four more years in the Marine Corps (and two more as an Army Reserve), then went into Contracting with Triple Canopy and Blackwater. "I spent the last twenty years, pretty much, in a military/ gun-carrying mode. Which brings me to now, and I'm unqualified to do any job here but security. Because it's not a transferable skill. It's like great; you carried a gun; you carried a gun and you carried a gun some more. And that doesn't 
really amount to anything. I'm like, I've done all these things, I've led 130 people in combat. 'Like, well you could get the tassels on your hat in a year and six months, I don't know what to tell you buddy.' That's why I want to go back to school." He started at a community college, was active in the Veteran Resource Center and with the Veterans on Campus. He was offered a job at the Veteran Outreach (VA) because of his involvement with so many Veteran groups and serving as an expert or consultant for numerous articles and documentaries. Now at local private university he is finishing his bachelor's in Psychology (it has a low math requirement) and is looking to get an advanced degree to help Veterans in the future.

Key Characters: Marines; Family (wife and two boys)

Briefly Mentioned: Dad; Mom; Buddies; Mother-in-Law; Older Lady in New York; Vietnam Veteran; Gold Star Mom on the Plane; Old White Lady (in Mental Health)

Summary: Lance has over two decades of "carrying a gun" and found that he needed to get an education to compete in the civilian world. However, his military career is more than just carrying a gun, as he led people through various dangerous and difficult situations as well. Also, he loves the Marine Corps. He gets emotional when he speaks of the duty to other Marines, the traditions, and the honor in the Corps. He is always a Marine, in addition to being the Veteran guy!

\section{Second Listening: I Poem}


I joined -

I actually just joined the military,

I didn't know there was actually a Marine Corps.

I mean

I watched my father ... my grandfather

I have a ... my grandfather is German. His brother- he fought for the US Navy as a Seabee; his brothers fought in the German Army in Germany. Uh, my other half of my family is Hawaiian/Japanese, so my mother's father fought for the Japanese Army.

I have a lot of military, but it was never really pushed on me.

I was aware of it

I was always around military stuff

I was always home alone

I always acted out those war movies

I played. Uh, we played soldier

I would do like missions up to the old cemetery.

I had to sneak there without being caught

I was getting older

I grew up in a pretty bad neighborhood

I grew up

I grew up on the mainland

I went to school in Japan for a while

I had a really good education for a while

I was told

I was in Japan, they said you're Chinese, that Chinese stuff's no good

I got put back a grade

I wasn't stimulated at all

I was Chinese, so they thought I knew Kung-Fu

I did a lot of fighting

I didn't really have a strong relationship

I was always angry

I wanted to get out of there

I knew if I stayed

I would not be alive

I would not have lasted long.

I had a uh, four or five friends get killed

I had one of my friends stand out and try to shoot out at the top of a house

I don't want to end up like that,

I'm going to end up like that

I have to get out of here

I was a victim of a sexual abuse 
I was like-

I wanted to kill everything and everybody.

I was just angry, like really bad.

I don't know how the Marine Corps recruiters let me in, you know.

I was in the Army first,

I told them I wanted to get special forces.

I placed really high on the ap-

I test really well,

I just didn't want to do the homework.

I placed really well; they were like what do you want to do?

I want to do special forces,

I just want to kill people

I just want to kill people, Well the marines kill, come on in

I tried to sign up as a sophomore

I was too young.

I went back as a junior

I was 17 , my mom had to sign my papers

I graduated

I was still 17,

I didn't even walk

I barely graduated

I had to go from class to class

I was in adult school

I just went from there

I joined the military

I needed something

I wanted to be something better

I knew

I wanted to be something

I want to be the heroes that I watched on the T.V.

I enlisted

I wanted to go to war

I'm a little older

I'm just going to die of gas?

I had- my nightmare was

I was going out pissing

I went out there

I'm out there using the restroom

I started coughing a little bit

I realize my lungs start burning,

I look down and my privates are on fire and burning.

I had that for three months 
I never would have got to

I love women

I was in Thailand and Hawaii

I was 17

I was just turning 18,

I was traveling the world

I had a lot of money for me, at the time.

I didn't grow up with any money,

I just got to be me.

I was a man, you know?

I was still a punk,

I had all this responsibility,

I had to do all this stuff

I got married really early on, like a contract marriage

I needed ...

I didn't want to be on base.

I hated being on base

I always lived out in town.

I always went to the strip bars,

I hung out next to the nudie places.

I hung out with all the drug dealers and pimps

I felt comfortable

I didn't want to be around all the corn-fed you know, Mid-West guys.

I just didn't fit in with them

I hate country music,

I just wanted to sit with all the gangsters and dope-dealers and hookers.

I felt comfortable there,

I felt that was my environment.

I thought

I was a little thug

I started living there, she told me after we got married, in Tijuana, that she had kids.

I took them in, like the oldest was like four years younger than me

I was just a guy, whatever. Crazy Marine stuff

I did my first four years

I couldn't get all my gear off

I got rescued

I worked for Colonel

I ended up staying in ten years

I kept maturing

I was like okay; I want something more than this

I was an instructor, 
I just kind of reached the pinnacle of my training,

I was honestly bored

I was like living this other life now,

I started to see there was a bigger picture

I started living off base, full-time and finally came to Orange County

I'm not white white so we had a great time up here, women-wise.

I was like man, it's fun up here.

I ended up staying in Orange County and had a blast up here

I got out and went into law-enforcement.

I went back in (after 9/11)

I was offered the entire county.

I want to go to South Central

I want South Central

I wanted to kind of go back to where I grew up and kind of try to make a change, do something different.

I want to think most law people- most people in law-enforcement; they want to make a difference.

I went to that department because like, we want you because you're active. We want a Marine, we want someone who's going to be out there and be aggressive. So, go out there and get some.

I was like okay,

I was active

I was aggressive

I tazed and beat people

I had to

I was respectful to gangsters, unless they were disrespectful to me.

I saw white and black

I could chase a gang member, committing an actual crime, chase them, get in a minor scuffle, injure them a little bit but the cuffs on them, put them in the back.

I look in the mirror and say, are we cool?

I had partners that were crazy

I tackled to the ground and tazed, but it wasn't uh, spiteful.

I started getting to that point

I was getting spiteful

I was becoming racist

I started becoming a straight racist.

I was an a-hole all the time at home

I became a cop all the time, always on.

I look at that guy, look at that girl

I'm like look there's a girl

I was like all right, then $9 / 11$ changed everything

I had to go back 
I just went back

I was finally like, you have to decide

I obviously don't care about this city

I'd rather be with my Marines

I didn't go

I lost six of the Marines I'd trained, since they were 18.

I was like,

I feel not uh survivor's guilt but it's more of a helplessness

I couldn't help out

I have to go back

I went back in and did another three or four years

I'm back in the Marine Corp

I couldn't go anymore

I didn't do the things to promote

I went to contracting,

I went with Triple Canopy and Blackwater.

I went for another four years

I spent the last twenty years, pretty much, in a military/ gun-carrying mode

I'm unqualified to do any job here but security.

I've done all these things

I've led 130 people in combat

I want to go back to school

I can't find a happy medium.

I know

I wouldn't be happy in a really quiet neighborhood

I would get in trouble

I couldn't go to a really dangerous neighborhood

I would get in trouble

I would be too active

I keep busting over and over again

I'm not effecting change arresting him

I've had a lot of people have helped me along the way, as a Veteran

I started going to school for uh, environmental studies

I started volunteering at the wetlands

I wanted to clean up

I really like working with kids

I really like talking about the environment

I watch- I live on Spongebob

I wouldn't say you know; well the bacteria of plankton are into the cell. Well, yeah, you know Plankton off of Spongebob.

I have a really good repertoire with kids 
I would be in Afghanistan-contracting- for four or five months, like living in like a village or a safe-house; shooting or getting blown up, doing whatever

I would go out there and just talk to kids

I was so happy and so relaxed,

I didn't care about anything.

I want to do something like that

I started going to school for environmental studies.

I live in Huntington, went to Saddleback

I was like woah, woah, too much

I backed off

I started getting help from the Veteran's center

I started meeting professors that were of a different uh political mind-set ss,

I would just-

I would hold my tongue.

I went back to the Veteran's center

I would just stand there for a little bit

I just threw this garbage

I need to get back to class

I realized it started working, like hanging out with other vets

I started getting resources

I'm on the GI BIll

I started doing that

I started finding more and more services that were helping vets and then uh, yeah

it just a uh, cathartic experience to start doing that.

I had signed up for Team Rubicon

I went back into the whole military mode

I have two- ten years of active military service

I'm proud

I left there fine.

I was a Marine

I spent in war; that was different.

I'm a combat Marine,

I have a lot more experience

I'm identified as a Veteran

I'm a Veteran

I do.

I used to be a Marine,

I was young.

I'm a Veteran, this encompasses my entire life.

I'm sitting, so I can watch the door.

I had to start relying on these services 
I saw it in New York (Hurricane Sandy)

I was like-

I had been calling for jobs

I wanted to help out,

I want to help out

I went there to help,

I started getting on the phone

I want to go, and it was a really trying point for my family

I had been going

I'm leaving

I'm going to go do a contract

I'm going to leave

I'm going to go back and serve in Iraq.

I have to go back

I need closure

I need to go back to work and fix New York ... because after 9/11...

I was bartending and bouncing

I don't know what we thought we were going to do

I was really in a pickle.

I just told my family

I want to

I'm leaving

I'm out of here

I left her in a lurch

I went there and initially it was a bunch of guys

I was like you're just a fat guy in uniform, you're not a soldier anymore

I found a bunch of Marine

I started working with them

I was like yeah

I can do that

I had responsibility, accountability,

I have a mission,

I know what to do now.

I started delegating,

I was working- it was amazing

I became an emotional wreck.

I was there from Halloween, to almost Thanksgiving.

I did all the raids in Afghanistan

I was like, there's still no power,

I'm like, crap.

I called her in there, and she had me in there for about fifteen minutes. 
I had really bad allergies

I'm done.

I'm like emotionally like done.

I sat with a Vietnam vet. You know, he was crying and hugging me

I'm like okay

I just want to get on my plane

I was in the Marines. She's like, oh my son was a Marine.

I know a lot of guys from there. She's like, yeah, he was killed in 2007.

I was like ah

I heard about her dead son for seven hours

I came back

I was like rah.

I went to the VA, started getting help.

I could never get through any of this stuff before.

I have two boys: seven and thirteen.

I'll make your brother.

I forgot to tell her that part.

I made him a brother

I've been in some pretty crazy relationships. But she stuck by me through all that, not without difficulties, obviously.

I can't tell her

I do therapy

I have PTSD

I don't tell her

I do therapy

I should

I don't ....

I'm working on it

I did go before

I'm going again now

I go and get massages for my bac.

I got blown up-

I got blown out of a vehicle, so my back and my neck are pretty jacked up.

I do the therapy, she knows

I was helping out one of the doctors at the VA

I got up there,

I got a little personal

I was like, this is really hard to talk about

I didn't do general timeline stuff

I'm really good about speaking about what our services are

I left out of there 
I don't want to do that

I don't want to deal with

I'm done

I'm like psych,

I'm out of here

I was like (deep breathe) ...

I went to the bathroom, tried to wash my face

I needed it

I let out a good cry

I never do

I don't tell her that stuff.

I don't know.

I want her to know me as me.

I mean, she knows

I don't want to tell her the things I did.

I don't want her to see and sound like a monster.

I don't know,

I'm not a ... yeah everybody likes to get a little limelight

I don't want to be glorified for things from in the war.

I don't want to tell her about some of the things

I think that makes it final

I think she'd rather keep a naïve view of me

I guess. (Nods.)

I don't know

I was going with that.

I talked to my doctor last night

I go home

I scheduled it ...

I'm kind of that same way

I try not to do it on her

I try to do it for myself

I try to let it out little things at a time

I'm more open on putting things up now

I'm not a child

I'm not an idiot

I'm fine,

I'll tell you

I'm fine

I have a friend

I have no idea, why

I'm sure you can explain why 
I don't know.

I'm over-compensating.

I guess

I mentioned this

I just brought it up again

I'm gonna have to at least offer.

I'm more close to her mom

I just did Veterans Day, Marine Corps birthday all last week.

I gave four or five speeches a day,

I was at four or five functions a day. $\mathrm{E}$

I'm a Veteran.

I do that all day long

I'm always on the on mode.

I just have been completely down all this week

I think that's every family situation.

I want to say it was a grand noble gesture but ...

I was doing environmental first

I wanted to transfer out of the school

I wanted to, uh,

I meet people from Vanguard University

I really liked it

I wanted to help people

I would like to be a medical doctor

I just don't have the time to do all that background work

I just turned 43, it's an easier place for me to be.

I get to attain quicker,

I still gonna take three years of masters, five years of PsyD,

I have to look it up.

I really like the program

I really like learning about psychology, it's really attainable.

I really understand it, it's something meaningful.

I love general, like classes and stuff.

I like to learn about art.

I'm at the Vet Center Public Relations.

I met a guy

I first started doing stuff with different Veteran's organizations

I was like Team Red, White \& Blue

I was like oh.

I started thinking about that

I might have still been at Saddleback at the time

I want to do your job, you have so much flexibility 
I went in and interviewed

I interviewed first, filled out application

I had some article...

I think

I started

I have a federal job

I started within a month.

I work

I'm not going that route.

I kind of have a career path lined up for me

I would like helping Vets

I don't know if I could sit there for eight hours either and listening to people, I gave that speech at the VA

I gave a caveat, but a brain surgeon doesn't have brain surgery to do brain surgery

I said it helps

I think that hurts a lot of non-combat Marines

I refer to it as our Super Bowl

I just went to the Super Bowl

I won.

I did this.

I've done that

I just did it

I literally went down the line

I went CAR, CAR, CAR, CAR, CAR, nope okay.

I literally did that to them

I was like that's kind of messed up

I was in civis

I was like, at least you went to Iraq, thank you for service, have a good day.

I discounted them.

I saw them; nope, no combat action, you don't rateI should be more tolerant.

I guess to someone not in the military, if the football analogy doesn't work then schooling.

I have accomplished this,

I think it's such a personal accomplishment

I have been able to do it.

I accomplished something, most men across generations, across men in general, and women.

I answer that call

I stood above it

I liked it

I did good at it

I'm a Marine, this is what I do. 
I'm actually had the capability of taking someone's life, as jacked up as that sounds, you were judge, jury, and executioner as long as you were within your mission with doing your job.

I need this right now,

I had to go back to school.

I went do oil for a couple of years.

I got sidetracked doing oil,

I couldn't find a job back here.

I found an oil company up there, did great, could have made millions

I'm not a businessman

I don't mind being deployed.

I was growing a company

I'm like whatever

I quit that.

I came back to school.

I can do it

I'm good at it.

I can't describe it.

I can never describe having a child to you.

I think that's amazing thing about my wife is that she created another life, and that's pretty cool.

I have a bond with my son,

I could never do that.

I went to the Army first,

I didn't know there was different branches.

I knew my dad was in the Navy ...

I guess in boot camp

I felt it.

I don't know,

I think

I've lived it.

I'm still a Marine to a lot of people

I'm always like rah,

I'm always get some,

I'm that guy that's like go.

I'm always yelling and screaming.

I run around like a moto.

I would go in right now, if I could, as a Marine

I'd be there right now

I didn't want to promote.

I'm going to ask, but for the Army 
I've timed out of the Marine Corps,

I'm going to try.

I'm at sixteen years total, fourteen years in the Marine Corps, two years in the Army-

I did the Army reserve for a while. They wouldn't deploy me

I'm at sixteen years,

I have four more years to go to get a retirement pension.

I'm like why not?.

I haven't talked to her.

I can't go on base.

I was in the Reserves,

I went back in after $9 / 11$

I was pretty hurt

I got ejected out of a vehicle.

I was rehabbing,

I had turned down the police academy the first time

I came out.

I really wasn't trying. Just trying to rehab myself, so

I really wasn't ...

I just wanted to get out of there,

I wasn't really thinking about it.

I kind of had a job set up.

I had started-

I had already planned on going into law enforcement

I had already set up

I started going back

I was working at oil

I couldn't get a job.

I can't concentrate

I don't have the attention span

I can't concentrate

I hate being in the classroom

I like learning

I have to...

I can crank it out.

I can crank out ten pages,

I need that pressure,

I need that stimulus.

I just wasn't doing good, and it was just kind of difficult.

I resigned myself, okay this is my job

I'm doing now.

I made it a job, but it was like really hard. 
I'm going to go to school,

I'm just going to live off the G.I Bill,

I'm not going to do anything.

I got a part-time job,

I started volunteering everywhere.

I think humbling would be the best word for it.

I went in just to do the initial push.

I went in for a year and a half, then went in for another year and a half, so just kept doing like small blocks

I just wanted to do my part.

I'm physically in pain, like my neck, my back.

I cannot function right now

I actually turned off the news for a while

I didn't care about what's going on over there.

I did my part, and as it got worse

I was like,

I need to go back

I went back

I discharged a third time

I don't want to leave

I just go play Marine when I want to play Marine.

I'm getting to the end of my time

I can't stay in any longer

I switched to the Army

I thought ... my friends talked me out of the National Guard

I went to a training command.

I'll train soldiers

I don't want to go to Texas anyway

I'm not going to go for a year without my family

I'm not going to uproot my family to go to Texas.

I don't even want that.

I want to go to Iraq or Afghanistan,

I can justify leaving my police department job

I understand the bigger picture

I'm too selfish for that.

I want to be the guy pulling the trigger

I don't want to be stuck here

I'm not going

I don't need any of that,

I'm not obligated

I've been in forever

I don't have to do that

I was already working as a police officer s 
I just drove home,

I was like that's it I'm done

I played a lot of football

I relate everything to football.

I felt like I got cut from the team because of age, not my abilities

I still have a lot to offer

I feel like

I still have a lot to offer now

I feel like

I could still go in there and out-perform most of those kids

I could have did things to keep myself in the military

I could have went through recruiting duty, but you can't put me at a high school campus with a bunch of teenage girls, that's not a good thing.

I was like,

I'm not going to go recruiting.

I'm a man whore.

I going to say, oh, the drill field

I don't want to leave the fleet to teach a bunch of kids how to be a Marine.

I'm with my own Marines, these are my Marines.

I'm too young to take that responsibility on

I'm like well now I'm too old to go teach,

I have my Marines,

I'm set in my ways, this is my platoon,

I have my structure, and change is bad.

I want to do this,

I want to be a grunt rah, rah, rah.

I stayed in

I kind of started getting the taste for the outside.

I met a beautiful young lady out in town

I started bartending,

I started bouncing out in town.

I'm like okay you know there is something else.

I'm at that ten-year mark for a twenty year career, which is always like that shit or get off the pot.

I'm like that's ten Marine Corps years, that's like dog years, that's a long time in infantry. It like physically wears and tears on your body.

I mean even at ten years, we have a twenty-one-year-old college kid Lieutenant tell me to eff myself and go run up and down a hill all day long, within reason I have to say yes

I always got stuck with that guy when they came in

I see the young lieutenants come 
I always get the hard, I'm so and so, stand attention, do this.

I'm like what the hell?

I asked my first Sargent

I was getting out

I was like crap, this was a good thing, thanks.

I met a young lady and her friend, and they were in the reserve system

I could do more.

I could have gone to Notre Dame, my dream school, been a college student for four years, get my commission, come back and serve the rest of my time in the military.

"I want to be an officer"

I'm an enlisted man

I turned it down

I'm like no, that's not-

I'm an infantry man.

I'm a grunt.

I can't leave my guys like that,

I don't want to be an officer.

I don't want to give this many more years.

I was really uncertain at that point.

I was uh,

I was living such a civilian- a dual-role life.

I went out of town

I'm not seventeen anymore,

I'm twenty-four, twenty-five, twenty-six.

I'm like man, there's this whole world out there, there's all these people out there. I have to run tomorrow, not that the Marines care, we would drink till three and go run at five

There's so less bullshit out here and there's such a life out here.

I was like, this is great.

I realized that there was so much more

I was like crap

I look back on that

I should this,

I should have done those things.

I just should have went to drill field

I should have taken that Marine Commissioning Program,

I would have had schooling out of the way.

I could have went to anywhere I wanted to.

I could have gotten the great education,

I could have done walk on Notre Dame Football, in my mind.

I could have been an officer,

I could have helped more Marines in the long run 
I could have made more change

I still get it, every birthday

I celebrated it for a week straight.

I went out every single night for a week straight.

I'm going to be in a wheelchair. $\left(250^{\text {th }}\right)$

I'm a military person, dropped in a civilian world.

I mean,

I am relaxed

I just look at things in a different way, and step back.

I went through this really big indoctrination of taking this seventeen or eighteenyear-old boys, individual brats, punks, and making them thinking about the collective unit.

I tell my guys; you're a United States Marine

I don't care what you do this weekend, ready to rock and roll Monday morning 0530, got it?

I put the fear of God in them, not to be a dirty civilian pig.

I don't give a fuck but be back here ready to work.

That's how they lived their life,

I live my life, still.

I'm not one of them, it's really hard to be like okay you're out.

I was in the Marine Corps.

I was in the Marines. Now you're a civilian piece, so it's hard to identify with that person that I always said I don't want to ...

I was taught not to be. Don't be like those people

I see the people leaving

I always go to class,

I missed my first class for the Marine Corps birthday

I've never missed a class

I have class every Tuesday from six to ten, it's not that hard.

I go.

I sit there no matter how tired I am, no matter how bored I am

I sit through it.

I was like you know what, it's my birthday. 240 years old

I'm going to see a bunch of my friends I haven't seen in a while

I'm going to go do it.

I'm already in the National Honor Society

I'm good.

I'm doing it.

I still see myself as a military person stuck in the outside

I can never let go, it's such a big part of my life. It's half my life,

I'm 43

I was seventeen 
I've known.

I may have been out for a while

I'm still ... especially this job,

I live being a Veteran every day.

I like your shirt by the way.

I actually get it.

I guess Freud would love me

I can't talk about it, like literally.

Now we're 240 years of being told our butt don't stink and all of us collectively, this is what we do and we're better than ... definitely better than civilians but we're always better than the Army, Navy, and all those other services because we've done so much ... we can do more with less.

I'm not going to tell you how

I don't care how you do it

I die, you still do it, if you die, your son does it

I'm going to rush forward in the traditions of the Marine Corps

I'm like oh, shit, now it's coming down to my own personal life.

I'm not going to let you down because you're a fellow Marine.

I stepped across that line, for the Marie Corps

I'm continuing because of you

I'm all done

I think.

I live in Huntington

I travel all the time

I do, throughout my day, three different colleges a day, usually.

I go to the Veteran Resource center

I'm always in that culture

I always identified with the Marines

I make my own schedule,

I should show up to work sometime

I have contracts

I do hit the four-year colleges but that time they are more mature, they kind of know what they want to do.

I make that available to them.

I go to a four-year college,

I deal with four-year student Veterans

I am, this is the services we offer to you

I was in the Marine Corps

I do. 
I work at the VA

I provide

I'm not going to sell crazy,

I'm not going to sell a home.

I just sell me, make a personal connection with me,

I use all the other things like Team Red, White, \& Blue, the Mission Continues

I purposely put my name all over the county

I can

I do both ends.

I have two prong attack.

I do hammer anvils,

I do the heads of departments, usually the counseling staff.

I develop and form trust with them, and they know me as a Veteran and the services we provide

I know

I got the student Veterans vouch for me and their getting it from both sides.

I had an Air Force guy, he was a total hippie

I'll try to do his accent but it's horrible

I've never had one Veteran, ever, ever ask me what my degree is or where I'm going to school at or what I do for my job

I'm biased but there is ... we support our Veterans, we want Veterans you know, it's the same likeminded community.

I was leaving the department

I had my non-Veteran friends who were like what are you doing? This is a good job. They can't fire you? Because this is all you guys have known.

I've seen a bigger picture, there's more than pushing a...

I worked graveyard for almost four years straight

I worked.

I worked one day shift

I had to

I hated it

I worked, if you were in my street, you're bad.

I'm going to pull you over

I always try to talk to Veterans or suggest Veterans not go into criminal justice because it's such a limited degree

I'd almost rather have them go to liberal arts so that way they get a broader education.

I tell them

I have a lot of law enforcement friends and it's just they are continuing on ... they are living the senior league of the Super Bowl

I know you want to go out there and change the world 
I'm going to live here in this town

I'm going to die in this town

\section{Additional Second Listening: We (Marines) Poem}

We needed so many of you

We worked our way towards Kuwait

We shot, Joe (camel)

We shot more of our own truck than anything else

We were off to Somalia and my helicopter crashed in the ocean

We were sinking because the helicopters are so big heavy on the top

We flipped over, started sinking

We imploded

We're going to get this guy; this is what he's done

We did a good job

We say oh the Japs, or the Nazis. Dehumanize things

We can make it a target

We pray for war

We're on a base

We're already in this country.

We're going to do squad patrols and they're going to lead up to it

We go

We have what's called a combat action ribbon. It's a CAR

We don't wear uniforms a lot that wear ribbons, well most real Marines

We joke about it

We hold onto that

We had just got back

We thought

We had won the war.

We went to Baghdad,

We're done, right?

We beat them

We're done

We have a twenty-one-year-old college kid Lieutenant

We would drink till three and go run at five

We need to do it this way instead

We should

We've been doing it 240 years this way

We just had, November 
We rule your entire world

We say when you eat, sleep, shit.

We're the good guys, you're shit, you're shit. You want to be us; you want to be like us.

We're like, screw you guys. So, eventually you start doing that group think of one kids bad, you need to take care of it.

We're different

We're the only ones

We laugh because

We're the only ones that celebrate our birthday

We live off of our traditions and it's kind like you have to live up to their standards

We always have

We're 240 years of being told our butt don't stink and all of us collectively

We do

We're better than ... definitely better than civilians

We're always better than the Army, Navy, and all those other services because

We've done so much ...

We can do more with less

We pride ourselves on not having anything,

We don't want ...

We'd love to live in barracks

We always live in the crappiest conditions

We always make due

We like that mentality

We give our orders in combat

We just keep moving forward

We just had the anniversary of Fallujah

We lost a lot of Marines in Fallujah

\section{Third Listening: Voices}

In the World: Not-white; Dumb jock; Troublemaker (High School); PTSD; Marine;

Listening; Veteran; Battle-tested; Listener; Narcissist

Within: Lifelong learner, not a student; Combat Veteran; Vulnerable and conflicted about family; Exhausted; Intelligent

\section{Fourth Listening: Politics \& Power}

Political: Dehumanize the enemy in war in order to kill them; Using a gun is not a 
transferable skill, so military experience is not valued; Marines measure service records, civilians measure career and education- everyone measures something

Social: Loves combat, and does not want to be glorified for things in war; If people know everything, it changes their perception of you; Listening to others is exhausting, but he'll do it; Marines with other Marines become more Marine like- which includes more efficient; Can never become what he was taught to despise (nasty civilian pig)

Cultural: Marines have a purpose and value in the Corps (it was revisited in Team Rubicon); Team Rubicon- helping in disaster zones at home is hard, because it is an American home; Veterans have a high standard, Marines' are even higher; Marines have traditions to uphold; War is the Super Bowl for Marines; Police Departments are not a second Marine Corps; Always a Marine; Always have a duty to other Marines

Economic: Not enough money to go to New York on 9/11; Lived paycheck to paycheck; Marines have the smallest DOD Budget (and do more with less) All Types: Social reproduction of the criminals his training officer arrested in LA

\section{$\underline{\text { Individual Meeting \#2, 12/28/15 }}$}

This meeting was about the stories from the pictures Lance gathered. Unfortunately, these pictures where gathered by someone else for another activity. So, while the stories were valuable and insightful, they were not exactly about his various identities.

\section{First Listening: Plot}

Recurring words/themes: Marines; Fun, partying; Water- surfing; Hurt in battel, still impacts him; Gone a lot; War, combat; Pride of service, various jobs, and 
duties; Gallows humor; Women/sex; Being the "face" for groups/organizations

Plot: Lance was a young Marine, in 1992. He spent time in the Philippines training, during which a child was killed during a training exercise. He continued his time in and had fun whenever possible, including at the Marine Corps Ball in 2001, with one of his fellow Marines dating R. Lee Ermey's (famous for his role in Full Metal Jacket or as the voice of Sarge in Toy Story) daughter. After discharging the first time, he went to the academy and met some other great people. One of those people became a traffic cop, who was killed while working the funeral procession of another fallen officer. After Lance reenlisted, he was sent to Iraq for the initial show of force. What they thought would be a few days turned into a month, and he (as well as many other Marines) got dysentery. During that time, he captured a flag that stayed in his breastplate throughout the war, and now hangs on his kids' wall. During combat he was in a bad accident, in which he was thrown from the vehicle and damaged his spine. However, he ran away from the medivac (with Rod) and had an adventure all over Iraq to reconnect with their unit. At another point in the war, his group of 11 Marines held a bank with some barbed wire and weapons to be relieved by a section of tanks and full company of infantry from the Army. There was another situation where they were taken care of by a village elder who offered them safe house, until they fell back to a bridge. "We're just waiting to get overrun and killed. So, we're like, all right, let's wait this out, then. But air got to it before we did." They also at the UN 
building (which was open and empty) and took a few pictures after stopping a group of Iraqis who "found" several UN cars. Lance also worked security for President Bush, and on Arnold Schwarzenegger's campaign. He discharged and became the Vet guy. He tried to obtain a job with the Park Rangers, but his extensive background worked against him. "'Well, this is ... this is three kids' packets. They're all 21 . They pretty much live ... they grew up together playing Little League. This one is a manager at McDonald's that these two work at. And all their parents know each other. I can do ... their 3 packets in a month.' He goes, 'This is yours. And where you've been for the last 20 plus years, half your friends are dead, or you can't find them. I don't even know half the places you've been in the world. But yours is going to take 6 months to get a thorough investigation.' He said ... he goes, 'I turn them in as I see them, one at a time.' I'm like, thanks (laughing). So, I didn't get a straight shake from the get-go." After 9/11, city policing was too small, so Lance started school, first in environmental studies, then in psychology. He served in the Student Veteran Organization, and as a student leader on campus at the community college and the local private university. He even because the "face" on marketing materials for the school. He also does tons of volunteer work and served as Santa for numerous groups over the holidays. "So, I did my ... the Vet Center Friday, or Thursday night. I did CHOC on Friday. I did the VA Hospital on Saturday, went to visit the ward on Saturday. Sunday I was in the pregame for the Chargers as Santa. Took Monday off and then Tuesday I did my old battalion 3/1, I did their ... their holiday. So, it was a big 
burden (laughing). I kind of didn't care to have all that responsibility, I guess, I don't know, as Santa. But whatever. It was ... it was pretty cool.” He liked the attention, and the service of it. Even if being Santa at CHOC was exhausting, "I like doing it, I mean look at that little dude."

Key Characters: Fellow Marines; Friends from the Academy; Wife; Kids; Rod;

Village Elder; Kids in the village; Girlfriend/Bartender \& her brother

Briefly Mentioned: Platoon Sergeant; President Bush; Arnold Schwarzenegger; Kathy Griffin; Hans Blix (desk)

Summary: Lance has numerous "war stories" about unbelievable experiences that he survived with his Marines. He has seen and experienced much in his time in the Marines, and after. As a result, he has been kept from "simple" positions because of his extensive background. He gives back to the community (specifically Veterans) whenever possible, as it is part of his career and who he is as a person.

\section{Second Listening: I Poem}

I just got back from the invasion of Iraq

I ...

I was going to say older

I was looking for gangs and dope

I was in the procession

I'm there, the happy drunk guy in the back

I was there ...

I think ... one of them, yeah

I can't remember all their names

I don't know whatever happened with that

I had just come off active duty

I was still a sergeant at the time

I was happy go lucky

I said, 2000, right before 9/11 
I was like, "Ah,

I'll do ...

I'll do the Reserves, it's no big deal."

I had on my breastplate the whole time

I got ...

I got hurt.

I had dysentery

I'm just going to take a piss

I was really sick, so.

I dropped like, 20, 30 pounds

I was small for me.

I was like 195

I was like tiny

I went there in the '90s for the Mount Pinatubo earthquake

I picked black and white film

I wasn't,

I'm not that old

I just thought it'd be cool

I went out drinking

I always ...

I always went by myself real far away

I at my police graduation

I went to L.A. County's academy

I got the big Elvis hair

I was like 17 or 18 maybe

I was a heavy machine gunner

I think 2 weeks after that

I was leading a training

I had $4 \ldots 4$ or 5 trucks lined up online

I was practicing doing

I said, you know, "On my command fire, fire." we ended up blowing up a kid, so.

I gave him a box

I was all like freaked out

I just thought he probably just wanted the box

I learned to surf down at San Onofre at Trestles

I think

I was just about to get out of the Marine Corp,

I went out

I wasn't working all the time, 
I was in charge of the Perimeter Security Forces

I was up on the OP for a couple of weeks at a time

I lived, up on that ... lived in that little bunker there

I had got hurt

I got thrown out of my vehicle

I was supposed to be Medivac-ed

I mean honestly, we'll try to make it a movie one day

I got hurt, was Medivac-ed

I was sitting between the ... the cabin, the bed, like in that space in between

I yell at my driver, yell at my gunner, yell at my guys to try to control everything.

I went out

I kind of ...

I didn't have anything holding me in there

I got like launched out.

I was like sideways

I went out and flew about 30 feet

I got thrown about 30 feet, hit my head, uh, fractured a vertebrae in my neck and

2 in my back

I was one of the first ones awake, and we started digging people out.

I remember like landing and then like hitting this rock,

I'd seen this rock

I fell .... Luckily it was like soft, like riverbed mud, clay ...

I should have broke my neck, like completely fractured ...

I could have drowned or hit my head

I should be lucky

I didn't pass out

I'm thinking we're going to Germany

I had bought a map at Barnes \& Noble prior to the war, of Iraq

I was tracking where we were going.

I kind of knew what we were ... our increments from it

I kind of had a plan ... a pre- ... pre-planned position of where we were

I kept on, everyday kind of like, okay, 10 to 15 miles a day.

I kind of knew where we would be, after about a week of trading grenades and rockets

I was pretty much completely useless at that point

I kind of just,

I was just a figure head

I was like, "Ah,

I can't see or move anything."

I was throwing up every time we started going anywhere

I was kind of useless

I still $\ldots$

I was out all last week 
I had that headache.

I went ...

I was doing the brain treatment; it gave me a headache.

I went to a massage place and she was like cranking on my neck

I was like ...

I was trying to do like this, and she was cranking on it and it would make me sick for like a week

I had like horrible headaches.

I've gone to the VA,

I've had them do X-rays and MRIs and the whole 9 yards. They're like, "There's nothing there."

I'm like, it's not normal if

I can't ...

I can't ...

I do the physical therapy,

I do just a straight, like head back and forth motion, it will make me nauseous

I'll throw up

I'm surfing sometime

I get twisted around under there

I'll come back up

I'll throw up for a little bit

I don't know

I need to

I just ...

I had just got back

I'm like really tripping out on him

I was on Pendleton and going everywhere, traveling, pre-war

I didn't really see him much before

I left

I was holding a, uh, we're holding a bank

I am

I'm it

I'm the platoon's last squad leader

I probably don't want to know

I've been holding it with 10 guys

I was playing football for the Marine Corps

I went to the All Marine Corps Team

I just got back.

I was volunteering

I ended up volunteering for Arnold's campaign

I joined him on his trip

I never ...

I never knew that 
I was with them for a few months

I think it ...

I did, uh, community college, to start with. And

I kind of started off with environmental science

I wanted to do something law enforcement related

I didn't want to do policing, street level policing

I wanted to do like the park ranger route

I wanted to make myself more compatible

I was like an easy hire for the park system

I pretty much got," you're kind of overqualified"

I got turned down ... or

I got my ...

I got pretty much like ...

I'm like, thanks.

I didn't get a straight ... shake from the get-go

I called, and like, hey, how's it going?

I'm like, did he get promoted?

I kept calling, finally got a hold of her.

I took it on my own to drop something off

I have this information.

I went to the police headquarters

I could see her

I had to explain the whole Marine Corps ethos about

I was looking at the bigger picture

I joined

I did too

I found something bigger than that

I didn't make that first cut

I went to the Reserves, for the college thing.

I could go sailing

I took sailing classes

I got to explore doing all this stuff

I start finally ... you know, getting ... doing stuff with different non-profits and doing Veteran stuff

I did the liberal arts classes

I love art and stuff like that

I want to go

I transitioned

I go straight into law, and it's scary.

I think

I told you before, you know, a law enforcement officer

I really didn't need school at that time

I finally gave up 
I'm like, crap, so now what's an ends to a means?

I'm doing my doctorate

I could do an MFT

I want that piece of paper

I want that respect

I want job availability

I'll have a certain level income

I made more doing contracting, which is carrying a gun and being rewarded,

I was like ...

I just saw you on TV a month ago

I guess, all we could really do

I'm in there as a student.

I don't know why

I went to school right there

I ...

I was like ... hey,

I'm just ...

I'm just nobody.

I'm like ...

I'll just ...

I'll just wave

I'm the esposo

I was ...

I'll have to find some

I got really into student government

I figure that was kind of a unique thing for me to be involved in

I'm meeting with my dean

I'll find ...

I'll find some picture

I could find some

I met her in Iraq, in 2008 or ' 9

I played ... my ... my football thing.

I don't know why any ... the ... the students didn't want to join our Vets Club

I don't know what it is about Marines, we're just very

I'm trying to find school stuff

I played Santa all through the holidays

I did our Vet Center

I was signed up for that

I did $\mathrm{CHOC}$ the next day

I'm like, of course, dude. 
I work for the County

I went to ...

I went to go talk to the kid

I was like, buddy, that's not really in Santa's hand

I really kind of put it on him

I'm not going to take that on

I'm like it's not on me dude

I can't

I don't want to set him up for failure

I kind of like ... pffft, you know, blocked it

I went up ...

I was going upstairs and like, Santa ... Santa ... that kid wants to take a photo with you

I'll go back

I went to go catch up with him

I'm like, crap, so it's like a 10 minute like cry fest

I go upstairs

I was down

I did the CHOC Hospital, the 3/1 Marines, Charger game

I went upstairs, like the third or fourth floor, like hey, that kid came back down.

I'm like, it's killing me. Like he wants to see you before he leaves. He wants to apologize for making Santa cry.

I'm like, give up kid

I did my ... the Vet Center Thursday night.

I did CHOC on Friday.

I did the VA Hospital on Saturday

I was in the pregame for the Chargers as Santa, Sunday

I took Monday off and then Tuesday

I did my old battalion 3/1

I did their ... their holiday

I kind of didn't care to have all that responsibility

I don't know, as Santa... But whatever, it was pretty cool.

I don't know.

I like doing it

I mean look at that little dude

I don't know

I'm a ham.

I like being the center of attention

I don't know who they are actually.

I should also do this one

I got someone to put that together for me

I had to walk home with this crazy ... crazy lady

I looked at ... like they have this sign, like no visitor for your safety. 
I have a knife, as always, like underneath my Santa suit.

I'm like, crap

I shouldn't be really in here with this.

I was a Marine Corps Santa

I never went there, but like the crazy lady

I was with, some, you know, some blonde white women, they're just crazy

I'm like, okay.

I have no idea.

I just know her from different events.

I could have something. Have to ... does it have to be PG?

I have to have clothes on?

I don't know

I'm kind of everywhere.

I don't know.

I don't really know

I don't know (laughing)

I don't know

I'm completely off

I will ...

I will forget

I'm narcissistic, remember

I know,

I'm detached.

I think

I should ... that is my ... the crest from my Japanese side

I'm very self-centered

I could obviously postpone for any reason whatsoever

I have a friend who is a Doctor of Physical Therapy

I have one at the VA

I got ... VA was just a consult

I went to, um, back to go work out with this guy

I do this and that

I'm like, what do we do?

I was like, why didn't they send me to you first? $\mathrm{H}$

I'll put a consult in for you to get your neck and back physical therapy

I could do that

I ...

I appreciate it

I guess it's kind of ... 
I have something every day

I'll try it

\section{Third Listening: Voices}

In the World: Marine; Police Officer; Young dumb Marine; Surfer; Security; Grunt; Leader; Detached from family

Within: NEVER a civilian; Protective of family

\section{Fourth Listening: Politics \& Power}

Political: Responsibility or duty to country is more important than to the city; Need a degree for a career or a job with any money; Difference in opportunities and respect for MFT, $\mathrm{PsyD}$, and $\mathrm{PhD}$ are not equitable to difference in responsibilities

Social: Timelines for the pictures are partially figured out by the size of their bellies (bigger before war, as they all lost weight during the war)

Cultural: Hurt, but still wants to fight, must avoid leaving the team; Parade in the Latino area of Huntington Beach- he felt privileged; 11 Marines held a bank to be replaced by a section of tanks and full company of infantry from the Army

Economic: The families in the Philippines would gather scrapes from the training exercises; VA difficulties solving some health conditions; They traded bullets for chickens to survive in Iraq; Cost of school, better schools sometimes cost more 


\section{Individual Meeting \#3, 1/5/16}

\section{First Listening: Plot}

Recurring words/themes: Always a Marine; Thrill of combat (good at it, enjoys it);

Sex; Found comfort among the rough; Fighter; World's Sherriff; Spoiled

Kids; Outdoorsy; Volunteer/service to others; The mission is more important than feelings

Plot: Only child of a hardworking Dad and quiet Japanese Mom, so he was alone and often got into trouble. They were poor, so he was raised in an area that was the best area of town. He had a history teacher that he butted heads with. "It was junior high so seventh grade it was like history was easy, dates for me. I was like zeros on my homework. I didn't do homework since. I don't think I ever did homework all through school, ever. She was like a ... One of the teachers that had a star chart and I had stars all the ways across, like 100s on all my tests. It got to the point that I would come in either before class or after class and she switched up times on me so I couldn't cheat, and she would do a one-on-one test with me. I'm like, 'Give it to me verbal.' Yeah. I was like, 'You can give it me verbal. You could have another teacher do it. I could stand in the middle room butt naked and you could give me it, but this is easy.' She was pissed because I'm always talking to people, always going, 'Whatever.' It was like I just had ... I can hear ... I hear. I'm an auditory learner so I hear you say 1875 blah, blah, blah like, 'Okay whatever,' and I see it and I'm like, 'Okay that's that,' and I just mark it. It's not that hard. You're just doing multiple choice or even if you have to spell it out. I've always been lucky taking tests." Then his father passed away from cancer, that they thought they had removed a year before. As result, he got really angry and wanted to kill everyone. This fit in with his idea to join the military. One of his teachers was a LtCol who tried to stop 
his enlistment but was unsuccessful. He graduated, ran around campus to ensure he really did graduate, and that night he was on a plane to San Diego. During his enlistment, he had a contract marriage, and he cared a bit. In fact, they still think he is deployed. He isn't their Dad, but he is the closest thing to it. During his time in he had lots of unprotected sex. When he discharged, he started dating a bartender. They were pretty serious, dating for 2-3 years, and her family bought them a house. Her brother taught Lance how to surf. Yet, he never told her about his contract marriage, which was still valid. So, they broke up. He then found his wife, at Fed Ex. They were friends, until he reenlisted after 9-11 and was headed to war. She got pregnant, and then a few years later got pregnant with their second child. In between, he went to war. He passed the test and had an elevated sense of self-worth. But war is a thinking man's wild west! While he had interesting stories from war, now that he has returned, he compartmentalizes his life, including Facebook. He thinks of himself as the world's sheriff, ensuring that people follow the rules. Part of his enforcement abilities, are related to his lack of fear about getting into a fight, based on his upbringing and training.

Key Characters: Dad; Mom; Contract Family; Family (Stephanie \& kids); Bartender girlfriend; Marines

\section{Briefly Mentioned: LtCol teacher}

Summary: Lance had a tough childhood, so the Marine Corps was an escape. Yet he still felt the most comfortable among the rough neighborhoods. He loved combat and wants to go back. He was also good at it and considers being battle tested and being in combat as the ultimate test, the Super Bowl of the Marines. 


\section{Second Listening: I Poem}

I can get off work early and go (fill sandbags to prepare for rain)

I can't afford to be gone for a week, two weeks at a time

I'd have to take the back roads

I say the first one to be childhood, like the whole drama of my childhood.

I was born in San Francisco

I moved to the mountains for a while

I was always on my own

I was 11 or 12 -ish, just messing around

I was 14 or 15 , my father passed away

I became a real turd after that, even worse

I was right in the beginning of junior high

I went in there and had fun,

I was kinda lost

I always hung out downtown

I sought them out

I went there

I went there at 16

I turned 17 on my birthday

I took half

I was in the delayed entry program for a year

I was eligible

I signed up

I went to boot camp at 17

I just wanted to get out of there

I had ... pretty much D minuses all through school

I was an angry little turd

I just wanted to kill everybody

I stated that

I wanted to join the military

I was like "okay, sure". Not healthy at all

I was in his class

I was going to join

I had the record for in-school suspensions

I was always suspended, just fighting, a troublemaker and doing whatever

I did some sports here and there

I only passed because they had to keep me at a $\mathrm{C}$ average, 2.0, to play football

I was like $\mathrm{D}$ minus, $\mathrm{F}$. 
I hated school

I was in night school, summer school, all the different schools, at graduation time I wanted to go

I wanted to join the Marine Corp

I was like literally running from class from class

I graduated

I did

I was packed

I was at the airport.

I was at the hotel by 6:00

I was already on the way to San Diego

I did Desert Storm

I did some smaller things

I traveled a lot

I saw a lot of people get killed in accidents

I almost died in an accident

I didn't do drugs but

I was hanging out with people like that, a lot of hookers, a lot of unprotected sex, unsafe sex, so just a lot of risky behaviors

I was like, "Great,"

I was like 19 and she was 30-something

I found something else like okay, and just kinda support her after that

I was pretty good for there until 9/11

I can, constantly going back, constant deployments, constantly wanting more

I just gave the new hire orientation at the VA

I was coming from

I was a little late

I'm not a thrill seeker.

I don't want to jump out of the plane

I think

I try to describe it in football terms

I relate to

I got out from those first 10 year

I was ...

I had a respectable career

I got a lot of awards

I did pretty goo

I served

I was scared at the same time because it's like the adrenaline rush and you're like 
"Ooh!"

I think that high point

I was like change that magazine, running into a dark building

I was getting shot, and being able to change that magazines with muscle memory

I was like, "Wow that's awesome!"

I'm thinking

"I'm doing it"

I'm not even thinking.

I'm just shooting

I was so excited

I got to the side

I was so stoked about that one thing and completely not thinking if any of those things would have hit me, my head would have been ripped into half

I was like, "That was awesome!"

I'm just in this elated moment

I was like, "All right, let's go. Let's do this."

I think the last one would be ... my own personal growth

I'm at now

I go

I want to go for a doctorate

I want to go

I'm going to do it

I'm just going to go do it.

I was going to bring ...

I completely forgot

I'm actually really calm about it

I'm like, "Whatever,"

I've already decided

I don't make it ...

I'm doing my GRE

I decided

I'm going to do it and see what happens.

I think it's a trial run

I'm all on my own

I was on track for the MFT

I'll try to slam it through

I have to

I have horrible credit

I was like 200,000 a year

I was living this ghetto-rich lifestyle

I made some investments here and there

I just let $\$ 50$ grand in debts go

I haven't paid them 
I think self-awareness of my abilities in school

I kinda tired of school, like in seconds grade, third grade.

I was never really pushed through school

I didn't really have to

I went to school in Japan for a while

I was put back a grade

I was like that's not tough

I even had a teacher in sixth

I was like zeros on my homework.

I didn't do homework since

I don't think I ever did homework all through school, ever.

I had stars all the ways across, like 100s on all my tests

I would come in either before class or after class

I couldn't cheat, and she would do a one-on-one test with me.

I'm like, "Give it to me verbal."

I was like, "You can give it me verbal. You could have another teacher do it.

I could stand in the middle room butt naked and you could give me it, but this is easy."

I'm always talking to people

I just had ...

I can hear...

I hear.

I'm an auditory learner

I hear you say 1875 blah, blah, blah 1

I see it

I'm like, "Okay that's that,"

I just mark it. It's not that hard.

I've always been lucky taking tests

I'll take it

I'm like, "I'm actually doing good in class,"

I have to be where they're at

I saw a guy like completely out of uniform

I would go out right now and just chew his ass

I know how to run.

I was always a good runner

I think Marines are confident because we've had such an intensive history boot camp

I think, or we feel that level of accomplishment

I have to do or die

I feel

I want to destroy

I don't think I'm truly a civilian 
I'm not talking

I will pull it next time.

I will drive up and pull over there

I'm always worried about everybody else

I'm that guy who for no reason would call somebody up for something stupid

I feel like

I have to be the one to stop and block them from messing everybody up

I'm waiting for them to say something.

I'm not going to fight them

I'll sit there

I make them wait.

I've done it where they talk to you like, "Oh my God."

I want to make a right

I don't care

I get in a fight,

I'm just in that mentality

I think so.

I don't care.

I have been in those situations

I get my ass kicked, I get my ass kicked, whatever

I've been in lots of fight

I actually went to that pizza place

I get to ... Its empowering the kids

I got the dates mixed up

I was like, "We're over here. Why don't we just go on and that?"

I have like one or two Marine Corps friends

I'm like, "Hey!" go out, volunteer, and all that stuff

I don't know

I think

I'm an extrovert

I'm actually an introvert

I do ...

I like the attention.

I think everybody likes attention here and there.

I like meeting famous people and doing cool stuff

I'm very private

I hate it when my worlds collide

I don't want people to look at pictures of my kids and stuff like that

I always feel bad

I say those aren't my real friends on Facebook

I never put how I'm feeling

I do it once in a while but mainly it's because look what I'm doing ... 
I'm out, and

I'm helping people

I have tons of military friends

I found that the more humanistic I am

I'm volunteering.

I'm at home

I'm that the freak on the corner with my windows shut

I am perfectly fine

I'm totally fine living in an island in the middle of nowhere

I don't want a bunch of naked dudes

I'm supposed to be retired.

I like Wilson but it's ... You need activity

I'm a jokester

I like entertaining

I think it's less hassle and less BS

I did a clean break from home

I left Oakland.

I went back once or twice

I've never been back.

I don't talk to anybody there

I mean there was an attachment there (with first wife)

I just,

I never really interact with her kids

I think they share one or two different fathers

I met them

I was 19

I was pretty much the same age as the 16-year-old

I didn't try to be her dad

I played volleyball with them

I hung out

I was like their buddy

I felt bad because

I don't believe I raised them

I feel bad.

I don't communicate with the mom and as far as they know, I'm still deployed.

I just send them a Christmas thing or a New Year's thing

I don't tell them I'm here.

I don't tell them I'm married.

I visited them on and off for a while

I felt like after like 10 years we can't amend things.

I had that kinda like real, kinda like fake marriage as quickly as, "let's go to

Tijuana \& get married"

I didn't know what I was doing at 19 
I finally ...

I kicked her loose for another girl that I liked and then I went through ...

I didn't really date in high school.

I had one or two over here and there but not really dating, more mating

I was down here in San Clemente,

I met a really nice bartender who was more nurturing

I would say four or five years older than me

I used to be married and that was hurtful for her

I didn't mention it

I was like it was not a real marriage or whatever

I'm horrible about taking care of things

I still haven't paid my taxes from last year

I'll get to it

I don't pay them.

I started working in FedEx

I met my current wife

I needed to get that break

I was still playing around and dating everybody

I don't care

I was like we meet after work

I had just gotten out of active duty

I was with the other girl for like two, three years.

I was pretty serious with her.

I was bar tending with her

I broke up

I was bartending in three or four different bars so

I knew every single available female in Orange County

I went through as many of them as I could

I had a fun time

I saw her working

I was like, "I'm going back," and she's like, "Oh shit."

She supported me in ever since

I felt obligated and when I decided that she should have my sons ...

I didn't tell her that

I made him a brother

I'll get married.

I still ended up deploying

I've been trying to keep it on track

I feel comfortable

I'm just myself

I will bitch about the traffic and the rain all day long 
I'm completely out of juice and just worn out

I don't want to do anything on the weekends

I don't want to build anything.

I don't want to do anything

I'm like, "That's why I make money, to pay someone else to do it."

I can do it, but I choose not to

I like to do

I like pointing my own guns and shooting people

I'm not pounding a nail and so I feel like...

I can get shot, you can shoot me, whatever.

I like that.

I'm entertained. It feels good to me.

I'm like

I don't know.

I'm like, "Hey at least I'll get that degree."

I don't use it, I don't use it.

I plan to.

I saw a lot of myself

I explained, "Okay, everybody else has the same problems."

I was doing the brain treatment center

I went ...

I go and talk to a doctor

I was like

I was okay

I started dreaming more

I was sleeping deeper

I had nightmares

I was having nightmares for a week

I didn't feel the lack of aggression

I was worried about that

I don't want to lose my aggression

I'm always going to be busy

I wasn't too ... Not too impressed

I think that they assumed

I only had one technician that measured every single time

I was done

I was like no more.

I just want to do my final ...

I'm going to see my results

I thought.

I thought it would be an actual map of

I thought it was going to be more

I was pretty disappointed

I don't know what her training is 
I know the science is probably there, but you can hype up shit a lot I wouldn't recommend it to anybody else until they get the hard science I don't know.

I've had some friends who swear by it

I take nothing.

I was really apprehensive

I was looking for something and it was available and it's free.

I'm like, "All right

I'll give it a shot.".

I want to be normal but

I thought

I was getting normal it scared me

I just did

I told them

I am going to this in- depth

I could just come up here and tell you this is what we do

I could be done in 30 seconds

I have 15 minutes up here $\mathrm{s}$

I just felt like being in the military it's just all the mission first.

I'll just

I'm going to destroy anything that's in my way.

I don't care what it is.

I might look at him, but my job is not to stop

I see my friends

I'm going to see the damage

I'm done

I can't stop, pause, and think

I have the next

I have to do that two to three times a day

I want them to be aware

I keep some of that fire,

I guess

I go into the practice or have a drive going through my training

I'm putting my paper

I want to keep that going

I have a reason

I'm doing it.

I didn't really go really in-depth

I just touched on it

I did say 
I'm a veteran and this kind of refocused

I've been refocusing on this population

I want to serve

I expanded on being a mentor later on

I get the mentorship done and then start a nonprofit

I kind of have my short, intermediate and my long-term goals

I just want my piece of paper

I don't how

I'm going to pay for it

I would like to send it to you

I'll send you their prompts

I stuck to their order

I didn't try to get cute

I just stayed with the same order

I don't have time for it if

I missed two or three in a row

I talked to my old dean and

I can't leave California

I'm not doing ...

I'm doing a PsyD not a PhD.

I worked ...

I had the same doctors going, "Excuse me, so where is the lobby at?"

I'm like, "Behind you, sir."

I think it's also where their mind is at

I'm just another front desk girl to them

I don't know.

I should talk to my doctor about that.

I kinda like where I'm at now

I'm working on the anger

I don't want to destroy somebody and go to jail

I use that exact same line every day.

I use that normal reaction

I give a speech

I use that

I use the hot stove

I say everybody has experienced it

I said about the alleyway

I can't just start shooting over here

I see something

I know they have my back

I'll kill the manager 
I'm not going to plan it all.

I'll get the guy in white.

I get killed you know "Okay, well he's gone, so I'll take on the head chef and the manager,"

I've never had to do it

I wouldn't either

I mean going into Fallujah

I'm looking at the guy in front of me like

I can't see him.

I can't shoot him.

I don't know what we were thinking.

I can guarantee you.

I am completely apathetic about everything else

I went there

I went to the same school in Japan as him

I know some of his friends

I was like almost second or third grade

I don't even care about people I met yesterday

I don't really care about any of this shit

I'm just here eating the food and watching football.

I really don't care about any of this stuff

I really don't give a fuck about any of this, dude.

I'm just here eating the food

I'm watching football.

I'm just here and he goes like, "Okay."

I don't not like your family. They're cool.

I just don't care about them

I don't even care about my family

I've been back there a few times

I'll be able to afford it

I could start planning

I will smash that electronic

I could care less about that.

I haven't really surrounded him by homeless stuff.

I don't neither. Dads are very like ... They'll figure it out.

I figured it out.

I think a good combination of both is right

I told somebody the other day

I'm not comfortable watching a girl 
I could still molest a boy child but

I do not want to be responsible for a girl

I don't want to raise that doubt in their mind

I just don't feel comfortable.

I think there's certain things that people are just so trusting

I could go back to my car

I guess.

I don't post.

I just post in bursts.

I might not do anything for two to three days

I don't want to be

I just drove to work and back today

I think

I'm trying to grow off of it and learn from it.

I can't stop looking at the car, the cop car down there

I saw him

\section{Third Listening: Voices}

In the World: Doer; Troublemaker; Smartass; Proud Dad of smart kids; Husband;

Marine; Not a civilian; Wounded PTSD

Within: Hurt; Intelligent, doesn't connect with people (not friends); Hippie \& Marine;

Loner

\section{Fourth Listening: Politics \& Power}

Political: Graduate testing is about privileged knowledge; PTSD perception strongly

linked to Veterans; Science needed to strengthen brain treatment research

Social: Need a network of support to succeed; World's sheriff (need to keep everyone following the rules); Not "normal"; Needs the passion and fire that comes with the aggression of PTSD

Cultural: Marines have a high standards and traditions to maintain; Marines do a lot with a little; Accountability is huge; The test of combat is compared to the Super Bowl for Marines 
Economic: Changing neighborhood when growing up, altered the need for a butcher; DOD gives the USMC the least amount of funds; Has horrible credit; Lives paycheck to paycheck; Free UC or Cal State tuition for children of Veterans with a certain disability rating

\section{Found Poetry from Group Meeting \#2, 12/13/15}

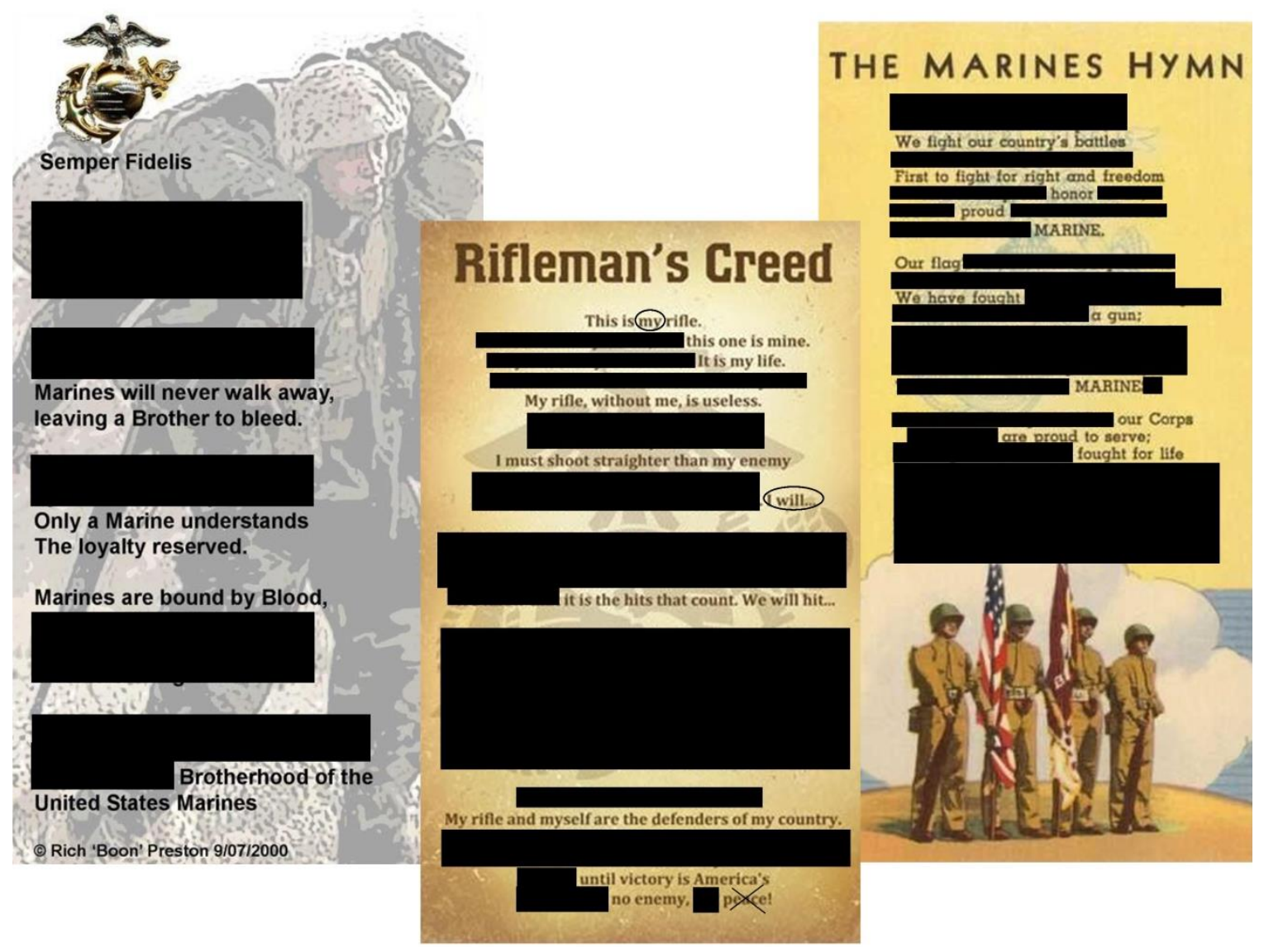




\section{Beaver Recon Report}

\section{Individual Meeting \#1, 10/14/15}

\section{First Listening: Plot}

Recurring words/themes: Variety in personality- Beaver v Tony; Always wanted to be a police officer; Marine behaviors stick- speed, efficiency, lack of patience Plot: Beaver got his nickname on first deployment. Everyone in their unit had a nickname, some nicer than others. After the curiosity for his first deployment was satisfied, the other deployments were endured begrudgingly. "There's nothing good over there, nothing." He saw combat and stayed away from Marines "wanted to go out there and just fucking lay bodies." It also meant that with his various experiences, he accumulated a stack of ribbons compared to some of his other friends in the Corps. He was good at being a Marine. However, he found that those ribbons and achievements did not mean much to civilians. When Beaver discharged in 2008, after having another Marine complete his discharge hearing test, he discovered that many police departments were frozen for hiring. As such, he had a difficult time finding a job, anywhere not just with police departments. He found a job in parking enforcement at San Gabriel Police Department, while there he had a few fix-it tickets signed off. After working at San Gabriel PD in, he decided to go to school at East Forrest College (the three-year program would work with his desire for speed and efficiency) using his Post-9/11GI Bill. A college degree would also give him a pay bump once he was a police officer. However, 
that plan did not go as hoped. As a Veteran, he found the screening process to be more invasive, as the background investigators worked to find minor negative aspects (the previously mentioned fix-it tickets) of candidates while ignoring significant positive attributes and awards. "They're there to find anything that you did to disqualify you. They're not looking to hire you. They're looking to disqualify you. It's your job to give them a reason not to." Since he always wanted to be a police officer, the numerous disqualifications led to significant disappointment. So, he planned to start the police academy, and hope to find an agency at the end. "And that's ... that's probably the worst part about my life right now, not knowing what to do next. Because see, the academy ... okay, so that's six months. So, for six months, I have that going. When I get out of the academy, what ... if I'm not hired while I'm in, I'm going to have to start trying to reapply to other places again. And if I don't get hired, then what? You know, I'm just dwindling down savings that I have. Eventually, I'm going to have zero dollars. What the fuck am I going to do? I don't ... I don't know." The academy was to start within the next three weeks.

Key Characters: Jennifer; Mom; Brandon

Briefly Mentioned: Ping-Pong; Ballarina; Brandon; Customer Service people Summary: Beaver had done everything he was supposed to do to become a police officer. But it still hadn't happened. He joined the Corps as a way into law enforcement. He went to school to help with his application and pay for being a police officer. He never saw himself in this position, and that is what lead to 
the frustration and borderline depression. "That's the worst part about my life right now, is the not knowing. Normally, I'm pretty good with that kind of stuff. Like, oh, I have like steps. Like I, uh, figure out something. Uh, I have no idea, because I didn't see myself in this position."

\section{Second Listening: I Poem}

I got the name, the nickname

I don't even remember

I forget

I can't even remember

I think we were there for like a month

I don't know how they got that pool so cold

I was swimming

I was like spinning around

I think I was a PFC or a Lance Corporal at the time

I left my Unit for the CG's office

I hated it

I mean we all had nicknames

I don't even know where that name came from

I always felt like it seemed racist

I mean what do ping pongs have anything to do with a Filipino kid

I have no idea

I didn't mind it at the time because, you know, we're Marines, and we're racist

I wouldn't...

I mean like you've heard me and the other guys talking

I still talk to him to this day

I never asked

I knew where mine came from

I don't know

I don't know

I have no idea

I couldn't tell you.

I remember most of it to be honest with you

I told you my primary MOS was 3531 which was a Motor-T Operator

I got sent to Missouri for my MOS school there

I didn't get a haircut

I didn't have a fresh haircut

I had my mom cut my hair

I went

I checked in

I had my ass handed to me so fast 
I didn't even get to do the general orientation

I went over there, got a haircut, came back

I had to do like a mock orientation

I was just getting my ass chewed left and right

I'm a Marine

I'm the shit

I was labeled as a shitbag

I had to work my ass off to prove that that my haircut didn't basically make who I was

I remember that

I remember the majority of those (deployments)

I was scared and nervous

I mean the fear is there

"I wonder what it's going to be like."

I don't give a...

I have arguments with Marines

I didn't give a fuck

I just wanted to get the fuck over it and be done and go home

I was so blase

"I don't give a fuck about killing people and shit like that

I want to get the fuck out of here

I hate this place

I want to go home

I want to get laid

I want to do normal people shit

I'm using the Marine Corps as a stepping stone

I'd get in arguments with Marines

I think we should have never been over there

I still strongly believe that

I believe that the government had a hand in creating 9/11

I do

I really do

I don't even like talking about it cuz it drives me nuts

I can explain it to him all I want

I mean he technically did a deployment

I don't care if you deployed once, twice, three times, four, five, six, seven, eight, nine

I don't care if you ever left the wire. For me, a Veteran is someone who spent 4 years honorably, or 6 years depending on if you were Reservist

I've never had children

I'm sitting here telling you how to raise your child how dumb does that make me sound

I've had puppies and dogs 
I've raised dogs and stuff, but they're two completely different

I, we just don't agree on certain things when it comes to that

I don't even talk to him about it

I went to his wedding

I was only in the Marines for 4 years

I found out he was just going to Kuwait

I didn't know he was just sitting over there

I cannot stress this enough; ratings make their world go round

I don't even wanna say this

I've seen plenty of those videos

I liked (one thing) about him...

I understood that

I respected the fact that he was putting it out that way

I can't even tell you how many times I had people, even people I, you know, grew up with and family members of mine ask if I killed people and stuff

I was always weirded out about that about how people were going to look at me if they knew absolutely everything that was done over there and stuff

I was really conscious of that and mindful of it

I didn't want that to affect the way people looked at me and viewed me as an individual

I wanted them to be able to separate the fact that there was me Beaver the individual, and then there was Sgt. Beaver the Marine or Corporal Beaver the Marine

I always wanted to make sure

I take very careful cautions and make sure that there was a difference

I got out of the Marines

I grew my hair out super long

I didn't really grow my facial hair out

I just didn't want to, I guess

I don't really care

I had my hair super super long

I was a Marine

I was a Marine

I have a huge problem with is patience

I have such a lack of patience

I contribute to the Marine Corps

I constantly move at a certain rate of pace

I'm constantly, whatever it is I'm doing, I'm doing that at a pretty reasonable pace

I'm like why don't you just sit down on the couch and let me do both things at once so we can finish faster

I'm waiting on you 
I don't have that kind of patience

I have to ask myself what's the hurry

I'm so used to having things done so quickly and so, with such speed and tenacity

I have to reset there, reflect

I don't like admitting it

I hate that

I hate too, when she calls me out on my bullshit

I hate that

I can't get her to understand where I'm coming from

I've been out of the Marine Corps for like eight years. Okay. And it's still there

I know that

I totally, I realize that

I was in high school; I was the the king of getting out of doing stuff

I'm not really getting out of It

I just want to do it as fast as I fucking can and be done with it

I feel like

I understand it has to be done

I'm like no, no, no, now!

I have a big problem

I'm explaining something

I'm about ready to rip her teeth out of her mouth

I'll get an average of about 4 words out

I'm trying to answer her insane, asining question

I not be able to finish the answer that she wanted

I now have to answer another question about the four words that just came out of my mouth

I don't know but she does it to me all the fucking time

I know it's not fancy but it's our favorite place, so for us it's where we went

I think we were in and out of there, food, ate, and everything, in 20 minutes

I think I gave him like a $\$ 30$ tip

I had to shit like you could not believe

I'm very picky about public restrooms

I'm sitting there

I've trained my entire life for this stuff

I'm not going to

I've shit in fucking porta-johns in Iraq and Afghanistan

I will only shit in a place I feel comfortable

I'm sorry the wet bathroom floor of a mall where everything is fucking wet all the time, and stinks in there, is not appropriate for me

I'm sorry

I had to jump out of my truck and walk around

I was taking deep ass breaths

I'm not fucking around, this is like real shit

I swear to God 
I could not believe I found myself in the situation

I'm a 29-year-old man

I'm pacing back and forth in a fucking parking lot

I was 'this close' to taking a shit behind one of the buildings

I can't do that

I'm out there pacing

I jumped in the truck

I get in there as fast as I can

I park and it is coming, man

I'm like sweating

I'm trying to act like supernormal

I'm like shivering and shit

I'm about to cry

I'm supposed to land nav myself

I walk outside to the little patio door

I'm pissed the fuck off

I felt like he should of took a little more time

I had to use the restroom

I would have gone in the direction that he pointed

I get in there and I slam my hand down

I got his attention

I came back.

I was already sweating

I get back

I asked him the first time

I have a very short temper

I'm only telling you that because that's the most recent example

I have a temper problem

I couldn't get it to sit properly

I'm out there

I'm cussin' at it

I'm still mad at it, but now I'm mad at you

I, I, again lack of patience

I get angry and frustrated

I do realize that

I understand that

I try my best to work on it

I'm mad

I'm visibly mad

I'm pissed off; get the fuck away

I just told you already, a million times, to leave me alone when you know that I'm mad."

I consider myself a funny guy

I'm more comedic, and comical

I like funny things 
I don't like to be serious if I don't have to be

I get to that moment where things aren't funny anymore

I'm pissed off leave me the fuck alone

I usually just let it kind of wash over me, you know

I usually I don't get mad at people

I'm not even mad at you

I'm clearly upset with this fucking part or whatever the case it is"

I had to set pilot holes everywhere

I'm not even mad at you

I have to

I'm just

I'm expressing my feelings

I feel like she feels that she draws the attention from whatever it is, that I'm no

longer, that she's like safe ground

I feel that she's drawing attention from whatever the thing is to herself

I'm like here we go

I don't question anybody

I tell you to do that all the time

I go to walk away

I don't get it

I don't get it

I told her a million times

I'm sure I will

I've tried ignoring her

I've tried ignoring her

I've tried telling her

I just want to give her the why

I don't want to give her all the other details that she, for whatever reason, needs to know

I told you already to leave me the fuck alone when I'm pissed off

I think

I know what I'm telling her

I know it ain't nice

I'd leave them the fuck alone

I feel like

I feel like she wants to be the person to break that

I think she may have realized that I've been like that for a very long time

I feel like she wants to be that one person that's been able to that puncture through that wall, that barrier.

I still talk to a handful of them

I'm going to tell random people that... No way in hell

I don't fault anybody for that

I can explain it over, and over, and over in detail and it doesn't do anything

I can provide the answers 
I mean now it's completely different from what I hear

I don't know if this is necessarily a good or bad thing

I'm checking out

I'm filling out all my stuff

I going to, basically it's like headquarters for Camp Pendleton, where you get your DD214

I explained to some female, some Lance Corporal

I tried to explain to her

I want to be very clear here

I'm not trying to be a dick or anything

I'm not telling you how to do your job

I'm just telling you where I'm gonna be and it ain't gonna be here

I'm pretty sure she got spoken to

I was out

I called my mom right as I was leaving Camp Pendleton

I go off base

I'm out

I'm discharged. That's it. Never again.

I went home, uh, hung out with my parents a little while, went and visited some friends

I pretty much didn't do anything all weekend

I started, uh, probably within the next month

I think it took about a month

I was going to take the month off

I was going to start applying to departments

I had no idea that the economy was in such shambles

I didn't know anything about this

I remember I applied with the Orange County Sheriff's Department

I'm like, "Oh, shit."

I started applying with smaller departments, which was even worse

I had no idea that this was going to happen

I ... I turned a month of leave that I was just going to take to myself, and it ended up being almost a year

I ... I was tripping out

I had to go on unemployment

I was actually on unemployment benefits for an entire year

I finally, finally ... somebody sent me an email saying that the city of St. Gabriel was looking for, uh, parking enforcement officers

I ... I applied and not thinking anything of it

I got uniforms

I started a week later

I ... I ended up being a parking enforcement officer there for about two years

I was there

"I want to be a cop" 
I thought about it for a little it

I went registered

I saw a commercial for, uh, Westwood

I was like, "Shit, a bachelor's in three years.

I went and did it

I start ...

I start the police academy on November $3^{\text {rd }}$

I'm going to have to bust my ass and hope

I'm not entirely squeaky clean

I was working at San Gabriel

I got some fix it tickets

I had them signed off

I stopped there

I was doing my background; they didn't like that at all

I tell you, that's the opposite of integrity

I could have easily told you, "Oh, no. I ... I had a ... I some tickets taken care of and took the tint off and put it on myself."

I could have told you that

I figure with ... with everything I have on my background, the ... the little things that ... that may be an issue should ... should be negative. They ... they should cancel each other out

I gave my LAPD background investigator my packet

I gave her all my awards and medals and citations

I just got to keep trying and see what happens

I don't ...

I'm ...

I don't know what option B is

I have no idea, no idea

I have that going

I get out of the academy

I'm going to have to start trying to reapply to other places again

I don't get hired, then what?

I'm just dwindling down savings that I have

I'm going to have zero dollars

I don't ... I don't know

I'm pretty good with that kind of stuff

I have like steps

I, uh, figure out something

I have no idea

I didn't see myself in this position

I always saw myself being hired at some point, but they're so fucking picky, it's not even funny

I hate saying this

I feel like because I'm a white male 
I'm ... I'm just getting shit on

I'm not (half Latino)

I don't ... I don't know what his race is

I don't know if he was married

I don't know what his actual race is

I've always put ... on my stuff

I have always put Caucasian

I ... do I look Hispanic?

I don't look Hispanic at all

I don't. I ... even if I claim white and I said I was like, uh ...

I know he is ...

I mean, uh, his name was Lopez

I know he's ... he has to be Hispanic

I mean, I ... it would make sense because my mom is ...

I guess

I've been putting white on all my things

I just feel like ...

I feel like right now that they're really picky about that kind of stuff, especially

because all you ever hear in the news is a white cop shooting a black guy

I'm saying ...

I think that ...

I never, ever, ever in my life thought I would ever have a degree, never

I didn't want one

I didn't care for one

I didn't ...

I didn't give a fuck about school

I still don't

I'm ...

I ... for me, school is, uh ... at the end of the day, if you do a good enough job, you get a piece of paper

I ... I have never cared about school

I still don't give a shit about it

I ... I mean, yeah,

I have like

I have a piece of paper

I have a bachelor's degree

I couldn't tell you

I took it to one of my background interviews

I can't find that packet that I had with it

I have no idea where it's at

I looked at school like a job

I went

I did whatever I needed to do, whatever was asked of me

I did it to the best of what I could do 
I mean there were certain things I could have tried a little harder on

I probably had other things going on

I looked at it as a job

I was getting paid

I ... I was lucky because my tuition was paid for

I was getting paid on top of it

I don't owe anything to anybody

I don't owe tuition to anybody

I didn't pay anything

I feel bad for the kids that went there that ...

I feel bad for Westwood

I feel like it's a ... like a low-income school

I needed things growing up, they ... they paid for it, no questions asked

I may have had to do extra chores

I pretty much got whatever I wanted

I ... I did not want college

I ... I was very adamant about that

I feel like, uh, you know, half of this ... more than half of the students at

Westwood ... are ... it comes from the low-income side of the bracket

I feel bad

I don't know what they fuck they're going to do to pay off those loans

I mean you know what I'm talking about

I'm not stupid

I know how things work like that, like ...

I ... I look at the students

I looked ...

I calibrate them

I'm looking at where they're at mentally

I swear to god, if Westwood does this

I'm going to be pissed

I'll ... I'll lose my shit

I'm back to nothing

I'm ... I ... I don't know how many years in the hole

I can't show ... what am I supposed to show that paper to?

I had a degree from them.

I only ... yeah

I only went to one school because I ... because they do a three-year degree

program

I was driving from Chino Hills to fucking, uh, uh, Anaheim, you know

I only went because it was a three-year program

I just didn't want to spend years and years and years in college

I just wanted to do it as fast as I could and get the fuck out. Again, quickness

I did

I learned 
I won't forget

I was there, where I really ...

I say this to everybody

I ... I totally understand the, the ... the arousal factor

I know what it's like to be aroused

I don't get is how the fuck children make somebody aroused

I cannot even grasp that

I want to crush children when I see them

I ...

I held a special place for children

I cannot stand little kids

I'm just like ... there's more tolerating than standing

I found out that grown men and women are having sex with children and minors and stuff like that, they're grossing me out

I feel like ... that's one thing that makes my stomach turn

I heard the story

I don't give a fuck

I was living with my ex, Rachel

I'm not just trying to sound funny

I'll never forget that

I was ...

I don't give a shit and less for me to worry about when I'm ... when I do become a cop.

I'm going to spank my kids

I am

I got spanked

I ... I don't have kids

I fucking tell you what

I will

I will definitely

I was ... when you're in boot camp, they may give you some of the most fucked up shit that just kills your whole body

I figure, fuck

I can actually kill them without even touching them

I'll just do that shit, no bruises, no nothing.

I know. They even call that verbal abuse. Uh ...

I don't want them to be obese

I want them ready

I mean, yeah, by definition

I mean ... yeah

I think that I identify myself as a student

I was a student at Westwood College but just by definition

I ... I went off with what I was

I was a Marine, and 
$\operatorname{I'm} \ldots$

I still will always say that

I was a Marine

I am never not proud of that

I will always be a college student of Westwood

I can't change that

I have a fucking degree that says I did

I can't ever change that

I'll always be a former Westwood student, a former Marine, uh, a former parking enforcement officer

I'll always be those things because

I embodied there as I'm there

I'm not a student anymore

I... I don't ever consider myself a student of anything until

I get into the academy

I'm going to be a cadet or a recruit, whatever they call us

I went to orientation over there, and they basically tell us ... told us that our lives are going to be hell

I felt like ...

I felt like they were hyping it up way more than it needed to be, you know

I mean it can't be that bad

I understand that I'm going to be on the hills

I don't see myself having a problem

I'm just going to have to do my best not to laugh

I don't know

I had a couple of people tell me

I'd rather try to stay under the radar as much as I can

I'll see when I get there

I'll be able to judge it, uh, fairly accurately

I'd give you my sweater

I don't have a shirt underneath

I'm not (happy)

I ...

I want ... the way

I felt in the Marines

I want that again

I had steady income

I had a ...

I had a good career if I wanted to make it one

I mean how many 18-year-olds do you know that are working ... well

I mean I had ...

I had a fucking $\$ 35,000$ car

I had my ... all my shit was paid for

I mean every ... everything was tax free 
I mean at 18 years old, you ... you're living a life, you know

I feel like I've ...

I feel like I've taken so many steps backwards after leaving the Marine Corps

I feel like ...

I feel like when I got out of the Marines

I had every intention to just blow up

I was ... I was getting ready to places

I was going to become a cop

I was going to get my shit together

I was going to have, uh, a ... a good life, uh, start a family or whatever the fucking case was

I was going to start my real life now, because the Marine Corps was, again, a stepping stone

I would have just gone straight to college (without the Marines)

I'd have been in debt

I'd have to take out massive loans

I'd have to have some bullshit McDonald's or Starbucks job

I wouldn't have anything that I could say to a police department

I mean really

I felt like I was only going to progress

I feel like I've taken so many steps back

I feel like I'm on a fucking standstill

I'm trying ...

I really have only one other option

I'm not happy

I, uh, fucking hate my life

I wish that I would have stayed in the Marines

I hated the Marines too

I, I ... I was used to it

I was good at it

I don't like doing the dishes

I'm pretty good at them

I do them by hand

I don't even use a dishwasher

I vacuum ...

I'm pretty good at that.

I don't like vacuuming

I was good at ...

I was good at being a Marine (chuckles)

I didn't like it all the time

I'll say it was 50-50 
I'll say it's 50-50

I enjoy it

I absolutely hate it

I'm not looking for, uh, handouts or anything like that

I had to remind her

I ... I handed it to her.

I, I ... I have to do the things I have to do

I cannot rely on

I was a Marine, and combat trained

I was a student in this

I can't rely on that

I have to keep doing the only things

I know how, and literally, the ...

I'm ... I'm doing the last thing that I could possibly do

I ... I don't know what else I can do that's going to help me become a cop

I think it was a great movie (American Sniper)

I think Chris Kyle should be held as the best sniper that probably ever lived

I do believe that his ... his attitude was not portrayed as accurate as the movie wanted to portray it

I'm not saying that he wasn't (a hero)

I didn't know him

I don't know what his vendetta was towards this guy

I'm ... I'm going to say that that was part of his PTSD

I think if people don't do their homework, it helps

I believe that he is (a hero)

I ... I didn't know Chris Kyle personally

I have no idea

I ... again, I'm not downplaying Chris', uh, heroism overseas

I mean, he, he ... he did his job

I ... I feel like he also hurt a lot of us if they go and do their ... if people go and do the research on it, you'll find that there are some inconsistencies in his story

I'll never know

I ... I feel like ... I feel like Chris may have had a ... had a case of where ... you never ... you never really want to talk about what happened overseas

I felt like since he never really wanted to do that because he didn't want to be labeled as that guy, he created his own war stories here

I feel like ...

I feel like given the shit he did talk about, he left a lot out

I think he even

I think he even acknowledged that he left stuff out

I can't remember, but I ... I'm pretty sure that there was some excerpt

I felt like ...

I felt like since he may not have been able to disclose everything about overseas

I felt like maybe he came back here and wanted to create stories that he could 
disclose here

I'd rather something happened, and you just tell me half of it rather than to just make something up out of your head, you know

I ... I don't know if that's ... has anything to do with his PTSD

I couldn't tell you

I have no idea

I first started reading about that stuff

I read that ... that Jesse Ventura file, the, uh, defamation act against him

I dug into that story

I found out there was other stuff

I saw the movie

I don't know

I feel like a lot of service members have that problem.

I feel like, uh ...

I feel like especially the ones that were like supply or admin personnel

I feel like they have the most stories than anybody

I always found that the oddest

I'll tell you what

I wouldn't believe a single one of them.

I ... I wouldn't believe not one of them.

I ... I don't understand why

I ... I knew plenty of kids when I went to high school

I wouldn't have passed it up either, bro

I just have to show you something right now

I wish I was still in the Marines right now

I wish my life was put back together in a specific way

I feel like it should have been, but it isn't

I feel like I'm complaining about it

I'm not one to complain usually

I'm still sitting here like this

I ... I feel like ... like I'm an, I'm an ...

I have a degree

I don't ...

I don't care that I worked parking enforcement and that shit

I don't care that I did four years in the Marines

I'm ... I'm just wondering what did in that duration of time that has prevented me from being hired

I'm wondering

I have all this good stuff in my past, what in my past has dramatically affected why my future is the way it is

I'll never know

I don't get it

I may be depressed about my ... my life right now 
I was depressed when I was in the Marines

I'm not ... I'm not going to talk to anybody until I feel like I've exhausted all avenues.

I feel like ...

I'm not ... if I'm not actually depressed

I'm a step below being depressed

I started gaining a ton of weight because

I don't ...

I don't understand how I can have a stack of fucking awards this fucking high and have three things negative on my background and keep getting shit on.

I score really high on the test.

I score really well on the physical agility.

I inter ... interview well.

I don't understand what it is that's ... that's so detrimental

I ...I can't do this anymore.

I started ...

I started trying to get a job at Amazon, Home Depot, um, uh, Lowe's.

I can't even think right now.

I ... I tried like a handful of places, no ... nobody wanted to hire me.

I ...

I don't ...

I don't get it.

I feel like I'm articulate.

I feel like I dress well when I go to interviews and stuff like that. I feel like I try to educate myself about the business and the company

I'm gonna have to get a job that I'm qualified for, which I feel like I am, that I haven't gotten yet, or

I'm going to be, um, trying to beg for a fucking $\$ 12$ an hour job.

I ... I don't get it

I looked at San Diego Sheriff's Department

I looked at Ventura, Oxnard, uh, Las Vegas

I guess Vegas is out

I don't know where

I'm just ... I'm just going to go do the most while I'm with the academy and hope I'm good for the job, you know.

I mean fuck

I don't know what else to do.

I feel like, uh, fellow cadets in my class aren't going to really like me I have a certain expectation

I'm going to have to help get them there

I'll just follow the same three steps I've always done 
I'll ask you to fix yourself

I'll tell you to fix yourself

I'll make your fix yourself

I'm going to make it really shitty for you

I'll be the one to make you quit

I feel like so many kids that just come straight out of high school and college and stuff like that that are going through the academy that don't have that, that, that ... that moral compass

I feel like they are.

I feel like they're just as, uh, much of a civilian as, uh, military personnel.

I was in the Marines

I was in uniform

I was on base

I was a Marine. Yes, sir. No, sir. Yes, Sergeant. No, Sergeant.

I was off base, the only thing that indicated my military stature was my hair

I didn't act like one

I didn't talk like one

I have a hard time

I'm working on things

\section{Additional Second Listening: We (Marines) Poem}

We were in Al Asad

We were doing there, I forget

We were just doing embark

We were there a while

We were there for like a month

We had some square away time

We went

We were all in the pool,

We were sitting there

We had a little Filipino kid

We don't.

We had a kid; his last name was Lambarino.

We didn't know.

We should have never been over there

We set up an electronic, or ah, communications footprint

We could talk to you guys about boot camp all day and night.

We could tell you the smells, the sounds, the the feeling

We just don't agree on certain things

We were,

We happened, my unit, my team happened to be in the area of where some of these instances took place.

We could get (information) from them

We didn't know something and see if 
We could help out. Oh my god. It's like they live on their own planet.

We would explain to them

We got this basically the same thing

We already had.

We move around the area and try to figure out what we're going to do

We don't...

We usually don't. You know, sometimes we do.

We talk about the things that made us laugh.

We'll talk about ...

We'll make fun of the some of the Marines

We do.

We don't really get into too much detail with deployments and specific things

We don't have to.

We don't even talk about it that much.

We experienced it together

\section{Third Listening: Voices}

In the World: Marine (Beaver); Tony; Son; Boyfriend; Liberal

Within: Cop (to be); Marine; Critical Thinking; Conspiracy Theorist

\section{Fourth Listening: Politics \& Power}

Political: The government knew about 9/11 (conspiracy theories); BIG difference between complaining about the government and complaining about the actual troops; Maybe it is because he is a white, heterosexual, male that he isn't able to get a position in a police department; Being a Marine, a Veteran, doesn't mean much to civilians, or is seen as a liability

Social: There is a hierarchy among Marines- "remain behind Marines", ribbons, number of deployments, when they occurred, duties while deployed, etc.; Marines who never experienced it cannot complain until they have earned that right to really complain; Marines are better than civilians; People might see him differently if they knew everything that happened when he was overseas;

Cultural: Civilians are nosy/curious, but they will never understand; Those who know 
what happened are the ones who were there, and they don't need to talk about it; Marines are the best in the world; Comradery of the Marines; Nicknames for other Marines are often mean or slightly demeaning

Economic: 2008 Recession hurt his job opportunities (PD hiring freezes); GI Bill helped for school as it provided for tuition, books, \& housing; Beaver made good money while he as in the Marines

All types: The media does not present the truth, it presents the stories that sell, often at the risk (and stupidity) of the journalists in search for the time/space

\section{Individual Meeting \#2, 10/20/15}

\section{First Listening: Plot}

Recurring words/themes: Cop hopeful, Mentee; Organized/clean; Marine; Proud, not showy or abusive; Have to dumb it down for civilians; Job difficulties; Government v Troop/Service Member complaints; No one care that you were a Vet; Military Industrial Complex; Politics (no Trump); More than a Marine

Plot: Beaver did just enough to get buy when he was in high school. He never cheated, but he was lazy. Then he enlisted, and he hated the structure, "I hated waking up at fucking ... I hated waking up when it was still dark, running for an hour and it's still dark. That's how early you're waking up sometimes, where you run for an hour, it's still dark and you're still running. And now, oh the sun is now coming up. So, it's like 5:30, 6:00 in the morning now, but you've already been up, running for an hour. I hated that." He met people he wouldn't have met otherwise. And got married after his second deployment, although he never lived with his (non-ex) wife. He was in a great unit, and he got to test gear before it went to other units. It was Beaver's 
choice to enlist, and his choice to leave- at a time when doing so was perceived as being a traitor. He wishes the Middle East would just disappear. Because there is no easy answer to the situation over there. He always made a joke out of everything, and never took anything too seriously. A year after he left, he joined the San Gabriel Police Department, Parking Enforcement. Then he left to go to East Forrest College, because it was the fastest path. Now he has two pieces of paper, DD-214 and bachelor's degree.

Key Characters: Ada; Christian; Nathan; Mom; Best Friend; Brandon

Briefly Mentioned: Bernie Sanders; Trump; Guy at the Gas Station

Summary: Beaver finds a need to separate his Marine self and a civilian self. He also hated the Marine Corps, but he misses it. He still feels a need to take care other people and ensure that everyone is okay. He is still planning and trying to be a police officer. The academy would start within the next two weeks.

\section{Second Listening: I Poem}

I told Jennifer

I was like you know

I'm not exactly sure

I would be telling neighbors

I'm a cop

I'm a police officer or whatever

I don't think so

I just told Jennifer

I was like you know when I'm fresh on the department,

I'm going to be gone weekend nights

I'll be weekend nights, holiday nights, holiday days, anything that's a fucked-up shift

I'm going to have it

I told Jennifer

I go the first thing that we're going to do is we're going to get you some dogs I want any perspective burglars that are casing the neighborhood to see a couple of big ass dogs

I want the option to always be the neighbors 
I told Jennifer

I was like they're going to be big dogs

I'll pay the money to get like big dogs

I've seen those

I thought they're hard to train, though

I'm sure.

I've seen these dogs.

I have small hands,

I mean ... But, a paw that's bigger than my hand

I would even be ... um

I mean yeah...

I don't even want the thought

I don't care what people think

I got her a stun gun.

I got her pepper spray

I bought her a gun

I took

I told her

I was like that's all

I go if you want your CCW, you do all that

I already got you the big stuff, you can do all the little stuff if you want

I don't need to

I know friends of mine

I'm like no, there's just a liability

I'll wait 'til I'm sworn

I can carry it anywhere

I'm going to

I get a slap on the wrist or whatever

I think

I'll keep it for the safety

I mean,

I, I get it, you know?

I would

I know that

I wouldn't

I would look at it

I know right away,

I would stack the doors

I think your odds are better

I doubt it's going to go through

I doubt that the round that struck anybody is going to kill anybody

I don't give a fuck. 
I don't talk to anybody over there

I stay in contact with is uh couple of the Marines, you know, couple of the veterans

I've talked to a couple of times

I heard,

I don't know

I remember when all that was going on

I heard you talk about it

I doubt it

I don't remember him being very thrilled

I already have the first segments

I need to

I have module three on disc.

I started looking at it

I'm looking at it

I'm like

I can't

I can't read all this on a disc

I printed it out

I can read better or, learn better

I'm flipping it like a fucking book

I just cannot ...

I'm like fuck this. No

I can't do that

I'm going to fail the academy

I already talked a girl that had gone through.

I'm just like no

I'm just going to bring the, the printout

I don't,

I don't like learning like that

I need to touch it.

I know

I hated that

I took one online class

I withdrew from it

I said fuck this

I'm not ...

I don't do well with it.

I mean

I do to a certain degree

I am, too

I feel like the leadership

I feel like my leadership skills are more competent than the person who's in 
charge,

I have a really hard time with listening to their direction

I just have a problem with it

I started at $\mathrm{SG}$ for the parking enforcement

I mean, she might've wrote a ticket or two

I listened to her shit and

I'm like, so

I'm already ...

I already am gauging her

I know

I say the wrong thing, she's going to have my ass handed to me

I'll be out the front door

I did

I knew,

I realized what type of individual I was dealing with, just a very micromanage

type

I started

I started becoming really close with the, with the officers there

I made it my mission

I'm going to be cool with these guys

I'm going to go out of my way to make them know who I am

I don't like it

I feel like

I'm at a fucking desk job

I would talk to the cops

I could tell that they were really into whatever it was that they were doing

I would just, okay, all right

I'll see you out there, man

I'll see you out there

I got them talking and engaging with me

I was going to bug the fuck out of them until they, they got on my level, or

I got on theirs.

I made friends with a guy named Christian

I got that impression

I hear his name throughout the hallways

I really focused on

I catch him in the report-writing room, big, fucking bald headed, yolked-out guy

I've only been around a couple months.

I'm Tony. He's like, Christian, man. He shakes my hand and breaks it at the same time

I was like good man

I was like, ah, it's not what I wanted this and that 
I was probably twenty-four at the time

I was like

I told him, you know,

I was like

I was in the Marines. He was like oh, you were a Marine?

I was like yeah. He's all like how long.

I was like four years and it got into the ... and right away,

I felt like he looked at me not as a parking enforcement officer, but as a veteran.

And he really respected that right away and

I got that impression from him really quick

I'd hear it

I'm like what the fuck does he want?

I'm like yeah, go ahead. He's all, hey, 9-11, which means meet up

I'm just about to grab something to eat,

I'm like oh. And even if I ate,

I was going to eat with him

I wanted his, his attention

I wanted him to, to know who I was

I started telling him little things

I would,

I would

I wanted to see how he felt about Ellen

I'd never seen them interact together

I didn't want to be like oh, fuck Ellen, she's this, she's that and him be like she lives down the street from me

I did

I, I, I primed him a little bit.

I would let him know little things here and there

I would,

I would not favor it

I would tell him exactly how I felt

I never made a derogatory comment about her

I was able to gauge his reaction

I'm like who?

I don't, he's like fuck the chief.

I'm like wow!

I'm like so,

I'm not going to tell him that ...

I told him,

I was like, that'll be ... he's like dude, he knows.

I'm like you guys don't like each other at all?

I said, when you hear Christian' name running down the hallway, it's said with reverence. 
I think that's what the problem was

I met him, he was twenty-five years in.

I've known him for about five years, he just

I mean, this fucking guy did damn near everything in the department

I was already,

I was able to gauge Christian really well

I started doing

I'm like yeah, you know

I started just letting him know like little things here and there

I had my name in the department, like oh, don't fucking, don't do anything around

him, he'll fucking, he'll get you,

I realized where I stood.

I'm like okay, so the officers are backing me

I was,

I was the only, c- uh, uh, non-sworn officer invited

I was like oh, fuck dude.

I was the only one, out of all six of us

I felt special

I went over there

I had a good time

I hang out

I'm like fuck you guys, dude

I said okay.

I head out over there.

I've got this subsection right here for you. Go ahead and write it up

I was like okay,

I'd never written a ticket for that

I've ...

I didn't even know I could

I write it up.

I submit my cites at the end of the day

I come in and Irene has a letter.

I said okay

I clock in,

I call her up

I'll never forget it

I'm like oh, yeah,

I was like well

I didn't even know I could

I'm like ...

I, I just told her

I'm like look,

I don't know how else to put this to you, 
I go, he's a sworn police off

I go if he told me to jump on a fucking desk and do a little jig,

I'm going to do it.

I don't care if you tell me no and he tells me yes.

I will always go with whatever he says.

I go you should take it up with him

I knew she wasn't going to go to Christian, nobody goes to him

I knew

I did.

I went up to him right

I did,

I wanted Irene to know

I said whatever beat he was,

I was like hey.

I was like clear for 9-11

I met him,

I met up with him

I told him

I was there for about another year. She never, she never wrote me anything

I was fine with that.

I was like, you know what, you're just mad

I would have said all that shit to her

I would have been gone

I didn't say anything to her,

I said something to Christian and he said something to her

I'm like yeah

I could rub my badge in her fucking face

I don't even want to know what the fuck they're making.

I know,

I know she makes enough

I'm like that thing's going to bite you

I've already spent an hour just bullshiting

I tried

I mean

I got out of the Marines, I,

I put the Marine Corp in my rearview mirror

I tried to keep it there

I tried to keep the actual Marine Corp in my rearview mirror

I don't even know what's going to happen

I think

I think he's saved everyone since they got married, that's how many he has 
I'm not kidding

I'll take a picture

I'll send it to you

I've had conversations with him

I told him

I said

I'm going to start stealing these and throwing them away

I'm like technically, it's Mom's

I'm going to ask her

I don't know how else I felt

I'm no longer a Marine

I mean

I am ...

I will always be a Marine

I will always be a college student

I always have that

I'm not an active duty Marine now

I understand that once a Marine, always a Marine

I totally understand that

I'm right there with it

I'm also a realist,

I know that it's just a saying

I've got to explain it to you as, as best as I possibly can

I got out as a sergeant major, a fucking full bird colonel, general, whatever, every day, you're always going to be a Marine.

I have a bachelor's degree,

I also have my DD214, essentially, they're two pieces of paper

I was a part of the military,

I was a part of said institution for education

I think it, it's, it's more hope, it's more uh fairy dust, if you will

I'm proud of my service.

I will always be proud of my service... what I did, where I went and the, and the

shit that I saw, good or bad.

I will always be proud of it

I can say that not everybody has done

I think the Marines have turned it into a ... like a fairy dust.

I would love for it to be, and to some people it is w- ...

it is what you want it to be, in your head.

I've never told anybody

I was in the Marines.

I, I ... if they ask, 
I tell them

I'm not in the Army

I'll tell you,

I'm very proud of my service

I wasn't in the fucking Army

I have to correct them

I'm not going to go yeah. Fuck no. Or even if they said were you a soldier? Nope.

No,

I'll never, ever, ever, ever say that I was

I, I was a Marine.

I also don't go around telling people.

I knew he,

I knew right away he was a Marine

I knew that

I got a little bit more comfortable with him

I let a little excerpt out, a little blip of um some Marine Corp terminology on him

I was like

I was

I didn't,

I have long hair, I,

I have facial hair.

I wasn't,

I didn't brand myself,

I wasn't Kyle

I'll never let somebody disrespect the Marine Corp in front of me

I'm also not going to sit there and broadcast to the whole fucking world

I was a Marine

I have a sleeve tattoo

I have my chest tattooed, tattoos all over the place

I choose to wear a short-sleeved shirt for you to see my tattoos

I'm tattooed.

I choose to wear something Marine Corp related

I was in the Marines, that's up for me to do.

I'm not out there to broadcast it and put the damn flag over my head

I was in the Marines, suck it.

I'm bad,

I'm,

I'm this,

I'm ... no.

I'm just going through the motions like everybody else in life

I just chose to make certain decisions

I don't know where I'd be had I not gone in the Marine Corp and gone straight to 
school

I probably wouldn't have finished it.

I don't ...

I can't say

I wouldn't, but knowing myself back then,

I don't think I would have

I was

I was, you know

I was able to get out of high school

I was able to ditch class and make it back to my house around the time when the office would call

and leave that recording and

I was able to delete it

I would

I wasn't able to

I was like fuck it

I'm not going to 'cause

I didn't want to hear my mom bitch at me

I just did not have any ...

I didn't have a scholastic bone in my body

I did not want to do anything school related. High school, college, no.

I graduated high school

I graduated college, but that was never in my wheelhouse.

I mean, high school, yeah, you kind of ... you have to.

I did the bare minimum

I did enough to get me to the Marine Corp because my buddy was going in

I did the Marines

I got out

I thought

I'm going to be a cop and then shit hit the fan

I'm still waiting on that

I, I, I did f-

I did much better at East Forest than

I did in high school

I think

I only f-

I only failed one, two classes at East Forest

I withdraw from, withdrew from two, two

I don't think I ever got anything lower than a C

I wasn't a cheater in high school.

I wouldn't 'cause

I just didn't want to get caught.

I'm sure I could have got better grades, had I cheated.

I legitimately earned them 
I didn't do the work.

I did just enough to pass and those were the grades I earned.

I never cheated

I just didn't want to get caught doing it

I had to explain to my mom that I was cheating

I'd rather just pass with Ds and have my mom bitch at me for a little bit

I did graduate

I graduated with the grades I earned.

I earned those fucking Ds

I sell that I was a Marine

I didn't even like it either

I didn't,

I didn't like all the structure.

I didn't like the fucking Monday morning formation, Friday evening formation, uh field day, uh f- fire watch duty, deployments, uh patrols, going through houses, convoys.

I didn't like all that shit.

I hated waking up at fucking ...

I hated waking up when it was still dark, running for an hour and it's still dark.

I hated that.

I mean

I was in the best shape that I'll probably ever be in

I do run,

I run early in the morning or late at night

I don't have to worry about getting fucking blown out by some car

I usually will go in the morning

I am not a huge group ...

I mean, if

I find somebody that works out on my level, um and doesn't talk a whole lot, then fine

I just kind of like putting the headphones in and just kind of doing my own thing, zoning out

I mean there's a lot of things

I do miss about the Marines is the relationships that you build with people that like ... complete strangers, you know?

I feel like it makes their transition way more difficult.

I'm sure that in some way or another, the majority has respect for your service

I don't know about now

I got down, there wasn't this draw down.

I got out in '08.

I could have

I could have probably reenlisted 
I had the highest reenlistment code you can get

I don't see why they wouldn't have taken me back,

I'm,

I'm, it's h-, that's kind of t to say

I'm trying to say that they need to dumb themselves down

I think that a lot of Marines, they ... or service members

I think that's a misconception in their head

I was a fucking Marine

I don't give a fuck what it is

I hate that,

I hate the fact that, that, that happens, that Marines

I understand there's a sense of pride and all that, but pride, that's in you

I feel like that happens more often than it should

I was a Marine

I was a Marine

I didn't say it.

I didn't say it.

I didn't say it.

I spelled it.

I have to like write out what

I mean or did the $\mathrm{R}$...

I didn't know.

I mean,

I forgot that one

I did as a Marine

I always found super odd.

I did really well as a Marine.

I don't know why

I felt like,

I felt like Marines that stayed in the Marine Corp

I figured they're staying in the Marines

I, I, I don't know why, like

I felt like,

I felt like

I got all the privileges of a lifer.

I, I, as fucked up as my unit was, it's probably one of the best units you could get into

I deployed a lot, um which was a fucking uh nightmare

I hated it uh

I could make the Middle East disappear with my mind, I would

I can't even explain it

I mean, we could, but we're not 
I don't know what that means for the Middle East

I'm not ... the problem is

I could make that place disappear with my mind,

I would

I feel like when you're forcing it on somebody

I know you're going to hear a lot of Marines

I'm not saying you do, okay?

I think, generally,

I think the general mass population

I think that they respect

I think that a lot of people expect so much more than just a pat on the back

I knew why

I got in

I knew what I was getting myself into

I mean, like

I told you before, the Marine Corp was only chosen based on what my buddy went to

I followed my buddy

I swear to God, we could be talking about the Army right now

I went to the Marine Corp because him

I weighed some of my options

I never even talked to another recruiter

I was sold

I was like fuck it, four years

I get to do all this crazy shit, you know?

I've ever focused on was getting myself hired, that's it.

I, I know

I can be an asshole

I know that a lot of people, they ... it's not that they don't like what I have to say

I can usually draw facts from

I can't,

I usually won't say anything,

I'll be like you know,

I'm not really sure,

I don't like doing because I don't like not being sure of something

I am

I'll try to research it a little bit

I guess it's the way I say it

I don't care

I'm not pampering it enough

I'm not softening the blow 
I look at it is like ...

I, I've had Marines tell

I'm kind of like the poster child for civilian life

I was like a POG you know, from a person that was a [grunt 01:04:23

I don't give a fuck.

I don't care, you can say whatever you want about me

I know what I did, doesn't change where I know I've been shouldn't apply to you, I can only draw so many conclusions

I'm ... if somebody feels like I'm talking negatively about the troops

I was one and they, they get a little defensive

I'm saying, it's not because they know I'm right, per se

I'm not saying that I'm a hundred percent accurate,

I know that the strong majority has a big problem with this

I'm going through

I wish somebody would be like, hey

I heard you were a veteran

I want to,

I want to hook you up

I have to,

I can't sit there and say man, like, like does nobody give a fuck about veterans?

I find myself almost drawing that same conclusion

I can't,

I have to,

I ... that's where I have to separate the veteran part of me

I'm feeling like, am I looking for a handout?

I, I don't want to say that I am

I know I'm going to earn everything

I ...

I earned my time in the, the Marines

I did it.

I earned my stripes in the Marines

I have to look at,

I have to look at my civilian time now the same way

I did my service time. Nobody gave me shit when I was in

I expecting shit now?

I have to draw that line

I make those comments,

I'm not sure if they, if they've reached that conclusion

I think when you, when you hear all these media outlets

I've met people that, that don't give a shit that you were in and um they uh completely disagree with, you know why we're out there. 
I'm one of those veterans that wishes we were never sent over there

I uh,

I uh

I don't really care ... um,

I don't really care that they say it

I generally agree with

I have a problem with is, you can disagree with the war, but don't ever chastise the troops that were sent there, especially if you never wore the uniform.

I don't care what branch.

I don't care.

I don't give a fuck if he was a Marine, she was a Marine, whatever. U, I don't give a fuck if Air Force, whatever. If you never wore a uniform and sent your ass over there, you cannot chastise the troops for being there. You can chastise the government all you want.

I did. Fuck the government, they, they make stupid decisions all the time

I hear them talking shit about um Iraq and Afghanistan and stuff like that I'd be fine with it.

I'd be like yeah, you're right

I totally agree with you.

I a hundred, a hundred and ten percent agree with you

I have a big problem with it because now you're chastising the troops, what they're doing over there

I can speak for myself and my unit and units that I worked with out there.

I've never seen that happen, done purposely. Never, ever.

I've never, ever heard a grid coordinates called out where I knew that my unit had intelligence that there were innocent people there that were going to lose their lives

I knew for a fact that that was not the case. Did it happen? Absolutely, it does, but it is not the purpose.

I do start hearing them open their mouth about the troops. About the war, go ahead, yeah, the war's stupid, we shouldn't be out there. Chastise the war all you want.

I totally agree

I think it's completely asinine

I think it's so stupid the reason why we're out there

I go, come with me,

I'll take you with me. See how you like it, see how, see how it is really out there.

I hate that.

I hate when

I hear people chastise the troops. It's not the fucking troops' fault.

I can say without any certain shadow of a doubt that $99.999 \%$ t of the time that any innocent lives were lost (it's an accident) 
I haven't been out there in a long, long time

I was out there, that was pretty much how things were

I always, being a cop has always been and probably always will be my number one priority

I'm going to be thirty in May

I got to East Forest,

I was twenty-five years old, twenty-six

I think

I might have been twenty-six. Either way, whatever.

I didn't want to go a four year

I was looking for the path of least resistance with the shortest from A to B

I want. It had no- ... if fuck-, if fucking Cal State had a three-year program,

I would have went there.

I didn't c- ... fuck

I would have went there

I saw the commercial, it said bachelor's degree in criminal justice in three years.

I said fuck it,

I'm going. That literally was the, the, to thought process.

I saw commercial

I went to East Forest, that's about all it took.

I weighed my options

I said three years,

I'll be this amount,

I'll be this age

I mean

I get discounts at Home Depot

I mean

I really don't use them to be completely honest with you

I remember

I got out

I first got out

I didn't really know

I might even have the list somewhere

I uh, can't remember what I did with it

I think I've ...

I think the only place

I've ever used a military discount was at the Orange County Swap

I mean you have to ...

I had to turn mine in

I don't know how the $\mathrm{f}-\ldots$ Yeah,

I don't know

I was like twenty-two, twenty-three. 
I know ...

I think

I ...

I, I was at a gas station not too long ago

I was getting gas and uh,

I h-,

I had just put on my military plates on my truck

I was like yeah, Ooorah.

I knew 'cause he saw

I was like Marine? And he's like Army.

I was like what the fuck?

I'm like why you Ooorahing me then, you're totally off your game here

I was like nope, forget it

I was like go away, you're damaging to the rest of my life

I talk to you any more than I am right now because that'll be in a file somewhere and the police department will get wind of it and they'll find out that I have A, B and $\mathrm{C}$

I was like oh, okay, thank you

I'm pretty sure that before I left the parking lot, uh the pumps, his card went in the trash somewhere, so maybe a homeless vet found it and picked it out of the trash and contacted him, but this veteran will not be contacting him.

I said,

I think they're

I want to believe that they have respect and a sense of gratitude

I th-,

I think with how long we've been in Iraq and Afghanistan and Kuwait and all that area over there,

I think that now it's I- so many people know somebody

I think you; you know and those, you know and those individuals, those

neighbors, they, they watched that kid grow up

I think we're,

I think we're about ... yeah, about fourteen, about fourteen years now.

I think that uh, more so, now

I think that uh, uh that, that they've watched um these individuals who they

watched as a kid grow up and go and defend their country

I don't give a fuck what branch, but what, any branch.

I think that they all, you know a lot of people know somebody and they have that tie and that connection

I mean, we've been there, like I said fourteen years now

I didn't lose my life or anything

I went and ... for four years and had a few deployments and came back and tried to start my life

I feel like uh 
I feel like they w-, they want to be proud of us and that they are.

I feel like they really are

I don't know to what degree

I think everybody's uh level of gratitude varies

I take it for what it is.

I don't feel like they're ...

I don't ever want to say that they're doing it out of obligation because it's the politically correct thing to do

I uh ... Yeah,

I mean, you don't ha-, you really don't have to

I mean,

I know, that's nice of you to do that

I'm sure they wanted to anyways

I mean,

I can't speak for everybody.

I, I just can't

I see veterans all the time and I don't say anything to them

I don't

I told you, Kyle took forever to figure out I was a fucking Marine

I was fine with it.

I don't like people being in my shit, usually

I feel like your nose is too far in it

I'll reach out there and pull it out for you

I feel like you're too nosy for your own good, I'll express my concern and you'll

make your decision at that point if you want to keep going further. And

I'll make a decision based on your decision on what I'm going to do next.

I'm not in your fucking business, you're not in mine

I chit chat with you and text saying how's it going, what's new, I legitimately want

to know what's new

I'm not going to go, and fucking beg for it.

I don't care. You obviously don't want me to know.

I don't need to know that bad.

I was just trying to make small talk.

I- I, I'm like that, you know?

I tell people what I want to tell them and that's it.

I don't tell them anymore,

I don't tell them any less.

I feel comfortable with telling them is what they get.

I was friends with prior to the Marines

I left and I went to the Marines

I grew up with

I tried to uh, when I tried to make contact with them and stay in contact with them after I, while I was in or whatever (door opening) like ... hey, how are you?

I was different 
I've known him since we were ... oh, my God, um like thirteen

I'm really busy, you know, getting ready for the Academy

I'm not kidding, he makes like twenty-six grand a month

I'm not fucking around, he makes fucking money

I said, not every Marine ... ... uh shares the same views that

I do on certain things, so we just part way

I got out of the Marines

I was in, it was just, hey, you want to stay in for the rest of your life, stay in

I got out of the Marines; you were looked at like a fucking deserter

I hear.

I, I don't know,

I'm not sure,

I hear, yeah

I don't think there's a huge separation ...

I'm trying to remember my time in.

I can't,

I want to say that it was fairly the same.

I lived on base

I was a PFC

I think, at the time, I wasn't married

I didn't really have time to even try to figure out a way to get out of the barracks

I live fucking an hour away from here

I'll just suck it up during the week and then, come Friday,

I'll just go home and spend the weekend at the house

I was living on base during the week

I'd come stay the night at my house on um the weekends and ... or friends' houses

I didn't have a whole lot of time to figure that out

I uh,

I got ...

I got to go outside of base

I lived um within the driving radius

I told you before

I first checked into my unit...

I was like Marine number sixty-three. So, we were still working up to become a full-strength unit

I think,

I think by the time we left on my first deployment,

I think we were only like at a hundred and eleven

I think we needed a little over two hundred to be at full capacity for our

I was like ...

I asked what the mileage was, and you needed to be within seventy-six miles of driving.

I was at like seventy-two 
I was driving an hour, hour and a half to base and all that. They didn't care.

I didn't, I sure as hell didn't care

I ended up uh getting married uh after my second deployment. But we never, we never lived together...

I mean we stayed with each other, but we never had time

I had my next deployment and so, we never really had the time to uh get a place

I came back, so ... Yeah, yeah, we- we're still friends.

I mean on each other's Instagrams and stuff like that.

I feel ... I, honestly,

I want to say that the, the community dynamics were roughly the same

I can't,

I can't draw any examples to, to differentiate the two

I figure the, they had to have been very similar for me not be able to differentiate the two.

I wish

I could supply you with any good examples,

I just can't remember any

I don't have a trunk.

I have a bed.

I wouldn't tell him.

I would go to a

I would go ...,

I would go to a novelty store or a surplus store

I would, just because that probably meant a lot to him and whether ...

I mean,

I'm sure he wouldn't hold that against you

I actually uh, I,

I sold a lot of my stuff uh back to the Marine Corp.

I have to,

I have to get them from her

I have a few things of my own, too

I have uh,

I have a set of boots from uh my second deployment. Oh, they have more than dirt

I have an AT4... A rocket launcher

I have a few things. I,

I'll have to go through ...

I have a little case in the garage that has some of my shit in it

I don't know where the fuck she put all of it

I don't have any moto tattoos.

I actually was going to say that, if a department asked me about it

I actually was going to say

I was in the service, so it was a patriotic piece 
I never actually got an eagle or anchor or Semper Fidelis or anything Marine Corp related

I just,

I just didn't want it

I just didn't want a moto tat

I just ... Maybe at some point in my life

I might

I could get any ...

I could get bulldog,

I could get something that would depict a Marine ...

I just said it, 'cause of the eagle with the cross flag, very patriotic looking

I'd be like well,

I was in the service, so you know, it's, it's 'Merica.

I don't know.

I got it 'cause I liked it

I liked it. That's the meaning behind it.

I don't have any Japanese in my family, and I have a full Japanese sleeve

I like them. That's it.

I've never been like well, it connects to me spiritually and ... no, fuck all that.

I liked it

I'm pretty good at reading and following instructions

I can't imagine the person in the wheelchair just being like okay, cool, you left me where I'm safe.

I'm looking at it as a number's thing

I, I, I want to say

I can see where their train of thought was. You're essentially leaving one life ...

I'd feel responsible for that person's life at that point... If him and I or her and I

both get shot,

I, at least I was doing what I felt ...

I was doing the right thing

I reckon it's

I couldn't,

I don't give a fuck, even if they were telling me not to, no.

I'll be,

I'll be all right.

I can write it.

I'm not familiar with that

I am, maybe

I've never heard it

I'm not stupid.

I follow,

I follow political issues as best as I can without it boring me too, too much

I read that statistic, 
I was like, there's something not right with that

I don't know, because they know that it's a money thing and it's, they're using military as a gambling service and an extortion and bullying program

I can't remember any other time where it worked out in their favor without them just being utterly cooperative.

I mean, not everybody died, but there was a strong majority that di- didn't walk away from certain incidents um, and that's just what the Marines do I never know what to do with any of the information we get, I want to say, it's probably like over f- three hundred high ranking congressional members, whether it be the House of Representatives or actual Congress. Uh, and only one of their blood relatives is a reserve officer,

I believe in the Air Force, um there's something not right with that.

I don't care, uh, okay.

I'm pretty sure

I, I've got to see the good in it, too.

I can't just sit there and be like that doesn't make any sense, there has to be something

I'm not really sure, you know

I didn't really look too much into it because, to be honest with you, the military is really big and it's very expensive.

I'm sure they have their own set of firearms

I ... uh, man,

I ... it's hard for me to answer that because

I've,

I've seriously thought about maybe trying my hands at, at politics one day

I mean, you know the scariest thing is not how much they lie to you.

I'm really wondering if I

I really dug into things

I really got a lot of information

I really started giving truth out to the American people

I wonder if that would scare them more than like if ...

I don't think they would either.

I don't think they want to

I strongly believe that Bernie Sanders would be the best bet for the next president of the United States

I don't give a fuck if he's a socialist.

I listen to what he says.

I listen to what he says

I listen to where he's coming from and he makes sense to me

I tell everybody

I'll show you what he, he wrote me and it, it pissed me off.

I don't give a fuck. 
I posted this, okay?

I'll read this to you.

I don't even know if I can call it an answer ...

I wrote my own little synopsis to it

I commented on my own picture.

I said, "ladies and gentlemen, please, please, please do not let this individual

(Trump) become the next president of the United States.

I generally do not get involved with politics, however this individual is not what America needs, so please do your homework on all the candidates and make a sound, responsible decision."

I never told anybody who to vote for.

I just, you know, put it out there, like do your own homework.

I know who I'm voting for. I didn't support Obama,

I didn't vote for him either time.

I didn't vote for anybody either time.

I told Brandon that

I told Brandon

I kept telling Brandon,

I'm like you can scream all you want Republican Party

I'm like uh, watch

I'm like you watch.

I go I, I'm doing the homework, bro.

I think you just think you know

I said support, no.,

I absolutely knew he was going to win a second term nomination

I said, don't get me wrong, there were a few issues that I support and could get behind with the Obama administration,

I think that could be said about any president that's in office.

I would have got

I totally agree with you about politicians lying all the time.

I would be fine with anybody, but Trump.

I strongly believe that Bernie Sanders would do this country some good.

I honestly believe for, he's for the people.

I'm going based off his track records and he has a rather impressive one

I think it is and

I get some of his points, I,

I ...

I feel like he,

I feel like if he wasn't such an extremist that his points of view might be, that some of them might be founded I'll do a ...

I'll,

I'll tell you like this

I didn't,

I ne-,

I would have never thought about it 
I'm like,

I told Brandon,

I was like don't, don't talk to me about politics, bro...

I go if it was so legitimate, dude, people would know about it.

I have to go, every time he tells me some fucking ... regurgitates some shit to me, I have to go on infowars just to know what he's talking about

I know that's where he gets his information from. It's never founded. I told him, I was like why don't you just do your own homework?

I tried to explain to him, you know,

I tried telling him,

I'm like look man, you've got to

I'm pretty sure that her

I can't tell. It's just kind of ...

I think the wings,

I think those wings 'cause, we have different sets of wings for our jump-school

I do it all the time.

I have plenty of fucking shit I need to read

I want to stay local

I would look at

I'd,

I'd rather,

I was going to apply to any state, it'd be the Highway Patrol

I guess for me. Maybe, like sixty-mile radius. It would be like driving to Camp

Pendleton all over again.

I'm looking at

I could get in the FBI and you know go to Academy in Virginia and they send me to fucking Jersey or something. Nope.

I'm not an East Coast individual.

I don't like the accents,

I don't like, no.

I, I don't like any of that.

I don't like any of their shit over there. East Coast can have all their, their

buildings and high rises and stuff.

I like grass.

I don't like the Atlantic Ocean.

I don't know why.

I just for some reason ...

I guess ...,

I guess because uh

I ... and I'm only just fishing here, for uh, for any reason, but my only reason why I can think of that

I don't like it is because when you fly to Iraq and Afghanistan, you fly over the Atlantic. 
So just the fact that that's the only time I've ever experienced that ocean was flying over it to a place

I absolutely hated

I just want to stay away from that area

I mean, we did training

I never, never.

I've never been ...

I never been on any base outside of Camp Pendleton other than my deployments for any longer than two weeks to a month.

I've never really spent any significant amount of time ... we went to, let's see ... Iraq, Afghanistan, Kuwait, Germany, Ireland, uh ... Florida, Maine, Texas, Arizona, California ...

I think that's it.

I think that's it, I can't remember. That's a ... that seems like a lot, but ... Yeah, I feel like I went more places.

I think one time we were snowed out for like three weeks

I guess you could say and uh we stayed close to the flight line and waited

I mean, we were, we only had our uniforms and we had to stay like ... we couldn't, we couldn't go very, very far

I liked it over there.

I'll never forget

I had a, a bratwurst um dog, with a bun

I mean all their stuff on it

I've had the ... like, you know, my uncles and you know people, my relatives have uh made them here before. It is nothing like having it from Germany.

I don't give a fuck what you do to it here. It would never taste the way it does over there. And that's the same ... but in a good way, it was much better there than it was here.

I've had curry here 'cause my dad likes it.

I don't really like it.

I've never really liked it when I was here um,

I had it here, prior to having it out over there, um, it is much saltier and um like fattier here,

I had a vegetable one over there. Um because over there, they only have lamb, you can't have cow and stuff like that

I just, j-

I just don't like the soup part of it.

I'm like how is this grisly? Why is this gross and you had to like choke it down because you know you're in somebody's home and you're trying not to be disrespectful.

I'm going to have diarrhea for sure because of this. 
I'm like how much longer are we going to be here?

I'd eat shit like that that would fuck my stomach up

I'm thinking of is how the fuck can I get back?

I need to call Quick Reaction Force, get me out of here. QRF, man down!

I never really took a lot of things serious, though.

I would always joke about everything and ...

I can't even tell you how many times they told me to shut up

I didn't finish what I was saying

I guess I'm done talking. When can I talk again. Well, when we say. When you go on another team, you can talk.

\section{Third Listening: Voices}

In the World: Not Army; Marine; Frustrated Vet; Son; East Forrest College Student

Within: Disappointed with Self; Want to be cop

\section{Fourth Listening: Politics \& Power}

Political: Power can be in the position or in power, like Christian at San Gabriel; Got to know that other cops at the Police Department, deal with the BS to get ahead; Get a PTSD diagnosis it equates to no job; Marines are bullies for politicians

Social: Most people know a Veteran somewhere; In high school did the minimum to pass; Meet people in the Corps that are similar, but you would never engage with them otherwise (as civilians); too honest or curt with civilians

Cultural: Enforces or unenforced laws; Marines experience is not as valuable as civilians experience to civilians; Never kill innocents on purpose; Don't leave someone behind that you could help

Economic: Online learning at East Forrest was cheaper; Best friend makes really good money; Military is used by politicians for extortion 


\section{Individual Meeting \#3, 11/9/15}

This meeting was unrecorded. This is a summary of the Field Notes taken after the meeting.

The academy was worse than Black Friday and he was not physically prepared. He had underestimated what would happen, particularly for upper body strength. Since he was unsponsored, thus he would be suffering without pay or guarantee of a job for six months, he quit. But all of his friends \& Jennifer couldn't understand how he couldn't survive. "If one more person says I'm a Marine, so I'm impenetrable, I'm gonna pull their fucking teeth out." He felt good about his decision to quit and was disappointed with the fact that he was physically unprepared.

The first day was not a PT (physical training) day, but they still did LOTS of physical activities, all in a suit. He commented that it hurt to bend the bill of his baseball cap because his palms were so sore, and bruised, from the push-ups, planks, and mountain climbers. And his abs were sore for a few days. Jennifer wondered what people would think about it, but Beaver didn't care. He is who he is, "fuck what other people think."

He wanted to become a police officer because of his grandma. They used to watch Cops together, and she said he would make a good police officer. It stuck! "She was the coolest, meanest, most awesome bitch" and she loved her grandkids, but hated everyone else. He was a total Grandma's boy, and if she was still alive, he would be over there every weekend, just to hang out.

He joined the Marines because of his buddy, Harper. He knew that Cops only needed a high school diploma, but a BA and military experience were a huge benefit. So, after Harper met with the recruiter, Beaver saw the recruiter as well. And he convinced Brandon to join as well. It was four years for active service, six for reserve, so he went 
active. Harper went reserve, and they lost touch.

\section{Individual Meeting \#4, 11/23/15}

\section{First Listening: Plot}

Recurring words/themes: Academy; Degree matters; 9/11 Conspiracy; Trump; Pissed v offended; War "wounds"; Some folks abuse benefits and get rated for unnecessary “disabilities"; Organized - OCD; Doesn’t care about religion

Plot: The Academy was worse than Black Friday, and with no guarantee for a job because of no sponsor, Beaver was not going to stay. He did however, get to spend one day at the Police Academy where he shared that the most important thing, in his mind, to do for an effective police force is to educate police officers beyond just the knowledge of the law. After leaving the Academy, Beaver began to ask his friend if they knew of any job opportunities, just so he could pay the bills. He was still searching, and he needed something as his savings account was running low. His friend, Ballarina suggested he go to the VA and get rated for PTSD, for the money. Beaver didn't think he had PTSD, and certainly did not want the label as he was trying to be a police officer. $\mathrm{He}$ had the occasional dream about something that happened in Iraq, but it never woke him up. Occasionally his hand will go numb, but nothing he felt was worth a trip to the VA. The one issue he did have was his hearing. He heard a high pitch ringing all of the time. "My hearing is supposed to be right up here at the top and almost all of it is, except for one section of it. And as soon as they throw the ... the pitch into that, that low ... or high frequency, um, uh, decibels, my hearing drops completely. And it shouldn't. It should be right 
there at the top. So essentially what it is, is I have normal hearing for my age, all the way up until you get to, I think she said like 5 or 6,000 , uh, uh, Hertz or decibels or whatever it was and it drops.... So, the problem is that I have normal, normal, normal (raises hand) and then drops off totally. I don't hear shit at a certain Hertz or whatever she said it was. Now, because I'm ... I'm missing a complete section of hearing, my brain, it's filling in that ... that ... that frequency that I'm not hearing. So, it's ... it's putting a sound there for me. It's like beep, so I can hear it ... It just happens to be the most God-awful annoying, beeping ... beeeeep sound." But he was not going to let the VA anywhere near his brain to try to fix that issue. Beaver was still with Jennifer, and while he loved he, he sometimes got annoyed with how she dealt with her family (and how he family dealt with each other). Courtney's Mom often got into her Dad's business, and they were divorced. They would say negative things about her Dad's girlfriend, things that were offensive to Beaver's mother (yet they did not acknowledge that). They would be upset with her Dad and his girlfriend but forgive her brother of any and all wrongdoing. And it often frustrated Beaver. This was particularly true when his friend, Derek, was helping process some financial paperwork for them and they started badmouthing Derek. That did not sit well with Beaver at all. At this time the concern for Syrian refugees coming into the US was all over the media. Beaver thought it a threat was going to occur, the people who would make it happen would already he in the USA, scouting possible locations. That the grunt soldiers were already here. 
Key Characters: Ballarina; Best Friend; Jennifer; Jennifer's Mom; Jennifer's Mom's

Boyfriend; Jennifer's Brother; Jennifer's Dad.

Briefly Mentioned: Jennifer's Dad's Girlfriend; Professor; Muslims or Middle

Easterners; Trump; Syrian refugees

Summary: He still wanted to become a police officer, yet that dream was becoming harder and harder to make a reality. As such, he was getting frustrated with the process. He began to look for any sort of job yet was still having difficulty. One of his Marine buddies told him to go get rated for PTSD for the money, which was not Beaver. He may have had a claim for his hearing but wasn't pursing that either. So, he kept himself busy job hunting and dealing with his girlfriend's family drama; hoping he would be able to be a police officer someday!

\section{Second Listening: I Poem}

I don't give a fuck who you are

I explained to him

I'm like, "You remember Black Friday?",

I was like, just as bad, if not worse

I'd still be there

I was going to be able to do that shit for six months

I was, if I was sworn and hired

I was telling ...

I was telling, uh, uh, them that

I guarantee you the people's shit that they were ripping up

I would have had a problem with that.

I had ...

I don't know what I would have said or done

I don't know

I'm like educate your cops.

I think cops need to be a little more educated

I said, "knowledge,"

I use that loosely.

I ... I think it ... it is the general statement for knowledge of the law, ethics, uh, 
knowing your people that you work with in the city, your business people, your residents. Know everything.

I texted my buddy

I asked him,

I'm like, "What the fuck are doing?"

I said, all right.

I put my application in with...

I want to work.

I mean, obviously

I mean, there will be some things where I draw the line

I'll say no

I mean,

I don't know.

I ... I wish security paid more.

I wish security didn't start at like 11 dollars an hour.

I don't ... if you're making 11 dollars as a security guard,

I guarantee you're not a full-time security guard.

I don't want to take anything that's part-time.

I just don't.

I hate this

I ... right now

I find myself relying on like people

I'm calling people

I'm telling you right now

I'm a little bit more,

I won't say aggressive, but, uh, straightforward,

I guess

I don't think that a lot of people like

I think people just don't like hearing how it comes

I think most people that meet me, need to get a better understanding of me before they figure out whether they like me/like me.

I want to say

I can't think of anything

I visited with him and he's just trying desperately to convince me to go to the VA and get rated

I don't think so

I ... I do know

I, um,

I do have characteristics of it

I know that most people with PTSD have

I don't ... 
I don't know

I have a bad sleeping pattern

I just know that it takes me fucking forever to fall asleep

I ...

I wish I could be like ...

I wish I could do that.

I can't ...

I can be like; I'm going to fall asleep in the next four hours

I'm still awake

I have the exact opposite of that

I cannot get myself to fall asleep

I've taken ...

I have taken almost every over the counter, uh, sleep aid that you can get.

I've even like mixed them

I've taken uh, like ZzzQuil and fucking, uh, Unisom together

I've tried little combos and little cocktails.

I wish I could

I'll be watching TV

I'll go into like a little daze

I don't remember what I was watching.

I'm like oh, what the fuck is this?

I guess ... like my eyes were open

I know I was watching TV

I just don't remember what it was

I just start like wandering

I might remember two dreams a year

I can never remember if I even dream or not

I am asleep,

I am out

I don't even ...

I have dreams of being deployed and stuff

I won't call them nightmares

I'll have dreams of like ...

I even have dreams of like, uh, a scenario, and then the outcome was different than what actually happened.

I have them, very, very

I mean,

I very rarely remember these dreams

I know.

I'm never going to do this 
I told them,

I go, do you understand, like I ...

I cannot

I can understand where you're going with that

I'm aspiring

I'll never have to worry about needing 1,200 bucks extra a month

I'm going to

I hope to have

I won't need it

I mean.

I understand, every little bit he can get, hey, go ahead

I guess

I'm like, do you realize that he doesn't deploy

I told him,

I don't know

I can think of my ear and then occasionally like my neck

I've had that forever

I get ...

I get a stiff neck all the fucking time. Like at least once or twice a week

I used to think it was because of the way I slept

I sleep on the same shit.

I've ...

I've even changed pillows and stuff.

I don't know

I do know though that occasionally if I'm on my phone, my hand will go numb.

I have no idea why, it just does.

I have to like shake my arm out and stuff. It is my thumb and these two

I'll feel it

I have to like let go

I'm typing

I have to switch hands

I'm not a leftie

I'm like, how stupid.

I could

I can't imagine what mine's going to be like

I bet

I don't know if she was necessarily referencing the PTSD thing

I could understand that, but

I ...

I feel like this ...

I told him,

I go, you've ... you've never gone through a background investigation. 
I go, if they want to know something, they're going fucking find out about it.

I go, and what's worse, is that they ... so say they asked me

I interview with somebody

I've already gone through the process

I'm going through for hearing, a nerve, whatever, all sorts of little issues that they're finding out about

I say no, because you know, I'm under the impression that it's sealed

I deliberately lied to them

I'm having problems getting hired now

I'm telling nothing but the truth

I'm going to have a problem again

I would love to see what would happen with my ears

I can legitimately

I know for a fact

I've had ...

I know

Ilied, yeah

I know that that is exactly the problem.

I know that ...

I know it is a Marine Corps-related thing

I ... even though

I doctored up the damn things

I shouldn't have, but they were going to keep me

I know that that is a Marine Corps-related incident, without a doubt

I ... I have good odds with that

I am little curious about that

I just ...

I just don't want that ... that label on me right now

I'm hired and stuff

I'll go look into it

I'm already hired

I'll wait until my operation and stuff

I don't ...

I don't care

I know the hearing aids don't do shit

I didn't have ringing ... I hear when I wake up and it's the last thing I hear before

I go to sleep, all ... all the time. Eeehhhhh. All day. Primarily in my left ear. All

the time.

I know is that one of my fucking hearing ... my ear plugs came out.

I'm pretty sure it is the left

I ...

I remember when it happened, (Laughing)

I remember like eek ... eek ... 
I froze. (Laughing).

I couldn't even move.

I remember

I shivered so hard (Laughing) oh, man, that's funny.

I remember

I shivered so hard and, uh, you have your Kevlar on

I remember since my fucking, uh, earplug came out

I was sitting there like trying to plug it with my fucking ... because you're trying to crawl

I had my shoulder ...

I was like, what the fuck happened

I'll never forget that

I thought

I was ...

I ...

I almost cried.

I remember it being so painful

I ... it went off like two or three times

I put it in, it ....

I prefer the ... the ... the ... Right.

I snap or whistle or click,

I get an echo.

I ...

I told her about that.

I told her that, uh, that if I was clicking or whistling or stamping or anything, that I was getting an, uh, echo.

I wore them for a day, two days maybe, and that was it.

I'm like no.

I can't ...

I couldn't take it.

I feel like ...

I feel like the ones that they showed me were relatively large.

I don't like it.

I do not like the fact that, uh, the ringing will never stop.

I don't know if I explained this to you

I have normal hearing for my age, all the way up until you get to,

I think she said like 5 or 6,000 , uh, uh, Hertz or decibels or whatever

I have normal, normal, normal and then drops off totally.

I don't hear shit at a certain, uh, uh, for, uh, Hertz or

I'm ...

I'm missing a complete section of hearing, my brain ... ... it's fill ... it's filling in that ... that ... that frequency that I'm not hearing.

I can hear it.

I wish it wouldn't.

I don't need to hear a squeak all day 
I'd rather them not, uh, go anywhere near my goddamn brain. No, especially the fucking VA

I don't want to go to some like, uh, world famous neurosurgeon or something. I would rather have Dr. V. mess with my brain, than to have these fucking idiots do it.

I don't care. He really knows a lot about the brain, though.

I only have a Bachelor's, okay?

I had it right on the top of my ... right on the tip of my tongue

I remember bits and pieces, but not enough to tell you where ...

I know that my fucking brain is filling a hearing issue, with the squeaking noise.

I stopped the hear ... the ... the ringing. The problem is ... It sounds like I'm under water

I get a stupid echo

I don't have ... my ... my whole hearing isn't messed up

I can't talk to you. You don't take anything seriously

I first put them in,

I go, is this supposed to sound like muffly

I don't want anybody walking up to me, signing,

I don't ...

I won't do that

I ...

I know that it makes me sound super shallow and all that,

I don't care.

I ... sometimes I forget about it

I'll be like, oh, I haven't that ring ...

I'll be like, oh, it's gone.

I was doing something else and it was distracting me from

I'll get excited for a split second

I haven't heard it in like an hour or two hours

I say something, it comes right back.

I don't hear ...

I get excited

I think about it, and as soon as it comes to my head, it's right back there

I do, it's not nearly as bad as it is on the left sideI feel like it comes and goes

I'll be laying in bed watching TV,

I feel like I'm completely deaf.

I can ... it just ... like

I don't hear anything

I hear is beeeep in both ears

I sit there

I'm like ...

I start like, uh, put my palms around my ears,

I close them

I try like sucking ... like creating ... 
I look stupid when I do that, but ... It's all right.

I'm not saying that they're not all refugees.

I'm sure the vast majority of them are

I ...

I smoke hookah a lot

I was smoking right before I got here

I completely forgot about today

I was like ...

I thought when you texted me,

I'm like, oh, fuck, because we normally meet like 11 .

I'm like, how fucking long has she been there?

I'm like,

I'm like fuck

I like was wrapping everything up

I called you

I'm like, oh, I...

I know

I'm going to be late

I'm ...

I'm enroute now.

I completely ...

I was like ...

I sat there

I was like, fuck

I felt so bad.

I was like, goddamn it,

I hope not. Um, so yeah,

I think

I was only like 15 minutes late.

I ...

I smoke those all the times

I used to go to hookah bars on the regular

I had a lot of people

I met there

I, stuff like that

I didn't have a problem with it

I'm like, you know, if ... if

I've deployed

I've dealt with those individuals in one fashion or another,

I can come back and hang out with them if I want to. Muslim or not. Uh, fucking Iraqi or not. Afghani or not. It doesn't matter. To me, if they're here in America, and they're cool with me, I'm cool with them. 
I am a little split on the, uh, refugee

I ... I do have a feeling that we are going to have another issue, uh, similar to Paris.

I know that for a fact they are.

I ... I know it. Um,

I think they've been here long before the refugees started coming,

I think the refugees are just their soldiers, in a sense, some of them

I don't think that they came here ...

I mean, I ...

I feel that they've been here before, um, uh, refugees started coming over here.

I happened to be one of them. Uh, to go and survey the areas in which we were going to be conducting and operating missions

I feel like that's what they've already done

I did when we went over there

I think

I think it is already happening here.

I think that we've already had or have had, uh, ISIS militant here and ...

Surveying.

I'm not ...

I mean, like my buddy, he flew out ...

I dropped him off and he was all nervous

I go, you know,

I don't think it's going to happen that soon

I go,

I don't ... Obama hasn't stopped letting them in yet.

I think it'll happen once they've done, because they want to ...

I ... my ... my guess on the matter is if ... if they're going to do, uh, an on-land

attack, like here on our soil, they're going to want to get the bang for the buck.

I think they're going to take every opportunity to get it right

I don't think they're going to do it until we close off

I think ...

I think every year

I think the U.S., uh, had already allowed, um, up to 1,200 refugees a year for ...

I would.

I would wait

I don't think it's going to happen within this year, give it a couple of years

I think we'll have something

I didn't even think about this, too, is that, um, we created the Taliban

I don't give a fuck if you're Al-Qaeda, the Taliban, ISIS, ISIL, whatever you want

to call them, they're all the same fucking thing

I don't think I'm the right guy for the job

I don't know.

I think that the first thing I would do

I would limit the terms on, uh, on the House, the Senate. 
I mean,

I love the kid to death,

I did all my deployments with him and trained with him

I met him when I got to the fleet

I ... when I heard him

I ... because he ... he said something like, he was very anti-Hillary

I don't want to say that I'm anti-Hillary.

I don't think that she'd make a great POTUS,

I said, yeah, you know, I'm not really a Hillary supporter either.

I go, but I ... I go, to be honest with you,

I don't care who you fucking vote for.

I go, just don't let it be Trump.

I'm like, really?

I'm sitting there

I'm like, he doesn't say anything

I mean,

I go, I go, he doesn't fucking say anything of merit

I told him

I was like ...

I go your Trump isn't going to win.

I go

I'm not ...

I'm not a huge political individual.

I go, but he's not going to win.

I ... I go he may win the, uh, Republican side, he might win that.

I go, I can see that happening. But he will not be the next President of the United

States. No. Not going to happen.

I think people ...

I think we live in a ... the reality TV, uh, era.

I think people are ... are more ...

I think people are really just entertained with Trump right now.

I ... Kevin Hart entertains me.

I think he's the funniest guy around. But would he ... would he make a good president? Absolutely not.

I don't think that's going to change.

I think he's going to ...

I think he's just going to deflect

I think he's just going to put down whoever the Democratic side is, without actually giving any facts.

I'm thinking about it

I don't want to get involved with that

I $\ldots$

I don't know, for me, 
I really, really, really got into it,

I ... if ... if like say you had a debate

I know somebody is deliberately lying

I have the facts to prove it

I know that they're just going around deliberately lying

I'm going to have a huge fucking problem with it

I'm afraid that they ... there wouldn't be civil debate

I wouldn't ...

I can't ...

I couldn't do that

I have a huge fucking ...

I have a huge problem with it now

I'm not sitting there listening to it all day,

I feel like if

I were a part of that, like

I ... I don't know how

I ... I don't want to say

I have a short temper ... temper, but I have a short temper

I think that would bother me a lot.

I can't remember his name,

I ...

I've ...

I used to want,

I used to want Chris Christie, uh, to be the next president.

I thought ...

I ...

I'm ...

I had ...

I don't ...

I never ...

I'm independent.

I'm not for or against Republicans.

I'm not for or against Democrats.

I guess if I had to swing to one side,

I guess I would go there, but

I really like to draw it right down the middle

I listen to everybody's shit and ... and pretend that maybe 10 percent of it is factual,

I'll look at that ...

I think would be the best candidate, you know. And

I used to think that Chris Christie would be

I felt like he was such a straight shooter.

I'd watch him in ... in town hall debates, um, and he would just tell the fucking residents, like hey, I'm taking a pay cut. You're fucking taking a pay cut.

I ... I'm paying more and your taxes 
I'm not just doing this to you guys and

I'm sitting up in my Eiffel Tower kind of thing.

I'm doing the same shit.

I'm, uh, cutting the fucking school board money.

I'm cutting the police money.

I'm cutting fire, education, all that. He cut everybody's shit, to include his own.

I don't give a fuck if you're happy about it or not. You have to understand things have to be done in order for shit to work.

I like that, because he didn't let people bully him

I'm never going to get re-elected

I think in the ... in the long run

I think that after people were done being pissed off and they realized, hey, like things seem to be getting a little better here.

I think they realized that

I like that. And then that stupid bridge scandal went down.

I'm pretty sure he should have everything that would incriminate him out of his

office by now

I ...

I have ...

I cannot,

I mean, dude, these ... these people have been working with him for years.

I'm not buying it.

I ...

I think you had everything going until you got mad.

I think you got upset

I think you probably got yourself a little

I like it when it gets really watery

I'll wait for it

I'll just sit there, and I'll just do this to get it to go all watery

I wouldn't drink it fast anyways.

I wouldn't even drink it fast, even if it came already watery.

I'll tell you, it ... it doesn't bother me at al

I do this sometimes,

I don't know why

I don't know why

I do that.

I do that from time to time

I've been busy

I will, though, I promise you

I ...I can find things easily. This is definitely a military, uh, a result of the military

I used to, uh,

I used to actually ...

I won't want to say get in trouble, but my mom would not necessarily be thrilled 
with the way my bedroom looked

I didn't like anything out of place

I didn't like the way ...

I'll tell you how bad it is

I threw dirty clothes in my little basket, my little hamper, and it ... like if it's a

shirt and it dangles over the rim

I have to put it all the way in

I have to go and physically put it in there

I'll try to ignore it

I'm in a hurry, I'll just toss it real quick

I'm like oohhh (Laughing) and have to go and put it in there

I just like having shit clean and organized

I don't think that's a bad thing.

I can understand if I have OCD about

I can't think of a bad OCD right now

I guess

I always tell her,

I'm like, you know,

I don't know how bad your eyes are

I'm like, what's wrong with you?

I can understand like that's a bad one and it bothers me that she does that.

I'm like you know what, it's not my house. Let her fucking do her thing

I walk upstairs and that's it

I could understand.

I could see that one being a ... a ... annoying and obnoxious.

I have to. She'll grab her keys from her thing and start clicking it

I have to look out my window to see if it lights up

I'm like, yup, she's okay.

I'm like, don't you know whether or not you locked your car when you get here?

I have a gun at the house

I am asleep, that's usually it. Um, but it does take me forever

I hate that.

I hate that it takes me forever.

I would rather be able to fall asleep fast and be a light sleeper, than to take forever and fall asleep and be a heavy sleeper

I don't like it.

I'm trying to think what else

I mean,

I don't want to ...

I don't want to burst your bubble, but you're scratching a cinder block wall, not just a bubble.

I mean, realistically, as far as America is concerned, the only ... the only good thing we do, uh, outside of war, outside of, you know, handling business out 
there, is Toys for Tots.

I don't know what the fuck you call it

I think what happens is, okay, so ... so Obama and his, uh, Cabinet members have been pushing ... pushing tremendously hard, to get, uh, businesses to hire more and more veterans

I guess. It's terribly hard, terribly hard

I don't know ...

I'm not sure if,

I'm not sure if ...

I mean,

I $\ldots$

I don't know ...

I don't know that many veterans that get offended very easily.

I think where we ...

I think one of our big ones is when it's, uh, a disrespect to the service.

I think that's one of the big ones that we have a huge problem with.

I mean, some ... some, uh, veterans ... they have a ... a very deep and surreal love for the commander in chief, which would be the President.

I mean ... Sometimes it's both. Because as ... as a Marine, you're taught that you don't always have to respect the person, but you have to always respect that person's rank.

I know ...

I didn't agree with whatever Bush did when I was in the Marine Corps. But he was the President of the United States, and we're his ... we are the President's Marines.

I feel like so many veterans don't really take offense to much because of we've dealt with some of the worst environments, the worst situations. And you make light of it as best as you can

I get mad about a lot of things, too.

I get ...

I got mad at ... on the way over

I was boogying to get over here, because I already knew I was going to be late.

I was going to ...

I was going to, you know,

I just continue driving.

I was thinking about doing was, uh, much worse.,

I wanted to, but, uh, you know, you ... being pissed off and offended is two different things.

I ... I'm not kidding you and

I almost deleted my Instagram

I actually prefer Coffee Bean over Starbucks.

I'm ...

I'm actually thinking about it now

I wouldn't ... 
I very rarely do

I tiptoe around them to talk

I've already told my mom

I think if they come over and do that shit

I'm going to lose my mind

I ... I ... I ... I ...

I told my mom,

I said, if they come around and do that shit

I might have some stories, too

I think that it's only fair that if they get to tell their stories, their fictional stories,

I get to tell factual stories and see which ones are worse.

I think

I might omit certain things and leave out certain things for my mom's sake. But, uh, just so she doesn't have to sit there and like think, oh, my God.

I know she already thinks it

I don't want to know

I don't think she wants to know it

I don't know,

I think ... or you know,

I'll just pull out the laptop, show them some pictures

I think that I'll do that

I drove one ...

I drove by one the other day.

I thought about going in and

I realized that I'm not insane.

I have a cross on mine, too.

I believe in God

I'm not a religious ...

I would say the same thing.

I honesty just like I ... I feel about politics,

I'm ... I'm divided.

I do the same thing with religion.

I am ...

I don't believe that I need to spend every week in a house of worship, to be a good individual.

I'm honest.

I treat people fair

I don't go out of my way to hurt anybody

I feel like I already do that on my own.

I don't need a, uh ...

I did ...

I laugh,

I also agreed with what he said ...

I just ... 
I couldn't believe how, um, accurate it was.

I would be the one to touch ... just when ... when somebody puts their plate down at ... at a restaurant, well, be careful, it's hot.

I do it.

I'm 30 and I do it.

I still do it.

I still do it. Why?

I don't know.

I'm stupid.

I do shit like that.

I don't believe how ... maybe my ... my heat tolerance is higher than theirs.

I no longer have fingertips ... fingerprints on my hand.

I thought it was really funny I ...

I have a huge ... Okay. So, scientists, um, uh, strong majority of them, who are ... right now a scientist, have been able to disprove and discredit certain aspects of the Bible

I ... if I believe something and somebody disproved it in hand, I have no choice.

I would be like, fuck,

I never would have guessed.

I'm going with what is factual.

I'm not going to go ... just because it goes against my belief, I'm not going to sit there

I'm not that naïve and stubborn,

I've believed this for the last 10 years

I believe,

I'm not going to believe it

I don't want to

I ... yes, motherfucker, you interpreted it that way. You did that. The Bible didn't do that, idiot.

I have ...

I have a huge problem with that

I have a huge nasty problem with that

I'll just start talking, just to use F words and stuff

I ... I was talking or something like that

I brought up a few fucks or something like that

I was like, yes

I was like well

I'm 28

I don't tell them to cuss any more than they should tell me not to cuss

I think they should cuss so much

I'm not saying all Christians are like this

I feel like they use that Christianity shit to like ...

I was supposed to be sympathetic or empath ... or respectful to their religion, 
because they don't swear.

I don't give a fuck

I'm sure he is. Yeah.

I ...

I don't like how they use it as like a defense.

I'll be there.

I'll be there

I was, uh, gotten on a bit of a rant

I think, uh, religion is a bunch of malarkey

I was editing a little bit

I'm sitting out there

I can't remember how the, uh, topic of religion and Christ and all that brought up, but it did.

I ... I just told them,

I said, you know,

I ... I ... I find it so odd that the ... the people that scream about, you know, forgiving others and stuff, tend to be the most hypocritical people about that I'm not stereotyping, I'm just basing it off certain facts of my own

I ...

I ... oh,

I ...

I remember saying, you know, I ...

I ...

I find it so hard to ... to believe that like if I were a Catholic

I would find it so hard ... you ... you know when the Catholics found out about priests having inappropriate relations with ... with the altar boys

I find it so hard for me to ever want to listen to any of that portion of religion is going to tell me, when they actively went out of their way to hide something so sick like that.

I didn't know that Ted, uh, was a Catholic

I didn't care, really,

I didn't care.

I didn't know. But maybe I wouldn't have been so harsh

I'm not trying to stir those waves

I'm not trying to

I wouldn't mind mixing it up or anything

I'm not trying to stir that up

I'm not going to go out of my way for that issue.

I didn't know that Ted was in that ...

I ... again, I wasn't denying that, but the fact that there was ... first of all, just like cops,

I'm not going to ... to chastise all cops for bad shit that they do. But at the same time, uh, change should have happened.

I knew that he was trying to do that, to ... to essentially say like see, you can't say 
that

I told him what I honestly feel.

I relied on training that was provided to me by the Marines.

I don't want to say contradicting yourself, but in a sense, you're like ... you're ... you're almost stuck in what you were raised in

I do believe there is something

I don't know what the fuck it is

I really care? Not all that much.

I ...

I ... not enough for me to start diving into research

I said so is my favorite answer

I don't like to pry

I'm asking about something

I can clearly tell

I say no

I said so.

I don't need to give you a reason

I said so

I also ...

I also don't need to give you a reason

I'm not giving you anymore, period.

I ...

I ...

I don't bug you about shit that you don't want to talk about, don't bother me.

I ...

I've known Derek since we were like 11 years old

I'm very close to him and his family

I try

I ... I looked at her as

I said,

I'm only going to say it again,

I said, it's nothing and

I suggest you leave it at that

I ... I will embarrass you. Uh,

I think she knew

I think she just wanted me to say it

I don't know what

I ever do to her

I mean, really

I was right there and

I was like, no.

I'll let Jennifer know and then she could just give me money

I'm the one that goes and gets it 
I go, but ... it's not like Jennifer is actively going out there and purchasing gifts for anybody in my family

I shut her down with that

I think was just for her to have some sort of argument point

I'm sitting there like, Deanna, you're ... you're 58 years old. Grow up.

I'm not on the mom's

I'm not marrying the mom. The mom is technically coming in ...

I think it's more she has to deal with me

I'm ... I'm the exact opposite of that, for the most part

I ... if you're ... if ... if I totally disagree with what's being said,

I'll ... I'll tell her, like

I totally disagree with this whole situation.

I think that they should leave the fucking dad alone

I don't give a fuck. Leave him alone.

I ...

I don't care.

I ... I get it.

I get it.

I also get why Greg didn't say anything.

I don't care

I get why, um, why Greg didn't say

I'm finding fault here is her brother. He knew a week prior

I go, if ... if I knew ... if the situation was reversed and it was on my end,

I don't give a fuck about my mom or dad, if I knew my sister had a massive

problem with this

I also

I think if you compare the two,

I think Nick weighed out a little bit better in this.

I ...

I'm telling you, if it was ... roles were reversed in my situation and this was me and my sister, who are 10 years apart

I know she likes to say that they're seven or six years apart, and that's probably why they're not so close

I would have sent the text.

I would have called.

I would have done something

I'm a phone call away or whatever the case is.

I mean, we don't ... like her and I, we don't go out and do things

I have mine. But you know, as far as ... Yeah. As far as that connection, that's

there. Hey, if, uh, if she needs anything,

I'm there, period.

I don't ... there is no like oh, fuck, I'm busy. No.

I drop what I'm doing, and I go and see what ... family ... 
I'm close with you, if I'm ... if I'm close with you and I treat you, uh, I consider you like family, you don't have to actually be family to be family I'm close with you and you need me, I'll ... if I can help, I usually will try.

I ...

I don't give a shit

I listen to Jennifer bitch about shit all the time an

I agree with maybe a third of it, maybe. I ...

I think

I do a little of the nodding,

I'll flat out just say like, hey, this is something that you can't control.

I go if you're just doing it just to keep doing it, then go ahead.

I wouldn't necessarily disagree with that.

I can assure you that any form of kindness that would have been reciprocated by

Greg was completely thrown out when you get Jennifer in her mode.

I can't blame him.

I'll tell you what, if ... if I'm in that situation, and you know, I'm ... I'm trying to be in a relationship at 65 years old,

I can't say

I wouldn't react any differently.

I don't ... I don't ...

I hate that shit.

I hear them start going off like that,

I ... I ... I told Jennifer,

I have a hard time holding my tongue.

I hear your mom's disgusting mouth go off like that and then you guys are sitting there, battering it back and forth,

I go ... it's very hard for me to keep my mouth shut.

I ...

I ...

I can't tell you how much I just want to shut both of you up

I normally would. Just throwing it out there

I ...

I remember things.

I listen.

I'm paying attention to detail here and I'm going to give it right back to you.

I was like you realize half of my family is Hispanic, right. So, when you and your mom start going off on wetback beaner this and beaner child and stuff

I may not agree with half of my family and stuff on certain things, you understand that

I grew up like this.

I don't ...

I'm going to be hungry, because she figured that normally when I'm with you, we 
normally eat.

I said, no, I ... we're ... we're not eating.

I was like but I'm still with her.

I'm going to be hungry. And so

I didn't ...

I haven't eaten since like 12.

I hear them

I don't give a fuck if ... if this lady is wetback beaner-ish, or whatever you want.

I don't care if she is or isn't. But if you fucking ... if you're going to talk about her

like that, that's fucked up.

I'm like ...

I'm like, when it comes to that, yes. Um, so apparently they were doing it for some tax benefit purposes...

I ... I thought the same thing.

I asked,

I'll stamp that you're not going to like what I have to say, especially after

I hear you talk about my buddy

I cleared that air

I don't know when ...

I'm going to make a fucking copy of it

I'm going to plaster it all over her bedroom

I'm going to make thousands of copies and it's going to go all over the bedroom walls

I'm going to tape a picture of Derek next to it, so she could see his face. That's the guy you were talking the shit about. That shit is pissing me off.

I know this kid my whole life

I was like 10 or 11 years old

I've known him. And you know, he's never done anything, he's never done anything to anybody. He's a good guy. And he's a very direct guy. He was never in the service, but he would have made a hell of a Marine,

I'll tell you that

I ...

I can't wait until he tells me the loan docs are filed and done.

I cannot wait for that day.

I'm going to, oh,

I'm going to smack Deanna in the face with it.

I'm not going to do that. That's assault,

I want to

I just don't understand.

I go, you guys don't have the greatest relationship.

I go, but I guarantee you, when we're out of here, it'll be a lot better.

I go, you're a walking stress ball. And 90 percent of it is self-induced.

I mean, when you get like this and you need to ... like when you can't hit people

I'm fine. 
I'm calm.

I'm cool.

I'm collected. She doesn't even bother me.

\section{Third Listening: Voices}

In the World: Straightforward; Marine; Hearing impaired

Within: Political interest; OCD

\section{Fourth Listening: Politics \& Power}

Political: Military scouts go ahead of the rest of the group to survey the terrain; We created the Taliban; 9/11 Conspiracy Theories

Social: Religion v Science; "No atheists in foxhole" it is all about Marien training; private persons, respects other privacy

Cultural: Marines $=$ War $=$ PTSD; Research is not going to change people; Degree adds value to people

Economic: Get rated at VA for money; Politicians are all about money; "Vet Friend" not really about Vets, more about marketing

\section{Individual Meeting \#5, 12/15/15}

\section{First Listening: Plot}

Recurring words/themes: Men and women, perceptions and abilities; Women in combat; Marines; Survival in the Corps- do what you are told; Sometimes you have to do stupid things in the Marines

Plot: Beaver joined the Marine Corps because his friend's sister's boyfriend was a Marine, and if he could do it anyone could. Also, it would be helpful in his path to become a police officer, as it would come with a pay raise and help build experience. So, he joined, and suffered (like all Marines) in boot camp. 
While on deployment, he got to know some of the other Marines at the various bases. One in particular was KIA (Killed in Action) while on a convoy. That made the war very real for Beaver; his unit was lucky enough to never lose anyone. After three deployments with ANGLICO, he was nondeployable, as it was his final year in. He ended up being nominated for a position with the Commanding General (CG) from his unit. After several rounds of selection, Beaver was chosen. So, his final year in the Corps was with the CG and was the easiest job he ever had. Most of his job was keeping schedules or visiting other units to let them know the General would visit in a few days, so they could "unfuck themselves." During that time, he was a Major get demoted to Captain because he did not want his command to wear their uniforms sleeves down as a show of support for the Marines in Iraq \& Afghanistan. He had never seen that before! When he got out, he ended up going to East Forrest College to use his GI Bill, again to help with becoming a police officer. Yet, had been unable to secure employment. And while in the civilian world, he is dealing with being hit on by a girl he knew from high school, even though he is in a relationship.

Key Characters: Harper, Marines, Supply Marine KIA; SgtMaj Kent; High school friend

Briefly Mentioned: Harper's sister's boyfriend; General Mattis; Demoted Major- to Captain

Summary: The Marines were an experience, full of strange tasks (like the Master Log) or busy work (like digging holes). However, it was something Beaver 
loved, and hated, and missed. His experiences created some wonderful stories. However, after leaving the Corps and even after getting his Bachelor's, Beaver was still stuck looking for the job he wanted (Police Officer) or any job at all. That frustration was palatable!

\section{Second Listening: I Poem}

I mean, no.

I mean

I'm over that now.

I spent a year in the CG's office, I got to know a ton of female Marines

I'll just tell you like this,

I don't,

I don't think they really know what they are getting themselves into I think, in my honest opinion,

I think maybe 5\% of female Marines are going to go there and kill it I think the other, 95-90

I am giving them some credit, they're going to get a real culture shock I know male Marines, I knew,

I knew male Marines that wanted to get out

I understand that.

I didn't like it.

I can guarantee-

I can guarantee what's going to happen.

I'm all about it, go ahead

I can't wait to see; what kind of stories are going to come out of this.

I'm more upset about that (ribbons stacks)

I am with the women going in a combat platoon

I wouldn't have had the money to go ...

I mean, yeah, my parent's would've paid

I mean realistically

I guess really it started with my parents

I started,

I started looking into college

I found out that he enlisted

I was like, "No".

I told him,

I went and talked to recruiters and that was it

I don't even remember. 
I think because you know, he sold it to me

I knew

I didn't really let that get to me.

I've always wanted to be a cop

I was like whatever

I'm only going to four years

I didn't know

I was like, "Fuck give me active ".,

I didn't realize, what that fully entailed.

I signed everything

I was good to go.

I know,

I was talking to my buddy Luke.

I can't remember.

I'm driving with my buddy

I just asked him,

I'm like, "So, what are you going to do?".

I enlisted in the Marines.

I'm leaving right when we get out of high school

I shit you not, that's how the conversation went.

I don't know.

I did.

I got orders to Anglico

I was done with that,

I got out

I had got out

I was at the CGs office,

I started putting in applications to police departments

I was only getting like, "Oh, thank you for your interest."

I didn't think,

I really didn't think anything of it.

I was getting the same shit back.

I was starting to trip out

I'm like, "I'm done with this".

I got on unemployment

I got uh, sent to San Gabriel Parking Enforcement

I was there, a lot of cops

I became friends with,

I want to become a cop, eventually.

I'm just waiting for agencies to start opening

I thought about it,

I didn't know where I was going to go

I was sitting at the house

I knew, bachelor's degrees were only like four years 
I said, "Okay".

I went to um, administrators over there, signed up

I quit San Gabriel

I never

I never saw myself getting a degree.

I was not very scholastic

I got it.

I mean,

I guess.

I got in the Marine Corp,

I got in ANGLICO

I was deployed

I remember we went

I can't remember the base

I was used to seeing on a fairly regular basis,

I was like, "Oh, where's so-in-so?"

I mean like, 'cause

I never lost anyone in my unit

I was like, "Fuck".

I mean, other than that,

I said, the basic fleet Marine Corps, that's easy.

I mean it is, really.

I mean it, you get up, you go run uh, you come back, and you shower and change over

I was there maybe a week.

I can't even tell

I was asked to do things

I was like sitting there like,

I told my buddy

I told him,

I was so happy

I finally picked up Corporal

I didn't have to do that shit.

I remember

I picked up,

I thought.

I'm no longer going to be on a working party.

I can't even tell you how many times

I almost had like an aneurysm

I would

I remember 
I remember (laughs),

I remember telling

I used to tell him

I don't know where it is.

I had to go out there knowing what was going to happen

I would go find him.

I'm like, "Sergeant wants the fucking uh, he wants the master log".

I'd be laughing

I'm not kidding you

I write in all block lettering

I shit you not

I used to write-

I used to write like, like printer paper.

I got four pages back and front,

I not had him as a supervisor,

I don't think

I would have ever worked with the CG

I was interviewing for that,

I told him no initially and he was pissed

I was like, "Wow, why are you so mad about it

I told him

I was like, "That doesn't mean anything for me.

I have a year left.

I'm non-deployable.

I'm pretty much in charge of my section.

I feel like

I go, I'm the boot again, not knowing what the fuck to do.

I haven't worked with that kind of command before".

I talked it over with, with my ex at the time, Courtney, and my parents

I let them know.

I know with Anglico, I'm not (deploying)

I was,

I was exempt from it.

I didn't have enough time on my contract

I knew

I was, uh, was deployment exempt.

I didn't know with the CG's office

I went back

I told Sergeant Deigo

I said, "Do you know if the CG's unit, if he deploys and this and that".

I said, "All right, fine, fuck it". So

I told him to submit my name, and he did,

I spent like four hours with him.

I said, "I don't think I should". 
I said, "Uh, I'm not really sure if I really want this.

I have no idea what to expect.

I told them,

I'm nervous.

I know that if I don't do well, I know what I'm coming back to

I like this unit anyways

I wasn't, it wasn't like I was losing anything really

I hadn't really done it before

I met with a One Star and his General

I was with Anglico

I knew the Sergeant Major there

I'd seen him before

I was the last

I was the last Marine uh ... No, no,

I was not the last,

I was the first Marine

I saw, saw Sergeant Major

I had a mustang

I have no idea what I'm going to do.

I know exactly what I'm going to do at Anglico.

I have no clue what I'm doing here

I went out there

I forget what his name was.

I talked with the Sergeant

I guess, Sergeant Major Kent emailed General Mattis

I got a call that afternoon

I told my command

I just got the call right now

I told Sergeant Diego

I told him what Sergeant Major Kent said.

I worked at Little Caesars,

I'm,

I'm telling you this is the easiest fucking job that I've ever had in my life.

I didn't do a fucking thing. Nothing.

I uh,

I went,

I went to work.

I went to the gym,

I never,

I never did these fucking death marches and death fucking runs anymore.,

I went to the gym

I stretched

I was there. 
I did my own version of PT.

I go there

I remember uh, right when

I got there,

I cannot remember his name,

I cannot fucking remember his name.

I actually know Sergeant Major Kent too

I already knew who he was

I talked to him,

I asked him,

I do.

I have,

I have, not from him

I have it from uh, uh, um, uh, Sergeant Major Reed d

I have it from uh, uh, well kind of, I guess kind of, General Helen

I don't really consider that,

I mean

I don't know how,

I don't know how to talk about myself.

I checked in

I only spent like, less than two months with them

I talked to him

I always told him

I was,

I never registered,

I would like,

I would buy one and

I would just throw it on my desk.

I would like to put a bookmark in it.

I made it look like

I was actually doing,

I had other things to do.

I had Facebook to check and all sorts of other shit to do.

I didn't have time to read.

I was a corporal and uh, yeah

I didn't know

I was, you know

I knew

I wasn't going to pick up Sergeant

I knew

I didn't have the score for it.

I didn't know that they were going to end up promoting me.

I was like, "Fuck it, whatever." 
I would prefer to be outside and doing things.

I feel like,

I feel like, 'cause okay, as easy as that job was,

I felt like that with Anglico days flew by.

I wasn't doing shit, oh my God, the days drug on and on.

I was like,

I would go,

I would go to like Sergeant Major Reed's office,

I'm like, "Hey. Do you need me to pick up anything? Or, is there anything that I could do today?"

I go do something,

I go just drive around for a little bit

I'm outta here

I did.

I get to go there whenever the fuck I want

I have to do is have the CG's truck with me.

I got the good food.

I had a feeling that the Lieutenants knew what I was doing but

I watched General Helen demote a Major to a Captain one time.

I've never seen uh, somebody get demoted before

I'd seen enlisted get demoted and that's, you know, that happens all the time.

I had never seen specially company grade officers getting um, or sorry field grade officers getting demoted to company grade officer.

I'd never seen that before.

I could tell he was agitated.

I didn't know about what.

I asked him,

I told Sergeant Major that

I could hear them talking

I don't know why

I saw major Reed had politely and as respectfully as he could told the Major

I couldn't hear anything until he started yelling.

I could hear it

I remember like turning off all my shit

I turned it off

I could hear

I remember

I had to turn it down, or off

I could hear what they were saying.

I still couldn't hear

I could hear

I heard uh, the general

I can't remember his name.

I could hear them 
I see the Captain, or sorry the Major, come in as a Captain

I'm like, "Oh, you fucked up".

I've never seen that before in my life.

I didn't know you could do that.

I guess there's not really much that at Three Star can't really do.

I'm pretty sure that he could do whatever the fuck he wants.

I remember

I would drive it around,

I'd go

I remember one time

I went over there

I went to his unit

I saw him

I'm like, "I'm just letting you know that the boss is coming down tomorrow".

I can't stop it. So, you better do what you need to do. Clean your shit up.

I can't stop it,

I'm just helping you out.

I didn't do that

I would go and every time

I went to go meet,

I would never tell them shit.

I'm just here, hanging out

I am.

I didn't,

I didn't drink.

I didn't do drugs,

I didn't party in high school.

I mean,

I mean really, when you're in that, that's kind of like your exciting stories.

I don't really have like any stories

I didn't do that shit.

I guess I fit the mold

I would be a big partier or drinker type,

I've known him since I was 11 years old.

I don't do it

I don't like it

I just reconnected with some girl

I knew from high school.

I told her the same thing.

I was like uh,

I don't or anything like that 
I'm 30, going to be 30 and I, I've been drunk maybe five time, maybe

I would consider drunk.

I was like that. Once.

I was with, with Derek, at his house.

I was like this laying down

I puked all over me. So

I crawled my way into his house

I found his downstairs restroom

I slept right there.

I was actually having a little problem with this girl

I reconnected

I started noticing

I was like,

I'm like, oh, ah-ha-ha,

I wouldn't acknowledge them.

I would,

I would continue the conversations

I would leave out whatever response I thought she was trying to get

I told her like

I was like,

I think so.

I've got pictures of her all over my shit.

I kind of thought you knew.

I thought you were just messing around with me

I was like, "Yeah, I think so".

I'm sure we're going to eventually get married or whatever

I care about her a lot

I always find ways

I find ways to put Courtney's name or, or reference her in a conversation piece

I appreciate all the compliments.

I appreciate the fact that you respect my relationship

I'm sure one day you're going to find yourself in the same situation as me

I'm like,

I don't know, it's weird,

I'm almost at the point

I have to tell her like, hey, cut the shit. I'm,

I'm,

I'm,

I could pick up on what you're doing here.

I'm really good at what you're doing to me.

I was really good at this game

I know this game well

I know.

I'm,

I'm like at the point 
I have this friend Brooke.

I'm her friend boy

I don't ever have a problem

I don't, you know,

I don't look at...

I don't-,

I don't have a problem telling Jennifer

I talk to Brooke and Debbie

I am.

I'm having a hard time

I thought in my mind, she's just messing with me

I had a girlfriend like that.

I'm getting at with girl.

I commented on it,

I didn't know it was salsa.

I never did,

I was like, nah fuck it,

I'm not going to do it.

I never did.

I'm like, "Nah, it's okay".

I wrestled a little bit in high school

I commented,

I said, "Awesome",

I didn't know this at the time

I didn't, this is my first-time hearing about it.

I'm not even telling Luke.

I won't,

I'm not even telling him

I don't want him to tell me,

I don't want him to tell me anything

I'm sitting there

I didn't,

I haven't mentioned it to him

I asked,

I guess

I have the problem

I wanted,

I went to high school with this chick

I don't really hang out with a lot of people from high school.

I want to tell Courtney

I reconnected with a friend $\mathrm{I}$,

I don't ever delete,

I never delete texts out of my phone.

I don't even want to tell her that I reconnected with this chick.

I feel bad, 
I even told this girl,

I told you

I mentioned Courtney on, on a regular basis.

I'm going to have to.

I'm going to have to.

I didn't want to.

I didn't want to be that guy

I'm not trying to say this to be mean or anything,

I'm not trying to say you're ugly or anything but, if my girlfriend sees that, that's

it.

I will not be friends or anything

I'm actually,

I'm actually headed back to my parents

I did.

I did uh-

I'll take pictures of that when I get to the house.

I wanted to take a picture of

I'll send you.

I have,

I have a ...,

I took this at Jennifer's house right now.

I usually wear the pin

I've had it ever since

I had somebody do it.

I had one of my other Marines do it.

I have the picture of me and my buddy at his wedding.

I thought.

I don't have anything appropriate

I just forgot how many pictures I uh, saved on here from uh, deployments and shit.

I had to uh,

I had to upload them and email them to myself and take em from here.

I was able ... Ugh, that was my buddy

I grew up with.

I saw him, or saw me in the chow hall

I could,

I hear somebody keep yelling Tony.

I ignore it because you know, nobody calls you by your first name.

I keep hearing it, keep hearing it.

I'm like, all right man, who the fuck is yelling Tony

I look

I see him, and he's fucking with a missing tooth 
I'm like (laughs),

I'm like, "What happened to you?

I don't like those.

I have a uh, have a wandering mind.

I get on one topic and the next thing

I know

I think

I'm just going to have to like send you

I might have to just like select ten at a time -

I'm just going to start doing that real quick.

I know a lot of Marines

I would say

I already have a uh, thing about my surroundings as it is

I mean to what I consider relaxation, you know. To be relaxing for myself.

I mean, um, I, like

I like watching TV and hanging out and just sitting there

I have another picture of him

I took a picture of it.

I can't remember his name

I think that is

I sent a bunch more

I'm behind it

I have ...

I don't know if I sent any pictures of me

I that

I took that picture

I think.

I know

I was about to say.

I'm like, what the fuck. (laughs)

I still had that picture of him. Um, and

I ended up working for him for a little bit.

I don't know, they're, it says they're sending on my phone.

I have some more at the house,

I'm- Yeah, 'cause

I have to go

I have to find it

I would testify

I don't know. 
I think

I would be a good teacher,

I just don't have patience.

I feel like students have an attitude problem,

I'm afraid that if it was up to me to correct the attitude,

I wouldn't make it very long in that career.

I would be fired

I'm fired. That's it.

I'm out. Forget it.

I don't know about now.

I don't know, I,

I think that's horseshit

I know,

I mean it's not that I don't want to.

I would just have to research it and figure out where

I need to go to get certified

I don't know for a fact

I never looked into it,

I could probably guarantee you you're going to need a Federal certification

I wouldn't say that.

I see it, honestly

I was getting out.

I remember distinctly that they had programs like that

I wouldn't say that last part

I understand where you're going with that.

I don't know about you but my toes, feel like they're frozen.

I feel like

I have poor blood circulation or

I have to take my shoes off,

I'm pretty sure they're going to be blue.

I've got slippers on.

I wouldn't, like

I didn't have anything planned today,

I was like, okay,

I've got to put on a tee-shirt.

I wear this around town and stuff

I have sweats on

I'm like, "I don't give a fuck.

I don't know them.

I have sweatpants on, like and slippers.

I mean

I'm totally like, like just comfy-ed out right now.

I don't even have a shirt on underneath this, 
I'm afraid that if

I were to bump them onto something

I can't use it anymore.

I think that would be a really good ideal though

I don't know if

I don't think that is realistic

I'm mean sure, you know, research can be done

I don't think it's going to apply to everybody

I'm sure that we can try to figure out the most practical solution I don't know.

I have,

I couldn't even tell you.

I have no knowledge of that whatsoever.

I think the only thing that might change would be admission loss per the state

I think really the only thing that you might have to re-certify would be like your admissions part of it.

I know, the, the GI Bill does, does cover trade schools.

I mean if you uh, if you dig a little bit more

I'll help out.

I'd,

I just don't know exactly

I just don't know exactly how we would get that started.

I graduated high school

I had um, uh, drivers ed and wood shop and uh, ceramics still.

I graduated they got rid of, like drivers ed, wood shop and ceramics.

I had foods.

I had foods.

I took that.

I had foods.

I took foods.

I took consumer economics.

I took wood shop and ceramics.

I did not like ceramics at all.

I get,

I have a very, what do you call it? Uh, um, patience.

I told you my patience ...

I don't like really care too much about.

I go over there, they're like, "If you open your mouth you're going to get smacked around".

I'm not even a massive football fan to begin with

I just kind of grew up liking them

I could care less. 


\section{Third Listening: Voices}

In the World: Marine; Boyfriend; Unemployed

Within: Police Officer Material; Overqualified; Frustrated

\section{Fourth Listening: Politics \& Power}

Political: The Marines changed their policies on wearing ribbon stacks because the new SrgMaj of the Marine Corps did not have a CAR

Social: Get used to seeing someone, then find out they were KIA; Part of his job was to warn units of upcoming visits, some units never received the warning; Being hit on by a girl from high school even though he is in a relationship Cultural: Women were now able to serve in combat roles

Economic: GI Bill for East Forrest College; Willing to take ANY job just to pay the bills 


\section{Found Poetry from Group Meeting \#2, 12/13/15}

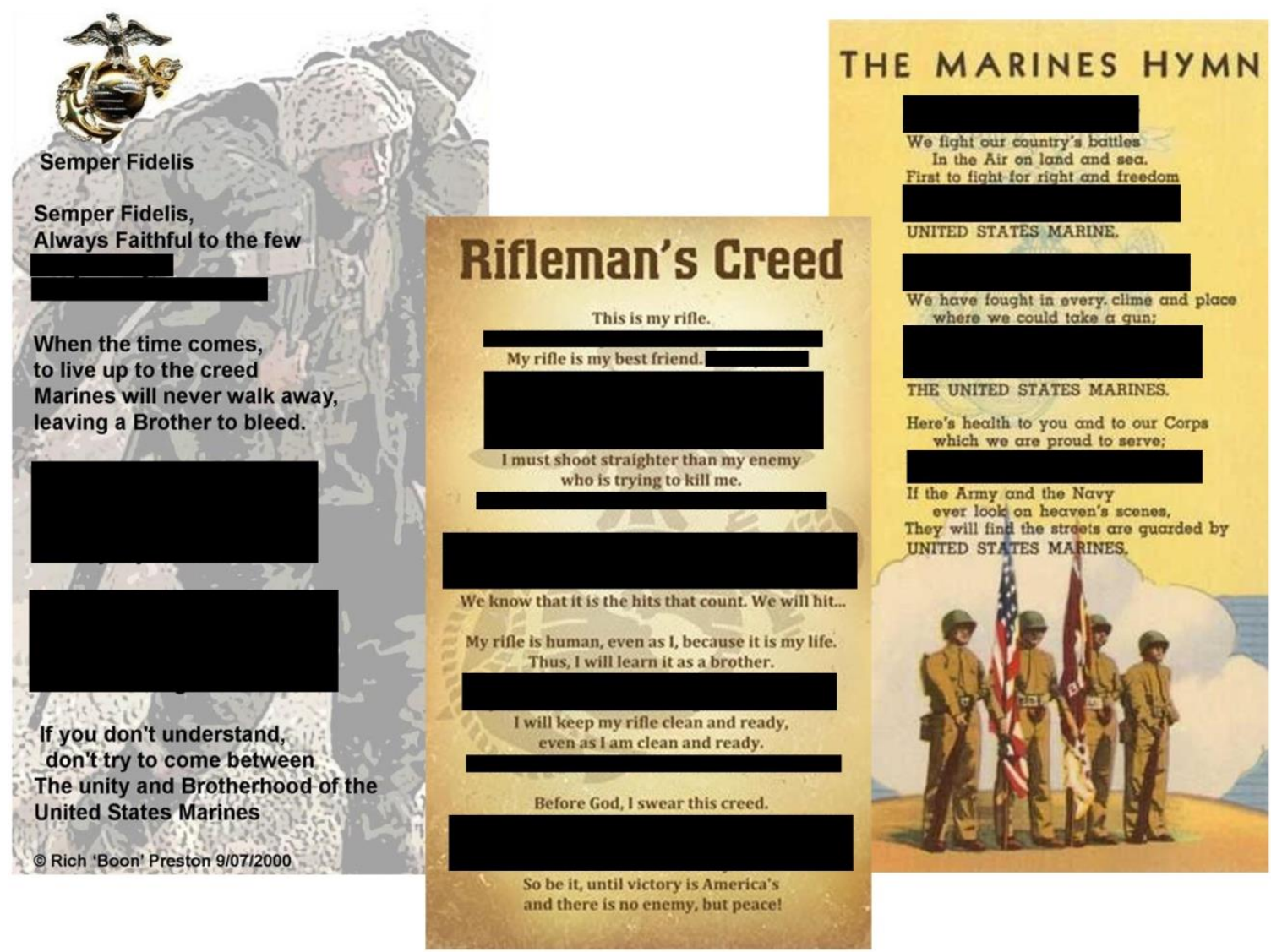

